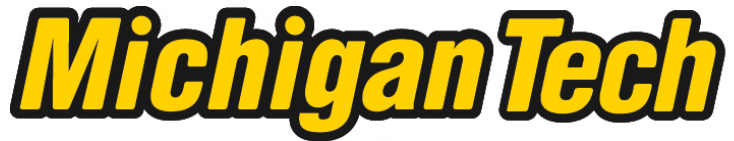 \\ Michigan Technological University Create the Future Digital Commons @ Michigan Tech
}

Dissertations, Master's Theses and Master's Reports - Open

Dissertations, Master's Theses and Master's

Reports

2008

Performance evaluation of VIP latrines in the Upper West Region of Ghana

James W. Dumpert

Michigan Technological University

Follow this and additional works at: https://digitalcommons.mtu.edu/etds

Part of the Civil and Environmental Engineering Commons

Copyright 2008 James W. Dumpert

\section{Recommended Citation}

Dumpert, James W., "Performance evaluation of VIP latrines in the Upper West Region of Ghana ", Master's report, Michigan Technological University, 2008.

https://doi.org/10.37099/mtu.dc.etds/514

Follow this and additional works at: https://digitalcommons.mtu.edu/etds

3 Part of the Civil and Environmental Engineering Commons 


\title{
Performance Evaluation of VIP Latrines in the Upper West Region of Ghana
}

\author{
By \\ James W. Dumpert \\ A REPORT \\ Submitted in partial fulfillment of the requirements for the degree of \\ MASTER OF SCIENCE IN ENVIRONMENTAL ENGINEERING \\ MICHIGAN TECHNOLOGICAL UNIVERSITY
}

2008

Copyright (C) James W. Dumpert 2008 
This report "Performance Evaluation of VIP Latrines in the Upper West Region of Ghana" is hereby approved in partial fulfillment of the requirements for the degree of MASTERS OF SCIENCE OF ENVIRONMENTAL ENGINEERING

\author{
Civil and Environmental Engineering \\ Master's International Program
}

Signatures:

\begin{tabular}{ll} 
Report Advisor & \\
\cline { 2 - 2 } Durtis G. Paterson \\
Department Chair $\quad$ Neil J. Hutzler \\
\\
Date
\end{tabular}




\section{Preface}

This report is based on the author's experience as a Peace Corps Volunteer in Ghana, West Africa from September 2005 to December 2007. During his service the author was assigned to work within the community of Kulkpong, located in the Wa East district of the Upper West Region, under the sector of Health, Water and Sanitation. His primary project involved working with communities to construct household latrines and improve environmental cleanliness as part of the Trachoma Control Program. In addition to sanitation projects, the author also worked with the Guinea Worm Eradication program, health education programs, and with local women's and farmer groups to setup small enterprise development projects.

This report was completed in partial fulfillment of the requirements for a Master of Science degree in Environmental Engineering as part of the Master's International through the Peace Corps and the Civil and Environmental Engineering Department at Michigan Technological University. The research study, which makes up the basis of this report, was planned and implemented during the last year of the author's service. The evaluation of the Upper West Ventilated Improved Pit latrines was coordinated in collaboration with the Carter Center, the author's advisor at Michigan Tech, and the participating households whose latrines were used in the study. 


\section{Table of Contents}

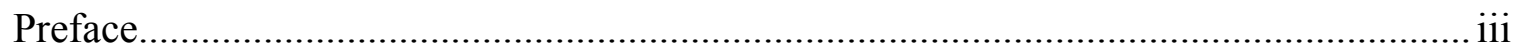

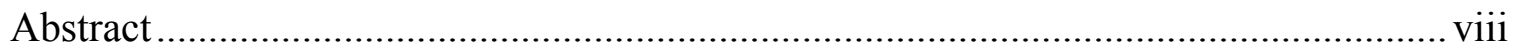

Acknowledgements ............................................................................................ ix

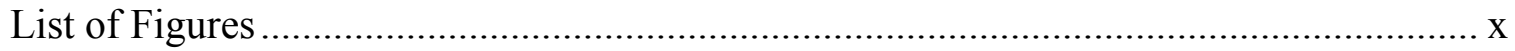

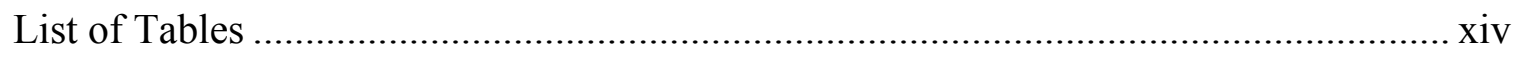

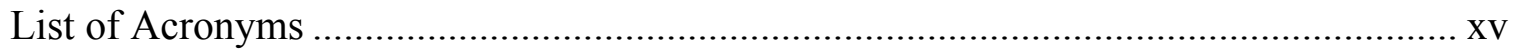

Chapter 1: Introduction and Study Objectives.............................................................. 1

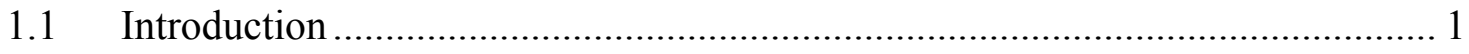

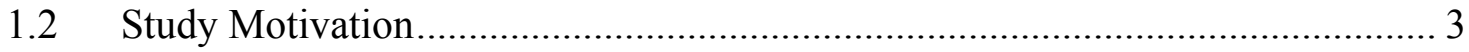

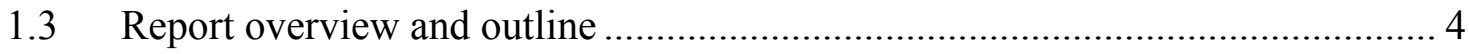

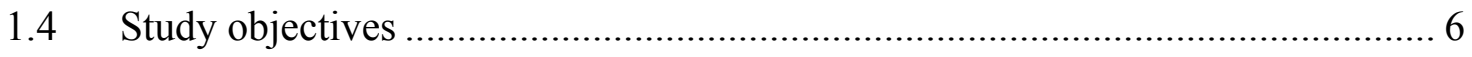

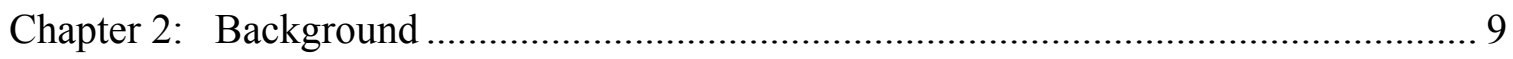

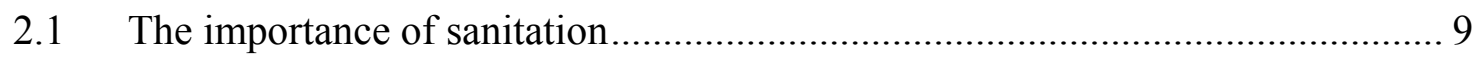

2.2 The problem of increasing access to sanitation................................................. 12

2.3 Rural improved sanitation technologies, Hardware ………............................... 13

2.3.1 Improved Traditional Practice and Hygiene Promotion .............................. 13

2.3.2 Simple Pit Latrine ................................................................................. 14

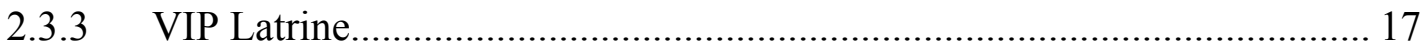

2.3.4 Pour-flush Latrine .............................................................................. 18

2.3.5 Septic Latrines ……………………………...................................... 19

2.4 Methods of sanitation promotion/implementation, "Software" ........................ 20

2.4.1 Top-down model............................................................................ 20

2.4.2 Social marketing model .................................................................... 21 


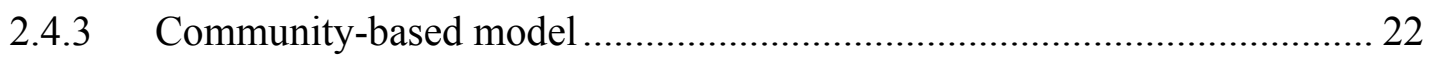

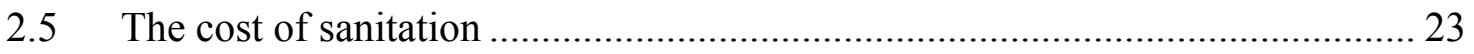

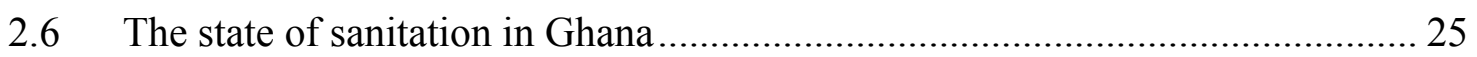

2.7 The Upper West Region and its state of sanitation ............................................ 29

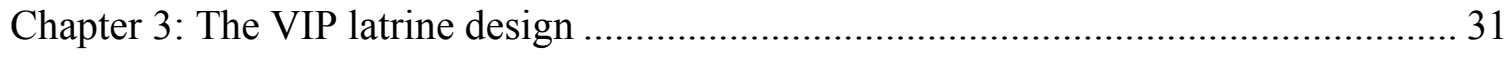

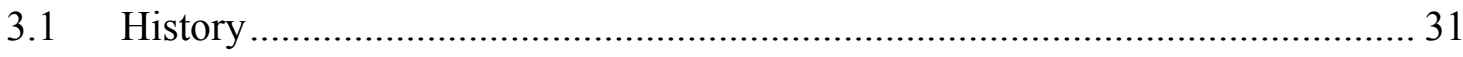

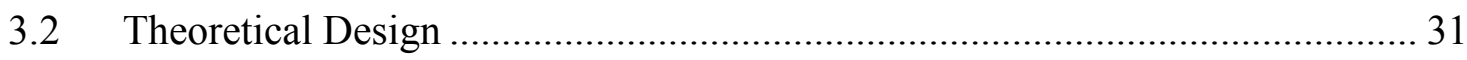

3.3 The Mara and Ryan Evaluation....................................................................... 32

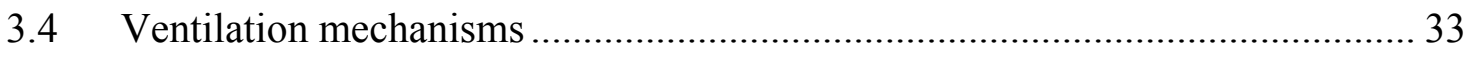

3.4.1 Wind across the top of the vent pipe........................................................ 34

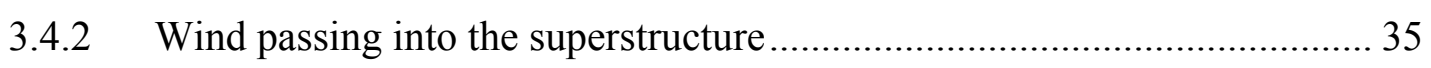

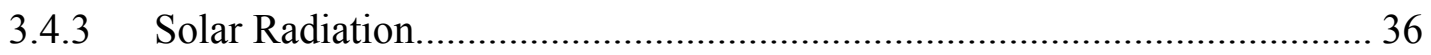

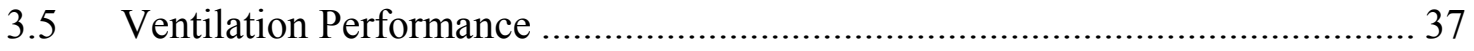

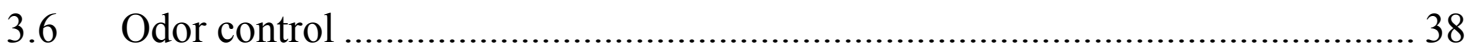

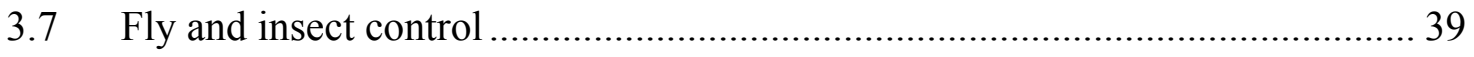

3.8 The Zimbabwean and the Upper West Region single-pit VIP latrine................. 40

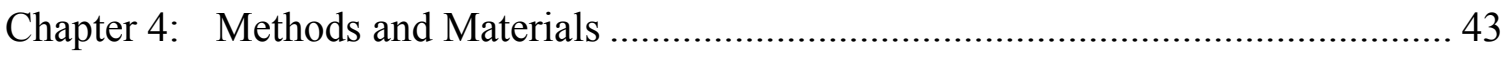

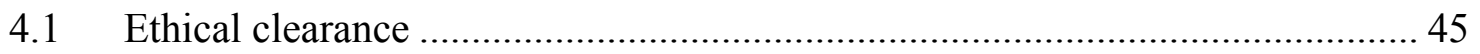

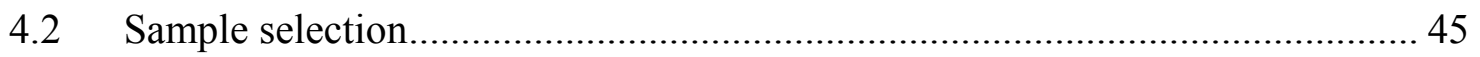

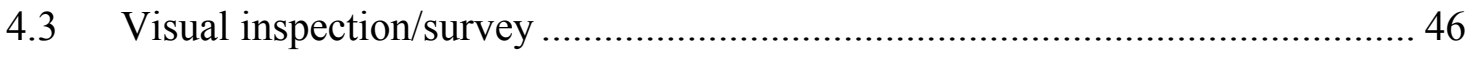

4.4 Performance monitoring/data collection ........................................................... 48

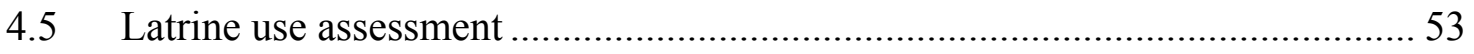

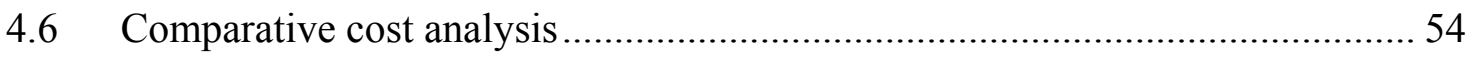

Chapter 5: VIP Latrine performance evaluation.............................................................. 55

5.1 Evaluation of the average flow rate............................................................. 55 
5.2 Evaluation of odorless conditions

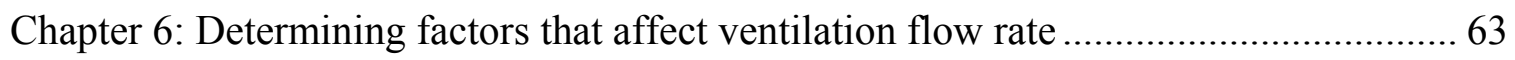

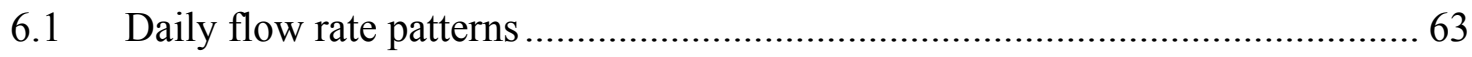

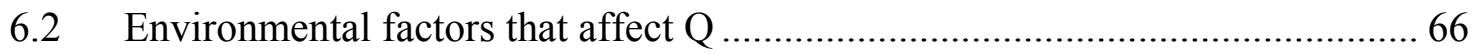

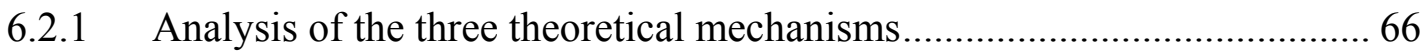

6.2.2 Analysis of temperature effects ................................................... 70

6.2.3 Analysis of monthly/seasonal variation .............................................. 75

6.2.4 Environmental Factors Summary .................................................... 76

6.3 Interpretation of the flow rate pattern with identified key variables................ 77

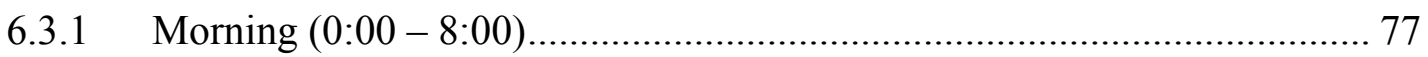

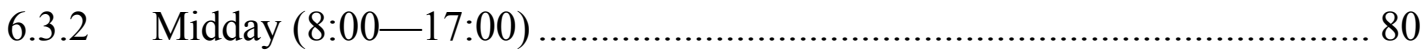

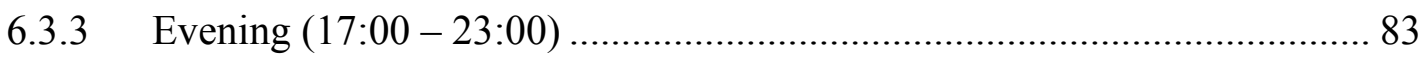

6.4 Comparing the average flow rate to individual flow rate behavior................... 86

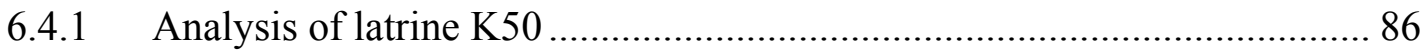

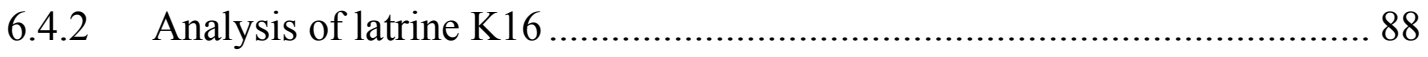

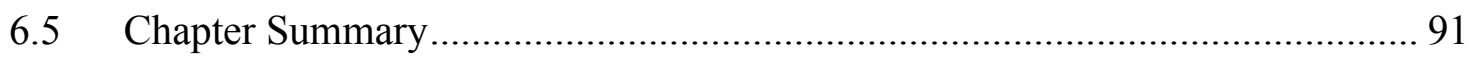

Chapter 7: Visual Inspection Results and Discussion........................................... 93

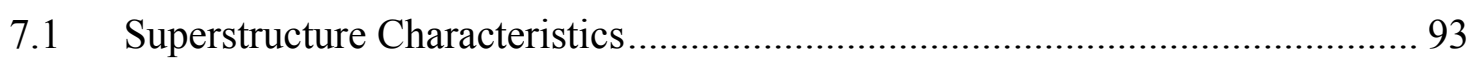

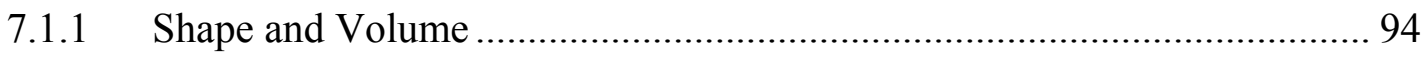

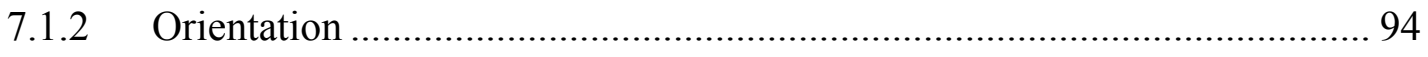

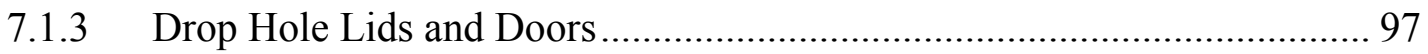

7.1.4 Additional Ventilation Openings ...................................................... 101

7.1.5 General Condition.......................................................................... 102

7.2 Ventilation Pipe Characteristics ........................................................... 103 


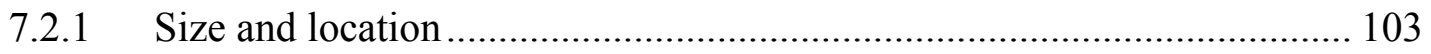

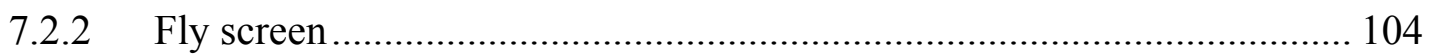

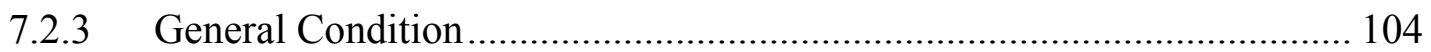

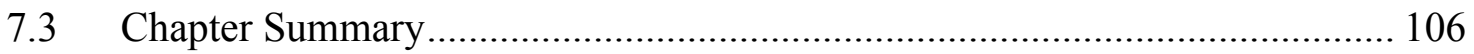

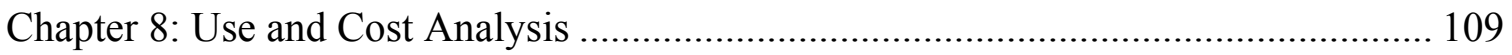

8.1 Use Assessment ...................................................................................... 109

8.1.1 User acceptance of sanitation facility ...................................................... 109

8.1.2 Proper use of UWR VIP latrines......................................................... 110

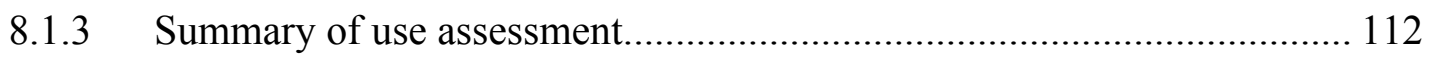

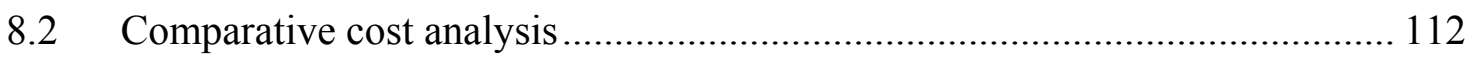

8.2.1 The cost of a UWR VIP latrine............................................................... 113

8.2.2 Comparing the cost of UWR latrines to other appropriate solutions......... 115

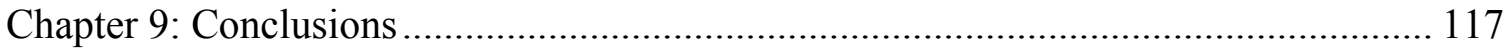

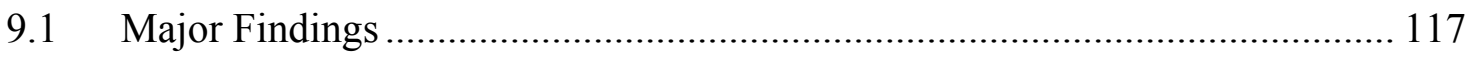

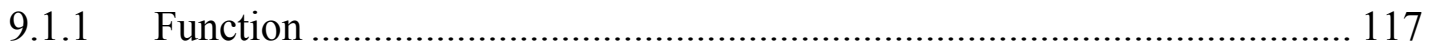

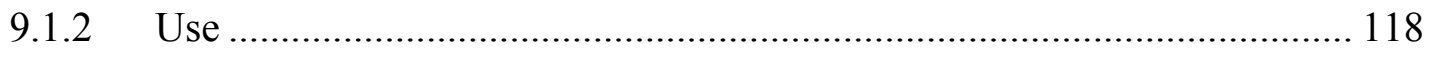

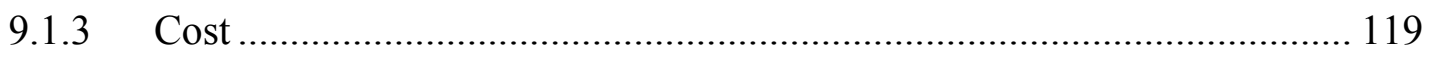

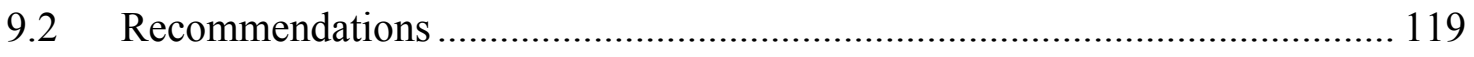

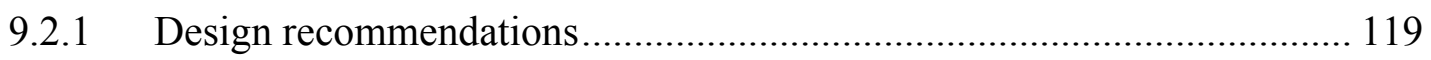

9.2.2 General recommendations .................................................................. 120

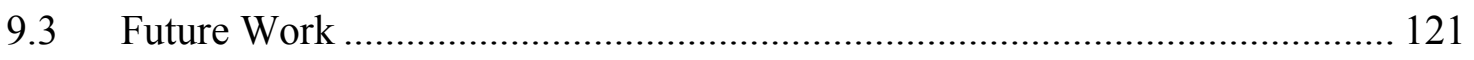

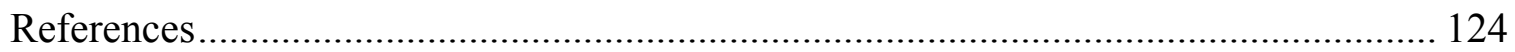

Appendix A: Visual Inspection Survey and Results................................................. 130

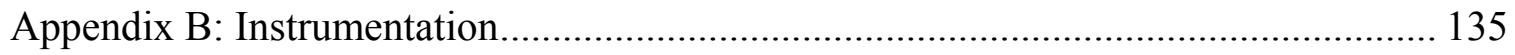

Appendix C: Recommended Structure of Feasibility Studies for Sanitation Program... 143 


\section{Abstract}

The prevalence of Ventilated Improved Pit (VIP) latrines in Ghana suggests that the design must have a high user acceptance. The two key factors attributed to user acceptance of a VIP latrine over an alternative latrine design, such as the basic pit latrine, are its ability to remove foul odors and maintain low fly populations; both of which are a direct result of an adequate ventilation flow rate.

Adequate ventilation for odorless conditions in a VIP latrine has been defined by the United Nations Development Program (UNDP) and the World Bank, as an air flow rate equivalent to 6 air changes per hour $(6 \mathrm{ACH})$ of the superstructure's air volume. Additionally, the UNDP determined that the three primary factors that affect ventilation are: 1) wind passing over the mouth of the vent pipe, 2) wind passing into the superstructure, and 3) solar radiation on to the vent pipe. Previous studies also indicate that vent pipes with larger diameters increase flow rates, and the application of carbonaceous materials to the pit sludge reduces odor and insect prevalence. Furthermore, proper design and construction is critical for the correct functioning of VIP latrines. Under-designing could cause problems with odor and insect control; overdesigning would increase costs unnecessarily, thereby making it potentially unaffordable for benefactors to independently construct, repair or replace a VIP latrine.

The present study evaluated the design of VIP latrines used by rural communities in the Upper West Region of Ghana with the focus of assessing adequate ventilation for odor removal and insect control. Thirty VIP latrines from six communities in the Upper West Region of Ghana were sampled. Each VIP latrine's ventilation flow rate and microenvironment was measured using a hot-wire anemometer probe and portable weather station for a minimum of four hours. To capture any temporal or seasonal variations in ventilation, ten of the latrines were sampled monthly over the course of three months for a minimum of 12 hours. A latrine usage survey and a cost analysis were also conducted to further assess the VIP latrine as an appropriated technology for sustainable development in the Upper West Region.

It was found that the average air flow rate over the entire sample set was $11.3 \mathrm{~m}^{3} / \mathrm{hr}$. The minimum and maximum air flow rates were $0.0 \mathrm{~m}^{3} / \mathrm{hr}$ and $48.0 \mathrm{~m}^{3} / \mathrm{hr}$ respectively. Only 1 of the 30 VIP latrines (3\%) was found to have an air flow rate greater than the UNDPdefined odorless condition of $6 \mathrm{ACH}$. Furthermore, 19 VIP latrines (63\%) were found to have an average air flow rate of less than half the flow rate required to achieve $6 \mathrm{ACH}$. The dominant factors affecting ventilation flow rate were wind passing over the mouth of the vent pipe and air buoyancy forces, which were the effect of differences in temperature between the substructure and the ambient environment. Of 76 usable VIP latrines found in one community, $68.4 \%$ were in actual use. The cost of a VIP latrine was found to be equivalent to approximately $12 \%$ of the mean annual household income for Upper West Region inhabitants. 


\section{Acknowledgements}

I would like to start by thanking my advisor, Dr. Kurt Paterson for his guidance on what it is to be an engineer and a worldly scholar. I would also like to thank him for the unwavering support he has been every step of the way though this project, including providing a place for me to stay while finishing up the report.

I am extremely grateful to Dr. Paul Emerson for helping me to develop this project, his willingness to provide me with the instruments needed, and for that bowl of soup noodles in Tamale. I would also like to thank the folks who work with Dr. Emerson at the Carter Center; Lisa Rotondo, Elizabeth Cromwell and Jonathan King, for taking the time to provide me with support whenever it was needed.

To Ann Rodgers, whom I cannot thank enough for her encouragement and for all the great discussions we have had about sanitation, development and health.

I would also like to thank Joseph Maal-ire Tang for being a good friend, and whose hard work, determination, and honesty is inspiring.

My thanks go out to all the volunteers who served with me in the Upper West Region and who helped me collect the data for this project in one way or another.

To my family and friends in Kulkpong, I would like to say "Barka" for putting up with and humoring me for the past two years.

I would also like to thank my editors; Patrick Collette, and Hazel-Dawn Dumpert.

And last but not least, my love and thanks to my family for putting up with and humoring me for the past twenty-seven years. This goes double for my sister Katie Collette. 


\section{List of Figures}

Figure 1: Minimum Evaluation Procedure ……………................................................ 5

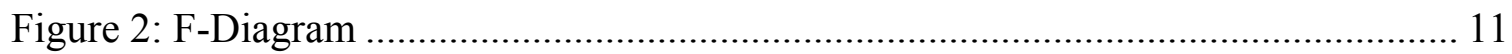

Figure 3: Woman adding wood-ash inside the pit of a VIP latrine ………………….... 17

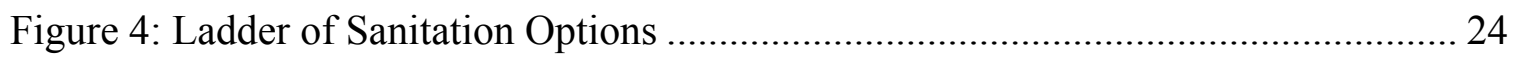

Figure 5: Photograph of an institutional latrine in Ghana................................................. 26

Figure 7: Location of temperature probes $\mathrm{T} 1$ through $\mathrm{T} 6$ and air pressure measurement

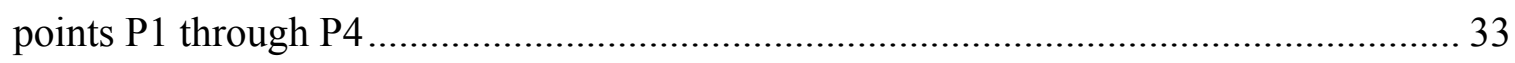

Figure 8: Cross sectional diagram of a VIP latrine showing wind passing over the vent pipe

Figure 9: Cross sectional diagram of a VIP latrine showing wind passing into the superstructure

Figure 10: Cross sectional diagram of a VIP latrine showing solar radiation heating the vent pipe 36

Figure 11: Top view of spiral shaped and rectangular shaped superstructures.

Figure 12: General location of the study communities in Wa East and Wa West 44

Figure 13: Photo of three unique Kulkpong latrines; a) the author's latrine; b) threequartered walled latrine; c) shaded latrine. 46

Figure 14: Photo examples of; a) 'none' drop hole lid covering; b) 'partial' drop hole lid covering; c) 'complete' drop hole lid covering; d) 'none' entrance way covering; e) 'partial' entrance way covering; f)'complete' entrance way covering. Photos by Author48 Figure 15: Photo of weather station setup. Photos by Author ........................................... 49

Figure 16: Photo of alternative WD/WS setup. Photo by Author...................................... 50

Figure 17; Photo of interior temperature probes setup. Photo by Author.......................... 51

Figure 18: Photo of Hot-wire anemometer setup. Photo by Author .................................. 52

Figure 19: Flow rate data for one latrine during one measurement setup. ....................... 56

Figure 20: Average flow rate observed for each setup plotted with $\mathrm{Q}_{\text {avg }}$ and $\mathrm{Q}_{\mathrm{Z}} \ldots \ldots \ldots \ldots . . .58$ 
Figure 21: Average observed ACH for each setup plotted with recommended ACH values

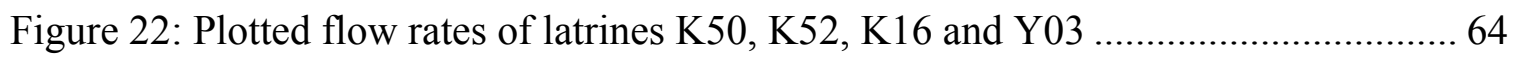

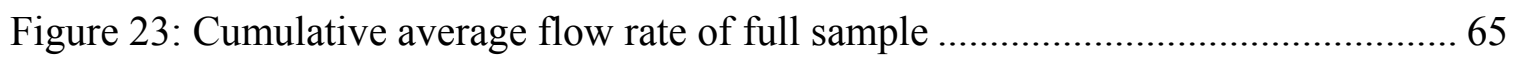

Figure 24: Histogram of the number of contributing data points to hourly averaged Q values $(\mathrm{n}=2649)$

Figure 25: Averaged values for flow rate $\left(\mathrm{Q}_{\mathrm{avg}}\right)$, and averaged normalized values for Vent Pipe $\left(\mathrm{U}_{\mathrm{VP}}\right)$ Wind Speed, Solar Radiation $(\mathrm{SR})$, and Door Wind Speed $\left(\mathrm{U}_{\mathrm{door}}\right)$............... 68 Figure 26: Wind speed at the height of the vent pipe $\left(U_{v p}\right)$ vs. the average flow rate , $Q_{a v g}$, (9:00-17:00hrs).

Figure 27: Averaged values for flow rate $\left(\mathrm{Q}_{\mathrm{avg}}\right)$, the ambient temperature $\left(\mathrm{T}_{\mathrm{am}}\right)$, and temperatures at the top of the vent pipe $\left(\mathrm{T}_{\text {top }}\right)$, bottom of the vent pipe $\left(\mathrm{T}_{\text {bot }}\right)$, inside the superstructure $\left(\mathrm{T}_{\mathrm{ss}}\right)$, over time.

Figure 28: Averaged values for flow rate $\left(\mathrm{Q}_{\mathrm{avg}}\right), \Delta \mathrm{T}_{\text {top-bot, }}, \Delta \mathrm{T}_{\text {ss-bot }}, \Delta \mathrm{T}_{\text {am-top }}, \Delta \mathrm{T}_{\text {am-bot }}, \Delta \mathrm{T}_{\text {am- }}$ ss, over time.

Figure 29: Average flow rate $\left(\mathrm{Q}_{\text {avg }}\right)$ vs. $\Delta \mathrm{T}$ superstructure - bottom of the vent pipe/pit74 Figure 30: Monthly variation among average values for flow rate, wind speed and temperatures.

Figure 31: Averaged values for flow rate $\left(\mathrm{Q}_{\mathrm{avg}}\right)$, the ambient temperature $\left(\mathrm{T}_{\mathrm{am}}\right)$, and temperatures at the top of the vent pipe $\left(\mathrm{T}_{\text {top }}\right)$, bottom of the vent pipe $\left(\mathrm{T}_{\text {bot }}\right)$, inside the superstructure $\left(\mathrm{T}_{\mathrm{ss}}\right)$ over time 0:00-8:00.

Figure 32: Averaged values for flow rate $\left(\mathrm{Q}_{\mathrm{avg}}\right), \Delta \mathrm{T}_{\text {top-bot }}, \Delta \mathrm{T}_{\text {ss-bot }}, \Delta \mathrm{T}_{\text {am-top }}, \Delta \mathrm{T}_{\text {am-bot }}, \Delta \mathrm{T}_{\text {am- }}$ ss, over time 0:00-8:00

Figure 33: Averaged values for flow rate $\left(Q_{\text {avg }}\right)$, and averaged normalized values for Vent Pipe $\left(\mathrm{U}_{\mathrm{VP}}\right)$ Wind Speed, Solar Radiation $(\mathrm{SR})$, and Door Wind Speed $\left(\mathrm{U}_{\text {door }}\right)$ over time 0:00-8:00.

Figure 34: Averaged values for flow rate $\left(Q_{a v g}\right)$, and averaged normalized values for Vent Pipe $\left(U_{V P}\right)$ Wind Speed, Solar Radiation $(S R)$, and Door Wind Speed $\left(U_{\text {door }}\right)$ over time 8:00-17:00. 
Figure 35: Averaged values for flow rate $\left(\mathrm{Q}_{\mathrm{avg}}\right)$, the ambient temperature $\left(\mathrm{T}_{\mathrm{am}}\right)$, and temperatures at the top of the vent pipe $\left(T_{\text {top }}\right)$, bottom of the vent pipe $\left(T_{\text {bot }}\right)$, inside the superstructure $\left(\mathrm{T}_{\mathrm{ss}}\right)$ over time 8:00-17:00

Figure 36: Averaged values for flow rate $\left(\mathrm{Q}_{\text {avg }}\right), \Delta \mathrm{T}_{\text {top-bot }}, \Delta \mathrm{T}_{\text {ss-bot }}, \Delta \mathrm{T}_{\text {am-top }}, \Delta \mathrm{T}_{\text {am-bot }}, \Delta \mathrm{T}_{\text {am- }}$ ss, over time 8:00-17:00

Figure 37: Averaged values for flow rate $\left(\mathrm{Q}_{\mathrm{avg}}\right)$, and averaged normalized values for Vent Pipe $\left(U_{V P}\right)$ Wind Speed, Solar Radiation (SR), and Door Wind Speed $\left(U_{\text {door }}\right)$ over time 17:00-23:00.

Figure 38: Averaged values for flow rate $\left(\mathrm{Q}_{\mathrm{avg}}\right)$, the ambient temperature $\left(\mathrm{T}_{\mathrm{am}}\right)$, and temperatures at the top of the vent pipe $\left(\mathrm{T}_{\text {top }}\right)$, bottom of the vent pipe $\left(\mathrm{T}_{\mathrm{bot}}\right)$, inside the

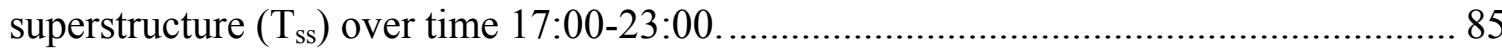

Figure 39: Averaged values for flow rate $\left(\mathrm{Q}_{\text {avg }}\right), \Delta \mathrm{T}_{\text {top-bot }}, \Delta \mathrm{T}_{\text {ss-bot }}, \Delta \mathrm{T}_{\mathrm{am}-\text { top }}, \Delta \mathrm{T}_{\text {am-bot }}, \Delta \mathrm{T}_{\text {am- }}$

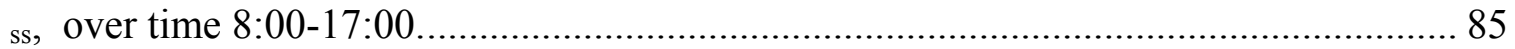

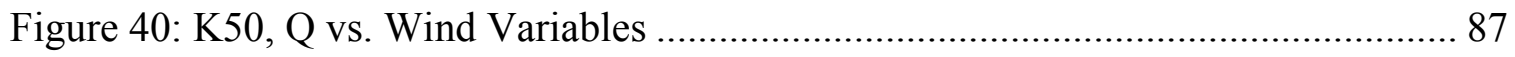

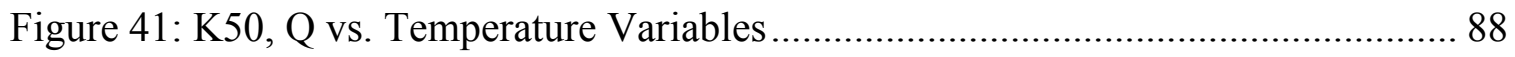

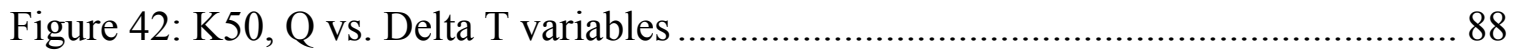

Figure 43: K16 - Q vs. Wind Speed Variables........................................................ 90

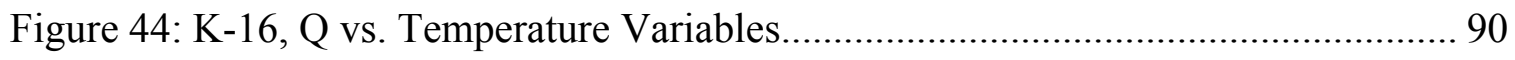

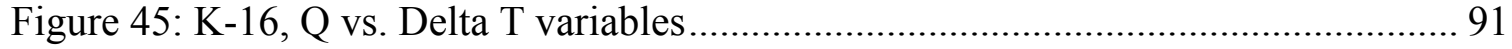

Figure 46: Cumulative average flow rate highlighted by the key driving mechanisms over

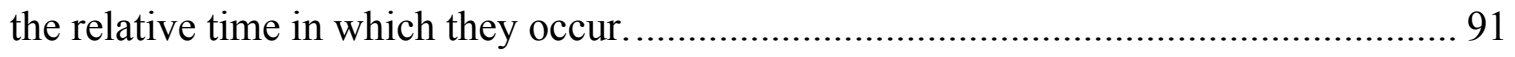

Figure 47: Latrine/Wind Orientation and its effects on flow rate............................... 96

Figure 48: Setups with 'low wind' recorded by anemometer WS compared to the average wind speed recorded by WS2

Figure 49: Proportion of sample with no, partial and full lid over the drop hole and the

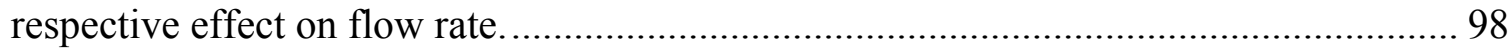

Figure 50: Proportion of sample with no, partial and full entrance covering and the respective effect on flow rate. 
Figure 51: Combined average flow rate for latrines categorized by the presence of a door over the entrance way and or a lid over the drop hole................................................. 100 Figure 52: Combined average flow rate for latrines categorized by presence of an additional opening in the superstructure 101

Figure 53: A collapsed superstructure, in this case the vent pipe remained intact. Photo by Author 103

Figure 54: A broken PVC vent pipe, cause unknown. Photo by Author. 105

Figure 55: Looking down into the top of a vent pipe, with a fly screen that has almost completely rusted away. Photo by Author. 105

Figure 56: A capped vent pipe. Photo by Author ......................................................... 112

Figure 57: Pie chart showing the proportion of the total cost for each item 114 


\section{List of Tables}

Table 1: Definition of access for sanitation ............................................................... 10

Table 2: Advantages and disadvantages of the Simple Pit latrine ..................................... 16

Table 3: Advantages and disadvantages of the VIP latrine ............................................. 18

Table 4: Advantages and disadvantages of the Pour-flush latrine .................................... 18

Table 5: Advantages and disadvantages of the Septic latrine........................................... 19

Table 6: Annual and total cost for meeting the MDG target on sanitation based on

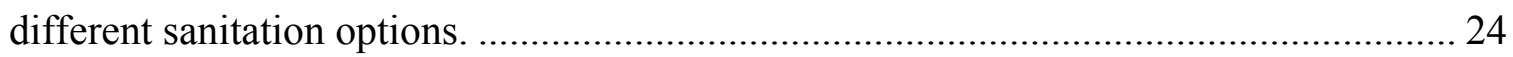

Table 7: Access to Improved Sanitation in Ghana............................................................ 25

Table 8: Regional breakdown of households without sanitation facilities and household

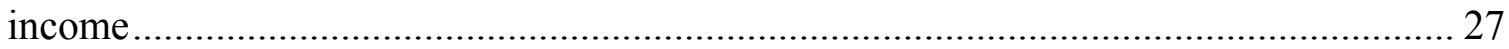

Table 9: Measured ventilation rates of VIP latrines in Zimbabwean single-pit latrines .. 37

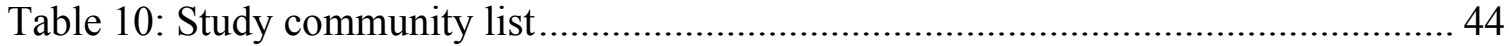

Table 11: Descriptive Statistics for Q over all setups.................................................... 56

Table 12: Recommended ventilation criteria for odorless conditions ............................... 59

Table 13: The number of latrine measurement setups that meet a given standard ............ 60

Table 14: Correlation coefficients for each averaged factor and $Q_{\text {avg }}$ during specific time

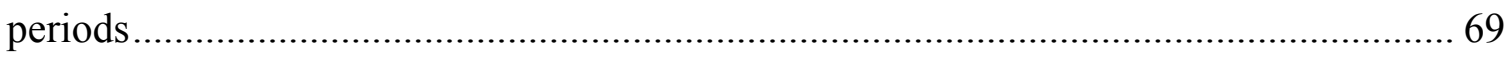

Table 15: Correlation coefficients for each factor and $Q_{\text {avg }}$ during specific time periods 71

Table 16: Correlation coefficients for each factor and $Q_{K 50}$ during specific time periods for Latrine K50

Table 17: Values for each variable correlated against $Q$ during specific time periods for

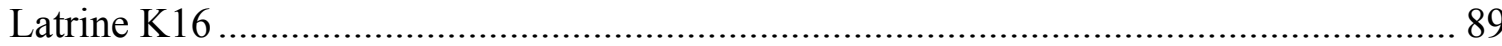

Table 18: Summary of findings from latrine use studies .......................................... 110

Table 19: Summary of user choice statistics from Chapter 7 ........................................ 111

Table 20: Itemized list and estimated cost of a UWR VIP latrine at 2007 prices .......... 114

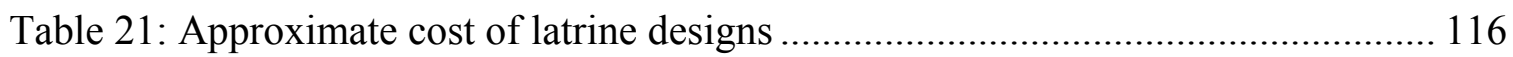




\section{List of Acronyms}

\begin{tabular}{|c|c|}
\hline ASHRAE & American Society of Heating, Refrigerating and Air-Conditioning Engineers \\
\hline CWSA & Community Water and Sanitation Agency \\
\hline GTCP & Ghana Trachoma Control Program \\
\hline JMP & Joint Monitoring Programme \\
\hline MDG & Millennium Development Goal \\
\hline MEP & Minimum Evaluation Procedure \\
\hline MLGRD & Ministry of Local Government and Rural Development \\
\hline NGO & Non Governmental Organization \\
\hline PHAST & Participatory Hygiene and Sanitation Transformation \\
\hline PRA & Participatory Rural Appraisal \\
\hline SP & Simple Pit \\
\hline UN & United Nations \\
\hline UNDP & United Nations Development Programme \\
\hline UNEP & United Nations Environmental Programme \\
\hline UNICEF & United Nations Children's Fund \\
\hline UWR & Upper West Region \\
\hline VIP & Ventilated Improved Pit \\
\hline WHO & World Health Organization \\
\hline WSSD & World Summit on Sustainable Development \\
\hline
\end{tabular}




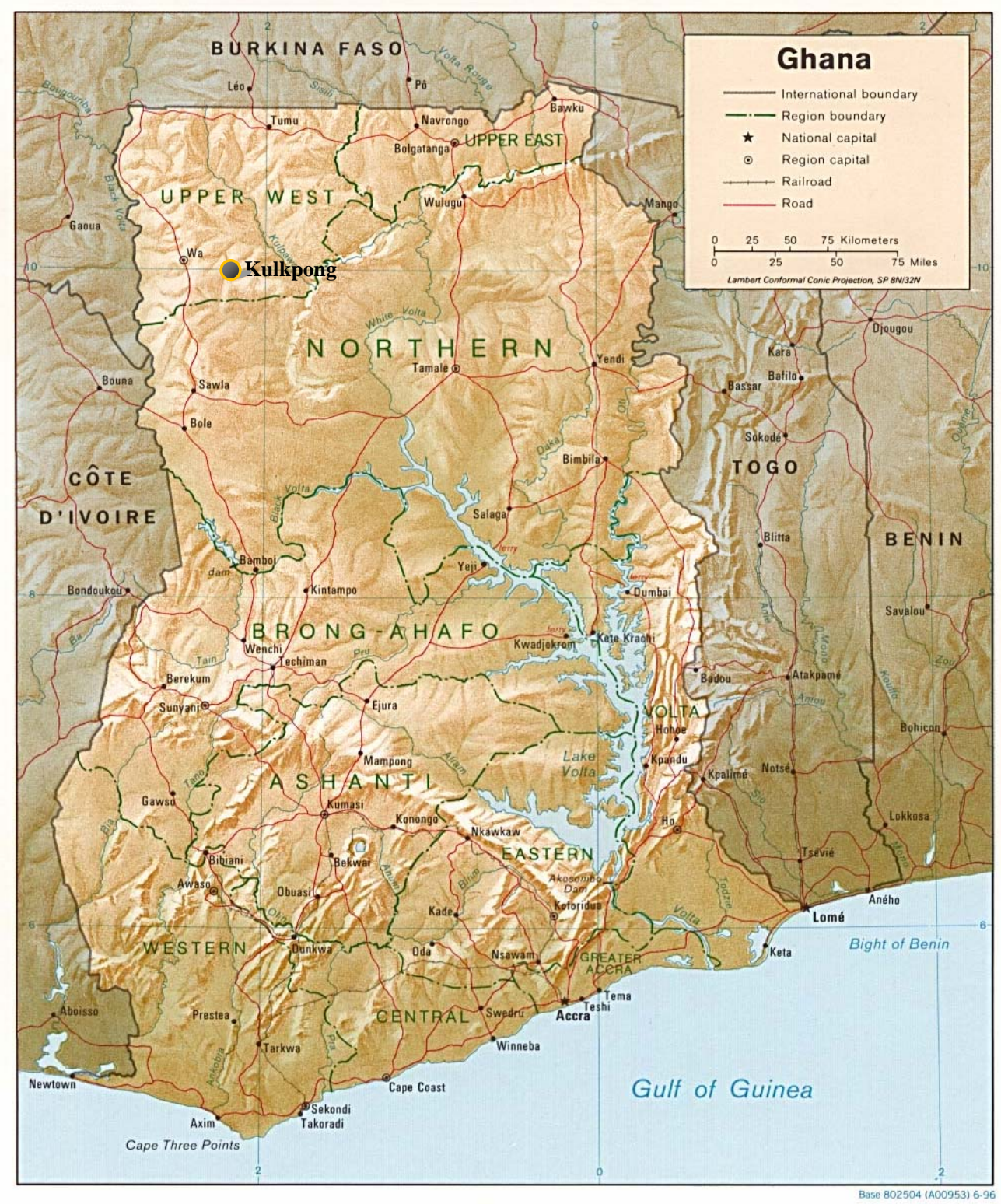

\section{Map of Ghana}

Source: Intute Consortium, Copyright 2006-2008

URL: http://www.intute.ac.uk/sciences/worldguide/html/892_map.html Accessed Date: March 29 ${ }^{\text {th }}, 20$ 


\section{Chapter 1: Introduction and Study Objectives}

"The poor of the world cannot be helped by mass production, only by production by the masses."

- Gandhi

\subsection{Introduction}

Kulkpong is a small farming village located in the Upper West Region (UWR) of Ghana. Its inhabitants number roughly 1,400, and it hosts one of the largest open air markets in the area every six days. One can get to Kulkpong by traveling twenty-six miles southeast down a dirt road from the regional capital of Wa. On the way to Kulkpong the road passes by many rural villages and through slow-rolling hills covered with tall grasses and loosely scattered shea trees. You know you have reached Kulkpong when you cross a hundred foot steel truss bridge that spans the river for which the village was named. Kulkpong in the local language of Waali means "big river."

At first glance Kulkpong does not appear to be remarkably different than any other village in the area. At its center one will often find groups of men sitting in the shade discussing politics or the going prices of crops. Nearby there may be are a couple of market women selling tomatoes and ingredients for the evening meal. And there is usually a large group of women pumping water from a borehole and carrying the water on their heads back to the houses. The houses are all square one-story structures made in an adobe mud-brick style. Some of the houses have slanted roofs made from corrugated iron sheets, while others use a more traditional flat roof made by laying sticks close together across supported logs and covering it all up with mud. Farmers like to lay out their maize, guinea corn, and peanuts on top of the flat roofs to dry them in the sun, keeping them out of reach from the roaming goats, pigs, and chickens. An observer scanning the tops of the houses may notice something else, something that's unlike most rural Ghanaian villages: gray, plastic pipes are sticking out of the roofs of small structures located near just about every house in the village.

In 2006 a non-government organization (NGO) came to Kulkpong and offered to assist the community in constructing household ventilated improved pit (VIP) latrines at no 
monetary cost. Resulting from this fortunate event, nearly every household received at least one VIP latrine, as indicated by the number of polyvinylchloride (PVC) vent pipes seen rising up from the roof tops. Before the NGO arrived, nearly everyone in the village was practicing open defecation in the nearby brush, or "free ranging" as many Ghanaians like to call it. This behavior has been linked to the spread of a number of fecal related disease such as diarrhea, ascaris, hookworm, schistosomiasis and trachoma (UNICEF, 2006). The portion of the population most susceptible to these diseases is of course the children: they are the ones who play in potentially contaminated soil or water, they are the ones who run around the village without shoes and who don't practice personal hygiene on their own. Open defecation has also been associated with higher risks of injury do to encountering snakes or other animals while searching through the brush for a place to defecate. For women, free ranging can also be a time of higher vulnerability to sexual harassment.

From a sanitation standpoint, Kulkpong is above average compared to the rest of the developing world. As of 2004 only $50 \%$ of the population in the developing world had access to basic sanitation. The lowest covered region is Sub-Saharan Africa, where it's estimated that $63 \%$ of the population are at serious risk of exposure to diseases caused by unsanitary conditions (Fewtrell, et. al. 2005). Increased access to sanitation has been associated with improvements in health, social and gender equality, and is considered a major stepping stone toward reducing poverty (Evans \& Haller, 2005; United Nations, 2007). Since the year 2000, the United Nations and its associated organizations have sought to reduce the proportion of the population without access to sanitation by half before 2015. With less than eight years remaining before the deadline expires, $18 \%$ of the developing world's population (approximately 1.6 billion people) will need to gain access in order to achieve the UN goal. For Sub-Saharan Africa, it will require a 30\% increase in coverage, but progress has been slow. From 1990 to 2004, the region had received only a 5\% increase in access to sanitation; a rate that does not even keep up with the rapid population growth. (Fewtrell, et al., 2005; Joint Monitoring Programme, 2006) 
To raise awareness and accelerate progress toward achieving the 2015 goals for sanitation, the UN has declared 2008 the International Year of Sanitation (IYS) - a time to reassess strategies, call attention to the initiatives that work, and to push those initiatives forward. Some of the objectives for the IYS are to, "Encourage demand driven sustainable and traditional solutions, and informed choices," and "Enhance the sustainability and therefore the effectiveness of available sanitation solutions (United Nations, 2007)."

To make informed choices and enhancements to sanitary solutions would call for a critical review of the technologies that play a major part in those solutions. Or in other words, an evaluation of the hardware side of sanitation development. If one were to scan the literature on low-cost sanitation over the last few decades, one would find papers written on advocacy, the effects of disparity, planning models, case studies and economic analysis. Specific to technology, there are books and reports that provide guidelines and instructions on how to construct basic sanitation facilities. Most guidelines however only provide design suggestions and tables that list the advantages and disadvantages of each technology. This information typically comes from the specifications and performances of the original design. Any evidence on the performance of design variations made since the original are observational or anecdotal. Such has been the case for the VIP latrine.

\subsection{Study Motivation}

The two key benefits of a VIP latrine over an alternative latrine design, such as the basic pit latrine, are its ability to remove foul odors and maintain low fly populations, both of which are a direct result of an adequate ventilation flow rate. The design and performance of VIP latrines are discussed in greater detail in the coming chapters. Yet here it should be pointed out that to the author's knowledge there has not been an evaluation of VIP latrine ventilation since the original study conducted on some of the first VIP latrines constructed in Botswana and Zimbabwe back in the early 1980s (Mara \& Ryan, 1983 A). Since that time the design has undergone adaptations as a result of policy and geographic locality. The objective of this study is to determine if these adaptations have resulted in lower or higher ventilation performances. Nevertheless it 
has sometimes been assumed by sanitation planners that constructing VIP latrines will automatically result in fewer odors, lower fly prevalence, and thus higher user acceptance; although there has never been any hard evidence in favor or against these assumptions. It could then be concluded that choosing a VIP latrine design as an appropriate technology based on the mentioned assumptions would not constitute an informed decision.

The question of what difference variations in design could make is perhaps best answered by the authors of the original VIP latrine ventilation investigation themselves: Duncan Mara and Beverly Ryan. They state clearly in their guidelines that, "Proper design of the vent pipe is essential for the correct functioning of VIP latrines. Under-design will normally cause problems in odor and insect control, and overdesign will increase costs unnecessarily. (Mara \& Ryan, 1983 B, p. 1)” Increased cost could then make it potentially unaffordable for benefactors to independently construct, repair or replace a VIP latrine. By definition this would make the VIP latrine an inappropriate technology. As exemplified in the quote at the beginning of this chapter; a truly appropriate technology would have to not only fulfill a function, but also be produced and or afforded by the beneficiary. This would assist in encouraging production by the masses rather than unsustainable mass production.

With all of this in mind, the motivation behind this study was to find quantitative evidence to support or dispel the theory that household VIP latrines in the UWR function adequately at reducing odor and fly populations. This evidence could then be used as contributive facts to evaluate the short term and the long term success of VIP latrines as an appropriate technology in rural communities such as Kulkpong.

\subsection{Report overview and outline}

The World Health Organization proposed a Minimum Evaluation Procedure (MEP) to evaluate completed latrine facilities. This procedure, shown in Figure 1, first evaluates function followed by use. 


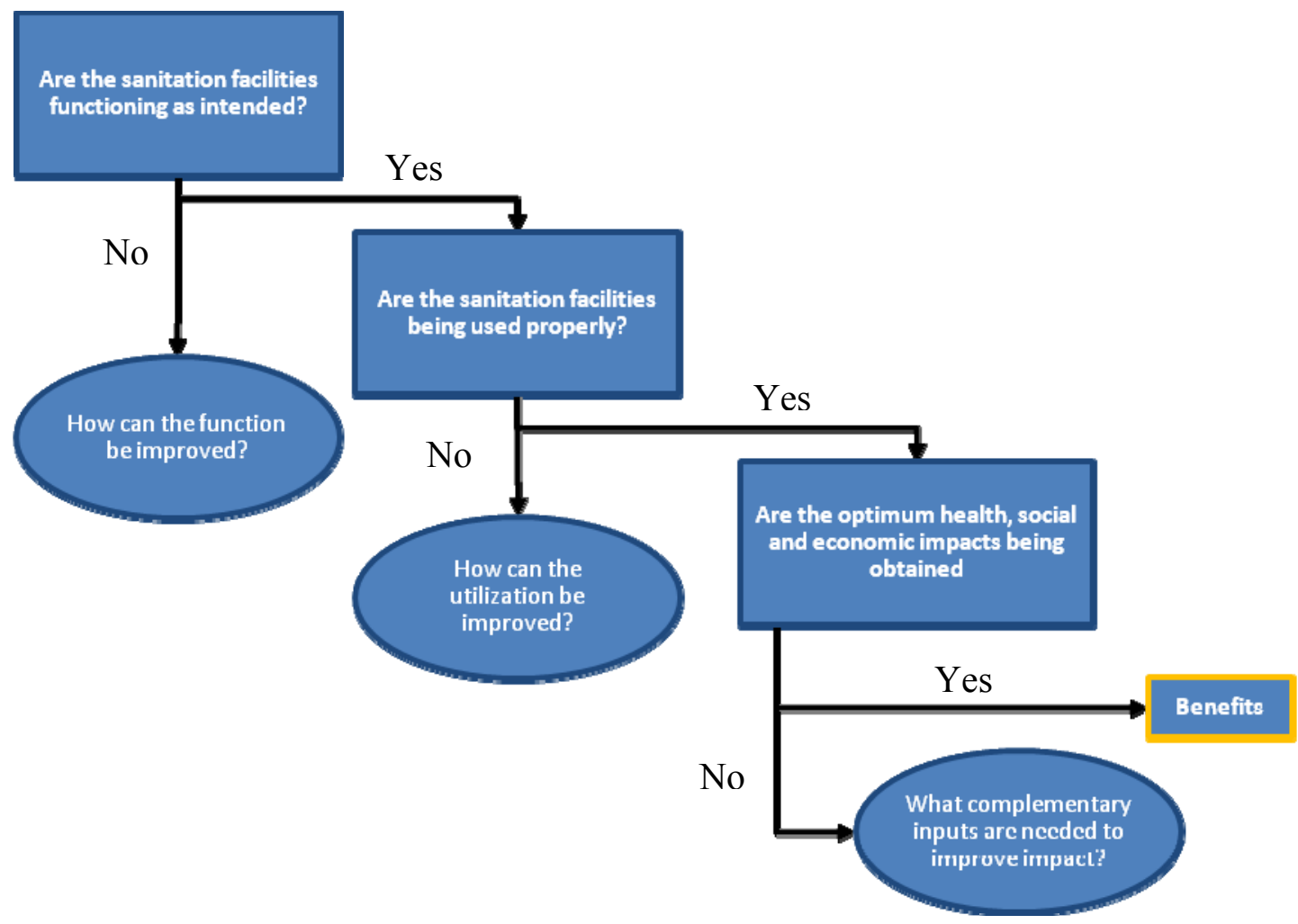

Figure 1: Minimum Evaluation Procedure Adapted from: Pickford, John 1995 p.138

This study focuses primarily on the first question of "Are the sanitation facilities functioning as intended?" Use and impacts are also taken into consideration, but not as directly. Function is addressed by analyzing empirical data collected from a sample of UWR household VIP latrines. That data is then compared with findings from previous VIP evaluative studies and design recommendations. With respect to use, observations made during the present study are compared with other studies that also looked at the adoption of basic sanitation technologies. To address the portion of the MEP regarding health and social impact, information is limited to indirect and anecdotal sources. Yet, enough information on cost of materials and annual household income was gathered to make an assessment of cost and affordability.

The report begins with a summary of the sanitation situation and its implications in the context of the developing world. The focus is then narrowed on sanitation in Ghana and 
the UWR. Included in Chapter 2 is a brief description of the technologies being used for rural sanitation development, and some of the methods by which they are being promoted. Then in Chapter 3, the construction of the VIP latrine is discussed in detail, from the original designs to the designs that are currently being used in the UWR.

Chapter 4 describes the methods and materials used to evaluate function and performance. In Chapters 5, 6, 7 and 8, the results are presented and discussed along with findings from related studies. Lastly, in Chapter 9, the major findings are reviewed, and imparted are the conclusions and recommendations for the future of latrine construction in the UWR.

\subsection{Study objectives}

In brief, the present study evaluated the design of household VIP latrines used in the development of rural communities in the Upper West Region of Ghana, with the focus of assessing adequate ventilation for odor removal and insect control. The general objective of this study was to create a database of observations for household VIP latrines deployed in the UWR. Specific study objectives were to:

1. Evaluate the actual design and condition of a sample of household latrines in the Upper West Region of Ghana, and compare them with the standard designs proposed by the Community Water and Sanitation Agency (CWSA) of Ghana, the United Nations Development Programme (UNDP) and the World Bank.

2. Measure the daily and seasonal airflow rates within vent pipes of a random sample and a selected sample of VIP latrines, and compare the observed findings against the theoretical flow rates specified for odorless conditions as specified by the UNDP and World Bank.

3. Measure the microenvironment and physical characteristics of the VIP latrine sample, and compare it to the concurrent flow rate data to determine if an adequate flow rate is a function of the vent pipe, the superstructure, the local environment, or any combination thereof.

4. For one of the sample communities, observe the proportion of usable VIP latrines compared to VIP latrines that are in actual use, as an indicator of user acceptance. 
Compare observations with studies that had similar objectives but occurred in different locations and with different types of latrines.

5. Conduct a comparative cost analysis of latrine options and an examination of the availability of materials to aid in assessing the VIP latrine as an appropriate technology for sustainable development within rural communities in the Upper West Region of Ghana. 


\section{Chapter 2: Background}

"Access to basic sanitation is a crucial human development goal in its own right, but sanitation is also a means to far wider human development ends (UNDP, 2006).”

\subsection{The importance of sanitation}

The necessity to increase the developing world's access to basic sanitation is well understood. In the 2006 United Nations Human Development Report, it was stated that, at any given time, half of all people in developing countries are suffering from water-and sanitation-related illness such as cholera, typhoid, trachoma, parasitic worms, and diarrhea. The portions of the population that are most susceptible to disease are children. Every year 1.8 million children die as a result of diarrhea $-4,900$ deaths each day, an under-five population equivalent in size to that of London and New York City combined.

As a means to mitigate the morbidity and mortality caused by sanitation-related illnesses, universal coverage of adequate sanitation facilities has been on the global development agenda for more than 20 years. The first major push came in 1981 with the declaration of the International Water and Sanitation Decade. The most recent initiatives have come as part of the United Nations' Millennium Development Goals (MDGs), which were also adopted by the World Summit on Sustainable Development (WSSD). Sanitation is highlighted in MDG 7, which aims to reduce the proportion of the world's population lacking access to water and sanitation by half before the year 2015. The challenge to meet that goal is no small matter. Today 2.6 billion people, more than a third of the world's population, are still without access to suitable excreta disposal (UNDP, 2006).

To achieve MDG 7, an additional 1.6 billion people will have to be provided with what the WHO and UNICEF Joint Monitoring Programme (JMP) has identified as "improved" sanitation systems. Sanitation facilities that fall under the definition of "improved" include the following: "connection to a sewer or septic tank system, pour-flush latrine, simple pit or VIP latrine, with allowance for acceptable local technologies (see Table 1). The excreta disposal system was considered adequate if it was private or shared (but not 
public) and if it hygienically separated human excreta from human contact (Joint Monitoring Programme, 2006).”

Within development literature the term "basic sanitation" is frequently used, but a clear definition of what "basic" means is not always given. For this report "basic sanitation" will be considered a non-networked sanitation system. This is also the definition used by the United Nations Environmental Programme (UNEP). With the exception of "connection to a public sewer," all of the sanitation facilities presented in Table 1 are considered basic sanitation.

Table 1: Definition of access for sanitation Source: Joint Monitoring Programme, 2006

\begin{tabular}{|c|c|}
\hline \multicolumn{2}{|c|}{$\begin{array}{l}\text { Access to adequate sanitation facilities is the percentage of the } \\
\text { population using "improved" sanitation }\end{array}$} \\
\hline Improved & Not Improved \\
\hline connection to a public sewer & public or shared latrine \\
\hline connection to a septic system & open pit latrine \\
\hline pour-flush latrine & bucket latrine \\
\hline \multicolumn{2}{|l|}{ simple pit latrine } \\
\hline ventilated improved pit latrine & \\
\hline
\end{tabular}

In general, the design of improved excreta disposal facilities should satisfy at least two criteria: 1. create a barrier between human feces and human contact, and 2. provide adequate privacy to the user. The importance of the first criteria is related to the prevention of diseases, some of which have been previously mentioned. Many of these diseases are caused by pathogens in feces which find their way back to humans. Diseases such as cholera, typhoid and parasitic worms follow what is referred to as the fecal-oral route of transmission, which is illustrated by the F-Diagram below. Figure 2 also shows us that when an excreta disposal technology is used, it creates a barrier stopping fecaloral diseases from passing along two to three of the transmission routes.

For trachoma, one of the principal vectors is the eye seeking fly Musca sorbens, which has a preferred breeding ground of isolated feces lying on the ground. Studies have shown that the $M$. sorbens fly does not breed within pit latrines. Therefore, removing feces from the outside environment limits the breeding ground for $M$. sorbens, reducing 
its populations and its threat as a vector for trachoma. (Emerson, Simms, Makalo, \& Bailey, 2005; Courtright, Sheppard, Lane, Schachter, \& Dawson, 1991) The same concept can be applied to other disease-carrying insects - different species of flies, cockroaches etc. - if a sanitation facility is properly functioning and maintained.

Just how much of an impact sanitation technologies have as a health intervention has been an elusive question to answer (Cairncross, 2007) but a recent study suggests that improving sanitation reduced diarrhea morbidity by $32 \%$ on average (Fewtrell L, 2005) This modest percentage translates into the preservation of 576,000 children's lives a year, and 1,500 children every day.

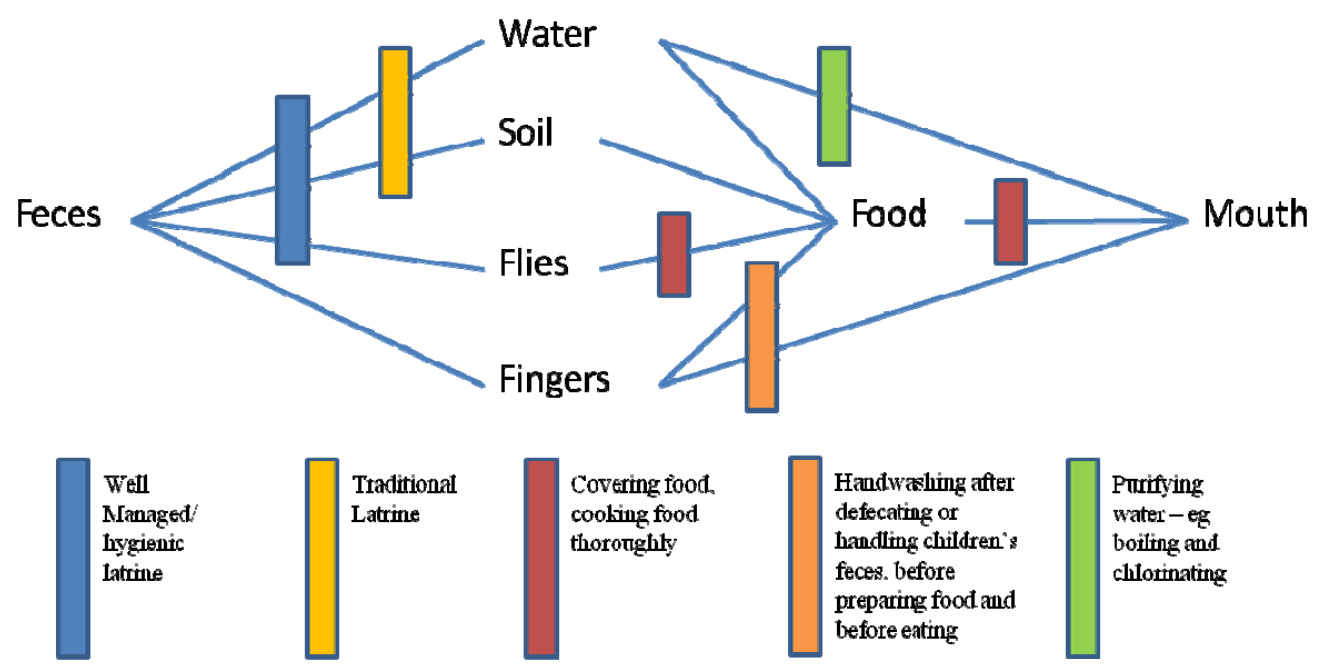

Figure 2: F-Diagram Adapted from Water Aid, (2007)

In addition to improved health, greater access to sanitation can also lead to an increase in social equality, especially for women. For instance, reduced child mortality is a precursor to lower fertility rates which in turn reduces a woman's domestic responsibilities. Furthermore, having close access to sanitation in the home reduces the risk of sexual harassment or assault when searching for private place to defecate. For this reason our second criteria, adequate privacy, is especially important. In some places, like Amhara, Ethiopia, it is culturally inappropriate for women to relieve themselves outdoors during daylight hours. Having access to a toilet in the home improves the quality of life 
for these Ethiopian women. (UN Millennium Project, 2005; O'Loughlin, Fentie, Flannery, \& Emerson, 2006)

On top of health and gender equality, improved access to sanitation has broader implications that aid in achieving other MDGs as well. Such coinciding MDG topics include: poverty, hunger, primary education and environmental sustainability. (UN Millennium Project, 2005)

Despite the overall acceptance that access to sanitation is a crucial element toward development, the fact of the matter is the world is faltering in achieving its 2015 targets. If trends continue as they have since 1990, the sanitation targets for MDG7 will be missed by nearly 600 million people (United Nations, 2007).

\subsection{The problem of increasing access to sanitation}

There are many reasons why providing sanitation to the world's population has been difficult. For one, there is the lack of donor interest and funding. There are also the problems that go along with developing effective local governments and sanitation institutions. (UN Millennium Project, 2005) And then, there are the challenges posed by the way basic sanitation technology has been approached. This last argument is perhaps best summarized by Dr. Sandy Cairncross:

"The problem lies in the fact that most technicians working in the field of sanitation originally trained as civil engineers, whose approach is not to design to a target cost, but rather to a technical specification. There is a need for technicians to take an approach more similar to that of production engineers who are making consumer products, such as motor cars or electric toasters, where the design is for a market niche at a target price. If the product made is too expensive, then there is a need for it to be modified so as to reduce the price. This approach needs to be applied to sanitation. (Cairncross, 2003, p. S129) 
Although the first two causes of slow sanitation development are valid, they are beyond the scope of this dissertation. The latter argument however is addressed in this report, within the context of VIP latrines in the UWR of Ghana. However, it is worth mentioning that when we look at the reasons why individual projects fail, as was done in a study by McPherson and McGarry (1987), the most common were:

- Design errors

- Poor construction

- Use of inappropriate technologies

- Lack of funds

- Opposition or apathy by the intended user

- Absence of an operation or maintenance program.

All six can be related to the design, especially the first four, but the last two have strong ties to how the technology is promoted, or, in other words, the software of sanitation development.

\subsection{Rural improved sanitation technologies, Hardware}

Before discussing the software side of sanitation development, let us first look at some of the common facilities used in the developing world. Keep in mind that this is not intended to be a comprehensive list of all the available technologies, and that there are variations to each of the designs mentioned. Diagrams of each of the technologies described in this section can be found in John Pickford's book The Worth of Water (1998).

\subsubsection{Improved Traditional Practice and Hygiene Promotion}

The most low-tech sanitation intervention is to promote hygiene through community education and motivation to improve traditional practice. Some of the technologies used under this category are digging tools (hoe, shovel etc.) and soap. To better illustrate this, take for example a community that does not have access to sanitation facilities of any kind, and is practicing open defecation. A health worker's first priority would be to educate the community on the hazards of open defecation and poor hygiene. Objectives 
would include stressing the importance of not defecating near water sources; using a tool to dig a shallow hole for defecation in the ground; covering up the feces with soil; and the importance of washing hands with soap and water after defecating and before handling food.

Studies have shown that hygiene promotion can be a very cost effective and sustainable health intervention (Curtis \& Cairncorss, 2003; Cairncross, et al. 2005). The estimated cost of hygiene promotion in most of the developing world is $\$ 10$ per person (Governing Council of the United Nations Environmental Programme, 2004).

Improved traditional practice and hygiene promotion should be one of the first and continuous steps during any community sanitation intervention. However, without improved sanitation, the community is still at risk of fecal-related infectious diseases. The dig-and-bury or "litter box" method described above does little in the way of separating excreta from humans. For instance, there remains the possibility that shallow buried feces could be carried into open water sources by surface water runoff during rain events. Moreover, the dig-and-bury method does nothing to increase privacy and thus social equality. The next step up should then be to develop simple pit latrines out of locally available material.

\subsubsection{Simple Pit Latrine}

Perhaps the most common sanitation facility is the Simple Pit (SP) latrine, primarily due to it being one of the most basic forms of improved sanitation. A SP larine consists of:

- a pit dug into the ground

- a slab on top of the pit that often consists of logs or planks covered by compacted soil, or a concrete slab

- an opening in the slab known as a drop-hole, which may have foot pads or a seat on top (depending on user preference)

- an enclosed structure for privacy (roofs are optional), technically referred to as the superstructure 
Some of the benefits of the SP latrine are that it is easy to construct, operate and

maintain. It does however have several disadvantages as shown below in Table 2 . 
Table 2: Advantages and disadvantages of the Simple Pit latrine

Sources: Pickford, John 1995; Myer, Elizabeth 2007

* Governing Council of the United Nations Environmental Programme, 2004

\begin{tabular}{ll}
\hline Advantages & Disadvantages \\
\hline Low Cost (estimated 45.00 USD*) & Odor \\
Simple Construction & Breeding of flies and other insects \\
Easy Use & $\begin{array}{l}\text { Risk of collapse due to soil structure, or rotting support } \\
\text { wood }\end{array}$ \\
Low Maintenance & $\begin{array}{l}\text { Hookworms and other pathogens breeding on wet, } \\
\text { unkempt slabs }\end{array}$ \\
Accepts all anal cleansing & Hazard of children and animals falling into drop holes \\
materials & that are made too large \\
\hline
\end{tabular}

Many of the disadvantages to pit latrines can be treated by using interventions such as building a tight fitting lid over the drop hole, or applying carbonaceous materials to the pit. The former would prevent odorous gas from rising into the superstructure when the latrine is not in use. Proper use of a lid would also aid in preventing flies from entering and breeding inside the pit.

Another method of insect and odor control is to apply regular doses of carbonaceous materials into the pit after every use. Applying carbonaceous materials with high $\mathrm{pH}$, such as wood ash, can raise the overall $\mathrm{pH}$ of the pile to as high as 12.5 . For most pathogens microbial growth is known to be hampered at a $\mathrm{pH}$ of 9 or greater, and the speed at which pathogens are removed increases with $\mathrm{pH}$ (Kaiser, 2006). If the ash is put in while it's still hot it can kill off maggots (Myre, et al. 2007) and, "cause bubbles of gas to explode, which flies do not like!" (Pickford, 1995, p. 109) This practice could also be used in VIP latrines as the photograph below demonstrates. 


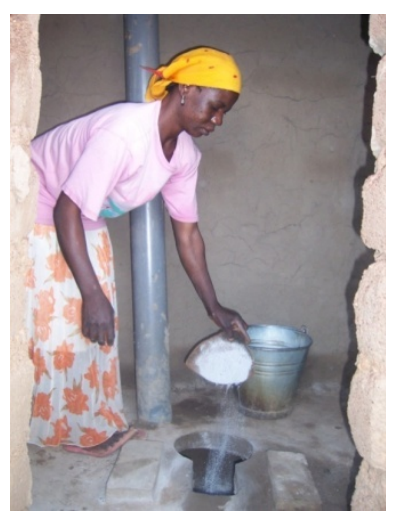

Figure 3: Woman adding wood-ash inside the pit of a VIP latrine Photo by Author

\subsubsection{VIP Latrine}

A detailed description of the VIP latrine is presented in Chapter 3. However, in summary the design of a VIP latrine is similar to that of the Simple Pit latrine in many ways:

- a pit dug out of the ground

- a slab on top of the pit that often consists of logs or planks covered by compacted soil, or a concrete slab

- an opening in the slab known as a drop-hole, which may have foot pads or a seat on top (depending on user preference)

The difference between the two types of latrines consists of:

- a vertical ventilation duct placed over an additional opening in the slab that allows air to pass from the pit directly into the atmosphere above the superstructure

- a screen placed near the top of the ventilation duct to prevent flies from entering

- a fully enclosed superstructure that must have a roof

The overall advantages and disadvantages of a properly constructed VIP latrine are shown in Table 3. 
Table 3: Advantages and disadvantages of the VIP latrine

Sources: Pickford, John 1995; Myer, Elizabeth 2007

*Governing Council of the United Nations Environmental Programme, 2004

\begin{tabular}{ll}
\hline Advantages & Disadvantages \\
\hline $\begin{array}{l}\text { Low Cost } \\
\text { (estimated 65.00 USD*) }\end{array}$ & Higher cost than SP latrine \\
Easy Use & Design is more complex than SP latrine \\
Less odor than SP latrine & Higher maintenance than SP latrine \\
\hline Less flies than SP latrine & $\begin{array}{l}\text { Risk of collapse due to soil structure, or rotting support } \\
\text { wood }\end{array}$ \\
Accepts all anal cleansing & $\begin{array}{l}\text { Hookworms and other pathogens breeding on wet, } \\
\text { materials }\end{array}$ \\
& $\begin{array}{l}\text { Hazempt slabs } \\
\text { that are made too large }\end{array}$ \\
\hline
\end{tabular}

Again, most of this information will be addressed in Chapter 3 with greater detail. For now it should be understood that the key advantages of a VIP latrine over a Simple Pit latrine are that it removes foul odors and maintains low fly populations within the latrine. To fulfill these advantages, the VIP latrine must be constructed properly, maintained, and used appropriately.

\subsubsection{Pour-flush Latrine}

A pour-flush latrine uses water to flush solids into the pit from a pan/bowl that is similar in design to what is commonly used in sewered communities. The pan and the use of water is the most crucial difference between the pour-flush latrine and the two previously mentioned latrines.

Table 4: Advantages and disadvantages of the Pour-flush latrine Sources: Pickford, John 1995; Myer, Elizabeth 2007

* Governing Council of the United Nations Environmental Programme, 2004

\begin{tabular}{ll}
\hline Advantages & Disadvantages \\
\hline $\begin{array}{l}\text { Low Cost } \\
\text { (estimated 70.00 USD*) }\end{array}$ & Higher cost than both the VIP and SP latrines \\
Low odor & Design is higher in complexity than the VIP and SP latrines \\
Low flies & $\begin{array}{l}\text { Not appropriate in areas where water is scarce } \\
\text { Not appropriate in areas where water or soft paper is not used as anal } \\
\text { cleansing materials }\end{array}$ \\
\hline
\end{tabular}

The pour-flush latrine does offer the benefits of being less odorous and having fewer flies than direct pit latrines like the VIP or the SP. Yet it is sometimes difficult to find locally made pour-flush pans that have a smooth enough surface to allow easy and clean 
flushes. In many cases manufactured pour-flush pans are simply not accessible. Despite accessible materials, perhaps the most limiting factor is access to water. To clean a pan requires between one to one-and-a-half liters of water (Pickford, 1995, p. 50). In many parts of the developing world, water is too inaccessible for the practical use of pour-flush latrines.

As an additional note, in many cultures it is not the custom to use water or soft paper for anal cleansing. In West Africa for instance it is common for people to use corn-cobs, sticks, or stones for cleansing materials. In such cases the introduction of pour-flush latrines would be ill-advised.

\subsubsection{Septic Latrines}

The septic latrine is a lower cost version of the septic systems that are commonly used in the developed world. The design of these latrines is similar to that of the pour-flush latrines or a pit latrine. However instead of waste being deposited into a pit they are instead flushed, or dropped, into a water-tight tank that has a built with an overflow pipe. Over time the solid waste settles into the bottom of the tank and excess liquids (graywater) are pushed up and out of the tank through the overflow and into a drainage trench, also known as a leach field or soakaway.

Table 5: Advantages and disadvantages of the Septic latrine Sources: Pickford, John 1995

* Governing Council of the United Nations Environmental Programme, 2004

\begin{tabular}{ll}
\hline Advantages & Disadvantages \\
\hline Low Odor & High Cost (estimated 160.00 USD*) \\
\hline Low flies & High Complexity \\
\hline Possible secondary use of gray-water & Not appropriate in areas where water is scarce \\
& $\begin{array}{l}\text { Not appropriate in areas where water or soft paper is } \\
\text { not used as anal cleansing materials }\end{array}$ \\
\hline
\end{tabular}

The number of parts and the level of complexity make the septic latrine the most expensive form of basic sanitation. Unlike other types of basic sanitation that can be replaced when full, the septic latrine is a more permanent facility that must be desludged when solids occupy more than three-quarters of the liquid volume of the tank (Pickford, 
1995, p. 48). This significantly adds to the maintenance cost of the facility, which is included in the estimated cost given in Table 5.

\subsection{Methods of sanitation promotion/implementation, "Software"}

As indicated in section 2.2, the failure or success of a sanitation project can be a result of how it was promoted. This section will briefly summarize a couple of ways in which sanitation has been promoted in the rural developing world. Again, this by no means is intended to be a comprehensive list and there are variations to each of the methods mentioned below. These methods were selected due to their common, though sometimes limited, use in the UWR.

\subsubsection{Top-down model}

The traditional model is a supply-driven, top-down approach. This is when the government or an NGO arrives in a community and offers to provide that community with a sanitation facility of some kind (usually selected by the NGO or government). The cost of the facility is either completely absorbed by the benefactor, or heavily subsidized. Using this method leaves the control of latrine implementation in the hands of the benefactor. In a well-managed program this can lead to a rapid construction of latrines and a high level of quality control.

On the other hand, studies and trends suggest that this model has had limited success at creating sustainable sanitation growth, especially when user participation, appropriate technology, and long term operation and maintenance is not fully taken into account (Rodgers, 2006). Furthermore, sustained coverage is often beyond the financial and logistical capacity of the sanitation institution. This is particularly true of NGOs as pointed out in this excerpt from William Easterly's book The White Man's Burden:

"(NGO) Donors consistently refuse to finance maintenance and operating supplies, with the idea that this is the responsibility of recipient governments, even though there is intense client demand for these goods.

"Besides the visibility bias toward new construction, the underfunding of maintenance reflects the elusive goal of 'sustainability' (best summarized by that tiresome cliché about giving a man a fish versus teaching him to fish). Donors envision the local government taking over 
the project, which they think it's necessary to make it last. This institution was once appealing, but the decades of evidence show that that dog won't hunt...Since we have already seen the weak commitments of many governments to development, and the inability of donors to transform governments, the takeover of the project usually doesn't happen. (Easterly, 2006)"

\subsubsection{Social marketing model}

A recent trend in sanitation promotion has been based on social marketing. Essentially what this model does is change sanitation into a consumer product. Like any marketing strategy it focuses on a consumer group and tries to market a product to them. In the case of sanitation, social marketing takes available technologies and uses tactics such as advertisements through radio, television, and billboards to entice people to purchase a sanitation facility of their choice and within their price range. In some cases there are even loan programs to assist customers with financing.

There are quite a number of benefits to the social marketing model. For one, it promotes behavioral change through strategic advertising rather than through public health messages. It also contributes to the local economy by encouraging private business which in theory would create more jobs. Finally, perhaps one of the most important lessons to be learned from the model is that it empowers the beneficiary by making her/him a consumer rather than a victim. This creates a heightened sense of pride and ownership of the facility by the beneficiary - which are indicators of sustainable use and maintenance. (Water and Sanitation Program, 2004)

There are of course downsides to social marketing. First, it requires the motivation and overhead cost of setting up businesses and marketing campaigns. Markets often take a long time to develop, so it is not an immediate solution. And finally, it does little or nothing for the poor rural communities as pointed out in a paper by $\mathrm{R}$. Rheingans: “... lack of sufficient population density discourages expansion into poor rural areas. As such, it is not surprising that often those people hardest to reach and with the fewest resources of their own are the least likely to benefit from market-based approaches. (2006, p. 38)" 
It should also be noted that without coordination by all local stake holders, especially among NGOs and government agencies, the social market stands a high risk of being undermined by the top-down approach. It makes it incredibly difficult to sell a product when someone else is providing that same product for free.

\subsubsection{Community-based model}

One more type of method that needs to be mentioned is the community-based model. This model works as follows: Extension agents from a government or NGO arrive in a rural community with poor sanitation. With community members, agents facilitate what is often referred to as participatory rural appraisal (PRA), or any variation thereof such as participatory hygiene and sanitation transformation (PHAST). Essentially PHAST is a series of exercises that aid communities in understanding and recognizing sanitation problems. In the end, the community develops its own strategy for handling the sanitation problem. The agents also take time to educate the community members on different types of latrines available and how to build latrines out of local materials by constructing demonstration models. Community members are also encouraged to develop their own latrine facilities.

The community-based model approach has been utilized since the early ' 70 s, but too rarely has it been actively used in the field of sanitation - that is until a recent revival of the method in Bangladesh. From sometime in the late ' 90 s to 2003, more than 400 villages and 15,000 Bangladeshi families had stopped practicing open defecation and were using some form of improved sanitation (Kar, 2003). The Bangladesh model has since been applied in India, Cambodia, Uganda and Zambia. A community-based approach in Ethiopia has also produced some impressive results. It was reported that in less than one year's time, 22,385 latrines had been constructed in the Amhara district (O’Loughlin, et al. 2006).

The benefits of the community-based model are numerous. First and foremost, it takes community empowerment a step further than the market-based approach by leaving the design and construction of facilities in the hands of the community. Since it is only knowledge that is being transferred, technological diffusion can happen rapidly and at a 
near zero cost. On the other hand, the drawbacks are that for successful application the model depends largely on the attitude and training of the extension agent. Furthermore, the quality of the latrine constructed may not be as sturdy or last as long as one made by experts. However, with adequate training of the agents and consultation from the experts, safety does not have to be compromised. With some speculation, the more likely problem will be convincing those in charge to loosen sanitation policy enough to relinquish control over the design and construction of latrines.

The purpose of mentioning these models is not to debate which one is the best at promoting and implementing improved sanitation. Rather, the point is that, regardless of the method being used, the design of the facility (hardware) plays a major role in the success of the promotion. In the case of the top-down model, if latrine design is low-cost and simple, then greater numbers of latrines can be constructed in less time, making better use of the limited financial resources of the providing institution. For social marketing, sanitation businesses need to be able to provide low-cost and simple solutions to appeal to a broader market. And finally, for the community based approach, it goes without saying that success for this model is highly dependent on finding low-cost, or nocost design solutions producible by community members themselves.

\subsection{The cost of sanitation}

Assuming the use of a supply-driven model, such as the top-down approach, the cost of achieving the 2015 MDGs for sanitation is beyond the capacity of the funds that are actually available. According to the UNEP, the cost of providing basic sanitation to fulfill MDG7 is 17 billion USD; and 70 billion USD will be required for wastewater treatment. The finance gaps are estimated at 16 billion USD and 56 billion respectively. For rural sanitation alone, the cost is estimated to range from 11-174 billion USD depending on the technology that's implemented, as shown in Table 6 below. (Governing Council of the United Nations Environmental Programme, 2004) 
Table 6: Annual and total cost for meeting the MDG target on sanitation based on different sanitation options.

Adapted from: Governing Council of the United Nations Environmental Programme, 2004

\begin{tabular}{lcc}
\hline Rural Sanitation Options & Cost per annum (US\$ bn) & $\begin{array}{c}\text { Total cost of meeting } \\
\mathbf{2 0 1 5} \text { targets (US\$bn) }\end{array}$ \\
\hline $\begin{array}{l}\text { 1) Improved traditional practice / } \\
\text { sanitation and hygiene promotion }\end{array}$ & $\$ 0.8 \mathrm{bn}$ & $\$ 11 \mathrm{bn}$ \\
\hline 2) Simple pit latrine & $\$ 4 \mathrm{bn}$ & $\$ 48 \mathrm{bn}$ \\
\hline 3) Ventilated improved pit latrine & $\$ 5 \mathrm{bn}$ & $\$ 70 \mathrm{bn}$ \\
\hline 4) Pour flush latrine & $\$ 6 \mathrm{bn}$ & $\$ 76 \mathrm{bn}$ \\
\hline 5) Septic tank system & $\$ 13 \mathrm{bn}$ & $\$ 270 \mathrm{bn}$ \\
\hline
\end{tabular}

To illustrate how technology can affect cost, the UNEP has devised a "ladder of sanitation options," shown here in Figure 4. The ladder uses cost estimates for different levels of sanitation services and technology options starting at the bottom from basic level and leading up to more sophisticated levels.

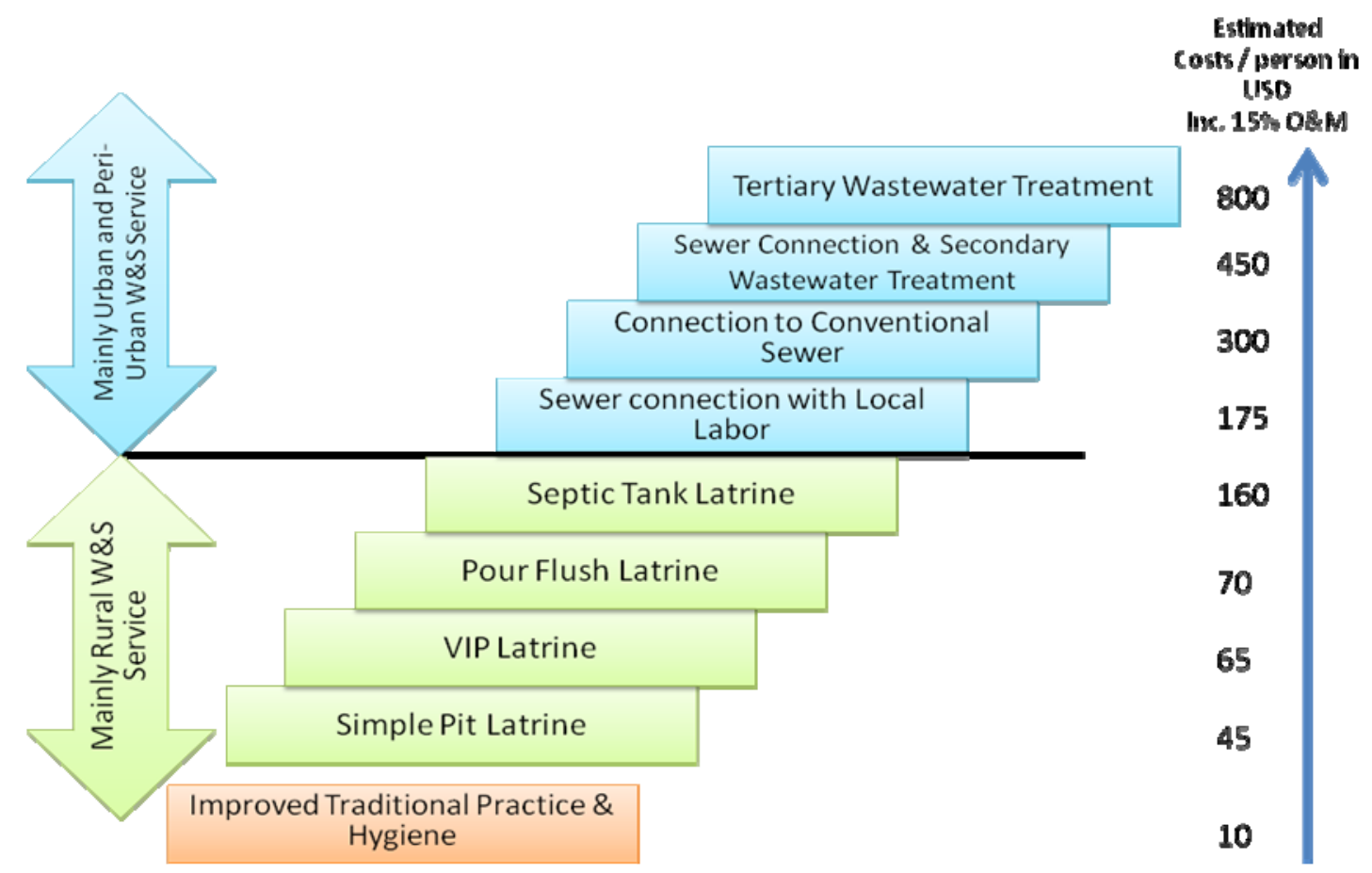

Figure 4: Ladder of Sanitation Options

Adapted from Governing Council of the United Nations Environmental Programme, 2004, p.7

Using the ladder of sanitation options, the UNEP succinctly point out that, "One conclusion that could be reached is that the funding gap between the current level of 
investment in the water and sanitation sector and the level of investment required to reach the WSSD agreed target on sanitation could be substantially reduced if lower cost technology is used in certain situations (Governing Council of the United Nations Environmental Programme, 2004, p. 8)" To elaborate more on this point; applying low cost or no cost solutions to the rural areas of the developing world would in theory provide economic savings that could then be allocated to the more expensive and complex problem of urban sanitation development.

\subsection{The state of sanitation in Ghana}

With less than $20 \%$ of Ghana's total population having access to improved sanitation, the West African country has still a long way to go to reach nation-wide coverage, or even their MDGs. Table 7 gives us an overview of sanitation in Ghana. As evident from Table 7 the majority of the population without access to sanitation resides in Ghana's rural areas.

Table 7: Access to Improved Sanitation in Ghana Source: Joint Monitoring Programme, 2006

\begin{tabular}{lc}
\multicolumn{2}{c}{ Source: Joint Monitoring Programme, 2006 } \\
\hline Total population= 21,664,000 (\% Urban = 46, \% Rural = 54) & Value (2004) \\
\hline Urban population with access to improved sanitation (\%) & 11 \\
Rural population with access to improved sanitation (\%) & 18 \\
\hline Total population with access to improved sanitation $(\%)$ & \\
\hline
\end{tabular}

In the past, the government of Ghana attempted to address the lack of sanitary excreta disposal by constructing large communal latrines, also known as institutional latrines. These were intended to service all of the households in an area. However experience has shown that communal latrines have been relatively ineffective due to a number of social and economic reasons. For instance, many communities face the problem of enforcing payment for the use of communal latrines, which eventually leads to a lack of funds to cover the operations and maintenance costs. The people's attitude toward communal latrines can be generalized by a frequently used Ghanaian expression: "Everybody's problem is nobody's problem." Once communal latrines fall into disrepair they are likely to become sanitary hazards with lower user acceptance. For this and other reasons the United Nations does not recognize communal latrines as improved sanitation. Ghana's 
sanitation policy has also turned away from institutional latrines, and instead is now focusing on providing sanitation access to individual households.

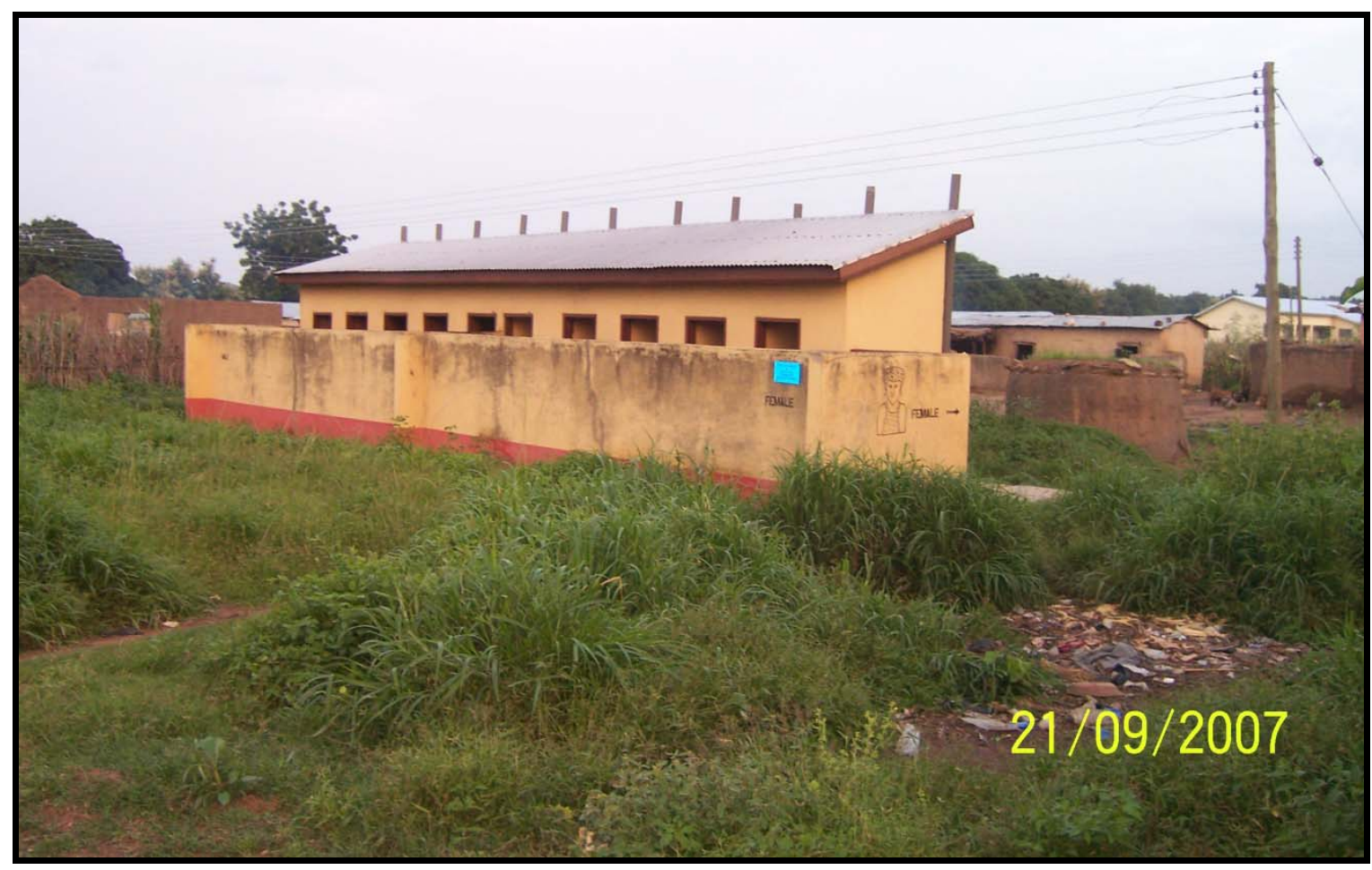

Figure 5: Photograph of an institutional latrine in Ghana Photo by Author

If we were to look more specifically at households with access to sanitation, broken up by region, as shown in the table below, we begin to see an even clearer picture of the state of access to sanitation in Ghana. (Note: it is common for a Ghanaian household/family to live in the same house/compound with other households, particularly in urban and periurban areas where space and housing is limited. This would account for the discrepancy between the number of houses and the number of households reported in Table 8.) A couple key facts that should be noted from Table 8 are:

- On average $65 \%$ of households are without toilet facilities.

- The three regions with the largest deficits make up Northern Ghana, an area which has the lowest household income compared to the rest of the country (highlighted in yellow on Table 8 and Figure 6) 
Table 8: Regional breakdown of households without sanitation facilities and household income Source ${ }^{1}$ : Quansah, 2006

Source $^{2}$ : Ghana Statistical Service, 2000

\begin{tabular}{|c|c|c|c|c|}
\hline Region & Houses $^{1}$ & Households $^{1}$ & $\begin{array}{c}\text { Households without } \\
\text { sanitation facilities (\%) }\end{array}$ & $\begin{array}{c}\text { Mean annual household } \\
\text { income, USD }\end{array}$ \\
\hline Ashanti & 328,751 & 682,759 & $391,878(57)$ & $\$ 701$ \\
\hline Brong Ahafo & 216,275 & 342,808 & $193,518(56)$ & $\$ 633$ \\
\hline Central & 223,239 & 365,777 & $220,205(60)$ & $\$ 403$ \\
\hline Eastern & 283,461 & 456,683 & $209,564(46)$ & $\$ 565$ \\
\hline Greater Accra & 287,840 & 626,613 & $297,486(48)$ & $\$ 923$ \\
\hline Northern & 177,785 & 245,617 & $224,913(92)$ & $\$ 427$ \\
\hline Upper East & 51,898 & 144,386 & $134,384(89)$ & $\$ 398$ \\
\hline Upper West & 88,401 & 80,635 & $71,549(93)$ & $\$ 397$ \\
\hline Volta & 264,451 & 345,821 & $200,581(58)$ & $\$ 536$ \\
\hline Western & 259,874 & 410,142 & $220,870(54)$ & $\$ 735$ \\
\hline
\end{tabular}

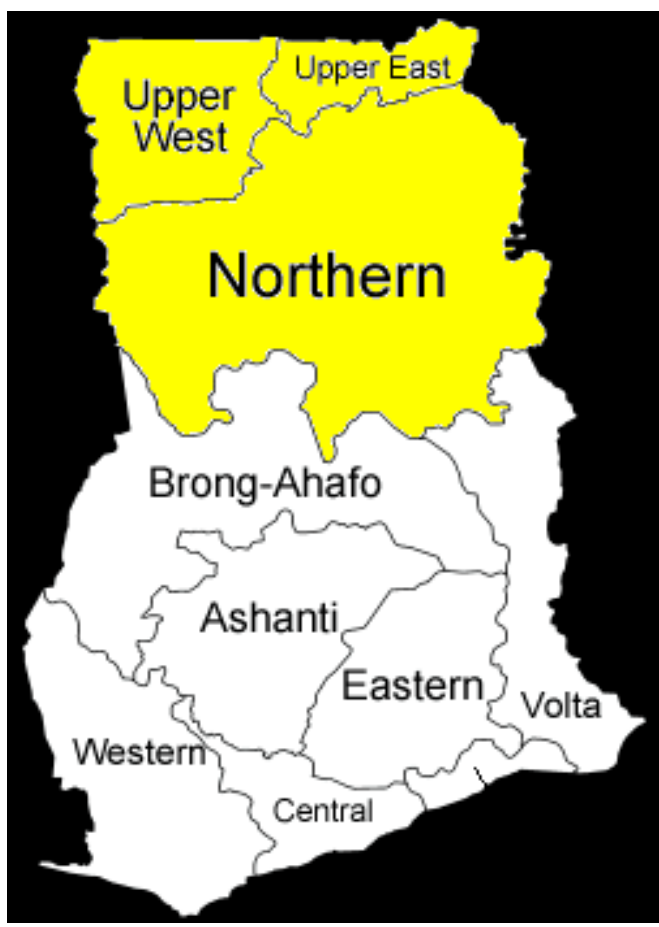

Figure 6: Map of Ghana

Adapted from: http://en.wikipedia.org/wiki/Image:Ghana_regions_named.png\#file.

Licensed under the Wikimedia Commons

The levels of poverty found in the northern regions of Ghana can be attributed to many factors including a lack of reliable transportation infrastructure, political influence, tribal wars, and the environment. The environmental geography of Ghana is divided into two regions by the Kwahu Plateau. Regions below the Kwahu receive rainfalls that range 
north to south from 1,250 millimeters to 2,150 millimeters over the course of two rainy periods: April through June, and September through November. The result is a dense tropical rainforest environment that offers a long and productive farming season.

Regions north of the Kwahu Plateau (Upper West Region, Upper East Region, and Northern Region) are characterized as sahel savannah and grassland savannah. The area experiences only one period of rainfall that begins around June and ends in September, leaving behind 1,000 millimeters of rainfall per year. The farming season in the north is therefore limited to the short rainy season and is highly susceptible to drought. (Berry, 1995)

Despite the differences in environmental characteristics and household income between the northern and southern regions, the national sanitation policy is the same for the entire country. Under that policy the following sanitation technologies are recommended (Ministry of Local Governement and Rural Development, 1999):

- the water closet,

- the pour flush latrine,

- the VIP latrine, the aqua privy,

- the chemical toilet (for emergency or temporary usage),

- any other proven technologies recommended by the Ministry of Local Government and Rural Development (MLGRD).

In order to achieve the MDGs for sanitation Ghana will have to provide facilities to half the proportion of the population that was without access in 1990, with consideration to an added $1.97 \%$ population growth rate. Using the population data provided in Table 7, and assuming an average of 10 people per household toilet, an estimated 1,142,000 household facilities will have to be built within the next eight years. This equates to approximately 143,000 facilities per year.

For comparison, Ghana's MLGRD estimates the percent population with access to sanitation in 2004 to be around 35\%, which is more optimistic than the WHO's estimate of $18 \%$ in Table 7 . Using the MLGRD's percent access figure, but keeping the growth 
rate and the assumption of 10 people per household toilet the same, 773,603 household facilities will be required in the next eight years. This works out to be 96,700 facilities a year. (Quansah, 2006)

Regardless of the figure used, the average rate of delivery for Ghana has been only 4,000 units per year since 1995. If this trend continues, Ghana will miss its MDG7 target by nearly 1,109,000 according to the WHO, or 741,603 according to the MLGRD. The conservative cost, as estimated by the MLGRD, will be roughly 241 million USD to cover rural areas, and 748 million USD to cover urban centers. Together the total estimate would be around 989 million USD. (Quansah, 2006)

\subsection{The Upper West Region and its state of sanitation}

The present study took place in the Upper West Region (UWR) of Ghana, where in 2000 the population was estimated at roughly 580,000, of which $90 \%$ were rural (International Fund for Agricultural Development, 2006, p. 4). The main source of income for the region comes from farming and small trade. As Table 8 above shows, the UWR has the lowest household income in the country. This is where one is likely to find many of Ghana's poorest of the poor - rural subsistence farmers who earn less than a dollar a day. The UWR is blessed with an abundance of land for both crops and livestock, and a low population density (approximately 29.8 person $/ \mathrm{km}^{2}$ ). However the climate of northern Ghana, as previously mentioned, has created low-productive and short farming seasons. Sluggish economic development is further hindered by poorly functioning markets for agricultural outputs, badly maintained feeder roads and lack of transportation services, a reliance on rudimentary farming methods and technology, and a lack of skills and inputs such as fertilizer and improved seeds that would increase yields. (International Fund for Agricultural Development, 2006)

The above factors result in more than $84 \%$ of the population living in poverty, with virtually no disposable income (International Fund for Agricultural Development, 2006, p. 4). These Ghanaians are the ones who are least likely to be able to afford health care or have access to clean water and sanitation without assistance. This is evident by an 
under-five child mortality rate in the UWR of 208 deaths per 1000 births, which is almost twice the national average of 107 per 1000 births. (Ghana Statistical Service (GSS), Noguchi Memorial Institute for Medical Research (NMIMR), and ORC, 2004) The level of poverty would also help to explain why $93 \%$ of households in the UWR are without sanitation facilities. In the few rural households where sanitation facilities do exist, most if not all have been provided by the government or an NGO. And in keeping with the national sanitation policy, nearly all household latrines are VIP latrines. 


\section{Chapter 3: The VIP latrine design}

\subsection{History}

In 1973 Dr. Peter Morgan and Ephraim Chimbunde of Zimbabwe's Blair Research Laboratory began developing the idea of ventilating pit latrines as a means by which to remove odor and discourage the breeding of insects, particularly flies. It was observed that the attachment of a mesh-capped vertical vent pipe to the cover slab of a common pit latrine significantly reduced the two undesirable by-products of flies and odor. In doing so the developers believed that they had found a low-cost way to make pit latrines more hygienically safe and more socially accepted. In Zimbabwe these vented latrines were called "Blair Latrines," but to many of the other countries in which they were adopted, Botswana, Lesotho, Tanzania and Ghana, they are known as Ventilated Improved Pit latrines, or VIP latrines. (World Bank, 2002)

\subsection{Theoretical Design}

The installation of a vent pipe creates a natural ventilation airflow path which, under the right conditions, allows for any foul odors inside the pit to pass into the atmosphere through the vent pipe rather than the superstructure. Since odors are expelled outside of the latrine via the vent pipe, insects that may be attracted to the smell of excrement gather around the mouth of the vent pipe rather than inside the superstructure. The gathering flies are unable to pass into the pit due to a mesh screen covering the mouth of the vent pipe. Without being able to detect any odors emanating from the superstructure, flies are thus prevented from breeding within the pit and becoming vectors for diseases associated with human excrement.

Fly control is further enhanced if light levels inside the superstructure are kept low enough so that the greatest source of light inside the pit is being cast down through the vent pipe. Given that most species of flies are phototrophic, any fly that may be inside the pit instinctively tries to leave via the vent pipe; it however cannot escape because of 
the fly screen. In properly functioning VIP latrines these fly control mechanisms have been found to be very effective. In a seventy-eight day study in Zimbabwe, 146 flies

were caught escaping from a VIP latrine while 13,953 were caught from an unvented, but otherwise identical, pit latrine (Mara D. D., 1984, p. 4). In theory, with minimal flies and odor inside the superstructure, beneficiaries are less likely to be discouraged from using the latrine rather than returning to the behavior of open defecation.

\subsection{The Mara and Ryan Evaluation}

VIP latrine ventilation performances, and the controlling mechanisms, were not completely understood until an investigation was conducted in 1983 by D. Duncan Mara and Beverley A. Ryan. These two researchers were developing a technical manual / design guidelines for the UNDP and the World Bank. The objectives of their investigation included (Mara \& Ryan, 1983 A):

1) To determine the effects of wind speed, wind direction and solar radiation on the ventilation performance.

2) To determine the optimum position, diameter and height of the vent pipe. This should include investigation into the differences between the vent pipe being located inside and outside the superstructure.

3) To evaluate the minimum air flow required to reduce odor in the superstructure to below (a) the level perceived as a nuisance, and (b) the threshold concentration for attracting insects.

To achieve their objectives the two researchers created a methodology for evaluating ventilation performance based on monitoring the temperature at various points in the latrine, the velocity of airflow within the vent pipe, the wind speed across the mouth of the vent pipe, and the variations of atmospheric pressure in and out of the latrine (see Figure 7). Using this methodology they ran performance evaluations on alternating twinpit VIP latrines constructed in Botswana and Zimbabwean single-pit VIP latrines. The latter design bears the closest similarities to those found in the UWR of Ghana, and therefore will be the one most frequently referred to and compared against in the present 
study. The differences between the Zimbabwean and the UWR designs are discussed later in this chapter. Differences aside, much of what is known today about VIP latrine ventilation mechanisms, and their design criteria, come from the Mara \& Ryan investigation.

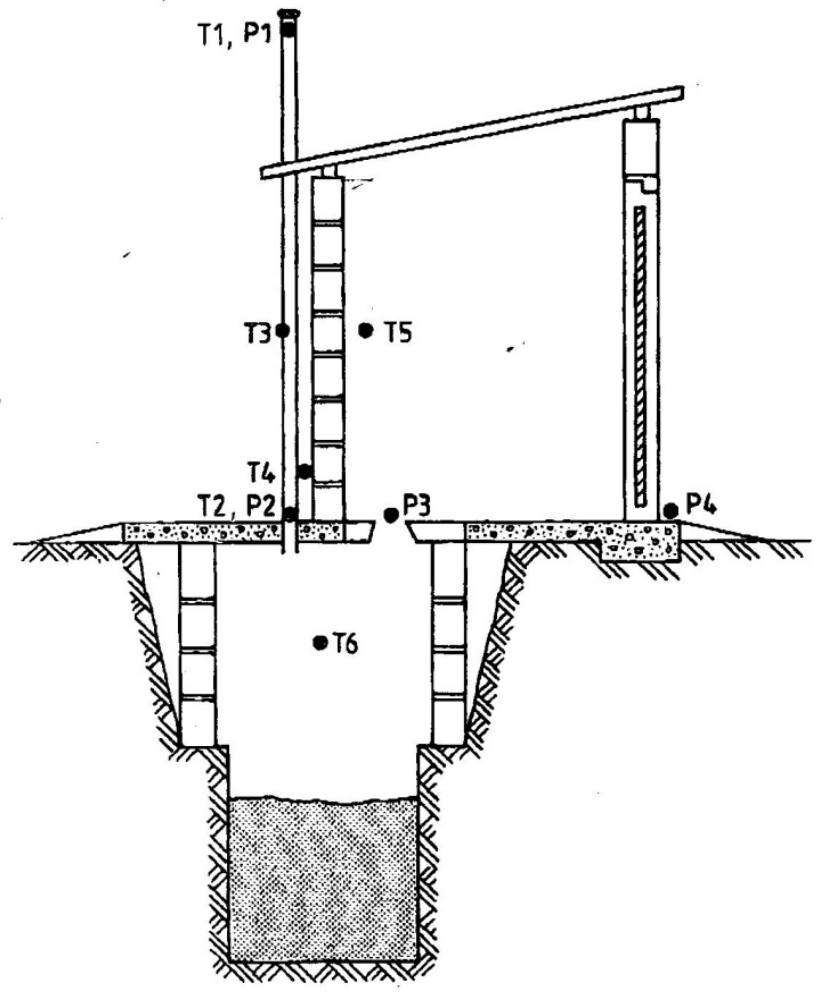

Figure 7: Location of temperature probes T1 through T6 and air pressure measurement points P1 through P4

Source: Mara \& Ryan, 1983, p. 10

\subsection{Ventilation mechanisms}

According to the Mara \& Ryan investigation there are three principle mechanisms that affect ventilation flow rates. They are: a) wind across the top of the vent pipe; b) wind passing into the superstructure; and c) solar radiation heating the vent pipe. Each mechanism can occur individually or in combination. Details of each mechanism and its design criteria, as described by Morgan, Mara \& Ryan (1982; 1983 B) are as follows: 


\subsubsection{Wind across the top of the vent pipe}

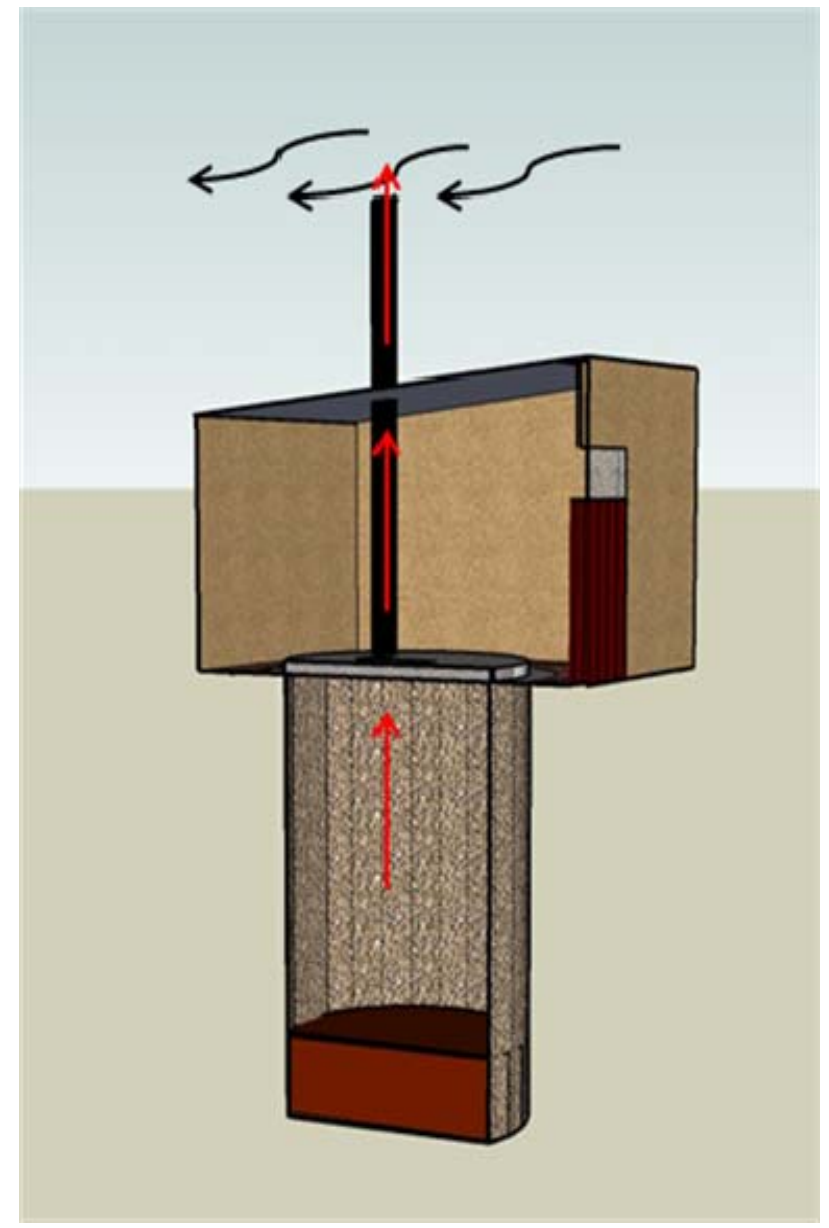

Figure 8: Cross sectional diagram of a VIP latrine showing wind passing over the vent pipe As wind passes perpendicular to the mouth of the vent pipe negative pressure (suction) is created within the vent pipe, pulling air from the latrine pit into the atmosphere. The optimal design criteria for this mechanism to occur are:

- the latrine is at least $2 \mathrm{~m}$ away from anything that may inhibit airflow over the mouth of the vent pipe

-with flat roofs the top of the vent pipe should be at least $500 \mathrm{~mm}$ higher than the roof, and in the case of conical shaped roofs the vent pipe should be at least as high as the apex of the roof

-PVC vent pipes should have a minimum internal diameter of $150 \mathrm{~mm}$ for installations with wind speeds less than $3 \mathrm{~m} / \mathrm{s}$, and $100 \mathrm{~mm}$ for installations with wind speeds greater than $3 \mathrm{~m} / \mathrm{s}$ 
-Fly screens with an aperture smaller than $1.2 \mathrm{~mm}$ x $1.5 \mathrm{~mm}$ may create an excessive impedance of air flow (headloss)

-vent pipes made from other materials like cement-rendered reed or hessian should have a minimum internal diameter of $200 \mathrm{~mm}$. Vent pipes made from brick should have a minimum size of $190 \mathrm{~mm}$ square.

\subsubsection{Wind passing into the superstructure}

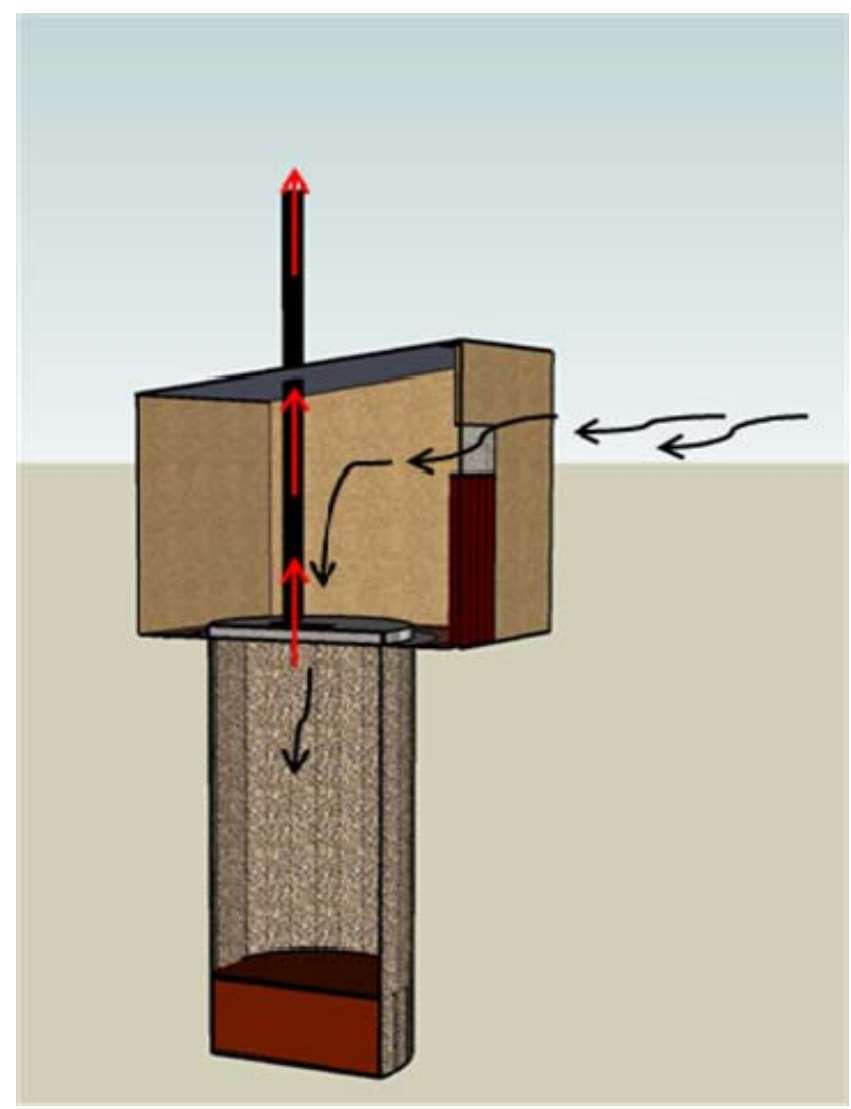

Figure 9: Cross sectional diagram of a VIP latrine showing wind passing into the superstructure

When wind is allowed to flow into the superstructure it creates a higher air pressure system within. The higher pressured air will move to an area of lower pressure, which can be found within the pit. Once in the pit the air will continue toward lower air pressure and naturally flow up the pipe, taking with it any foul odors emanating from the pit below. The optimal design criteria for this mechanism to occur are:

- an entrance, or ventilation opening - that's at least three times the cross sectional area of the vent pipe - should face the direction of the prevailing wind 
- no openings on the opposite sides of the entrance or ventilation opening, as this would significantly reduce the pressure differences that cause updraft in the vent pipe

- the drop-hole should remain uncovered to allow air to pass from inside the superstructure into the pit.

\subsubsection{Solar Radiation}

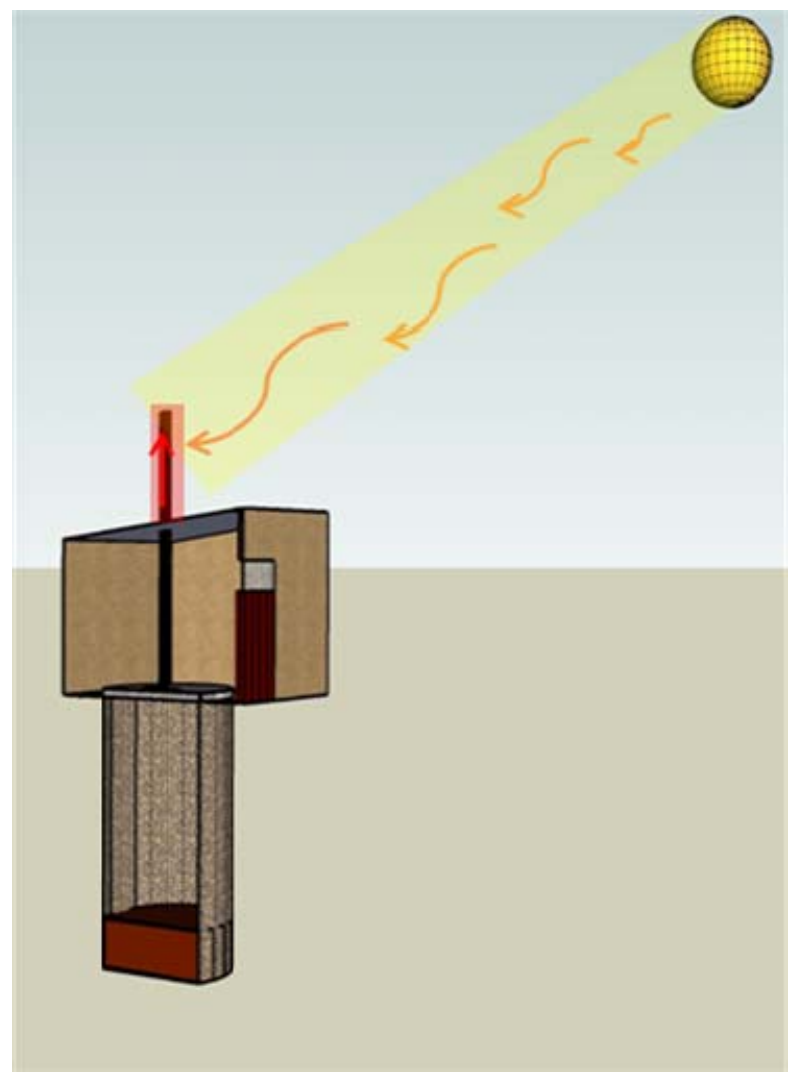

Figure 10: Cross sectional diagram of a VIP latrine showing solar radiation heating the vent pipe

During daylight hours, and on non-cloudy days, radiation from the sun heats the material of the vent pipe. This in turn heats the air inside the pipe to a greater temperature than the outside air. The warmed, less dense, air rises out of the pipe and is replaced by cooler air from the pit; this is known as the stack effect. The optimal design criteria for this mechanism to occur are:

- as much of the vent pipe's surface area should be exposed to the sun as possible 
- in areas where wind speeds are less than $0.5 \mathrm{~m} / \mathrm{s}$, the external surface of the vent pipe should be painted black to increase the absorption of solar radiation. In areas where wind speed is greater than $0.5 \mathrm{~m} / \mathrm{s}$, the color of the vent pipe is not important.

\subsection{Ventilation Performance}

The Mara \& Ryan investigation found that the primary driving mechanism of ventilation was wind passing over the top of the vent pipe. This mechanism was further enhanced when an opening in the superstructure of the latrine faced the direction of the wind. Thermally induced updraft was found to be of little importance unless the latrine was located in a low wind environment. (Mara \& Ryan, 1983 B, p. 5) Furthermore, the researchers were able to determine flow rates for various types of vent pipe designs and materials such as cylindrical cement pipes, PVC pipes, and square brick chimneys. A summary of their results are presented in the table below:

Table 9: Measured ventilation rates of VIP latrines in Zimbabwean single-pit latrines Adapted from: Mara \& Ryan, 1983

\begin{tabular}{|c|c|c|c|c|}
\hline \multicolumn{2}{|c|}{ Vent Pipe details } & \multirow[b]{2}{*}{$\begin{array}{l}\text { Superstructure } \\
\text { volume }\left(\mathrm{m}^{3}\right)\end{array}$} & \multirow[b]{2}{*}{$\begin{array}{l}\text { Ventilation } \\
\text { rate }\left(\mathrm{m}^{3} / \mathrm{hr}\right)\end{array}$} & \multirow{2}{*}{$\begin{array}{c}\text { Superstructure air } \\
\text { volume changes per } \\
\text { hour }(\mathrm{ACH})\end{array}$} \\
\hline Material & $\begin{array}{l}\text { Internal Diameter } \\
(\mathrm{mm})\end{array}$ & & & \\
\hline PVC & 100 & 1.8 & 11 & 6 \\
\hline PVC & 150 & 1.8 & $18-47^{*}$ & $10-26^{*}$ \\
\hline Asbestos Concrete (AC) & 150 & 1.8 & 18 & 10 \\
\hline Reed/cement & 280 & 1.8 & 32 & 18 \\
\hline Pole/soil & 280 & 1.8 & 32 & 18 \\
\hline $\begin{array}{l}\text { Hessian/wire } \\
\text { mesh/cement }\end{array}$ & 250 & 1.8 & 43 & 24 \\
\hline Brick & 230 square & 1.8 & 36 & 20 \\
\hline
\end{tabular}

* Ranges are due to variation in wind direction

At the conclusion of the investigation, certain design characteristics became obvious:

- the ventilation rate increased as the internal diameter of the vent pipe increased

- the performance of rural vent pipes (vent pipes made from less expensive and local materials) was equal to that achieved by AC or PVC pipes of approximately half the diameter (Mara \& Ryan, 1983 B, p. 7) 


\subsection{Odor control}

Commonly used as a measurement of indoor air quality, the air exchange rate measured in air-changes per hour $(\mathrm{ACH})$ is a comparison of airflow to volume. The equation used to calculate $\mathrm{ACH}$ is:

$$
A C H=\frac{Q}{V}
$$

Where,

$\mathrm{Q}=$ Ventilation rate $\left(\mathrm{m}^{3} / \mathrm{hr}\right)$

$\mathrm{V}=$ Volume of superstructure $\left(\mathrm{m}^{3}\right)$

Since ACH is a function of the superstructure volume and the ventilation rate it can be observed that $\mathrm{ACH}$ increases directly with increasing ventilation rates, as shown in Table 9 , but decrease inversely with superstructure size as suggested by equation 1 .

In an ideal VIP latrine air circulatory system, the higher the value for ACH the less likely odors will be able to accumulate within the superstructure. As previously mentioned, fewer odors in the superstructure would theoretically mean less flies and greater user comfort.

When evaluating odor control, Mara \& Ryan concluded that odorless conditions were associated with flow rates of $10 \mathrm{~m}^{3} / \mathrm{hr}$ and above. This corresponded to an air exchange rate of approximately six air changes per hour $(6-\mathrm{ACH})$ of the air volume inside the superstructures they were investigating. The researchers also noted that a flow rate of 20 $\mathrm{m}^{3} / \mathrm{hr}$ (12-ACH), which would provide a comfortable buffer for odor control can be relatively easy to achieve. (Mara \& Ryan, 1983 B, p. 5)

Acceptable ACH values for odorless conditions vary depending on the source. Mara \& Ryan concluded that $6 \mathrm{ACH}$ was an acceptable value because it fell within ventilation standards for toilet rooms in domestic properties of the U.K./England. A toilet room was defined as a room with just a flush toilet and possibly a small sink. (Mara D. D., 2008) An article from 1964 titled Ventilation Control of Odor suggested a ventilation range of 8 $-20 \mathrm{ACH}$ for toilet areas (Viessman, 1964). Alternatively, the American Society of 
Heating, Refrigerating and Air-Conditioning Engineers (ASHRAE) give a minimum specification of not less than $2 \mathrm{ACH}$ for a utility room, bathroom, toilet, or lavatory (ASHRAE, 2005). However, a minimum specification does not necessarily imply odorless conditions.

In this study, the ACH observed in UWR VIP latrines will be compared to each of the above recommended values. Yet there will be a focus on the Mara \& Ryan values since they are the most applicable toward VIP latrines.

\subsection{Fly and insect control}

There are several key points to a VIP latrine design that allows it to maintain low fly population within the pit and the superstructure. They are described by Mara \& Ryan (1983) as:

- a fly screen securely fastened to the top of the vent pipe

$>$ the fly screen must be fully intact and uncompromised (no rips or tears)

$>$ the fly screen aperture must not be larger than $1.2 \mathrm{~mm} \times 1.5 \mathrm{~mm}$.

$>$ the fly screen must be made of material that is corrosion-resistant, since it must withstand strong sunlight, high temperatures, intense rainfall, and the corrosive environment of vented gases

- the vent pipe is fastened securely to the slab without any cracks or holes that insects might be able to crawl in or out of

- the vent pipe is straight and vertical to allow as much light as possible to shine down into the pit

- the interior of the superstructure is kept as dark as possible to ensure that the greatest source of light is cast down from the vent pipe

To elaborate on this last design point, a study in Botswana and Tanzania found that when vented latrines had their doors closed, resulting in less light inside the superstructure, almost $90 \%$ of the flies emerging from the pit went up the vent pipe. When the doors were left open, only $50 \%$ went up the vent pipe, the rest left through the drop hole (Curtis \& Hawkins, 1982). 
Where latrines are installed in a high water table, mosquito breeding can also be a problem. Although the mosquitoes that breed inside latrines are not the malaria carrying Anopheles, they are potential vectors for filariasis. Unlike flies, mosquitoes are not phototrophic. Therefore, by itself, a VIP latrine can offer little added benefit to maintaining low populations. For that reason, a mosquito trap was developed to fit over the drop hole of VIP latrines, but rarely have they been used in practice and little is known about its affect on ventilation. Other temporary solutions to mosquito breeding include the application of kerosene, engine oil, or chemical larvicide. The downside to these methods is that they also indiscriminately kill off predators of mosquito larva. Without predators, the mosquito population could return in even greater numbers after the chemical treatment has loss its potency. (Morgan \& Mara, 1982)

One other suggestion was to dump small polystyrene balls into the pit to float on top of the water where mosquitoes breed. However it was pointed out by Morgan \& Mara that "the long term efficacy and practicallity of this method of mosquito control and it's effect on sludge accumulation rates in pits subject to seasonally variable groundwater levels remain to be determined. (Morgan \& Mara, 1982, p. 3)"

As of yet there has not been a difinitive solution to the problem of mosquito breeding inside pit latrines. Nor has there been a solution to the frequent problem of cockroache infestation. Until a solution is found, these insects will remain a common pest in VIP and SP latrines alike.

\subsection{The Zimbabwean and the Upper West Region single-pit VIP latrine}

The design studied in the Mara \& Ryan investigation with the closest resemblance to the UWR VIP latrine was the Zimbabwean single-pit latrine. In actuality, there are three variations of the Zimbabwean VIP latrines mentioned in the Mara \& Ryan reports. The first was a brick latrine used for urban or peri-urban settings. The slab and superstructure were constructed with concrete and brick, and the vent pipe was made from PVC. The second variation was built more for rural households by using more locally made materials for the superstructure and the vent pipe. And the last variation, called the "rural spiral" was made completely out of local materials. 
From the design perspective the differences between the Zimbabwean VIP latrine and the UWR VIP latrine include the shape of the superstructure, and the air volume of the superstructure. A typical Zimbabwean design uses a spiral shape superstructure, which allows for darkness, privacy and unimpeded airflow without the need of a door. The UWR VIP latrines in this study were typically made in a rectangular box shape, which require a door of some kind for adequate darkness and added privacy. However if the latrine lacks an added ventilation opening the presence of a doorway could adversely affect air flow.
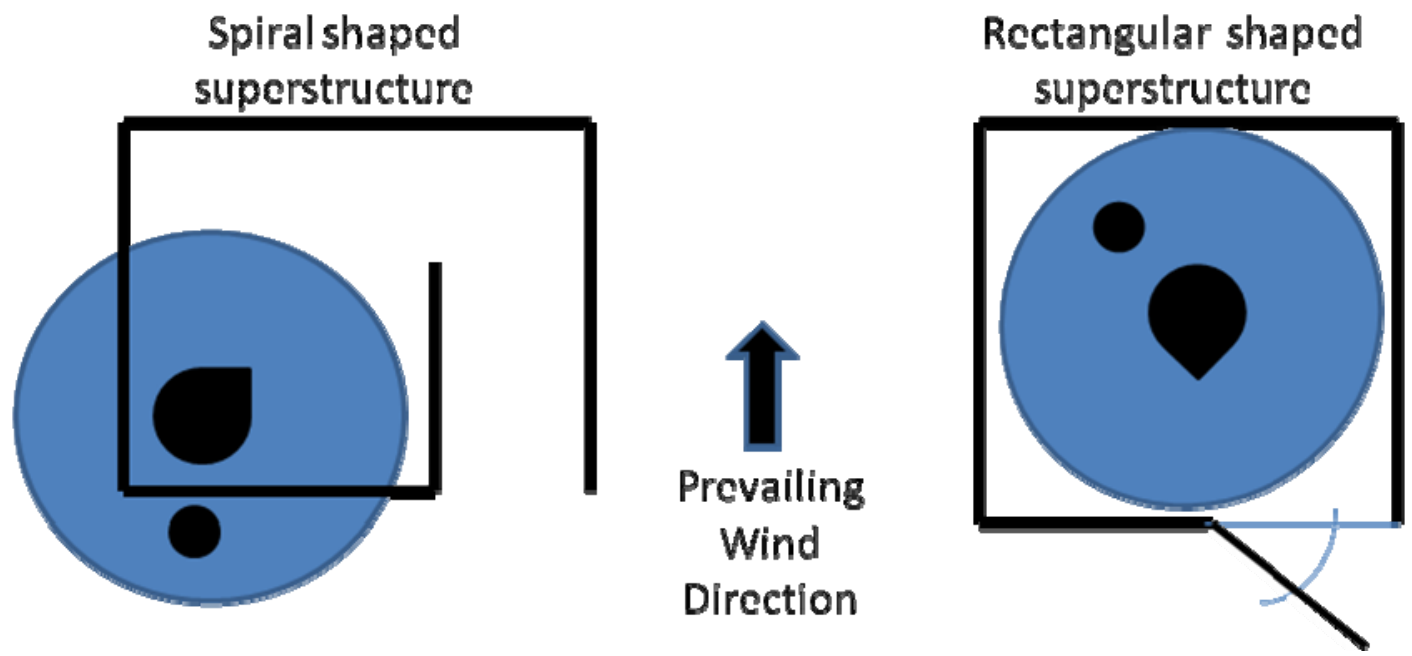

Figure 11: Top view of spiral shaped and rectangular shaped superstructures.

Furthermore, Mara \& Ryan recorded the volume of a Zimbabwean VIP latrine to be 1.8 $\mathrm{m}^{3}$, as shown in Table 9 above. The average volume for a UWR VIP latrine in this study was found to be significantly larger at an average of $5.1 \mathrm{~m}^{3}$.

One last comment about the design differences between the UWR and the Zimbabwean VIP latrine superstructures is that it is unclear whether the latrine superstructures used in the Mara \& Ryan study were constructed by skilled labor or by the latrine beneficiaries themselves. As for the UWR latrine superstructures, most if not all were constructed by members of the household in which the VIP latrine was to benefit. 


\section{Chapter 4: Methods and Materials}

The results for the present study were obtained from an investigation conducted in the Upper West Region of Ghana from September through November of 2007. The investigation consisted of four parts:

1. Visual inspection survey

2. Performance monitoring / data collection

3. Use assessment

4. Comparative cost analysis

In the study 30 latrines from six communities located in the Upper West regional districts of Wa East and Wa West were sampled. Ten of the 30 VIP latrines were measured in triplicate, once per month, making the total number of measurement setups 50. Five out of the six communities had received VIP latrines within the last two years through a sanitation promotion conducted by the Ghana Trachoma Control Program (GTCP). The outlying community had received VIP latrines in 2005 as part of a promotion sponsored by UNICEF. Included within the six communities was the village of Kulkpong, the community where the author was serving as a Peace Corps Volunteer during the time of the study. 


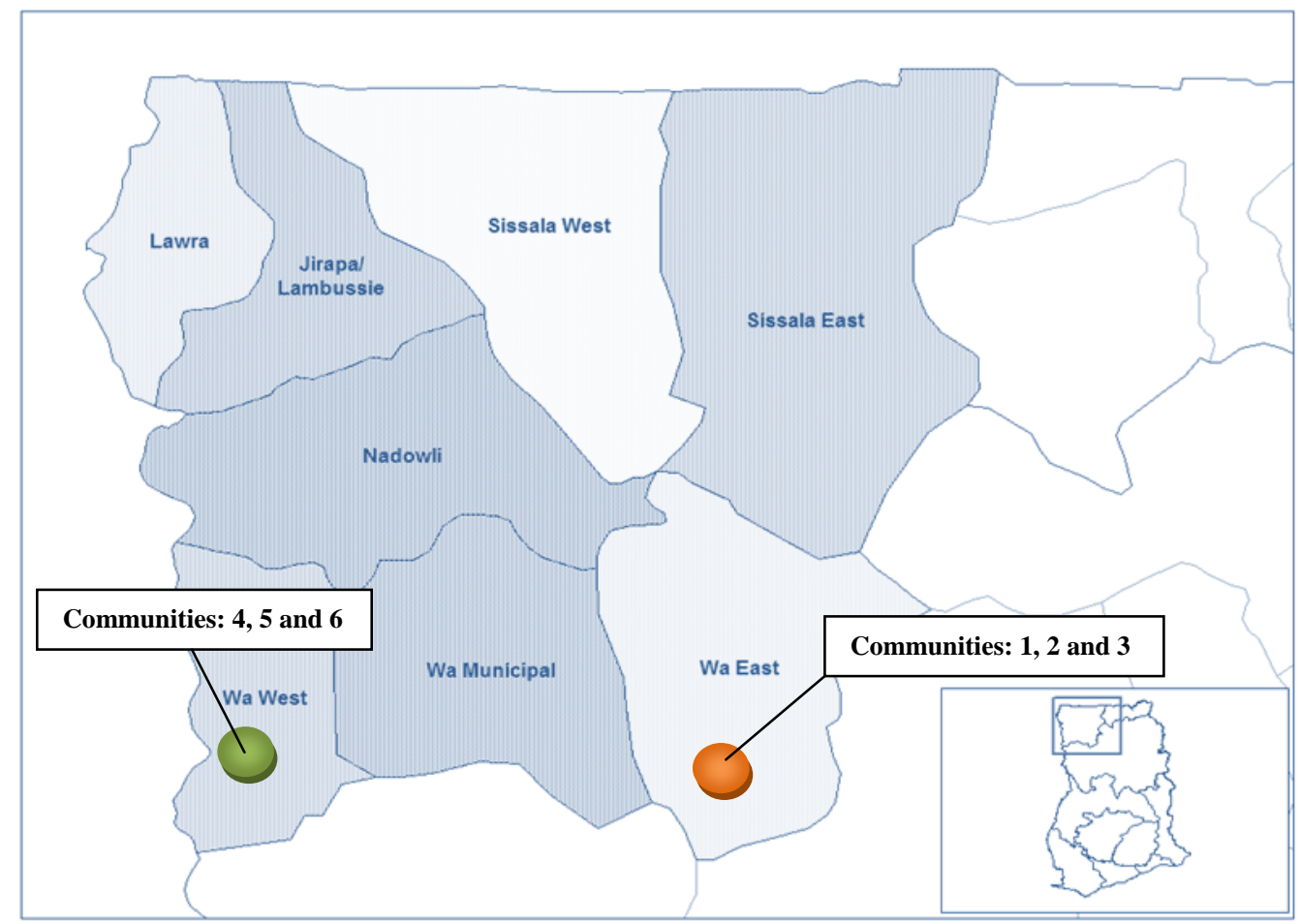

Figure 12: General location of the study communities in Wa East and Wa West Modified from: http://en.wikipedia.org/wiki/Image:Upper_West_Ghana_districts.png Licensed under the Wikimedia Commons

Table 10: Study community list

\begin{tabular}{lcccc}
\hline $\begin{array}{c}\text { Community } \\
\text { Name }\end{array}$ & $\begin{array}{c}\text { UWR } \\
\text { District }\end{array}$ & $\begin{array}{c}\text { Map } \\
\text { ID Number }\end{array}$ & $\begin{array}{c}\text { Number of } \\
\text { Latrines Sampled }\end{array}$ & $\begin{array}{c}\text { Sanitation } \\
\text { Promotion (Year) }\end{array}$ \\
\hline Kulkpong & Wa East & 1 & 13 & GTCP (2006) \\
Yippani & Wa East & 2 & 5 & GTCP (2006) \\
Buurayiri & Wa East & 3 & 6 & GTCP (2006) \\
Kandeu & Wa West & 4 & 2 & UNICEF (2005) \\
Gorgiyiri & Wa West & 5 & 2 & GTCP (2006) \\
Tumayiri & Wa West & 6 & 2 & GTCP (2007) \\
\hline
\end{tabular}

In following with the five study objectives, this chapter presents the methods used to select and evaluate the design, performance, and use of a sample of VIP latrines in the UWR. Methods used to measure latrine performance were based on the methodology used by Mara \& Ryan in their 1983 investigation. 


\subsection{Ethical clearance}

Before collecting data, permission to conduct the study was obtained from each community's head and from each of the selected latrine owners. Proof of informed consent from the latrine owners was obtained as a signature or thumbprint made on the original survey form. Verbal consent to conduct the study was also granted by the Community Water and Sanitation Agency (CWSA) Director of the UWR.

\subsection{Sample selection}

The focus community in the UWR identified for this research needed a minimum of twenty completed VIP latrines in order to make a random selection of ten. A completed VIP latrine was defined as one which possessed a cover slab with a fitted vent pipe, a superstructure with a roof, and evidence of use (i.e. feces within the pit). The community of Kulkpong, located in the Wa East district of the UWR satisfied this requirement.

From the focus community 52 completed latrines were identified. Each of these latrines was given an identification number starting with the first letter of the village, in this case ' $\mathrm{K}$ ' and then numbered 1 through 52 . Ten latrines were then randomly selected and monitored one day out of each month throughout the three months of the study. The purpose of this sampling method was to capture any effects of daily and or seasonal variations on the same set of latrines. Sampling occurred from September $2^{\text {nd }}$ through November 25th, 2007. This time frame corresponded with a seasonal transition of the end of the rainy season to the beginning of the cool dry season.

To account for variation in VIP latrine design, three additional Kulkpong latrines were selected due to a unique property with each of the latrines. The first was the author's personal VIP latrine which was constructed by a professional water and sanitation consultant based out of the regional capital, Wa. The second possessed walls that reach approximately three quarters of the height to the roof, and the third latrine was located in a heavily shaded area. All three unique Kulkpong latrines are shown in Figure 13 below. 


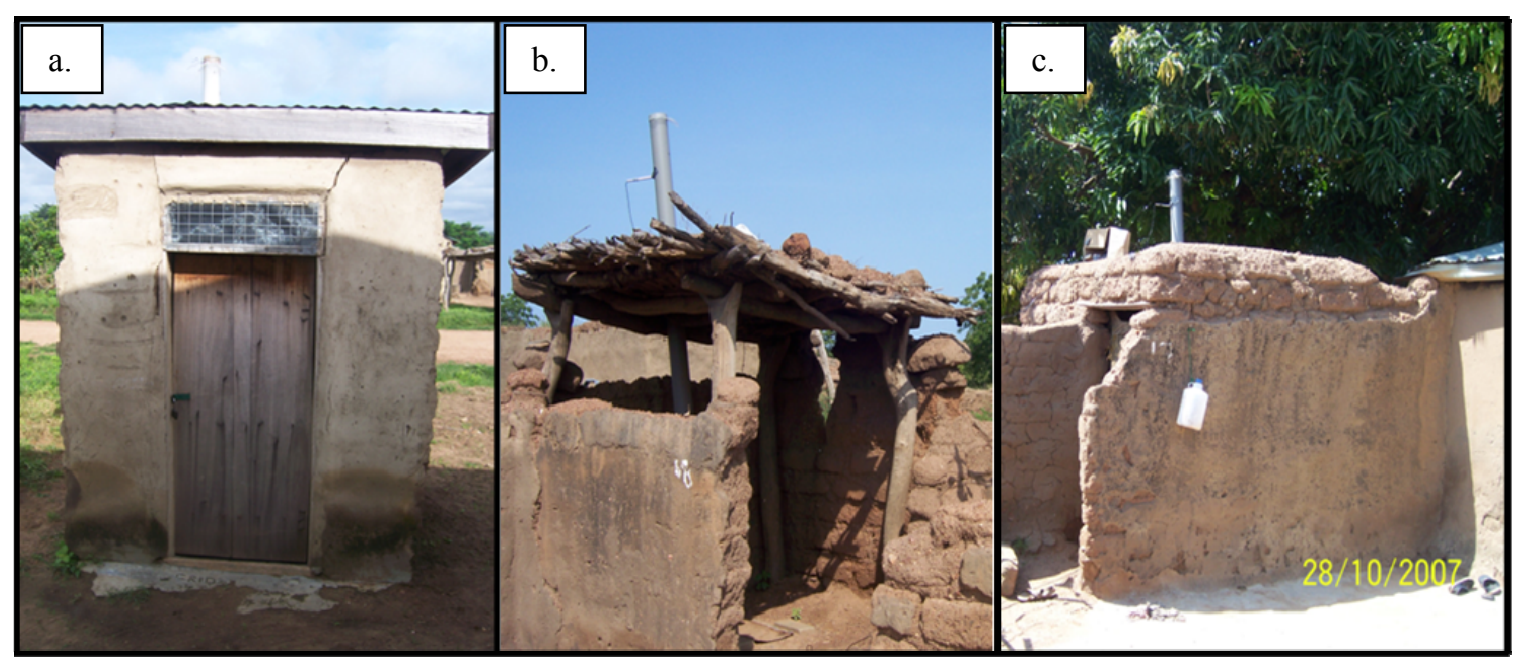

Figure 13: Photo of three unique Kulkpong latrines; a) the author's latrine; b) three-quartered walled latrine; c) shaded latrine

Photos by Author

Seventeen additional VIP latrines were sampled from five communities outside of the focus community. Three of the communities were located in the district of Wa West, while the remaining two were neighboring communities of Kulkpong in Wa East. VIP latrine selections from these five communities were again based on meeting the criteria of a fully completed latrine. The identification number given to each latrine was once again the first letter of the village's name followed by the order in which it was monitored. For example B01, B02, Y01, Y02 etc. If first letter had already been taken, such as in the case for the village of Kander, then the second letter in the name was used. Due to time and logistic constraints these 17 latrines were monitored only once throughout the course of the three month study.

\subsection{Visual inspection/survey}

The first step in the study was to conduct a visual inspection/survey for each selected VIP latrine. The purpose of the survey was to record the latrine's design specifications and condition of the superstructure and vent pipe. The survey was also designed to look at user choices that would affect airflow such as entrance orientation, presence of a door, and or the presence of a lid over the drop hole. The survey form used in this study is included in Appendix A. Latrine households were not given any prior notice of when the 
survey was to be conducted. This was done to avoid alterations to the latrine's environment prior to the survey. It had been observed by the author on previous latrine inspections that when prior notice was given, some households would alter the normal condition of the latrine such as by cleaning or placing a temporary door over the entrance way.

During the survey, particular attention was paid to the orientation and the location of the latrine with respect to anything that may have restricted airflow. The orientation of the superstructure's main ventilation opening was later compared with data collected on prevalent wind velocity and direction in front of the latrine. The latrine was considered to face the prevailing wind direction if the angle of the opening was within $30^{\circ}$ of the recorded wind direction. If the angle of the ventilation opening was greater than $30^{\circ}$ but less than $60^{\circ}$, then the latrine was considered to partially face the prevailing wind. Any orientation greater than $60^{\circ}$ was considered not facing the prevailing wind.

Further measurements included the interior dimensions of the superstructure, and the dimensions of any openings such as windows or doorways.

Observations made during the survey included the condition of the vent pipe and the mesh fly screen; the presence of a door over the entrance way; and the presence of a lid over the drop hole. For both the door and the lid their presence was further described as either "none", "partial", or "complete." Examples of each are shown in Figure 14 below.

Notes were also made on the number of flies and other insects found inside the latrines and gathering around the top of the vent pipes. However, due to constraints which prevented this measurement from occurring consistently and at the same time of day, this information was later disregarded.

For record keeping and reference purposes, digital photographs were taken of the sampled latrine's front and side profile as well as the drop hole. GPS coordinates were also taken from the location of each of the selected latrines using a handheld Garmin eTrex ${ }^{\circledR}$ GPS receiver. 
The condition in which the latrine was found during the survey is the condition in which the latrine was monitored. For example, if a latrine was found to have no door and a lid over the drop hole, then the latrine was monitored with no door and a lid over the drop hole. Typically the survey and the monitoring occurred on the same day. Yet in the case of the Kulkpong latrines, where monitoring occurred repeatedly, any changes to the condition of the latrine were noted before monitoring commenced and evaluated as it was found on that particular day.

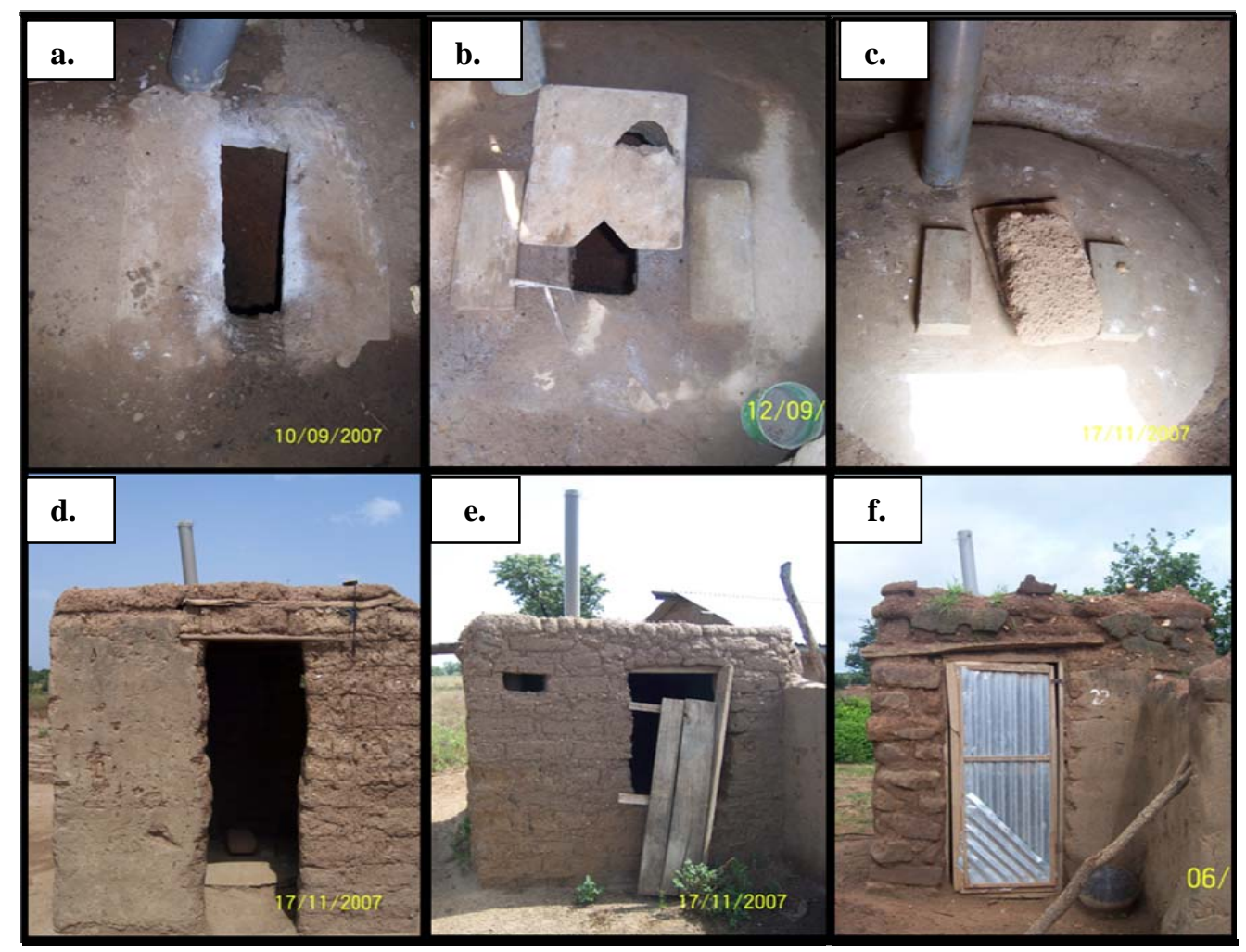

Figure 14: Photo examples of; a) 'none' drop hole lid covering; b) 'partial' drop hole lid covering; c) 'complete' drop hole lid covering; d) 'none' entrance way covering; e) 'partial' entrance way covering; f)'complete' entrance way covering. Photos by Author

\subsection{Performance monitoring/data collection}

Analytical data was collected from each of the selected latrines in order to determine their ventilation performance and to investigate the contributing mechanisms. Collecting the data consisted of monitoring the microclimate around a selected latrine, temperatures at various locations within the latrine, and the velocity of the airflow within the vent pipe 
(see Figure 15 and Figure 16). To monitor the outside microclimate an Onset HOBO ${ }^{\circledR}$ weather station was set up and leveled within close proximity (less than 2 meters) to the main ventilation opening of the latrine superstructure (typically the entranceway). The Onset sensors located on the weather station included one temperature and barometric sensor (T1), one pyranometer to measure solar radiation (SR), a dual wind directional and wind speed sensor (WD/WS) placed near the mid height of the superstructure to record wind behavior in front of the ventilation opening (In cases where the ventilation opening was in close quarters or due to the short height of a particular latrine, the WD/WS was removed from the tree and attached to a smaller, one meter high, quad-pod; which was then set in front of the ventilation opening and leveled). One additional wind speed sensor (WS2) was set at the top of the weather station assembly at a height of approximately three meters; the relative height of the top of the vent pipe to measure wind velocity passing perpendicular to the mouth of the vent pipe. All of the above sensors were connected to an Onset data logger, programmed to average and record data every 10 minutes.

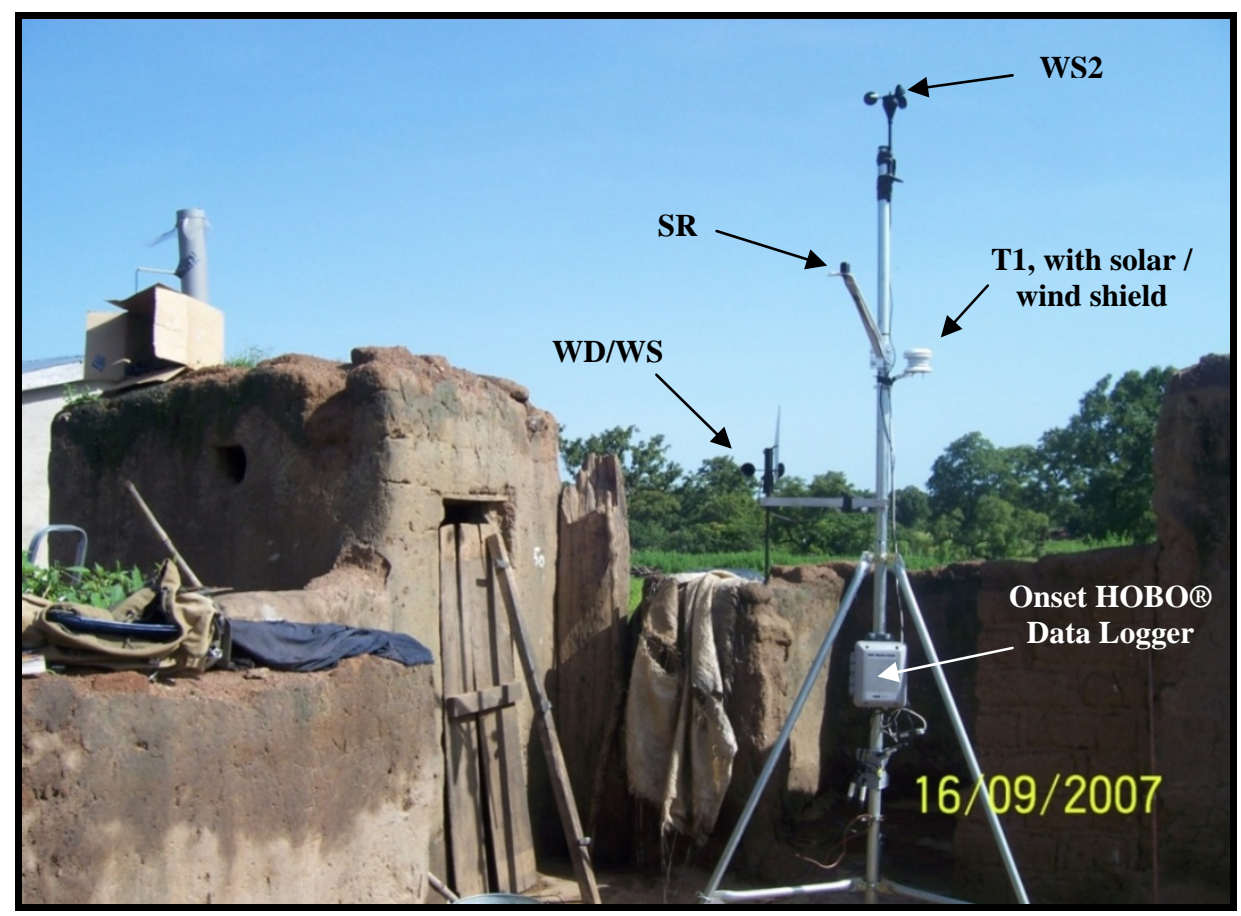

Figure 15: Photo of weather station setup. Photos by Author 


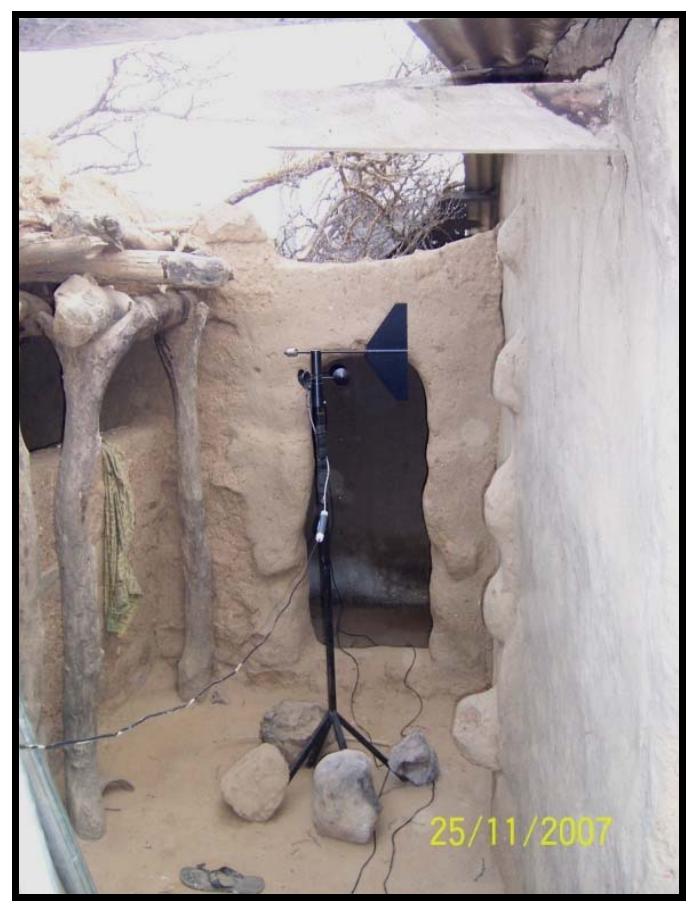

Figure 16: Photo of alternative WD/WS setup. Photo by Author

Also attached to the Onset data logger were three additional temperature probes used to measure the interior environment within the latrine. The first temperature probe (T2) was suspended near the three-dimensional mid-point of the superstructure's interior in order to measure the air temperature inside the superstructure. The second probe (T3) was fed a meter through the drop hole in order to measure the air temperature within the pit. A third temperature probe (T4) was placed into the bottom of the vent pipe. This was done by drilling a small hole into the bottom of the vent pipe of approximately $1 \mathrm{~cm}(0.4$ inches) in diameter, placed at a height of roughly $15 \mathrm{~cm}$ (6 inches) from the latrine slab. The temperature probe was then fed through the hole, and any space between the probe feed wire and the hole's edge was sealed using duct tape. 


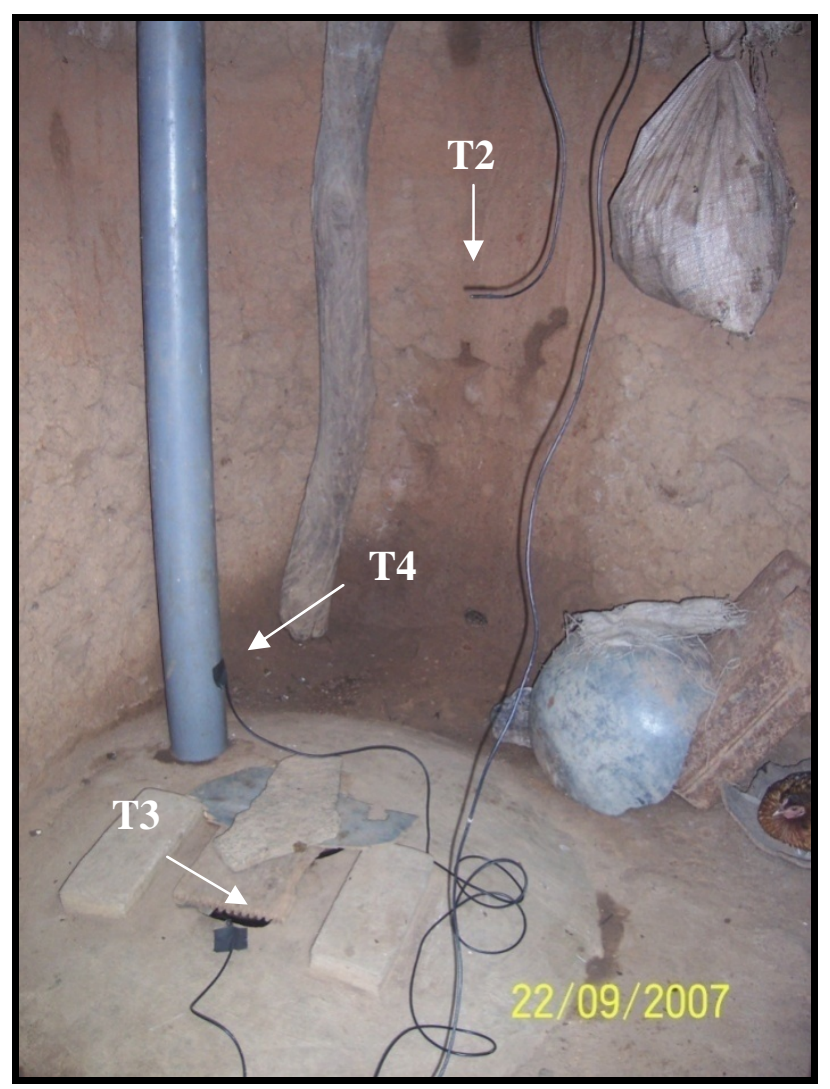

Figure 17; Photo of interior temperature probes setup. Photo by Author

As a side note, early into the study (six recordings into the study to be exact) the outside temperature sensor (T1) ceased to communicate with the data logger. Due to the time it would take to receive a replacement sensor from the U.S. it was decided that the best option would be to record the outside temperature with one of the other sensors. A brief analysis of the temperature data collected prior to the malfunction showed little or no difference between the pit temperature (T3) and the temperature at the bottom of the vent pipe (T4). This suggested that the two measurements were somewhat redundant.

Therefore, throughout the remainder of the study the pit temperature sensor was removed and placed on the weather station tree in order to continue recording outside temperature data.

The last piece of equipment used in the study was a Mannix dual hot-wire anemometer (Q) and temperature probe (T5). This probe was set within the top of the vent pipe to measure the airflow velocity and temperature within. This probe was installed by drilling 
a hole of approximately $2 \mathrm{~cm}(0.8$ inches $)$ in diameter, placed down from the top of the vent pipe at roughly $30 \mathrm{~cm}$ (12 inches). The probe was carefully fed through so that the sensor would be located near the mid-point of the pipe's diameter and facing perpendicular to theoretical airflow path. It was then secured, and sealed into place, using duct tape from the outside of the vent pipe. The hot-wire anemometer came with its own programmable data logging function, which was set to record temperature and air velocity measurements every 2 minutes.

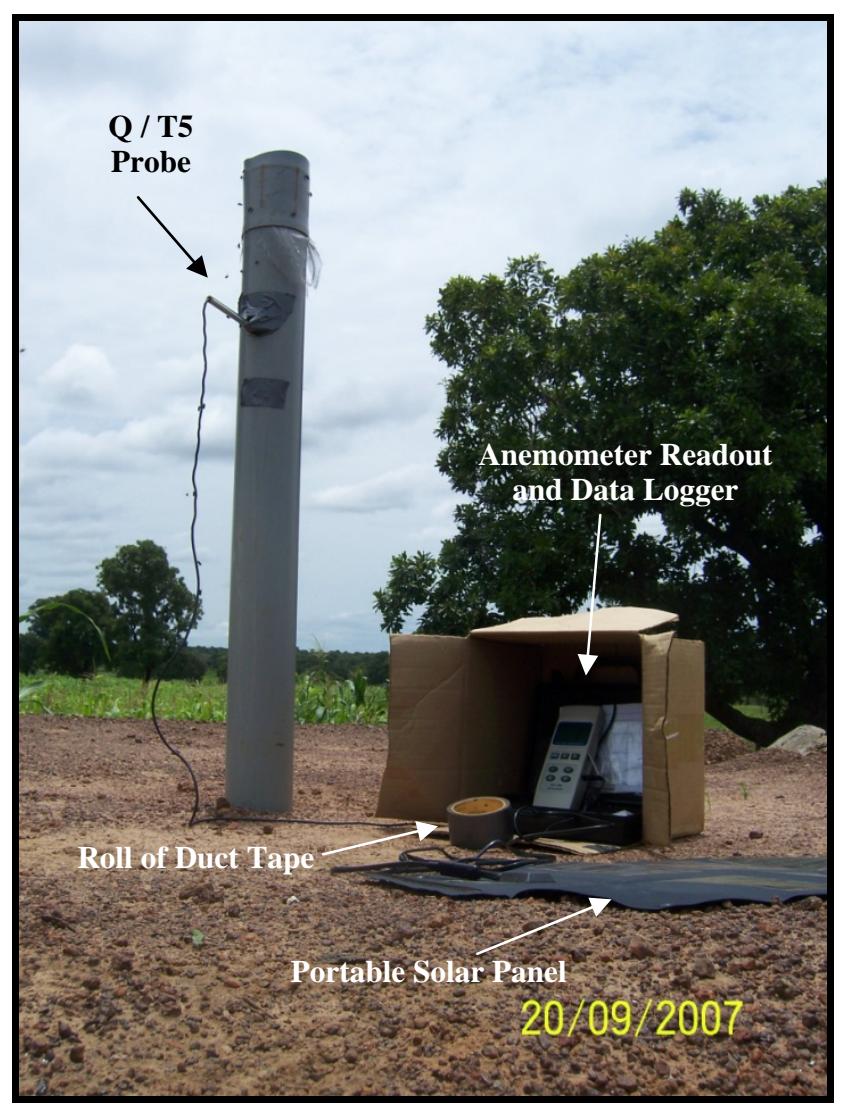

Figure 18: Photo of Hot-wire anemometer setup. Photo by Author

At the end of every sampling, data from the Onset logger was downloaded and stored on to a laptop computer. Data from the hot-wire anemometer was later downloaded at the end of the data collection. All of the data was later imported into MS Excel where the 2 minute interval data from the hot-wire anemometer was averaged into 10 minute intervals and matched up with the data collected from the Onset logger. A detailed description of each sensor and its specifications are available in appendix B. 
During the months of September and October, the ten selected latrines from the focus community were monitored one day out of the month over a time period of six to twelve hours. The goal time period was twelve hours, however due to technical difficulties with the hot-wire anemometer and its aversion to rain events, 12 hours was not always achievable. In the month of November, 24 hour monitoring of the ten latrines was attempted without the risk of rain events occurring overnight. However, battery power within the hot-wire anemometer would not always last throughout the entire evening, which made it difficult to record a full 24 hour period. Power loss to the hot-wire anemometer during the day was not as much of a problem because battery power was supplemented with the use of a portable solar panel. Power supply to the HOBO ${ }^{\circledR}$ weather station and data logger was never a problem. The equipment was routinely checked every thirty minutes except during 24 hour monitoring, in which case the last check was made at 20:00 and resumed the next day at 6:00.

The remaining twenty VIP latrines were measured only once during the study. For this set of latrines, sampling periods varied from four to twelve hours per latrine. In most cases, due to limited time and availability of transportation, two latrines per day had to be sampled. For example, if latrine A was monitored from 8:00 till 12:00, then latrine B would be monitored from 12:30 to 16:30. The performances of these latrines were later compared with different latrines but over the same time period.

In total, thirty UWR VIP latrines were measured. Ten of the thirty were measured three times, making a total number of fifty measurement setups. From those fifty setups the total number of usable monitoring hours came to approximately 451 .

\subsection{Latrine use assessment}

To assess use within the focus community, during the initial latrine survey to identify the Kulkpong sample group a discrepancy was noted between usable and completed latrines. A usable latrine was defined as a latrine which possessed a pit covered by a slab, a vent pipe, and a roofed superstructure. Completed latrines, as previously defined, vary from usable latrines only in that there are feces present inside the pit. From this information 
the proportion of latrines that are in use was determined by taking the total number of completed latrines and dividing it by the total number of usable latrines.

$$
\text { \% Usage }=\frac{\text { Gompirtas Eatring }}{\text { Egable Lathes }} \times 100 \%
$$

This value was later used in order to make a quick comparison of use data found within other latrine evaluative studies that used different communities and studies that looked at different basic sanitation technologies.

\subsection{Comparative cost analysis}

An assessment of the cost for constructing and maintaining a VIP latrine was made in order to further explore the VIP latrine as an appropriate technology in the UWR. To conduct this analysis, the costs for a rural household to construct one UWR VIP latrine was determined using locally researched prices for materials, transportation (if necessary), as well as skilled and unskilled labor. The costs of replacing and maintaining a VIP latrine was also researched. The same method was then applied to other low-cost sanitation technologies that are available in the UWR for comparison with the VIP latrine. To gain even further insight into affordability, information on UWR rural household income was collected from the Ghana Statistical Service. 


\section{Chapter 5: VIP Latrine performance evaluation}

The results presented in this chapter, and Chapters 6, 7 and 8, are the product of data collected from 30 UWR VIP latrines. Measurements of each latrine occurred on individual days over the course of 3 months. During data collection, the ventilation flow rate was recorded by a Lucent hot-wire anemometer/data logger every two minutes. Concurrent measurements of the ambient and interior environments were collected by the Onset weather station and logged every two minutes and averaged into ten minute periods. The amount of time that each latrine was measured varies from 4 to 24 hours due to the design of the methodology, logistical constraints, and technical difficulties.

Due to the limitation of the sample size and the period of time in which monitoring occurred, the results presented in this, and the following chapters, can only provide observational insights into the factors that affect performance. In most cases, enough information to make statistically significant conclusions beyond the sample set could not be obtained. Nevertheless, the data collected does provide enough information to make a thorough assessment of the 30 UWR VIP latrines used in the study. Other implications will be discussed in the conclusions of this report.

\subsection{Evaluation of the average flow rate}

The data collected in this study shows that the ventilation flow rate (Q) varies within a latrine from minute to minute. A typical flow rate pattern in a latrine over the course of one day in ten minute intervals is shown in Figure 19. 


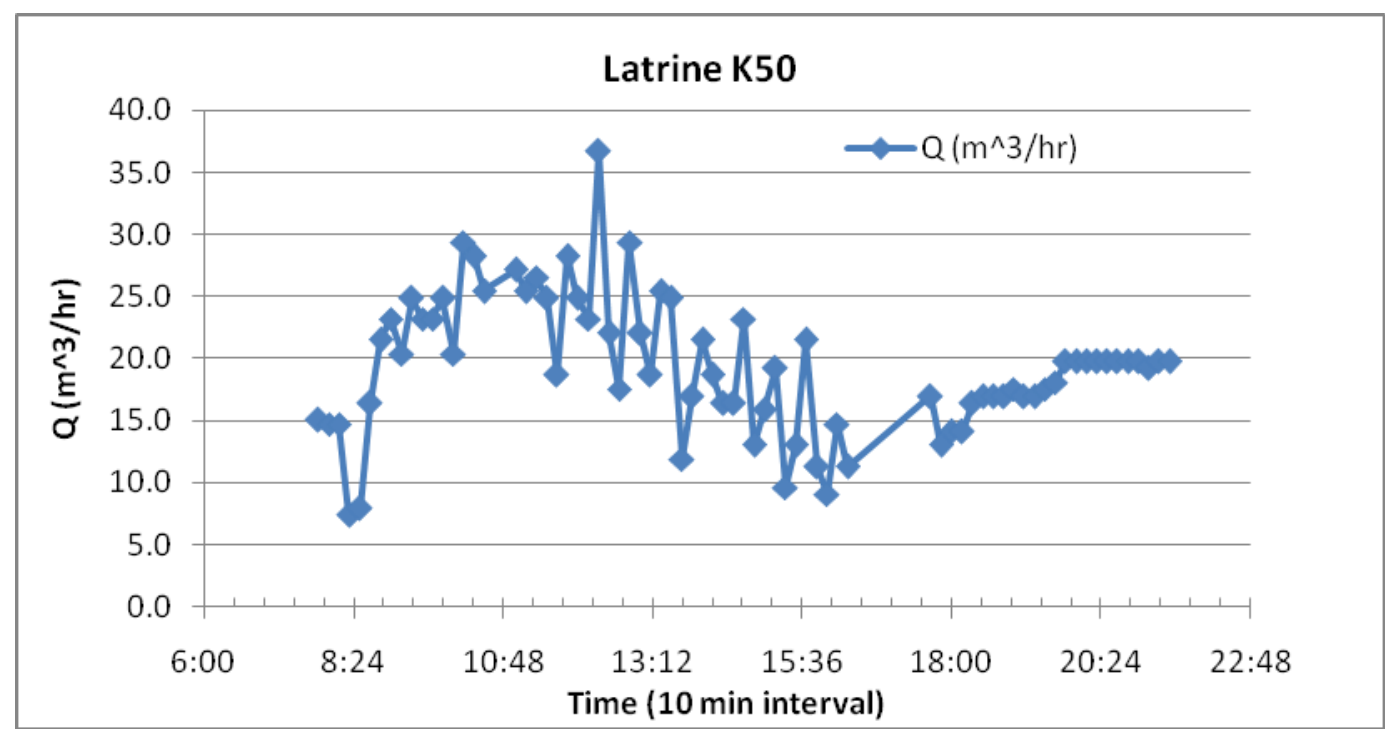

Figure 19: Flow rate data for one latrine during one measurement setup.

The average flow rate observed for this measurement of Latrine 50 was $19.3 \mathrm{~m}^{3} / \mathrm{hr}$; the maximum and minimum were $36.8 \mathrm{~m}^{3} / \mathrm{hr}$ and $7.35 \mathrm{~m}^{3} / \mathrm{hr}$ respectively.

A summary of the descriptive statistics for all fifty recorded measurements during the study is presented below in Table 11 under the column heading Q. The next column,

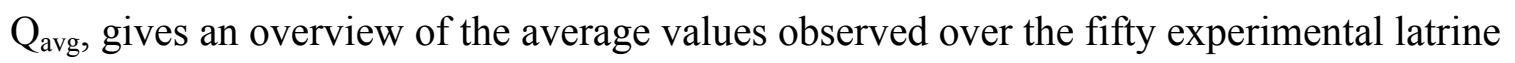
setups. One item to note in this column is the difference between the maximum and minimum average flow rates of $20.58 \mathrm{~m}^{3} / \mathrm{hr}$ and $0.12 \mathrm{~m}^{3} / \mathrm{hr}$ respectively. This shows a drastic variability between the ventilation performances among the latrines sampled.

Table 11: Descriptive Statistics for $Q$ over all setups

\begin{tabular}{lccc}
\hline & $\boldsymbol{Q}\left(\mathbf{m}^{3} / \mathbf{h r}\right)$ & $\boldsymbol{Q}_{\text {avg }}\left(\mathbf{m}^{3} / \mathbf{h r}\right)$ & ${ }^{*} \boldsymbol{Q}_{\mathbf{Z}}\left(\mathbf{m}^{3} / \mathbf{h r}\right)$ \\
\hline Mean & 12.60 & 12.25 & 11 \\
Standard Error & 0.13 & 0.60 & \\
Median & 13.01 & 12.52 & \\
Standard Deviation & 6.45 & 4.26 & \\
Sample Variance & 41.58 & 18.16 & \\
Minimum & 0.00 & 0.12 & \\
Maximum & 46.65 & 20.58 & \\
Count & 2649 & 50 & \\
\hline
\end{tabular}

* (Mara \& Ryan, Ventilated Improved Pit Latrines: Vent Pipe Design Guidelines, 1983 B) 
Included in the last column of Table 11 is the flow rate observed by Mara \& Ryan for Zimbabwean single-pit VIP latrines with PVC vent pipes of $100 \mathrm{~mm}$ in diameter $\left(\mathrm{Q}_{\mathrm{z}}\right)$. As evident, the average flow rate for this study $\left(\mathrm{Q}_{\text {avg }}\right)$ is approximately $10 \%$ greater than $\mathrm{Q}_{\mathrm{z}}$; but as indicated by the standard deviation this cannot be said for all UWR VIP latrines. Therefore, due to the known variability between samples each latrine should be looked at separately to gain a more precise appraisement of performance.

In Figure 20 , the average flow rate for each experimental setup is plotted in ascending order and compared against $\mathrm{Q}_{\mathrm{avg}}$ and $\mathrm{Q}_{\mathrm{z}}$. Figure 20 illustrates the key points of this section, which are:

- there is variability in flow rates among the sample group, and even among measurements taken of the same VIP latrine

- $52 \%(\mathrm{n}=24)$ of the sample are below $\mathrm{Q}_{\mathrm{avg}}$, and

- $32 \%(\mathrm{n}=16)$ of the sample are below $\mathrm{Q}$.

The reasons for variability in ventilation rates will be explored later in Chapter 6 . 


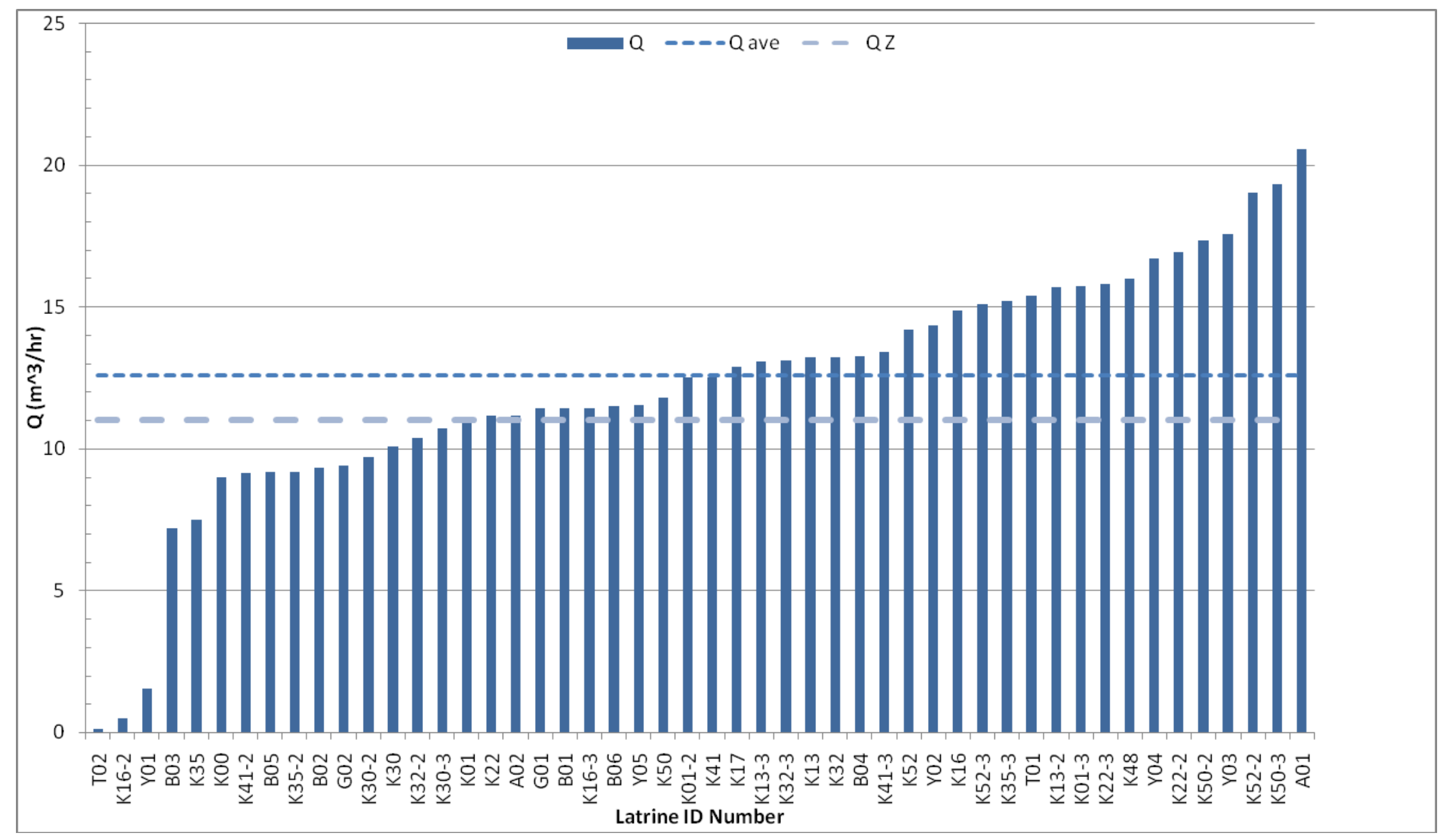

Figure 20: Average flow rate observed for each setup plotted with $\mathbf{Q}_{\text {avg }}$ and $\mathrm{Q}_{\mathrm{z}}$. 


\subsection{Evaluation of odorless conditions}

After the flow rates were recorded, the next step in the evaluation was to determine if rates were adequate for odorless conditions. As previously discussed in Chapter 4, Mara \& Ryan associated odorless conditions with six air changes per hour $(6 \mathrm{ACH})$ of the air volume of a VIP latrine's superstructure (Mara \& Ryan, 1983 B, p. 5). The value of 6 $\mathrm{ACH}$ fell within the indoor air quality standards for a toilet room in the U.K. at the time in which the Mara \& Ryan study was conducted (Mara D. D., 2008). Although there has not been another flow rate recommendation for VIP latrines since Mara \& Ryan, there have been other standards for household sanitation facilities. A summary of some of those standards along with Mara \& Ryan's recommendations are listed in Table 12.

Table 12: Recommended ventilation criteria for odorless conditions

\begin{tabular}{|c|c|c|c|}
\hline \multicolumn{2}{|r|}{ Source } & \multirow[t]{2}{*}{$\begin{array}{l}\text { Ventilation } \\
\text { Criteria }\end{array}$} & Description \\
\hline 1) & $\begin{array}{l}\text { Mara \& } \\
\text { Ryan } \\
(1983)\end{array}$ & & $\begin{array}{l}\text { The recommended ventilation for odorless conditions in VIP latrines. The } \\
\text { researchers extracted this from "the building regulations in England (or } \\
\text { possibly the relevant British Standard) stated that this ACH was required } \\
\text { in toilet rooms in domestic properties in England/the UK* ("toilet room" } \\
\text { = room with just a flush toilet, possibly also a small sink) [Mara, 2008]" }\end{array}$ \\
\hline 2) & $\begin{array}{l}\text { Mara \& } \\
\text { Ryan } \\
(1983)\end{array}$ & $10 \mathrm{~m}^{3} / \mathrm{hr}$ & $\begin{array}{l}\text { VIP latrines in the Ryan and Mara study were able to achieve a 6-ACH } \\
\text { with this flow rate. Therefore the researchers recommend } 10 \mathrm{~m}^{3} / \mathrm{hr} \text { as a } \\
\text { minimum required flow rate }\end{array}$ \\
\hline 3) & $\begin{array}{l}\text { Mara \& } \\
\text { Ryan } \\
(1983)\end{array}$ & $20 \mathrm{~m}^{3} / \mathrm{hr}$ & Recommended as a factor of safety to the $10 \mathrm{~m}^{3} / \mathrm{hr}$ \\
\hline 4) & $\begin{array}{c}\text { Viessman } \\
(1964)\end{array}$ & $8-20 \mathrm{ACH}$ & Suggested ventilation design criteria for control of odors in toilets \\
\hline 5) & $\begin{array}{l}\text { ASHRAE } \\
\text { Handbook } \\
\quad(2005)\end{array}$ & $\begin{array}{l}34 \mathrm{~m}^{3} / \mathrm{hr}(20 \\
\mathrm{cfm}) \text { or } \\
\text { Not less than } \\
2 \mathrm{ACH}\end{array}$ & $\begin{array}{l}\text { Continuous mechanical exhaust airflow rates for a utility room, bathroom, } \\
\text { toilet, lavatory }\end{array}$ \\
\hline 6) & $\begin{array}{l}\text { ASHRAE } \\
\text { Handbook } \\
(2005)\end{array}$ & $\begin{array}{l}85 \mathrm{~m}^{3} / \mathrm{hr}(50 \\
\mathrm{cfm}) \text { or Not less } \\
\text { than } 2 \mathrm{ACH}\end{array}$ & $\begin{array}{l}\text { Intermittent mechanical exhaust airflow rates for a utility room, bathroom, } \\
\text { toilet, lavatory }\end{array}$ \\
\hline
\end{tabular}

The American Society of Heating, Refrigerating and Air-Conditioning Engineers

(ASHRAE) standards listed at the bottom of Table 12 are for mechanical exhaust, and not the passive ventilation that occurs within VIP latrines. However, what is interesting to note about these two standards are that both recommend an air exchange rate of no less than $2 \mathrm{ACH}$ for a toilet. 
Currently there is not any evidence to suggest which of the above standards most accurately represents odorless conditions inside a VIP latrine. Yet the most relevant are those recommended by Mara \& Ryan for they are the only ones determined specifically for VIP latrines. Therefore, in order to evaluate VIP latrines for odorless conditions this study uses the Mara \& Ryan standards as bases for comparisons. The other standards are, of course, still taken into consideration.

Odorless ventilation performance was evaluated by first determining the air exchange rate for each of the 50 measurement setups using the equation for $\mathrm{ACH}$ given in Chapter 4.

As an example, if $Q_{\text {avg }}\left(12.25 \mathrm{~m}^{3} / \mathrm{hr}\right)$ and the average air volume in UWR VIP latrines $\left(\mathrm{V}_{\text {avg }}=5.05 \mathrm{~m}^{3}\right)$ were plugged into equation 1 then the average $\mathrm{ACH}$ for the entire sample would be 2.4. This is obviously short of Mara \& Ryan's recommended ACH value; however it is just above the ASHRAE standard. Again, to gain a precise picture of UWR VIP latrine performance, each measurement setup must be assessed individually. A breakdown of the sample compared to the stated standards is given in Table 13. This is then illustrated in Figure 21, on the following page with the respective ACH values for each latrine setup plotted and compared with the suggested ACH standards of 2, 6 and 8 $\mathrm{ACH}$.

Table 13: The number of latrine measurement setups that meet a given standard

\begin{tabular}{llcc}
\hline Source & Standard & n & \% of Setups \\
\hline ASHRAE (2005) & $\geq 2 \mathrm{ACH}$ & 39 & $78 \%$ \\
\hline Mara \& Ryan (1983) & $\geq 10\left(\mathrm{~m}^{3} / \mathrm{hr}\right)$ & 38 & $76 \%$ \\
Mara \& Ryan (1983) & $\left.\geq 20 \mathrm{~m}^{3} / \mathrm{hr}\right)$ & 1 & $2 \%$ \\
Mara \& Ryan (1983) & $\geq 6 \mathrm{ACH}$ & 2 & $4 \%$ \\
\hline Viessman (1964) & $\geq 8 \mathrm{ACH}$ & 0 & $0 \%$ \\
\hline
\end{tabular}




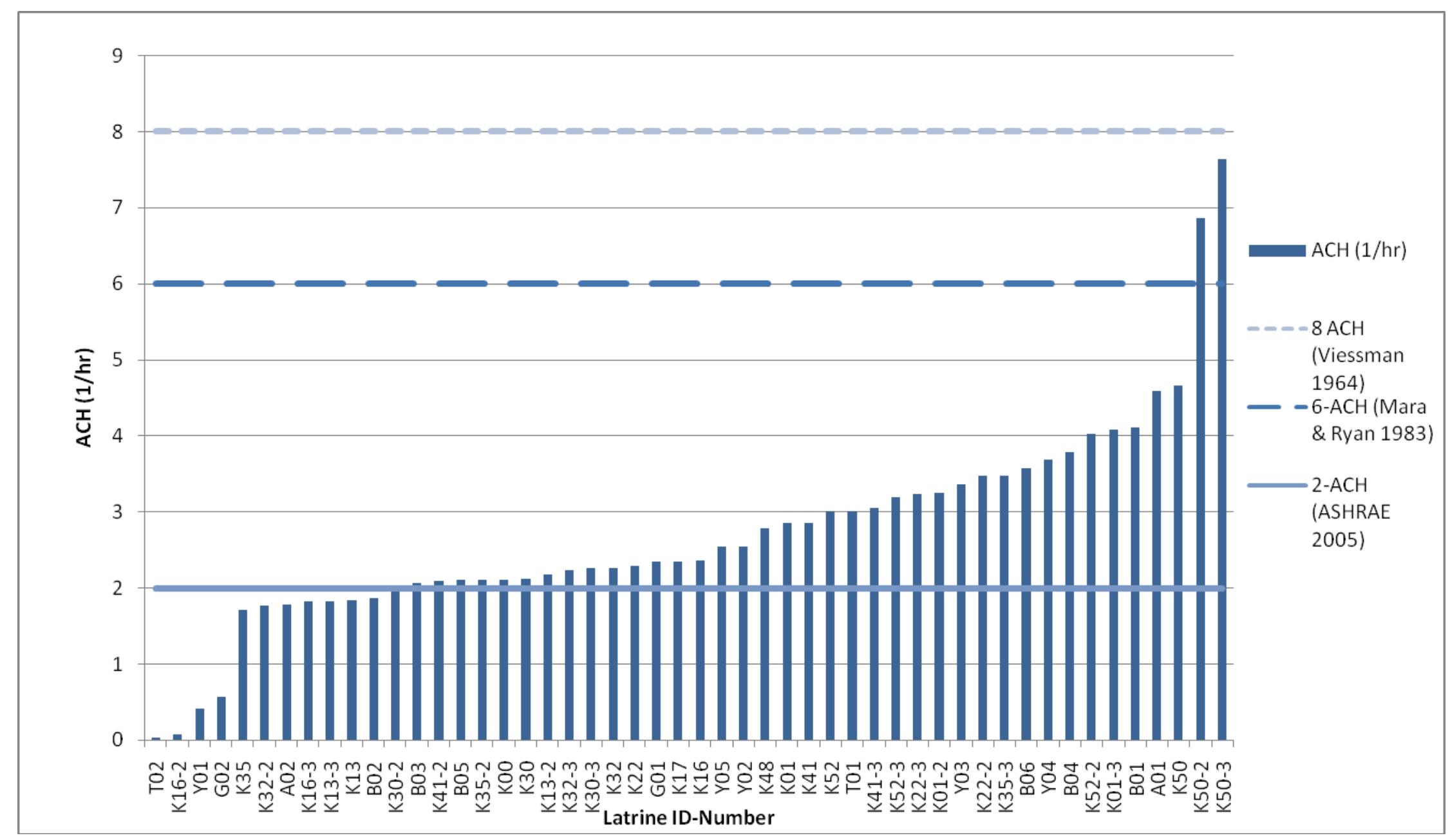

Figure 21: Average observed ACH for each setup plotted with recommended ACH values 
From Table 13 and Figure 21 it appears that when Mara \& Ryan's ventilation recommendation of $6 \mathrm{ACH}$ is used then only one latrine, $\mathrm{K} 50$, appears to achieve odorless conditions. However, K50 does not achieve $6 \mathrm{ACH}$ consistently. The first time it was measured $\mathrm{K} 50$ only reached 4.7 ACH. However, if the ASHRAE standard is used, which incidentally coincides closely with Mara \& Ryan's recommended minimum flow rate, then most latrines provide adequate ventilation most of the time (78\%).

This brings back the question of which recommended value is used to evaluate ventilation performance for odorless conditions. Given that Mara \& Ryan's recommendation of $6 \mathrm{ACH}$ was determined from a standard for ventilating toilets in the early 1980s, and yet another more recent standard states that a minimum $2 \mathrm{ACH}$ is adequate; the logical conclusion is that the more recent standard could also be applied to VIP latrines. However, one could also debate that latrines generally produce more odor than a typical toilet, and therefore VIP latrines would require a greater amount of ventilation. Using the same standard for both facilities would thus be an unfair assessment. If one were to split the difference between the two $\mathrm{ACH}$ standards and use 4 $\mathrm{ACH}$, the result would be an achieved proportion of only $14 \%(\mathrm{n}=7)$ of the measurement setups

Unfortunately, until a study is conducted to quantifiably associate ACH with odorless conditions in VIP latrines, an approximation of the most appropriate value will have to be used. For this study, the most appropriate value appears to be $4 \mathrm{ACH}$. This is based on the facts that it has proven to be achievable, as shown by six of the sampled latrines; it accounts for latrines of larger volume then those observed in Zimbabwe; and it realistically accepts that UWR VIP latrines have a higher propensity to be more odorous than the typical water flush toilet.

Using $4 \mathrm{ACH}$ as the minimum standard for odorless conditions, Figure 21 illustrates that $86 \%(n=43)$ of the experimental setups did not observe an average rate of $4 \mathrm{ACH}$. Yet, as previously demonstrated, seven of the setups were able to achieve this set minimum air exchange rate. 


\section{Chapter 6: Determining factors that affect ventilation flow rate}

In continuation from Chapter 5, where the overall ventilation performance was evaluated, this chapter's focus pertains to identifying the factors that influenced the ventilation flow rate in the 30 UWR VIP latrines. To due so, daily air flow patterns were determined using data collected from the Lucent hot-wire anemometer. Concurrent measurements of the ambient and interior environment collected by the Onset weather station were then compared to the observed flow rate to determine existing correlations.

\subsection{Daily flow rate patterns}

The evaluation begins with a study of the daily ventilation flow rate pattern observed. Figure 19 in Chapter 5 showed the flow rate pattern for one latrine, K50, averaged every 10 minutes. K50 is again shown below in Figure 22; however the data is now presented after being averaged into hourly periods. For demonstrative purposes, flow rate data from three additional latrines are displayed alongside K50. This is to allow the reader to observe the differences and similarities among a portion of the samples. With the exception of K50, these latrines were randomly selected from the pool of experimental setups that had a sample period of longer than eight hours, in order to show signal variation throughout the day.

Differences in the individual daily flow rate patterns could be a result of inconsistencies in which the latrine was constructed, or differences in environmental conditions on the day in which the latrine was monitored. These possibilities are explored in later sections. Despite the apparent differences, there are a number of similarities that can be observed among the individual signal patterns.

Beginning with the early morning hours, an increase in flow rate was observed in most cases. This is demonstrated by latrines K50, K16 and Y03 in Figure 22. Throughout the midday, an overall negative slope in values for $\mathrm{Q}$ was detected for nearly all samples. Yet, many of the samples exhibited intermittent peaks throughout this time period, as illustrated by K16. However, even the amplitude of the peaks was found to decrease 
throughout the day. By early evening all of the latrines showed an increase in ventilation flow rate.

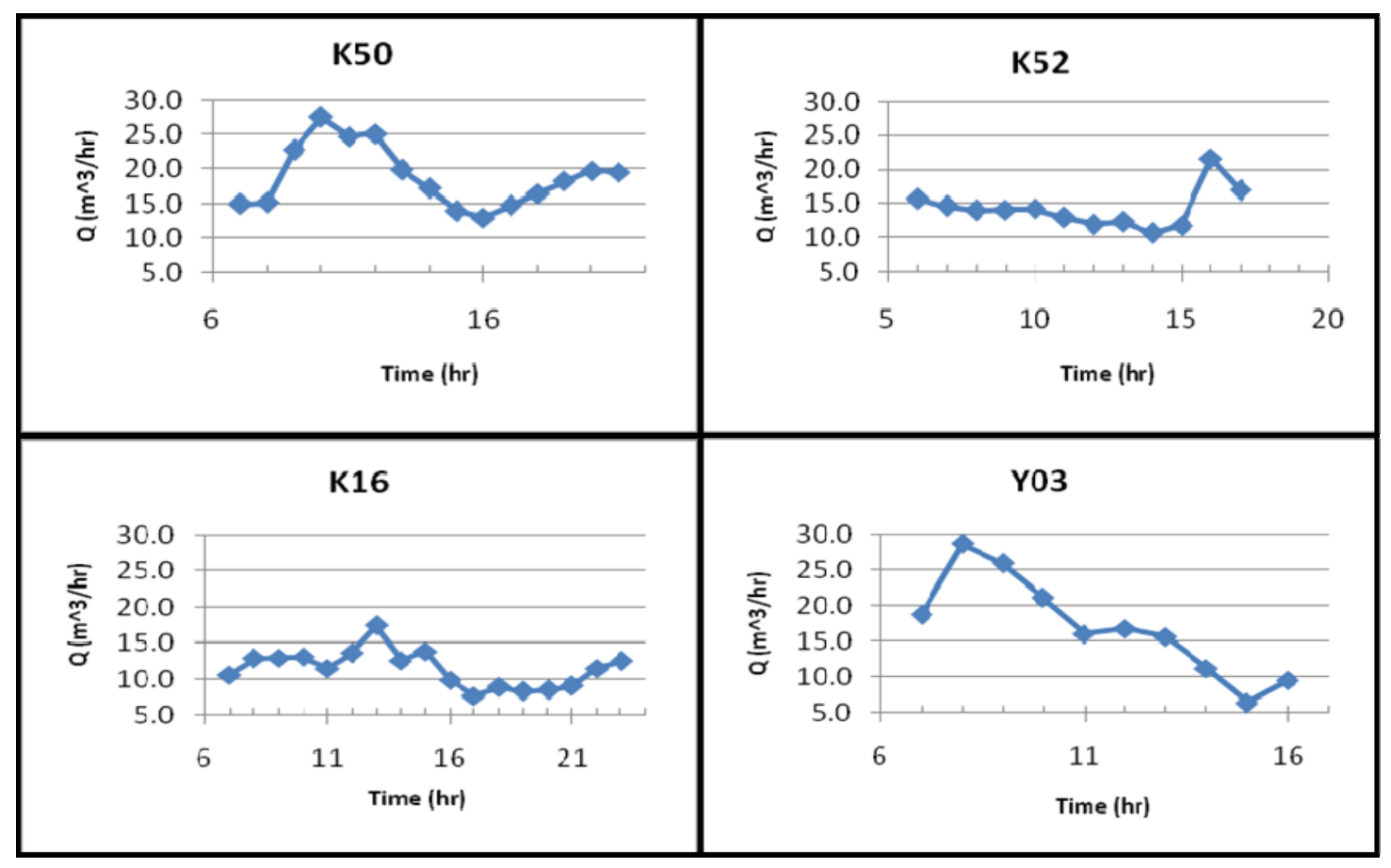

Figure 22: Plotted flow rates of latrines K50, K52, K16 and Y03

In order to better identify a common flow rate pattern, and in a sense wash out some of the variability among individual samples, data from each of the 50 experimental setups were averaged together to create one daily pattern. The result is trend line shown in Figure 23. Throughout the remainder of the report this trend line will be referred to as the average flow rate and denoted as $\mathrm{Q}_{\mathrm{avg}}$.

The average flow rate signal appears to fit the description used for the similarities among individual latrines. It can again be observed that in the early morning hours there is a slow increase in flow rate. Then, starting around 4:00 there appears to be an overall negative sloping trend, with intermittent peaks and valleys, until about 16:00 hours. At which point Q rapidly increases, tapers off, and then begins to decrease. Due to this being a continuous cycle, it is likely that the flow rate would increase again towards the early morning hours. However, the certainty of this last point is questionable. 


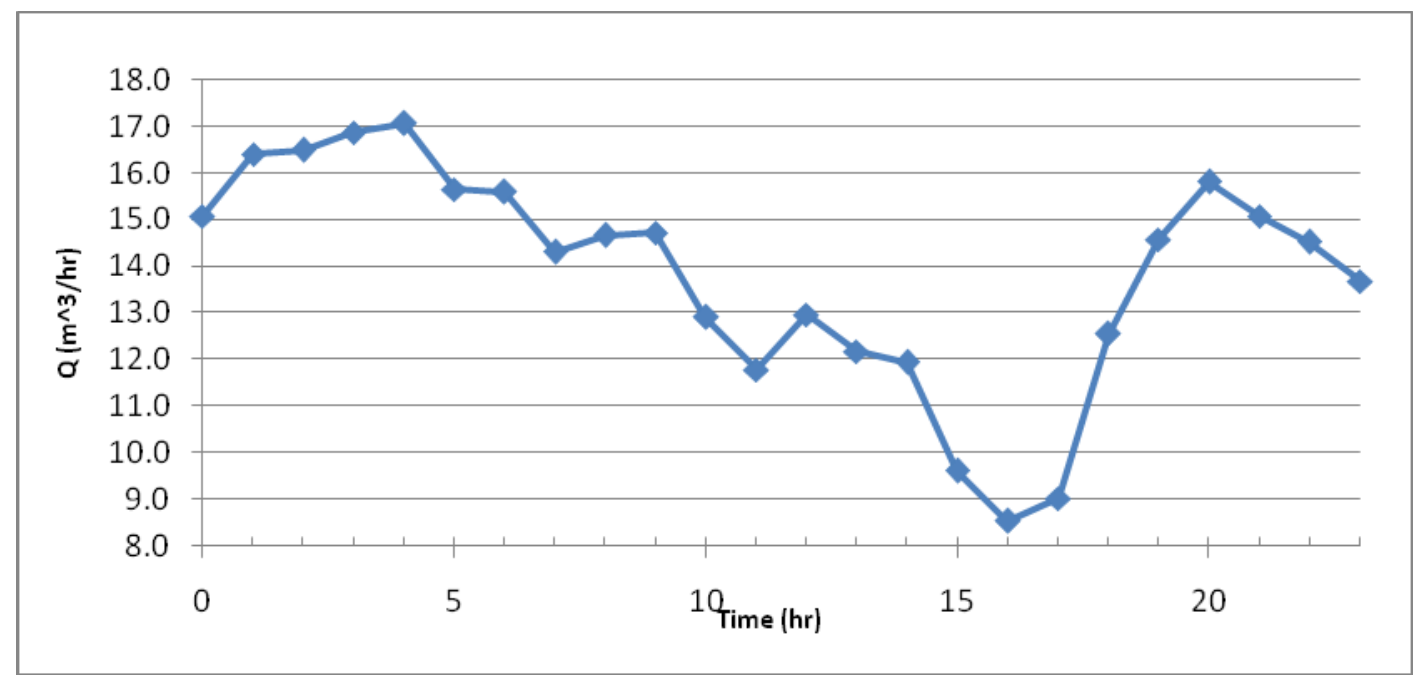

Figure 23: Cumulative average flow rate of full sample

One of the limitations of the dataset is the few observations made during the late evening and early morning hours. The number of data observations averaged to make one hourly data point is shown by the histogram on Figure 24. The reason for the lack of information during the late evening and early morning hours is primarily due to technical difficulties of maintaining power to the Mannix hot-wire anemometer during these times. Therefore, our confidence in the values for $Q_{\text {avg }}$ between 18:00 to 5:00 hours are not as strong as those between 6:00 and 17:00 hours. 


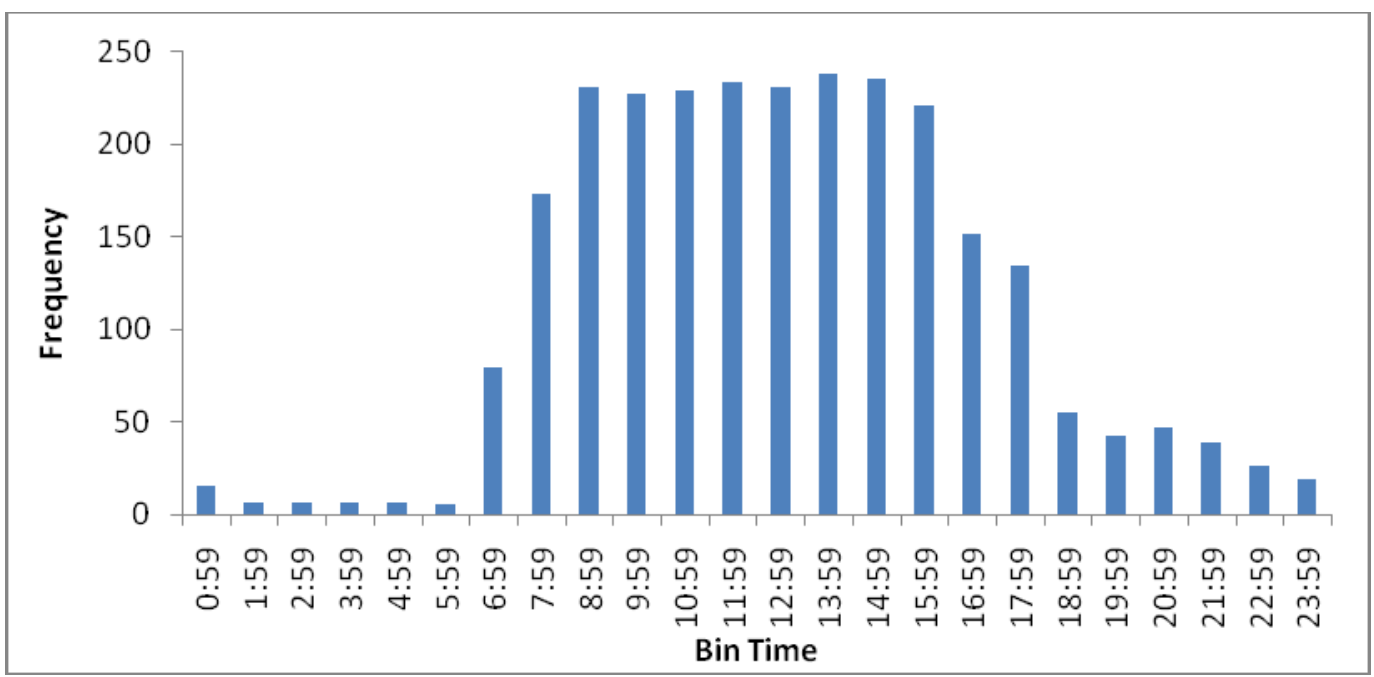

Figure 24: Histogram of the number of contributing data points to hourly averaged $Q$ values $(n=2649)$

\subsection{Environmental factors that affect Q}

\subsubsection{Analysis of the three theoretical mechanisms}

To reiterate, the three theoretical mechanisms that influence ventilation in a VIP latrine as identified by Mara \& Ryan are, a) wind passing over the top of the vent pipe, b) wind flowing into the superstructure, and c) solar radiation.

In order to investigate how these mechanisms might influence ventilation flow rate, the cumulative hourly averaged signal pattern for each variable was compared with the pattern observed for $\mathrm{Q}_{\text {avg }}$ as demonstrated in Figure 25.

Studying Figure 25, an obvious correlation appears between the factors of vent pipe wind speed $\left(\mathrm{U}_{\mathrm{vp}}\right)$, entrance wind speed $\left(\mathrm{U}_{\text {Door }}\right)$, and solar radiation $(\mathrm{SR})$. This is to be expected since all three factors are not necessarily independent of each other, particularly $U_{v p}$ and $\mathrm{U}_{\text {Door. }}$ However in order to simplify the analysis each of the factors was treated as an independent variable.

Based on the literature review these three factors should in theory have positive influence on $\mathrm{Q}_{\text {avg. }}$ Therefore it was expected that there should be an increase in flow rate as the 
three factors increased, yet initially this appeared not to be the case. In fact, observing the three factors and their relationship with $\mathrm{Q}_{\text {avg }}$ over a full day would conclude a negatively correlated relationship, as reported on the first column of Table 14. Perhaps the most striking aspect of this data comes from observations made at the beginning and end of the daily monitoring period. At these times the values for $\mathrm{U}_{\mathrm{VP}}, \mathrm{U}_{\mathrm{Door}}$ and $\mathrm{SR}$ are at or near zero. Conversely, $\mathrm{Q}_{\text {avg }}$ is registering some of its highest values.

When focus is returned back to when values for $U_{V P}, U_{\text {Door }}$ and SR are at their highest, a similar signal pattern was identified between wind speed and $\mathrm{Q}_{\mathrm{ave}}$. This indicated that a relationship between the two variables did exist throughout much of the midday. By isolating data throughout the midday, and through trial and error, the strongest correlations between the three factors and $\mathrm{Q}_{\text {avg }}$ was determined to exist from 9:00 till 17:00 hours. Table 14 shows the correlation coefficients for each of the three variables, and how at different, but closely related time steps, stronger $\mathrm{R}$ values were not found. Of the three factors, the strongest correlated variable was found to be wind speed passing over the mouth of the vent pipe. 


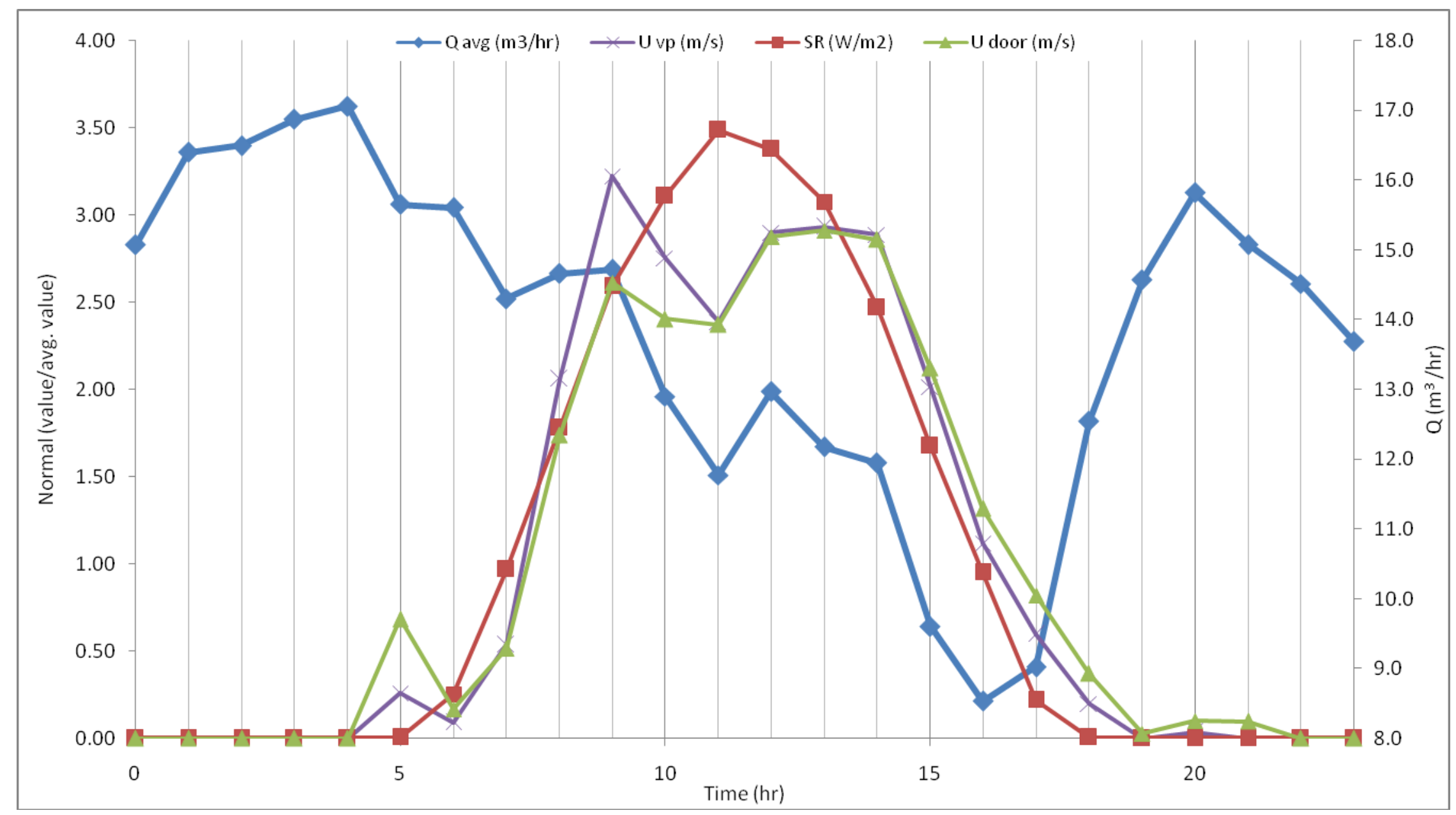

Figure 25: Averaged values for flow rate $\left(Q_{\text {avg }}\right)$, and averaged normalized values for Vent Pipe ( $\left.U_{\mathrm{VP}}\right)$ Wind Speed, Solar Radiation (SR), and Door Wind Speed $\left(\mathbf{U}_{\text {door }}\right)$ 
Table 14: Correlation coefficients for each averaged factor and $Q_{\text {avg }}$ during specific time periods

\begin{tabular}{lcccc}
\hline Factor & $\begin{array}{c}\mathbf{R} \\
\text { (entire day) }\end{array}$ & $\begin{array}{c}\mathbf{R} \\
\mathbf{( 8 : 0 0 - 1 7 : 0 0 )}\end{array}$ & $\begin{array}{c}\mathbf{R} \\
\mathbf{( 9 : 0 0 - 1 7 : 0 0 )}\end{array}$ & $\begin{array}{c}\mathbf{R} \\
\mathbf{( 9 : 0 0 - 1 8 : 0 0 )}\end{array}$ \\
\hline $\mathrm{SR}\left(\mathrm{W} / \mathrm{m}^{2}\right)$ & -0.43 & 0.62 & 0.79 & 0.55 \\
$\mathrm{U}_{\text {Door }}(\mathrm{m} / \mathrm{s})$ & -0.54 & 0.58 & 0.79 & 0.49 \\
$\mathrm{U}_{\mathrm{VP}}(\mathrm{m} / \mathrm{s})$ & -0.47 & 0.76 & $\mathbf{0 . 9 1}$ & 0.60 \\
\hline
\end{tabular}

To examine this relationship further, the average VP wind speed was plotted against $\mathrm{Q}_{\text {avg }}$ from 9:00 till 17:00 hours (see Figure 26). The positive second order relationship apparent in Figure 26 heavily suggests that $U_{v p}$ has a significant influence over $Q_{\text {avg }}$ throughout the midday.

On the other hand, data from these three variables were insufficient to explain $Q_{\text {ave }}$ 's pattern at any other time of day, or the reason for the overall negative trend throughout the midday. Therefore, further investigation was necessary.

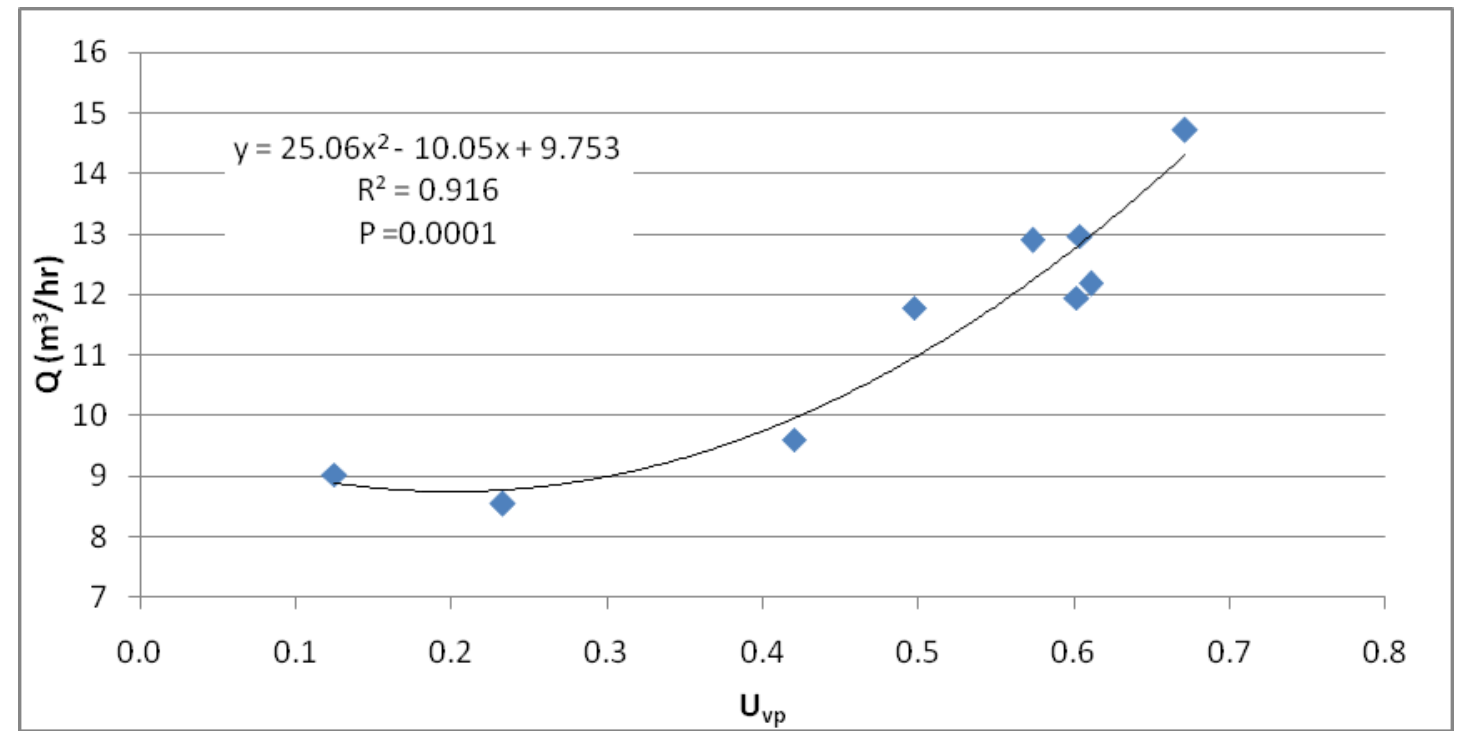

Figure 26: Wind speed at the height of the vent pipe $\left(U_{v p}\right)$ vs. the average flow rate , $Q_{a v g},(9: 00$ 17:00hrs). 


\subsubsection{Analysis of temperature effects}

To try and shed some light on what other factors may be affecting $Q_{\text {avg }}$, the effects of temperature were next to be studied. Figure 27 shows each of the temperature variables plotted alongside $Q_{\text {avg. }}$. As anticipated, the temperature signals follow roughly the same sinusoidal pattern, however with different degrees of amplitude. For instance the temperature inside the pit would not be expected to fluctuate as much as the ambient temperature due to the influence of insulation provided by the earth. This same behavior can be observed in Figure 27, which helps to further support the validity of the measurements.

Once again, for simplification, each of the temperature measurements were treated as independent variables, despite the known correlated relationships that exist among them. However, to some extent these relationships between temperature variables were recognized by observing the differences in temperature between two measurement points $(\Delta \mathrm{T})$. The values for various $\Delta \mathrm{T}$ are plotted separately in Figure 28.

By first evaluating the temperature data's relationship with $Q_{\text {ave }}$ throughout the entire day revealed some fairly strong negative correlations. Table 15 shows that the variables with the most correlated values are the ambient temperature $\left(\mathrm{T}_{\mathrm{am}}\right)$, the change in temperature between the superstructure and the bottom of the vent pipe/pit $\left(\Delta \mathrm{T}_{\text {ss-bot }}\right)$, and the temperature at the top of the vent pipe $\left(\mathrm{T}_{\text {top }}\right)$.

For further scrutiny of the temperature data, the daily measurement period was broken up into three time period segments based off of the information learned from the analysis of $U_{v p}$. The first time period was set to be the time leading up to when $U_{v p}$ was observed to have the most significant influence over $Q_{\text {avg }}(0: 00-8: 00)$, the second period was segregated by when $U_{\mathrm{vp}}$ 's influence was at its peak (9:00 - 17:00), and the last period was the remaining time that followed (18:00 - 23:00). In more general terms, these three time periods were referred to as early morning, midday and evening respectively. 
To assist with identification, the strongest correlations were ranked one through three from each time period, as demonstrated below in Table 15. As one can observe from Table 15, $\mathrm{T}_{\mathrm{am}}$ has the highest $\mathrm{R}$ value for the entire time period. This makes sense due to its influence over all temperature data, but this would not necessarily indicate that $\mathrm{T}_{\mathrm{am}}$ has a direct influence on $\mathrm{Q}_{\text {avg. }}$. Low $\mathrm{R}$ values during the three segregated time periods indicate that the ambient temperature may not have as much influence as some of the other variables.

The next strongest overall correlation was identified as the change in temperature between the superstructure and the bottom of the vent pipe/pit $\left(\Delta \mathrm{T}_{\text {ss-bot }}\right)$. During each of the segmented time periods it was observed that $\Delta \mathrm{T}_{\text {ss-bot, }}$, and or one of its contributors, was of the three top factors in each case. This suggests that $\Delta \mathrm{T}_{\text {ss-bot }}$ could be one of the most influential factors affecting $Q_{\text {avg, }}$, especially during the time period from 0:00 to 17:00 hours. To test this theory, and to learn more about the behavioral influence of $\Delta \mathrm{T}_{\text {ss- }}$ bot, the variable was plotted against $Q_{\text {avg }}$ (see Figure 29).

Table 15: Correlation coefficients for each factor and $Q_{\text {avg }}$ during specific time periods

\begin{tabular}{|c|c|c|c|c|}
\hline Factor & $\begin{array}{c}\text { R } \\
\text { Entire Day (rank) }\end{array}$ & $\begin{array}{c}R \\
0: 00-8: 00 \text { (rank) }\end{array}$ & $\begin{array}{c}\text { R } \\
\text { 9:00 - 17:00 (rank) }\end{array}$ & $\begin{array}{c}R \\
18: 00-23: 00 \text { (rank) }\end{array}$ \\
\hline $\mathrm{T}_{\mathrm{am}}\left({ }^{\circ} \mathrm{C}\right)$ & $-0.82(1)$ & -0.61 & -0.26 & $-0.59(3)$ \\
\hline $\mathrm{T}_{\text {bot }}\left({ }^{\circ} \mathrm{C}\right)$ & -0.66 & -0.22 & $-0.85(1)$ & $-0.64(2)$ \\
\hline $\mathrm{T}_{\mathrm{ss}}\left({ }^{\circ} \mathrm{C}\right)$ & -0.78 & $-0.70(3)$ & $-0.76(2)$ & -0.54 \\
\hline $\mathrm{T}_{\text {top }}\left({ }^{\circ} \mathrm{C}\right)$ & $-0.79(3)$ & $-0.73(2)$ & -0.18 & $-0.65(1)$ \\
\hline$\Delta T_{\text {am-bot }}$ & -0.76 & -0.59 & 0.02 & -0.54 \\
\hline$\Delta \mathrm{T}_{\mathrm{am}-\mathrm{ss}}$ & -0.48 & -0.21 & 0.59 & -0.52 \\
\hline$\Delta T_{\text {am-top }}$ & -0.75 & -0.39 & -0.23 & -0.54 \\
\hline$\Delta T_{\text {SS-bot }}$ & $-0.81(2)$ & $-0.85(1)$ & $-0.69(3)$ & -0.48 \\
\hline$\Delta T_{\text {top-bot }}$ & -0.70 & -0.68 & 0.07 & -0.55 \\
\hline
\end{tabular}




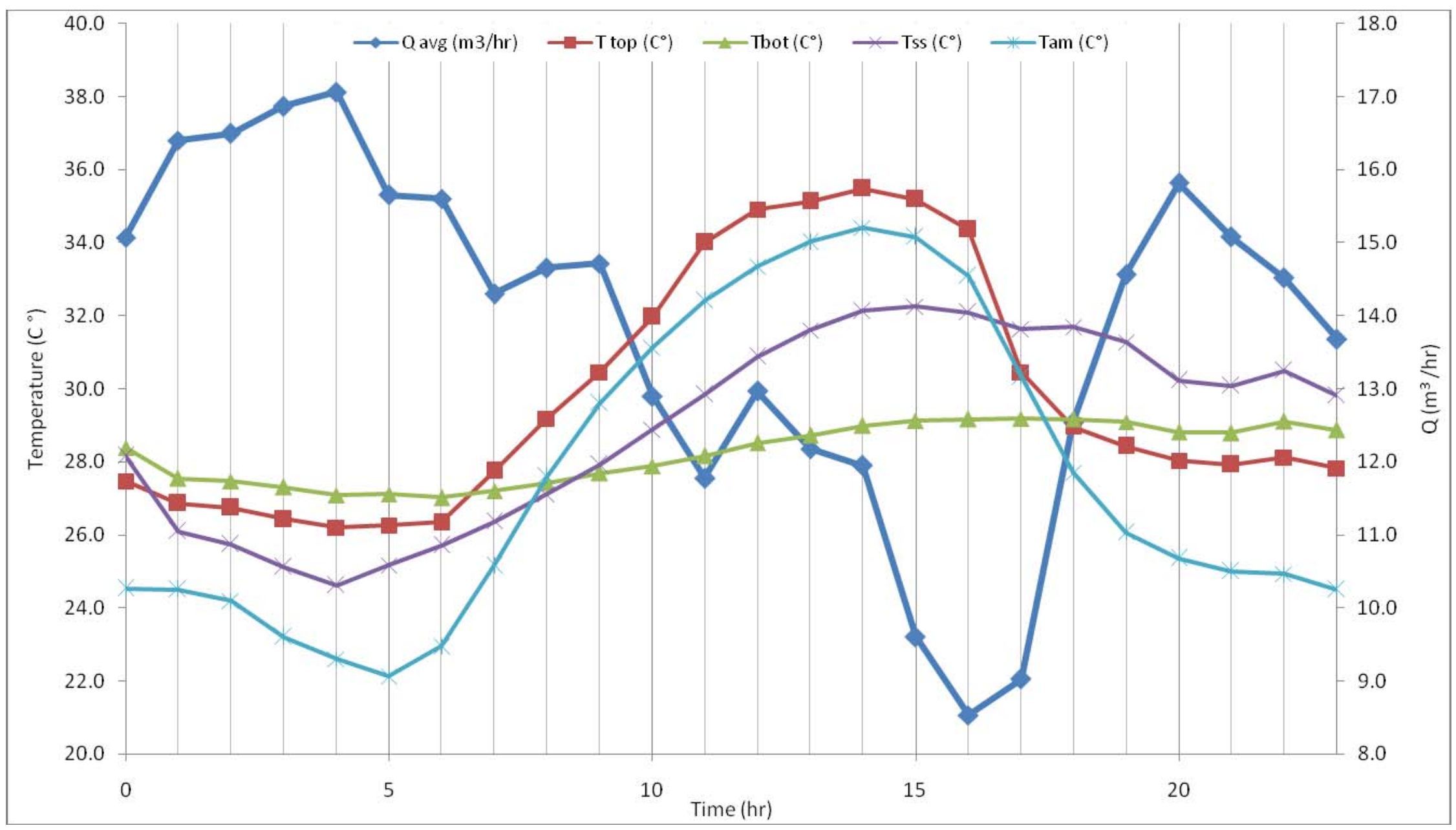

Figure 27: Averaged values for flow rate $\left(Q_{a v g}\right)$, the ambient temperature $\left(T_{a m}\right)$, and temperatures at the top of the vent pipe $\left(T_{\text {top }}\right)$, bottom of the vent pipe $\left(T_{\text {bot }}\right)$, inside the superstructure $\left(T_{s s}\right)$, over time. 


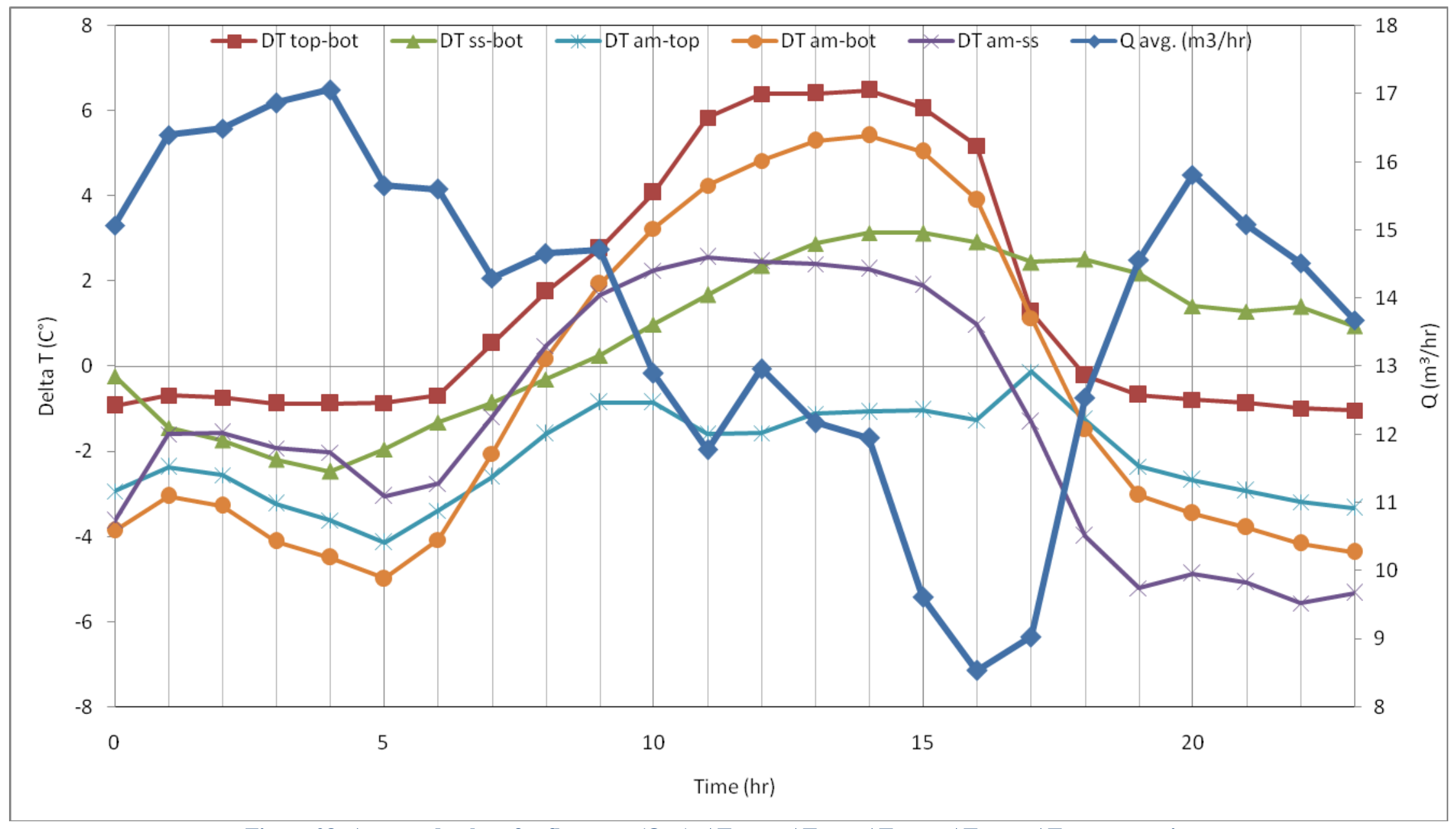

Figure 28: Averaged values for flow rate $\left(\mathrm{Q}_{\text {avg }}\right), \Delta \mathrm{T}_{\text {top-bot }} \Delta \mathrm{T}_{\text {ss-bot }}, \Delta \mathrm{T}_{\text {am-top }}, \Delta \mathrm{T}_{\text {am-bot }} \Delta \mathrm{T}_{\text {am-ss }}$, over time. 
The regression line in Figure 29 shows that a trend is apparent. Perhaps more notable about Figure 29 is how $\Delta \mathrm{T}_{\text {ss-bot }}$ values above zero appear to be less correlated with $\mathrm{Q}_{\text {avg }}$ than those found below zero. When just the negative values for $\Delta \mathrm{T}_{\text {ss-bot }}$ and $\mathrm{Q}_{\text {avg }}$ were plotted, the $\mathrm{R}^{2}$ value becomes $0.72(\mathrm{P}=0.003)$. Interpreted from this is that $\Delta \mathrm{T}_{\text {ss-bot }}$ plays a more significant role in influencing $Q_{\text {avg }}$ when superstructure temperatures are lower than the temperature at the bottom of the vent pipe/pit. Referring back to Figure 28, it was observed that $\Delta \mathrm{T}_{\text {ss-bot }}$ crossed from negative to positive at approximately 9:00 hours; roughly around the same time wind speed was found to start having a more significant affect on $Q_{\text {avg. }}$ The fact that these two incidences occur exclusively at the same time further singles $\Delta \mathrm{T}_{\text {ss-bot }}$ out as a potentially significant variable.

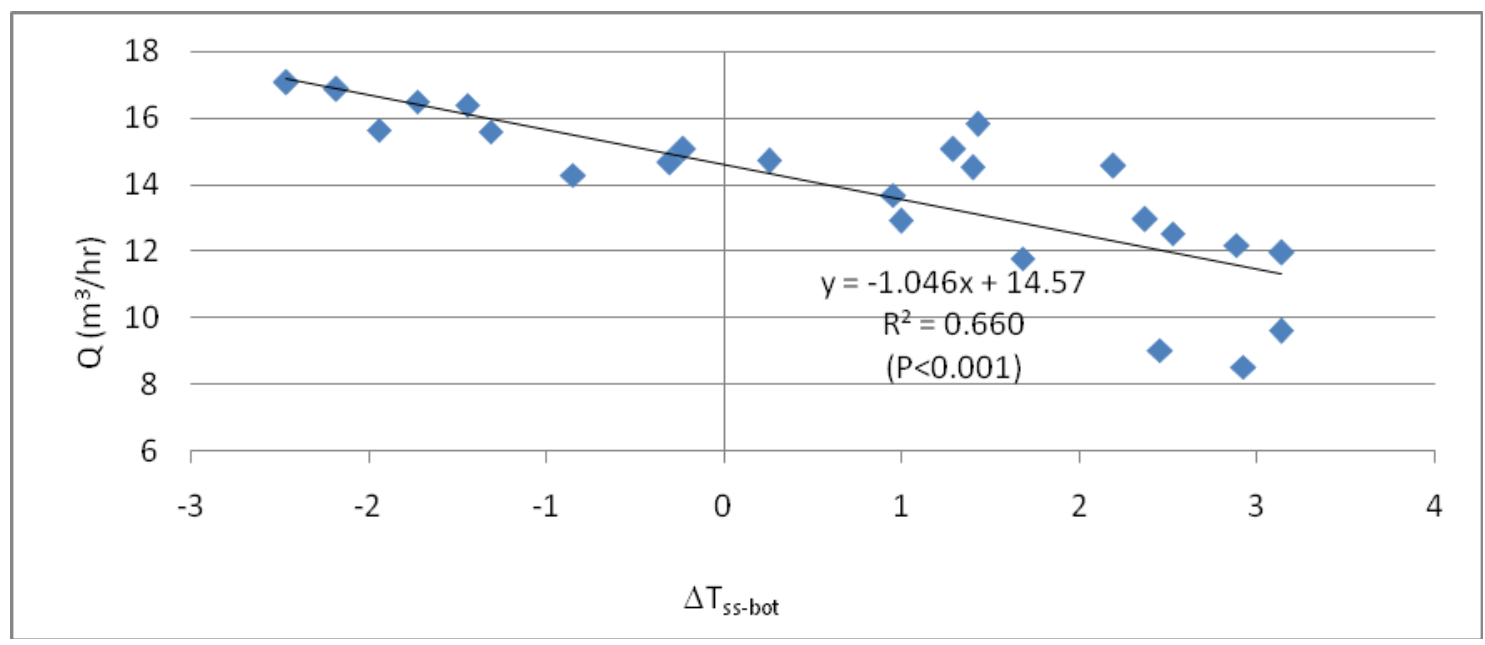

Figure 29: Average flow rate $\left(Q_{\text {avg }}\right)$ vs. $\Delta T$ superstructure - bottom of the vent pipe/pit

The third most correlated variable was the temperature at the height of the vent pipe $\left(\mathrm{T}_{\text {top }}\right)$. During the early morning and evening hours the top temperatures were found to be just below the bottom/pit temperatures. This suggests that during these times $T_{\text {top }}$ was dependent on the temperature of the pit. On the other hand, once $T_{\text {top }}$ became higher than the pit temperature a decrease in $\mathrm{Q}_{\text {avg }}$ was observed. The complete opposite effect was seen to occur during the evening between 17:00 and 18:00 hours, roughly the same time $\mathrm{U}_{\mathrm{vp}}$ ceases to have as much of an influence on $\mathrm{Q}_{\text {avg. }}$. Therefore $\mathrm{T}_{\text {top }}$ appears to be a influential variable during the instances in which the ambient temperature transitions 
above or below the bottom/pit temperature. This is particularly evident during the evening temperature transition.

\subsubsection{Analysis of monthly/seasonal variation}

The three months of the present study coincided with the end of the rainy season and the beginnings of the cool-dry/Harmattan season. To observe if the change in season would have any effect on $\mathrm{Q}_{\mathrm{avg}}$, ten Kulkpong latrines were measured once a month throughout the three months of the study. This information was also useful in providing insight into which of the environmental factors had significant influence over $\mathrm{Q}_{\mathrm{avg}}$.

The cumulative average flow rate from the ten Kulkpong latrines for each of the three months is shown in Figure 30. The values for $\mathrm{Q}_{\mathrm{avg}}$ were normalized in order to compare trends of other variables on the same graph. As illustrated in Figure 30, higher flow rates were observed for November compared to September or October. To try and explain why this occurred, the cumulative average value for each of the measured variables were examined for correlation with $\mathrm{Q}_{\mathrm{avg}}$. For example; when wind speed at the top of the vent pipe was studied, as shown in the second group of columns on Figure 30, there appeared to be very few similarities between its monthly variation and that of $\mathrm{Q}_{\mathrm{avg}}$.

The variable with the most evident resemblance to $\mathrm{Q}_{\mathrm{avg}}$ was found to be $\Delta \mathrm{T}_{\text {ss-bot. }} \mathrm{A}$ plausible explanation of why this occurred can be drawn from what is characteristically known about the seasonal transition that is occurring over this time period. The typical characteristics of the cool-dry/Harmattan season are similar to that of desert conditions: hot-dry days with cool/cold nights and mornings. During this time the change in ambient temperature can by quite dramatic. The average difference between maximum and minimum ambient temperatures for the month of September was $9.69^{\circ} \mathrm{C}$, whereas the average difference for the month of November was $13.82^{\circ} \mathrm{C}$. An increase in the difference between the maximum and minimum daily temperature creates a larger gap between the superstructure temperature, which is more responsive to the ambient temperatures, and the bottom/pit temperature, which is less responsive to ambient temperatures. This creates ideal conditions during the morning and evening periods for 
warmer air from the pit to rises into the cooler atmosphere via the ventilation pipe. This mechanism is sometimes referred to as the stack effect, and will be discussed again later in this chapter.

Therefore, what is likely being observed in the monthly comparison is an increase in $\mathrm{Q}_{\mathrm{avg}}$ as a result of colder evening and morning temperatures, which fuels the mechanism of the stack effect.

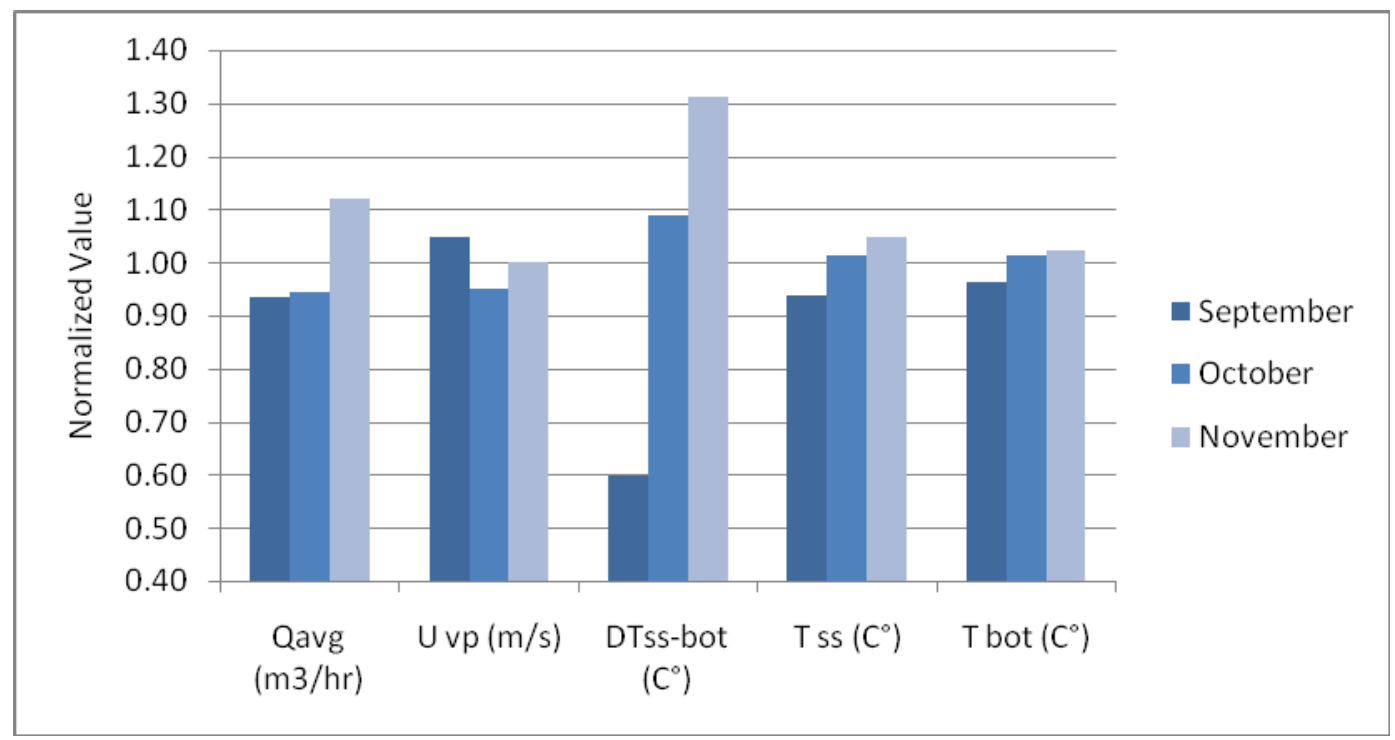

Figure 30: Monthly variation among average values for flow rate, wind speed and temperatures.

\subsubsection{Environmental Factors Summary}

Based on the analysis above, the environmental variables that were singled out as the most likely to have influence over $\mathrm{Q}_{\mathrm{ave}}$ are as follows:

1. From the correlation data and the analysis of the monthly variation, it was observed that differences in temperature between the superstructure and the bottom of the vent pipe/pit $\left(\Delta \mathrm{T}_{\text {ss-bot }}\right)$ had a significant relationship with the average flow rate; particularly during the early morning periods when both $\mathrm{T}_{\mathrm{am}}$ and $\mathrm{T}_{\mathrm{ss}}$ were less than $\mathrm{T}_{\text {bot. }}$.

2. During midday hours, wind passing over the top of the vent pipe $\left(U_{V P}\right)$ was found to have a strong correlation with $\mathrm{Q}_{\mathrm{avg}}$. 
3. Temperature at the top of the vent pipe ( $\left.T_{\text {top }}\right)$ shows a relationship with the $Q_{\text {avg }}$ primarily during times in which $\mathrm{T}_{\mathrm{am}}$ transitions above or below $\mathrm{T}_{\mathrm{bot}}$. This is particularly evident when this phenomenon occurs in the evening.

\subsection{Interpretation of the flow rate pattern with identified key variables}

Now that the primary variables have been identified, it becomes easier to explain the behavior of $\mathrm{Q}_{\text {avg }}$ over the course of a day. For reference, Figures 25, 26 and 28 are again shown with annotations at the end of each subsection.

\subsubsection{Morning (0:00 - 8:00)}

In Table 15, between the hours of 0:00 and 8:00, $\Delta \mathrm{T}_{\text {ss-bot }}$ was the variable with the highest correlation $\left(\mathrm{R}^{2}=0.72, \mathrm{P}=0.003\right)$. This is confirmed by the visual pattern seen in Figure 31 , which shows $\Delta \mathrm{T}_{\text {ss-bot }}$ having an inverse relationship with the average flow rate. The highest average flow rate was observed at 4:00 hours, the same time at which $\Delta \mathrm{T}_{\text {ss-bot }}$ was recorded to be at its largest absolute value (see Figures 31 and 32, annotation numbers 1 and 2).

How $\Delta$ Tss-bot could theoretically influence flow rate during the period of 0:00 to 8:00 $Q_{\text {avg, }}$ can be explained by considering the buoyant forces of warmer air inside the pit rising up into the cooler ambient environment through both the ventilation pipe and the superstructure. As previously mentioned and for the remainder of the report this mechanism will be referred to as the stack effect.

During these periods where no wind is present and temperatures inside the pit are higher than that of the superstructures, there are essentially no environmental forces preventing air from rising from the pit through the drop hole and into the superstructure (see Figure 31, annotation number 3). This can be supported by anecdotal evidence that the worst time to frequent a VIP latrine is in the early morning due to the odor in the superstructure being at its strongest. Therefore during this time, although there is a high flow rate 
coming out of the vent pipe, there is also in theory a high air flow coming out the drop hole and into the superstructure.

Not only can the building envelope of the superstructure retain odor, it can also retain some of the heat given off from the pit. This would likely explain the increase in superstructure temperature and the reduction in $Q_{\text {avg }}$ between the hours of 4:00 and 5:00 shown on Figure 32 (annotation number 4).

Further evidence of the stack effect was revealed by the close correlation of the temperatures at the top and bottom of the vent pipe between the hours of 0:00 and 6:00 $\left(\mathrm{R}^{2}=0.95, \mathrm{P}<0.001\right)$. Since at this time there was no solar radiation to heat the pipe, the only other variable to account for the temperature at the top of the vent pipe being higher than the ambient temperature would be due to warmer air rising from the pit. Later in the period, between 6:00 and 7:00, the temperature at the top of the vent pipe became greater than the bottom of the pipe, possibly due to heating by solar radiation (see Figures 31 and 33, annotation numbers 5 and 6). Once the top of the vent pipe was heated beyond $\mathrm{T}_{\text {bot }}$ there was a decrease in $\mathrm{Q}_{\text {avg. }}$. Therefore, instead of warmer temperatures at the top of the vent increasing ventilation they may actually be reducing it by limiting the stack effect. 


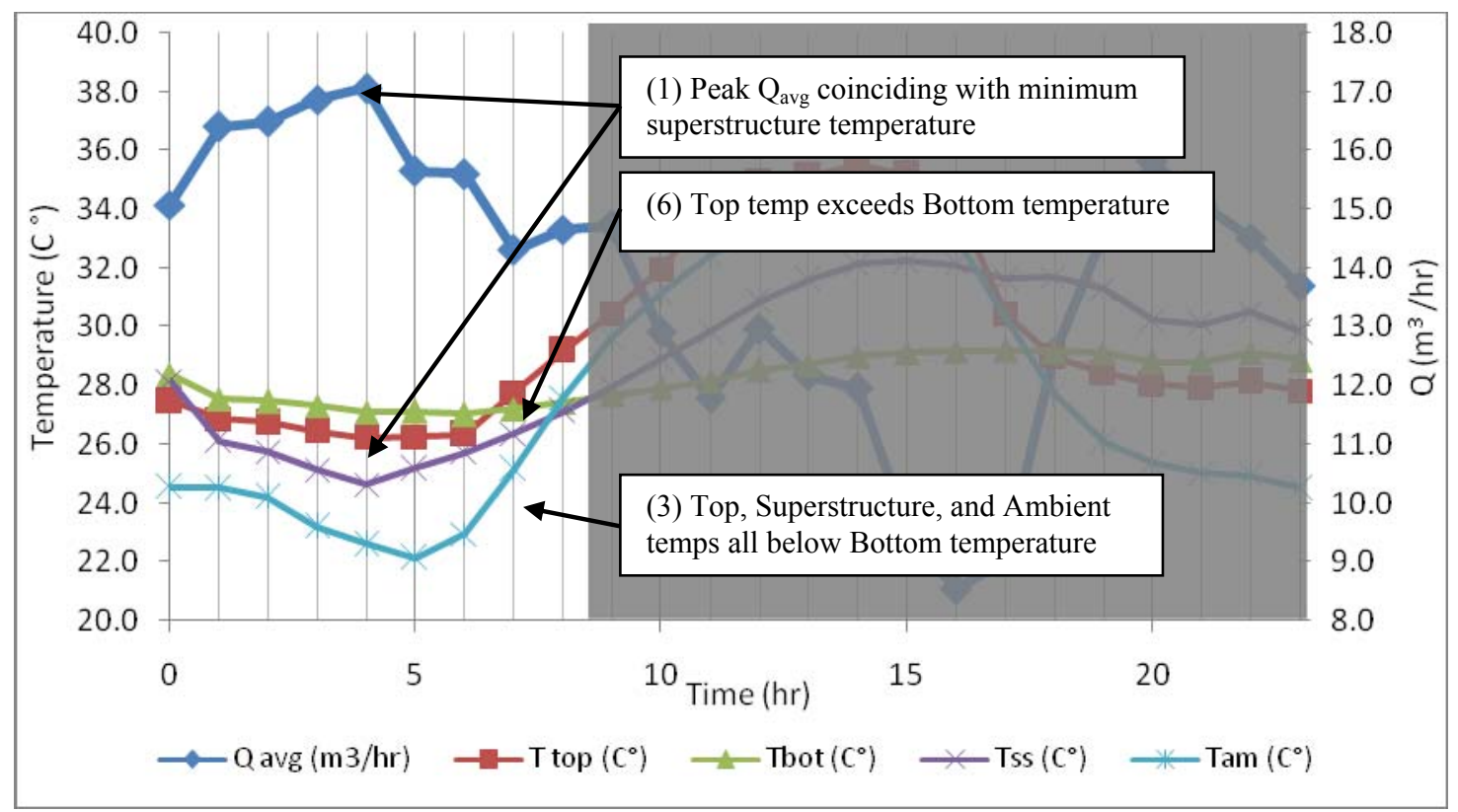

Figure 31: Averaged values for flow rate $\left(Q_{a v g}\right)$, the ambient temperature $\left(T_{a m}\right)$, and temperatures at the top of the vent pipe $\left(T_{\text {top }}\right)$, bottom of the vent pipe $\left(T_{\text {bot }}\right)$, inside the superstructure $\left(T_{s s}\right)$ over time 0:00-8:00.

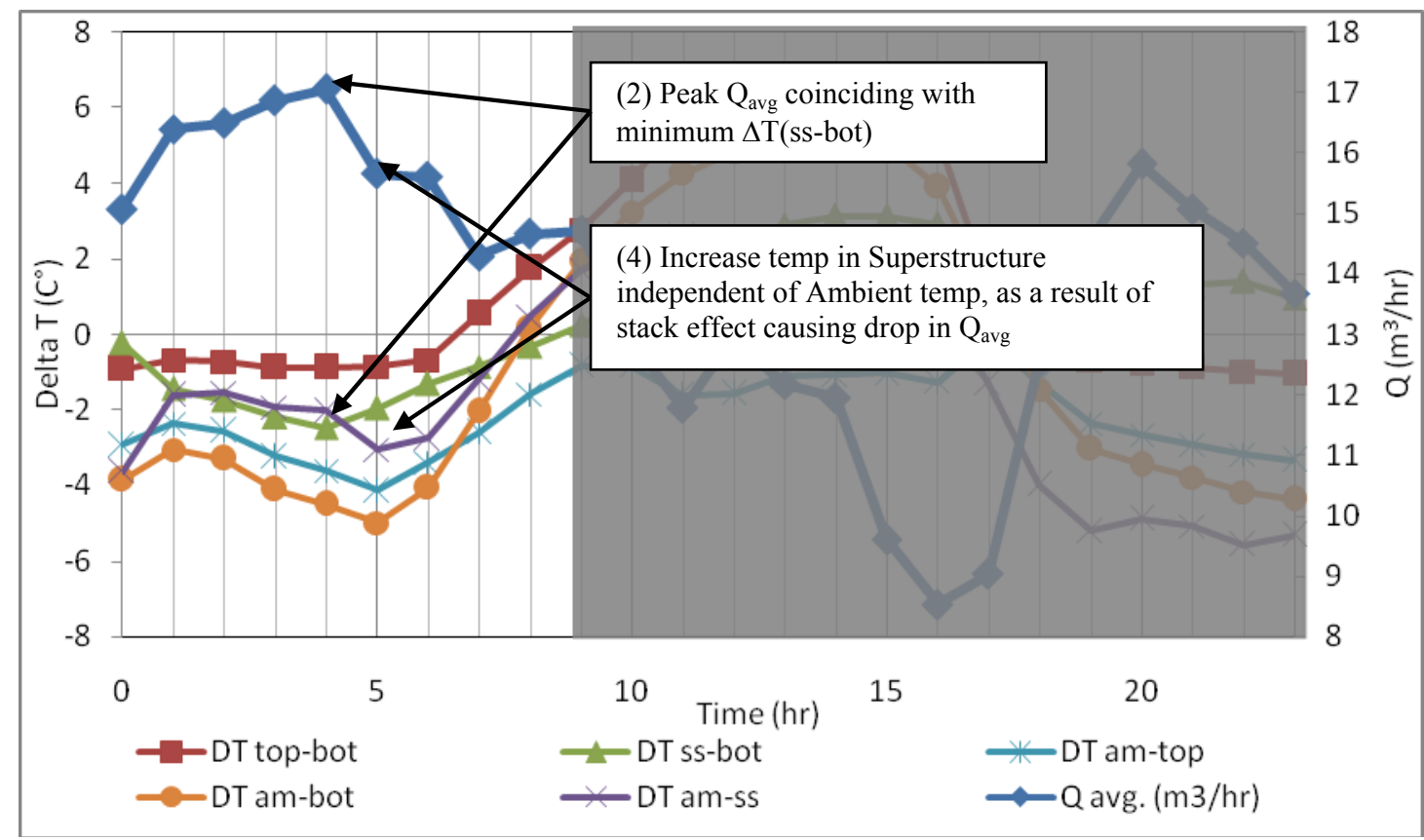

Figure 32: Averaged values for flow rate $\left(\mathrm{Q}_{\text {avg }}\right), \Delta \mathrm{T}_{\text {top-bot }} \Delta \mathrm{T}_{\text {ss-bot }} \Delta \mathrm{T}_{\text {am-top }}, \Delta \mathrm{T}_{\text {am-bot }}, \Delta \mathrm{T}_{\text {am-ss }}$, over time 0:00-8:00. 


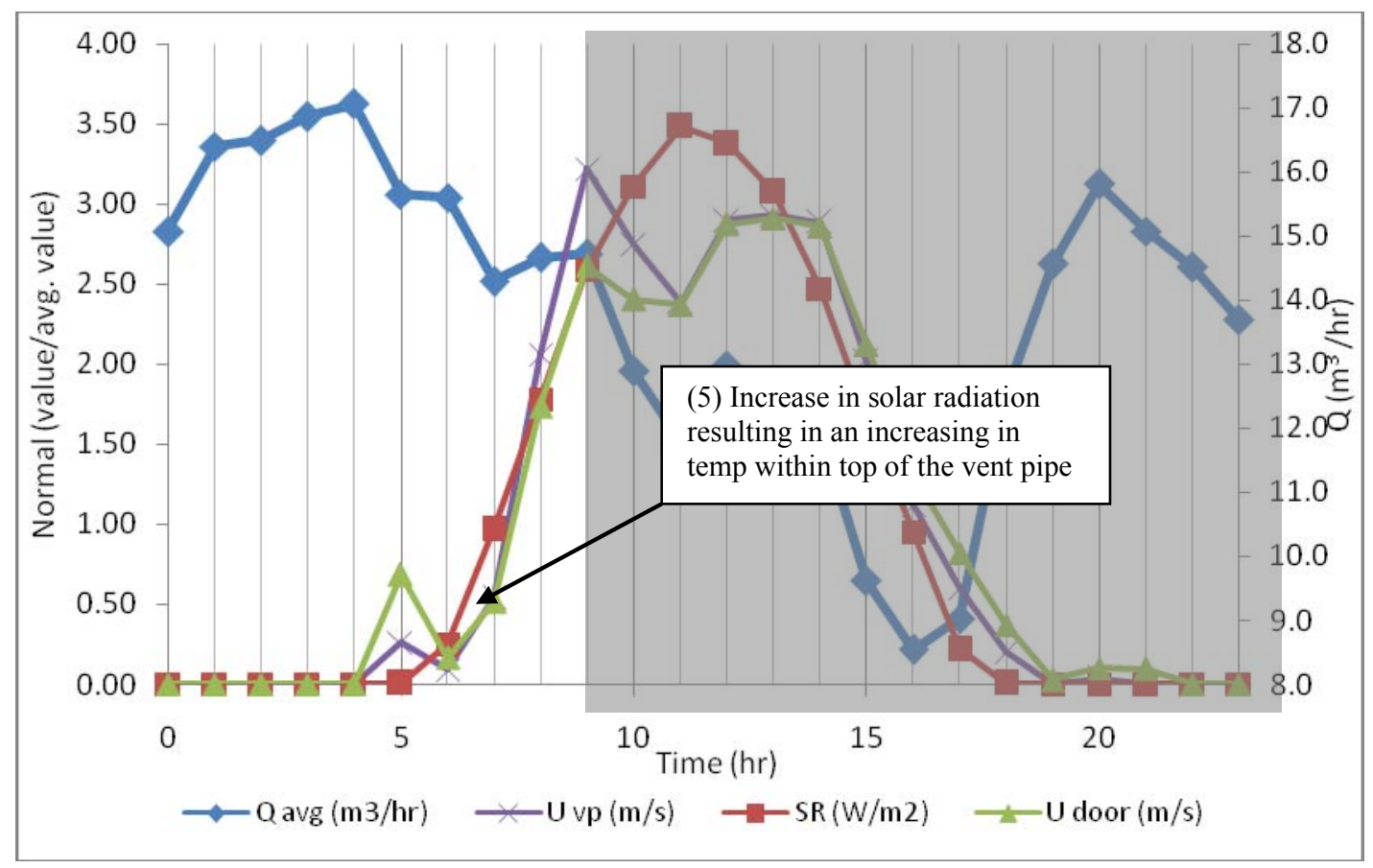

Figure 33: Averaged values for flow rate $\left(Q_{\text {avg }}\right)$, and averaged normalized values for Vent Pipe $\left(U_{V P}\right)$ Wind Speed, Solar Radiation (SR), and Door Wind Speed $\left(U_{\text {door }}\right)$ over time 0:00-8:00.

\subsubsection{Midday (8:00-17:00)}

The first major transition occurred from 7:00 to 9:00 hours at which time increased ambient temperatures and wind speeds were observed. Although the increasing wind speeds may be a contributing factor to a slight rise in $Q_{\text {avg, }}$, it was observed that $U_{v p}$ did not become a major influence until 9:00 hours (see Figure 34, annotation number 1). Also occurring at approximately the same time was that $\mathrm{T}_{\mathrm{ss}}$ became warmer than the bottom/pit temperature (see Figure 35, annotation number 2) and $\mathrm{U}_{\mathrm{VP}}$ exceeded $0.5 \mathrm{~m} / \mathrm{s}$. These two events may be contributing factors to why $U_{v p}$ has its strongest correlation during the midday.

Despite the positive correlation between $\mathrm{Q}_{\text {avg }}$ and $\mathrm{U}$, an overall negative trend still appeared throughout this time period. A plausible argument that this is a result of continued influences of buoyancy forces could be made. This is supported by the high correlations shown in Table 15 for $\mathrm{T}_{\mathrm{bot}}, \mathrm{T}_{\mathrm{ss}}$, and the difference between those two variables, $\Delta \mathrm{T}_{\text {ss-bot. }}$. Further analysis of the relationship between $\mathrm{T}_{\text {bot }}$ and $\mathrm{Q}_{\text {avg }}$ revealed 
what appeared to be a third order quadratic trend, however due to the few number of data points the analysis of this relationship was limited to a linier regression which showed an $\mathrm{R}^{2}$ of 0.73 ( $\mathrm{P}=0.003$ ). The fit suggested that during this time period $\mathrm{Q}_{\text {avg }}$ continued to follow inversely with the sinusoidal pattern of the temperature data, even though wind speeds were at their highest and most influential levels.

A plausible interpretation of the data is as follows: since the air inside the pit is cooler than the ambient temperature, the stack effect observed in the early morning can no longer play as significant a role in updraft as it had in the early morning hours. Therefore at this point wind becomes the driving factor. However, as the ambient air temperature increases throughout the midday it also becomes less dense, which in turn makes it more difficult for the wind to draw up the denser, heavier, air of from within the pit. This is best illustrated in Figure 34 between the hours of 12:00 and 14:00 where the amplitudes between the $\mathrm{Q}_{\text {avg }}$ signal and $\mathrm{U}$ signals deviate. Concurrently, Figure 36 (annotation number 4) shows that $\Delta \mathrm{T}_{\mathrm{am}-\mathrm{ss}}$ reaches its highest point during this time period.

Without the effects of wind or the stack effect, there was negligible ventilation, as can be observed from the hours of 15:00 through 17:00 hours. In accordance with the air buoyancy theory, as long as the temperatures in the superstructure remained higher than that of the pit then odorous air would remain for the most part inside the pit. This effect would also occur for vent-less pit latrines under the same conditions. 


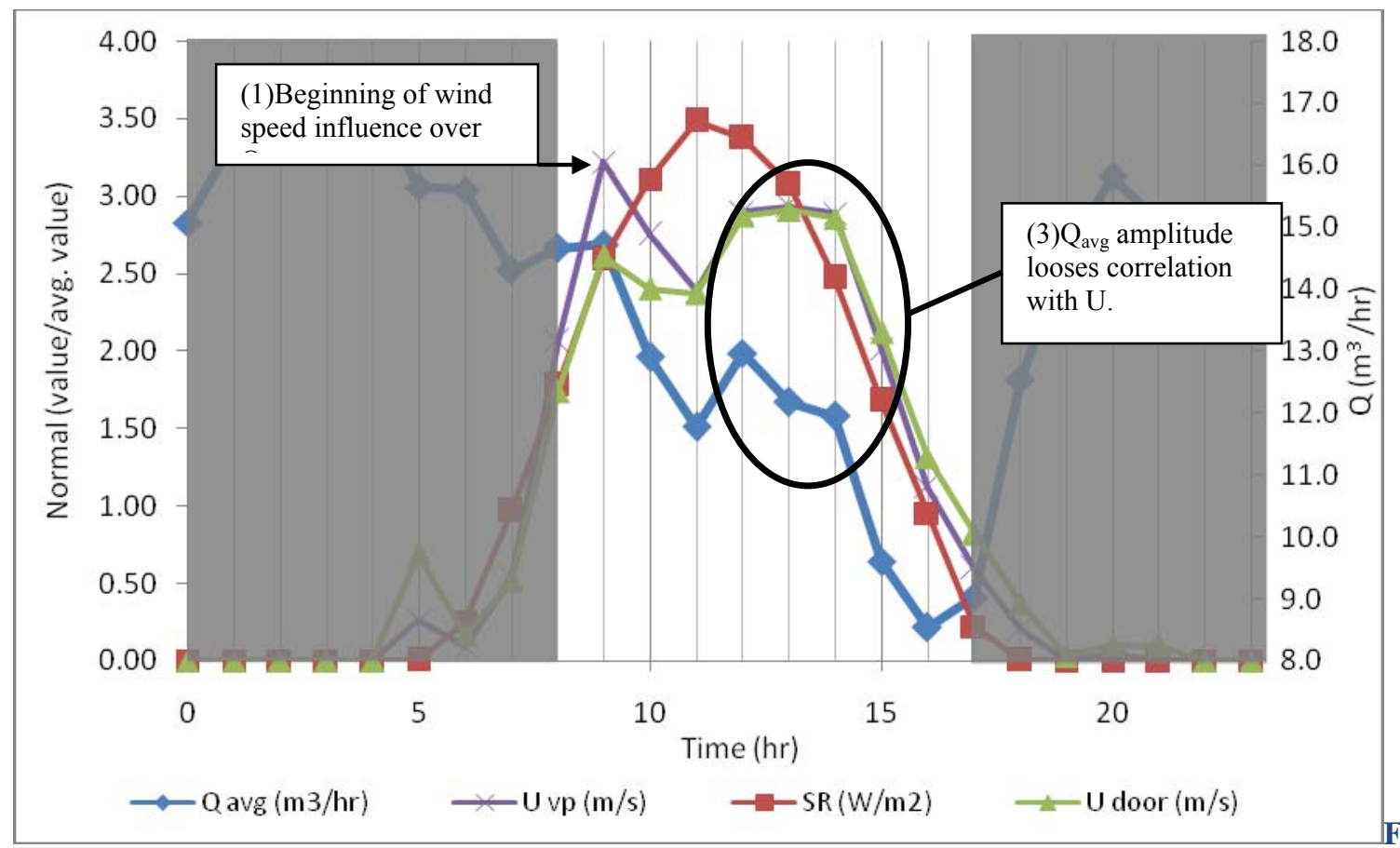

igure 34: Averaged values for flow rate $\left(Q_{\text {avg }}\right)$, and averaged normalized values for Vent Pipe $\left(U_{V P}\right)$ Wind Speed, Solar Radiation (SR), and Door Wind Speed $\left(U_{\text {door }}\right)$ over time 8:00-17:00.

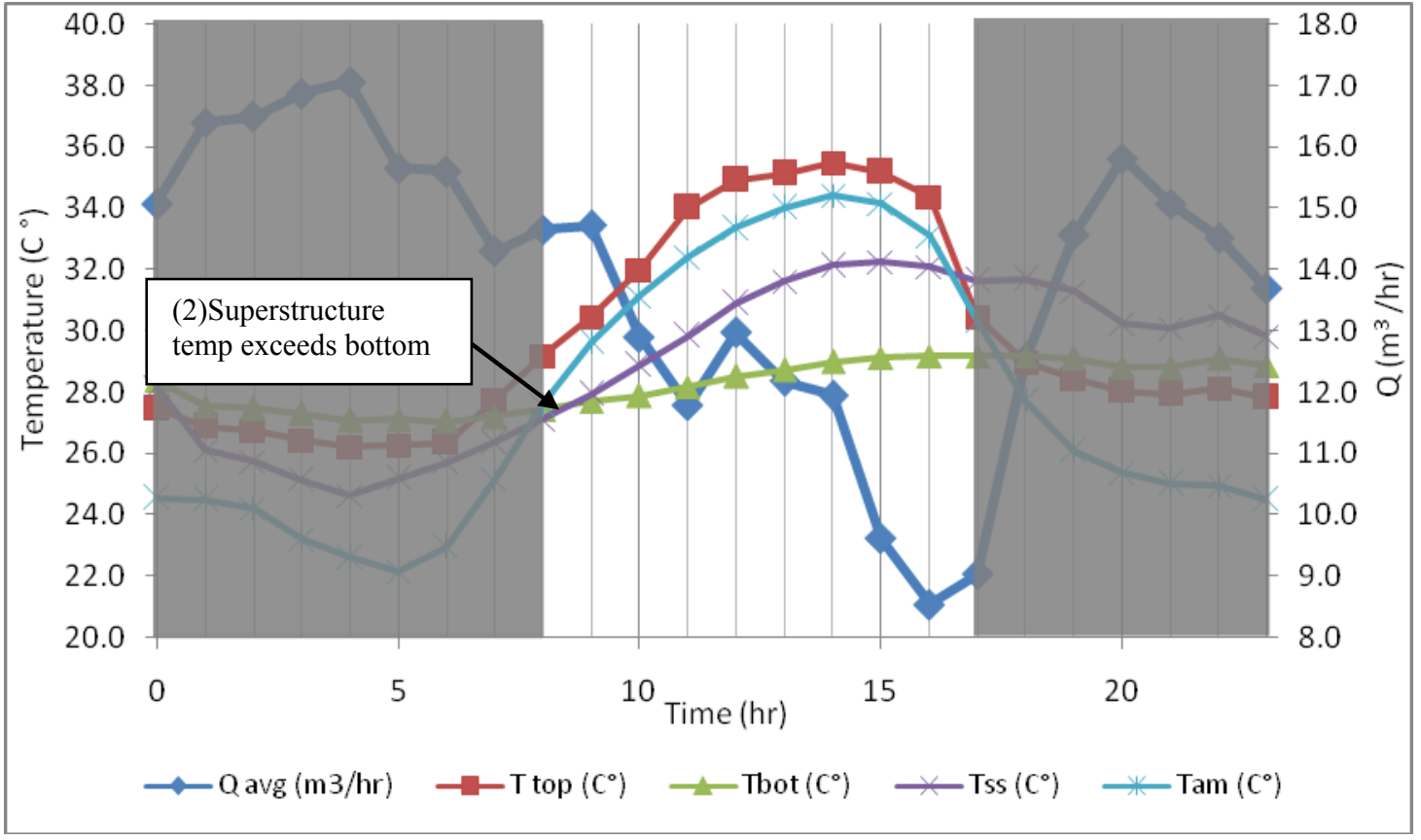

Figure 35: Averaged values for flow rate $\left(Q_{a v g}\right)$, the ambient temperature $\left(T_{a m}\right)$, and temperatures at the top of the vent pipe $\left(T_{\text {top }}\right)$, bottom of the vent pipe $\left(T_{b o t}\right)$, inside the superstructure $\left(T_{s s}\right)$ over time 8:00-17:00. 


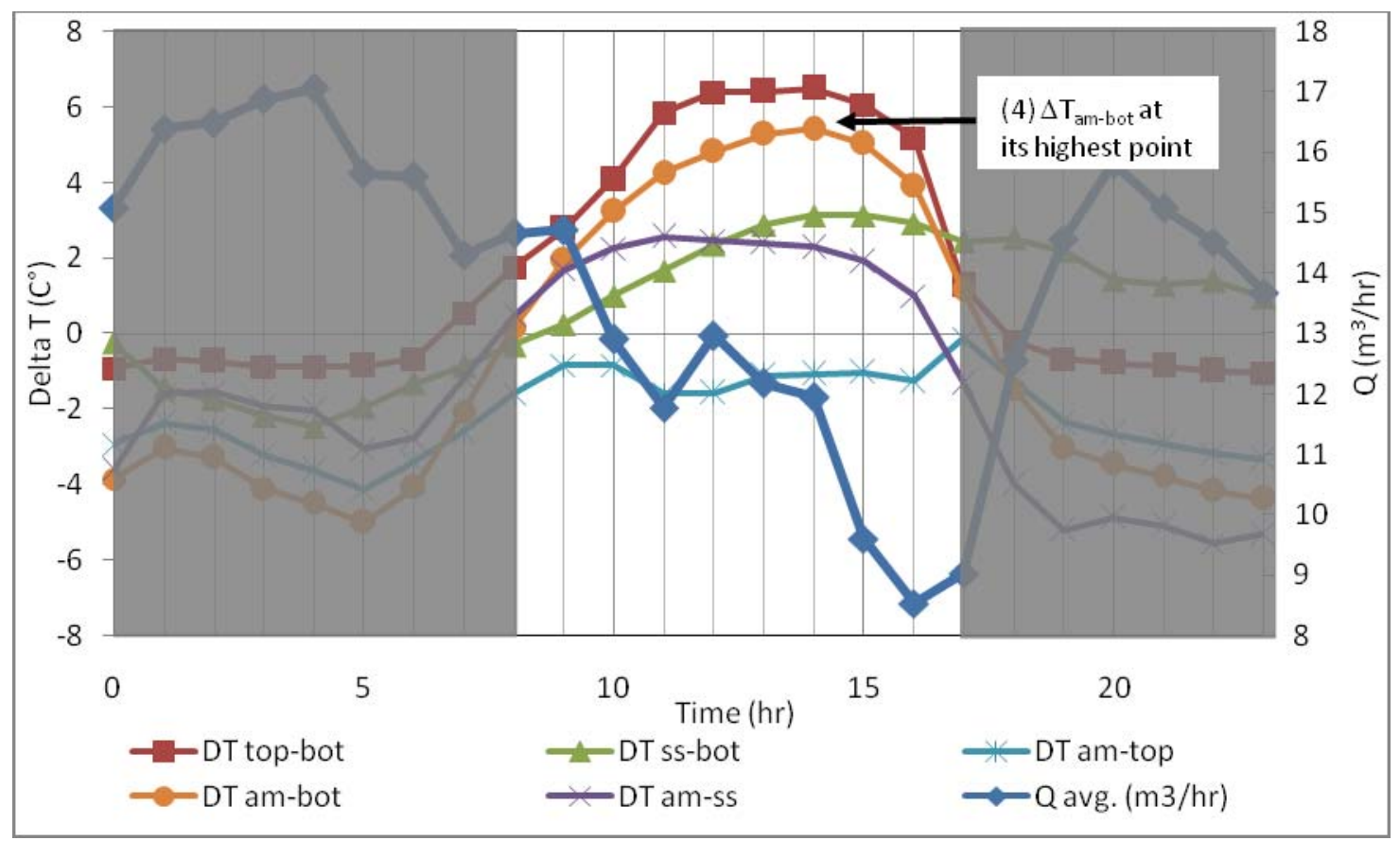

Figure 36: Averaged values for flow rate $\left(\mathrm{Q}_{\text {avg }}\right), \Delta \mathrm{T}_{\text {top-bot }} \Delta \mathrm{T}_{\mathrm{ss} \text {-bot }} \Delta \mathrm{T}_{\text {am-top }}, \Delta \mathrm{T}_{\text {am-bot }} \Delta \mathrm{T}_{\text {am-ss, }}$ over time 8:00-17:00.

\subsubsection{Evening (17:00 - 23:00)}

A sharp increase in flow rate was noted between 17:00 and 18:00 hours, approximately the same time in which the ambient air temperature dropped below the pit temperature (see Figure 38, annotation number 2). This was indicative of a reversal in buoyancy forces that were previously preventing the stack effect from occurring.

However, as can be observed from any of the Figures below, $Q_{\text {avg }}$ 's maximum value during this time was not as high as it was from the early morning peak. One likely reason for this is that the building envelope of the superstructure was still retaining residual heat from the midday, keeping the superstructure temp higher than the pit temp. Recalling that most of the surface area of a UWR VIP latrine vent pipe is located inside the superstructure, there is the likelihood that the warm air of the superstructure is insulating the vent pipe to a certain degree, which would slow down air cooling and vertical updraft.

Finally, throughout the last three hours of the day, a decline in $\mathrm{Q}_{\text {avg }}$ was observed. Again, this can be explained as a result of buoyancy forces. When temperature in the 
superstructure cools down and approaches the temperature of the pit, the differences in temperature that drive buoyancy forces becomes less, or in other words $\Delta$ Tss-bot would approach equilibrium. However, once the superstructure temperature falls below the pit temperature and $\Delta$ Tss-bot becomes increasingly less than zero, as is the case from 0:00 to 4:00 hours, $Q_{\text {avg }}$ once again increases.

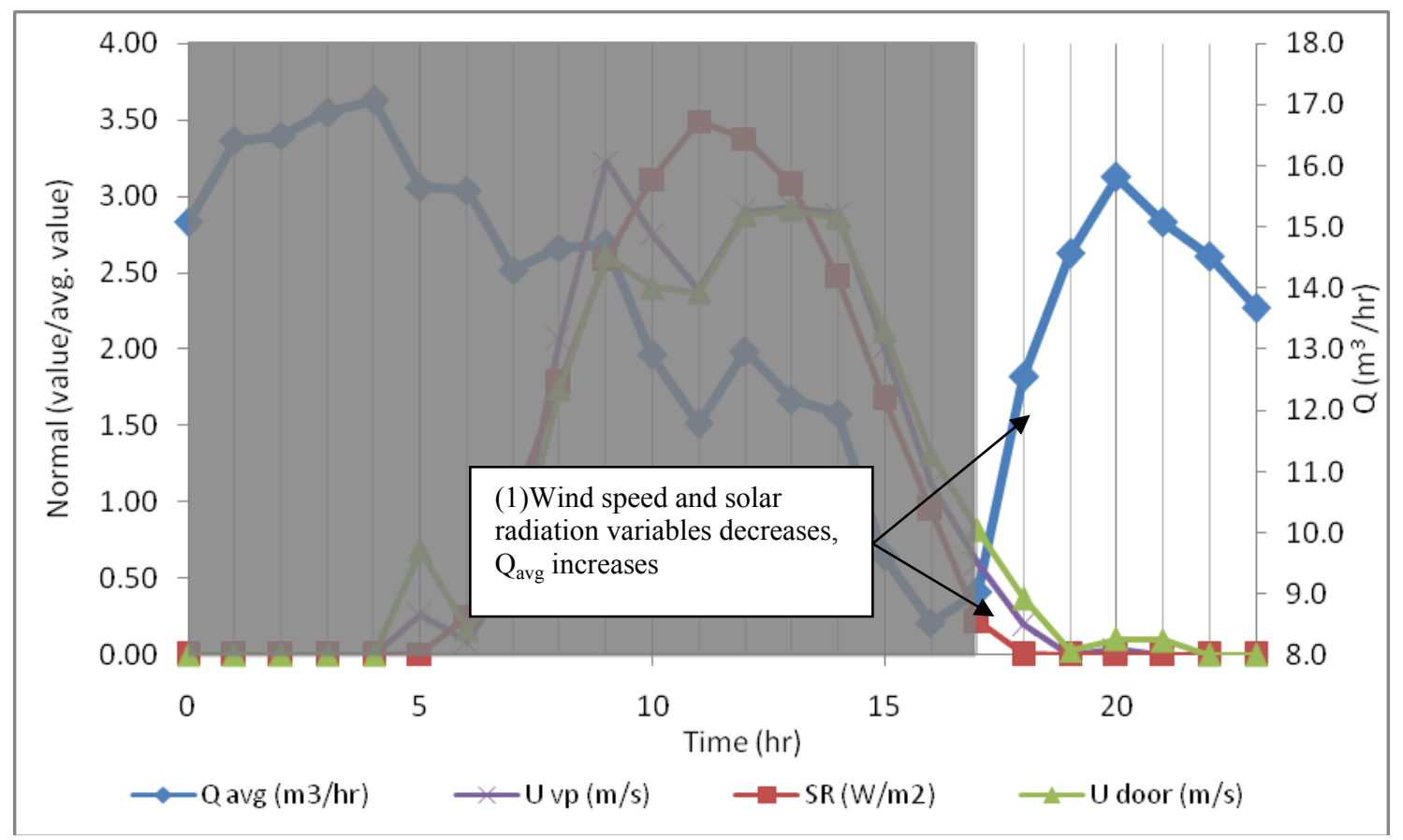

Figure 37: Averaged values for flow rate $\left(Q_{\text {avg }}\right)$, and averaged normalized values for Vent Pipe $\left(U_{V P}\right)$ Wind Speed, Solar Radiation (SR), and Door Wind Speed ( $\left.U_{\text {door }}\right)$ over time 17:00-23:00. 


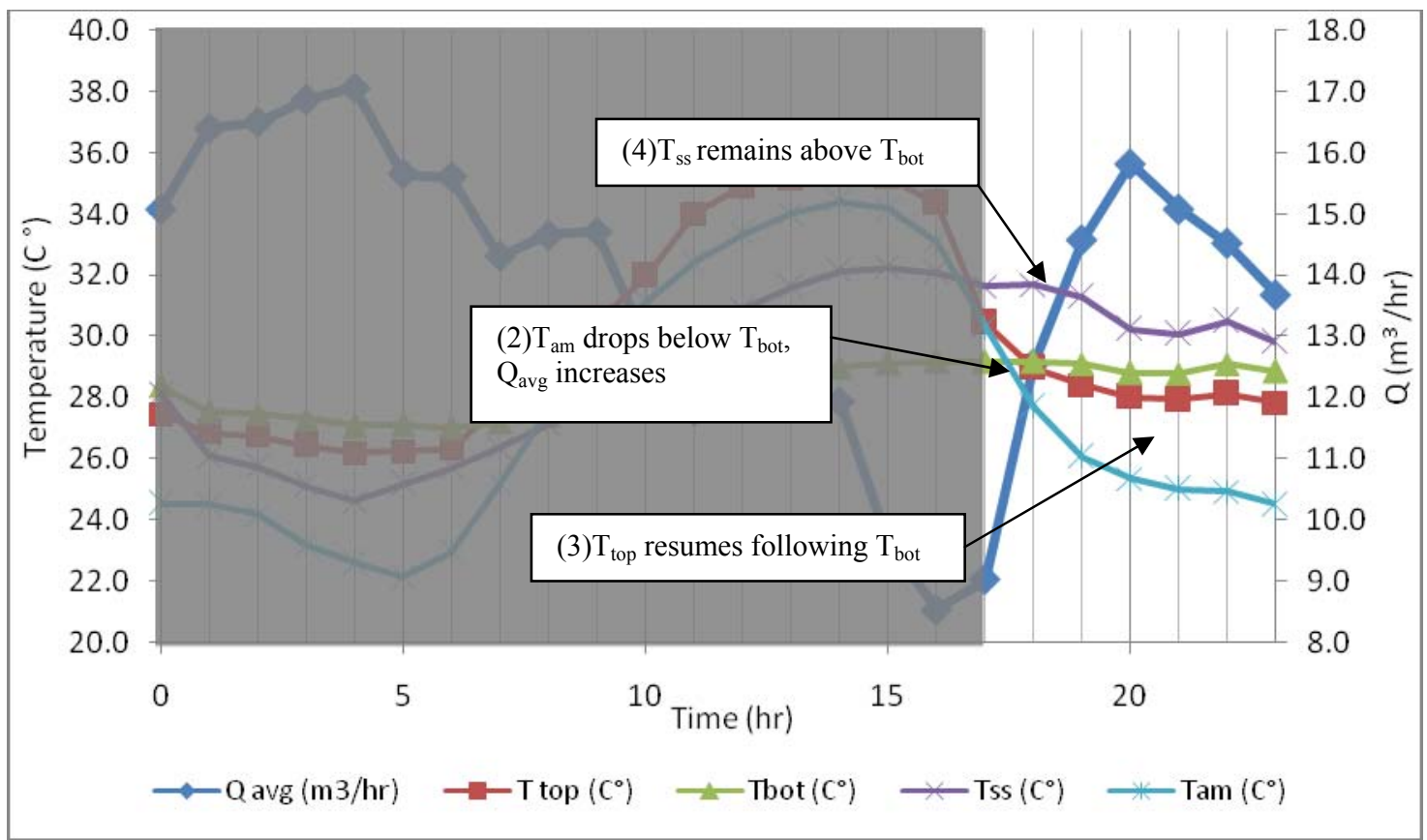

Figure 38: Averaged values for flow rate $\left(Q_{a v g}\right)$, the ambient temperature $\left(T_{a m}\right)$, and temperatures at the top of the vent pipe $\left(T_{\text {top }}\right)$, bottom of the vent pipe $\left(T_{\text {bot }}\right)$, inside the superstructure $\left(T_{\text {ss }}\right)$ over time 17:00-23:00.

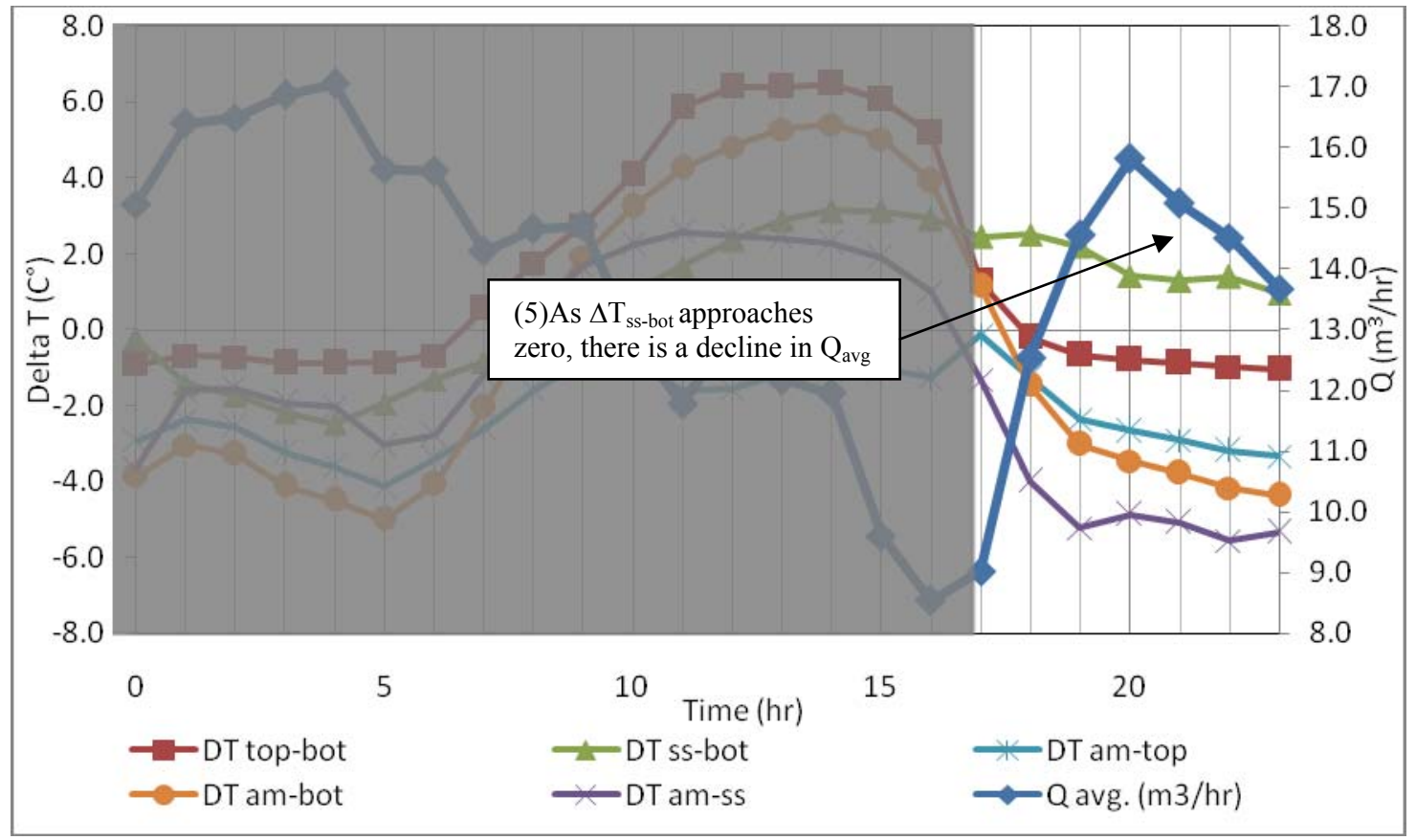

Figure 39: Averaged values for flow rate $\left(\mathrm{Q}_{\text {avg }}\right), \Delta \mathrm{T}_{\text {top-bot }} \Delta \mathrm{T}_{\text {ss-bot }} \Delta \mathrm{T}_{\text {am-top }}, \Delta \mathrm{T}_{\text {am-bot }} \Delta \mathrm{T}_{\text {am-ss, }}$ over time 8:00-17:00. 


\subsection{Comparing the average flow rate to individual flow rate behavior}

As a means of verification, two of the four latrines introduced in the beginning of this chapter were analyzed to determine if the factors that affect flow rate for individual latrines are the same ones identified from the average data. The two compared in this section, K50 and K16, were selected because they have longest measurement time periods out of the four.

Differences in environmental conditions during the days in which these individual latrines were measured will cause variation to the time periods in which the strongest correlation among variables occurs. For instance, wind speed for latrine K50 may start to be the most correlated variable an hour before that which was observed during the assessment of $\mathrm{Q}_{\mathrm{avg}}$. This is not as important as whether of not the event occurred within a general time period of the early morning, midday, or evening.

\subsubsection{Analysis of latrine K50}

Looking first at latrine K50, it was observed that during the midday (8:00 to 16:00) the variable with the most significant influence was wind speed at the height of the vent pipe. From 17:00 hours on, the variables with the strongest correlation appeared to be those related to the bottom/pit temperature (see Table 16), which during this time period includes $\mathrm{T}_{\text {top }}$. Unfortunately a lack of data points during the latter period prevents further statistical analysis, and could account for the strong correlation among most of the temperature variables. Nevertheless, the primary variables identified in both periods are consistent with those observed previously when assessing the cumulative average data.

The observed behavior is as follows: during the middle of the day wind speeds have a positive effect on updraft. When wind is not present, flow rates appear to be dependent on the bottom/pit temperature and its relation to other temperature throughout the latrine. This behavior is demonstrated in the graphs for K50, (Figures 41 and 42) where it can be observed that as ambient temperature fell below the bottom temperature $\mathrm{Q}_{\mathrm{K} 50}$ increased 
and followed a similar signal pattern to that of the temperature and temperature difference data.

Table 16: Correlation coefficients for each factor and $\mathbf{Q}_{K 50}$ during specific time periods for Latrine K50

\begin{tabular}{lccc}
\hline Variable & $\begin{array}{c}\mathbf{R} \\
\text { Entire Day }\end{array}$ & $\begin{array}{c}\mathbf{R} \text { (midday) } \\
\mathbf{8 : 0 0 - 1 6 : 0 0}\end{array}$ & $\begin{array}{c}\mathbf{R} \text { (evening) } \\
\mathbf{1 7 : 0 0 - 2 1 : 0 0}\end{array}$ \\
\hline $\mathrm{U}_{\text {Door }}(\mathrm{m} / \mathrm{s})$ & 0.61 & 0.83 & 0.48 \\
\hline $\mathrm{U}_{\mathrm{VP}}(\mathrm{m} / \mathrm{s})$ & $\mathbf{0 . 7 2}(\mathbf{P}=\mathbf{0 . 0 0 2})$ & $\mathbf{0 . 9 0}(\mathbf{P}<\mathbf{0 . 0 0 1})$ & 0.0 \\
$\mathrm{~T}_{\text {top }}\left(\mathrm{C}^{\circ}\right)$ & 0.04 & -0.43 & -0.96 \\
$\Delta \mathrm{T}_{\text {top-bot }}$ & -0.10 & 0.53 & 0.90 \\
$\mathrm{~T}_{\text {bot }}\left(\mathrm{C}^{\circ}\right)$ & -0.10 & -0.30 & $\mathbf{- 0 . 9 8}$ \\
$\Delta \mathrm{T}_{\mathrm{ss}-\text { bot }}$ & -0.04 & -0.65 & $\mathbf{- 0 . 9 8} \mathbf{( P = 0 . 0 0 2 )}$ \\
$\mathrm{T}_{\mathrm{ss}}\left(\mathrm{C}^{\circ}\right)$ & -0.06 & -0.51 & $\mathbf{- 0 . 9 8}$ \\
\hline $\mathrm{T}_{\mathrm{am}}\left(\mathrm{C}^{\circ}\right)$ & 0.20 & 0.04 & -0.95 \\
\hline
\end{tabular}

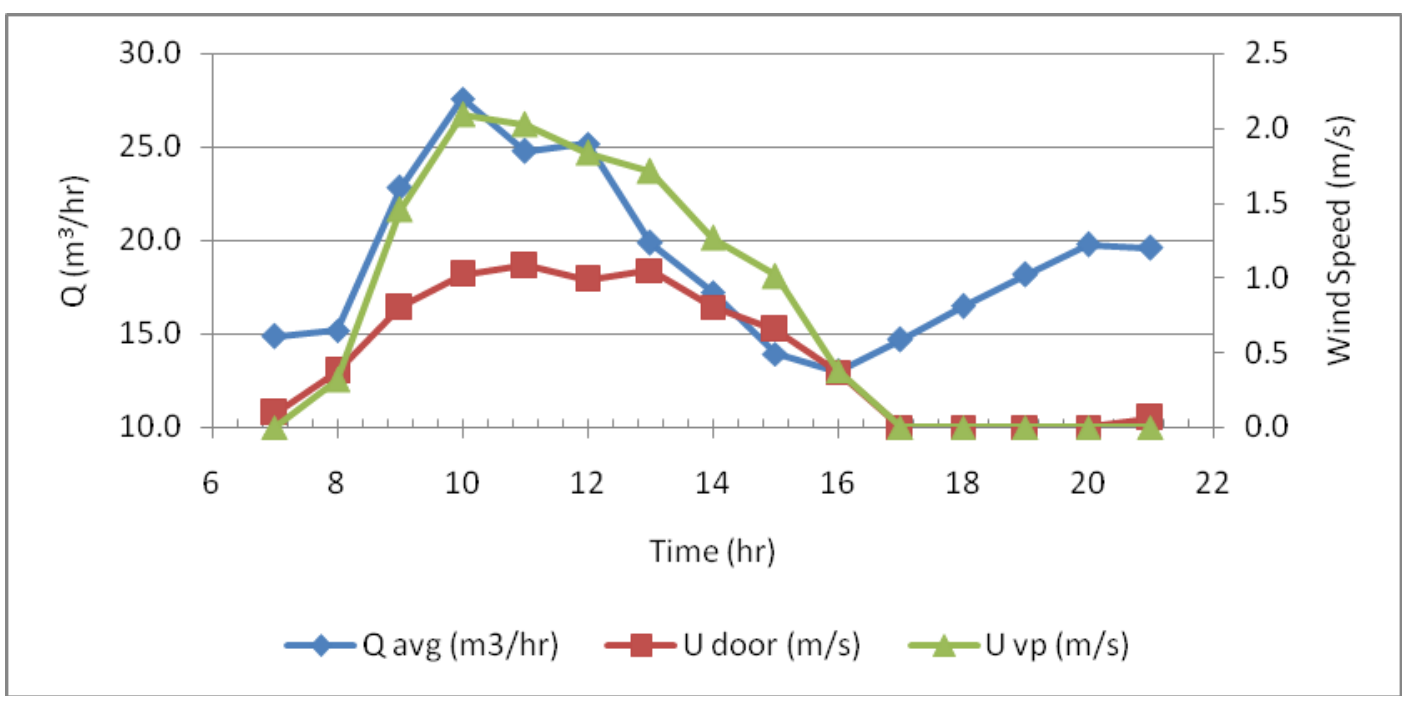

Figure 40: K50, Q vs. Wind Variables 


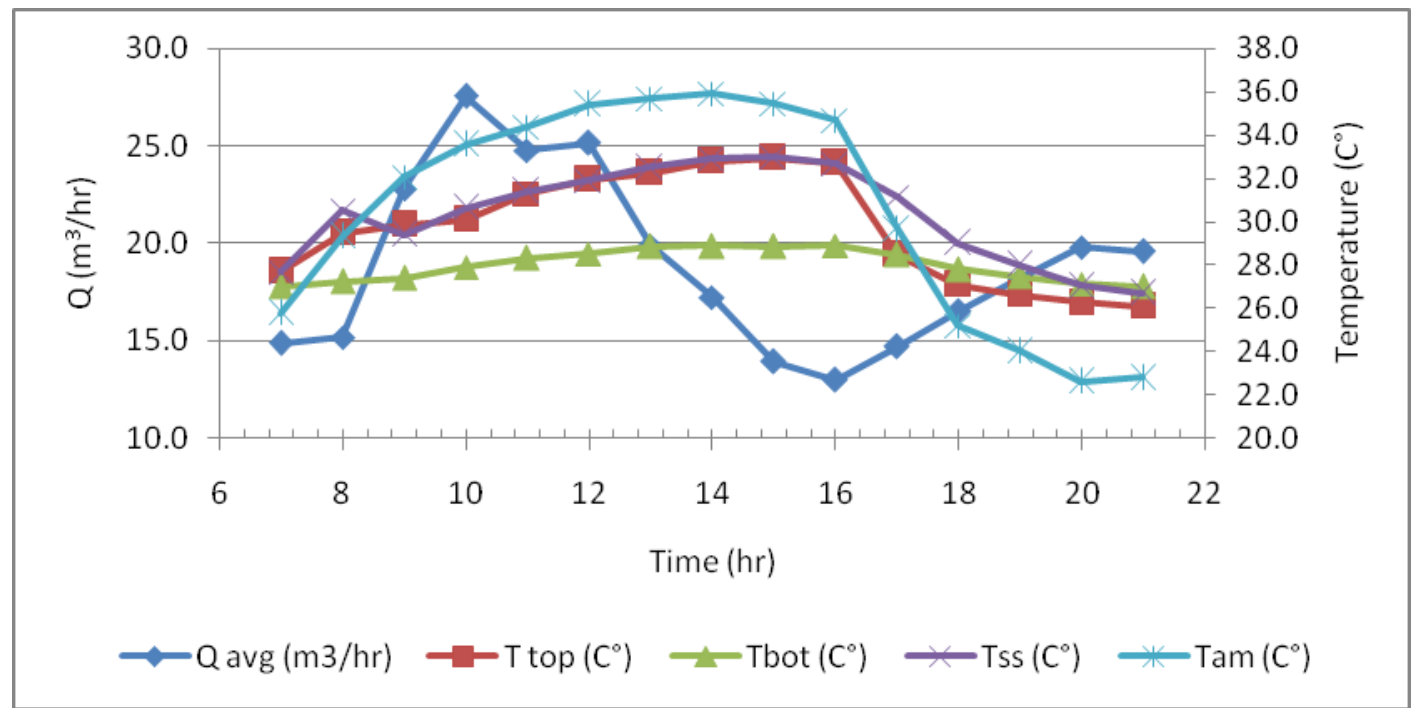

Figure 41: K50, Q vs. Temperature Variables

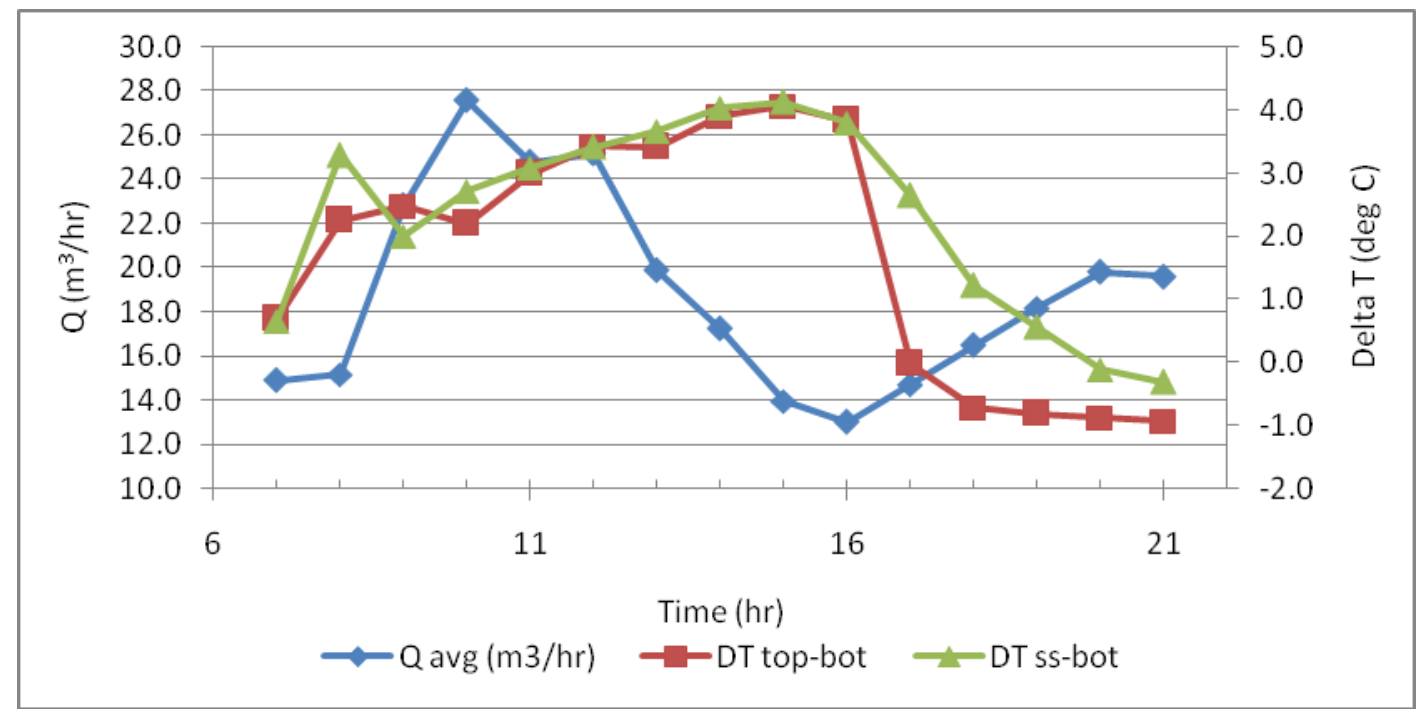

Figure 42: K50, Q vs. Delta T variables

\subsubsection{Analysis of latrine K16}

Next, latrine K16 showed quite a bit of variation from K50 and the average latrine data. As displayed in Table 16, the strongest correlations were found from 8:00 till 11:00 which showed a relationship between $\mathrm{Q}_{\mathrm{K} 16}$ and wind speed. The next period in which an apparent statistical relationship occurs was not until 17:00 to 23:00. There is a correlation between $\mathrm{Q}_{\mathrm{K} 16}$ and $\mathrm{T}_{\mathrm{ss}}$, closely followed by $\mathrm{T}_{\text {bot }}$. However, during the time period of 12:00 to 16:00 hours there appeared not to be a strong correlation among any of 
the variables. Yet when we look at Figure 43, there appears to continue to be a similar signal pattern for $\mathrm{Q}_{\mathrm{K} 16}$ and vent pipe wind speed. A possible reason that wind speed does not show up in Table 17 as the dominant variable could be due to the fact that wind speeds were too low, generally below $0.5 \mathrm{~m} / \mathrm{s}$. This suggests that $\mathrm{K} 16$ may be bordering on a certain threshold wind velocity needed to have a significant effect on $\mathrm{Q}_{\mathrm{K} 16}$.

Nevertheless, where relationships between variables and $\mathrm{Q}_{\mathrm{K} 16}$ are detected, they do appear to be consistent with those observed for K50 and the cumulated average. Again, K16 shows wind speed having some positive relationship with $\mathrm{Q}_{\mathrm{K} 16}$ in the midday, and later the most prevalent correlation is found relating to $\mathrm{T}_{\mathrm{bot}}$ and $\mathrm{T}_{\mathrm{ss}}$.

Table 17: Values for each variable correlated against $Q$ during specific time periods for Latrine K16

\begin{tabular}{lcccc}
\hline Variable & $\begin{array}{c}\mathbf{R} \\
\text { Entire Day }\end{array}$ & $\begin{array}{c}\mathbf{R} \\
\mathbf{8 : 0 0 - 1 1 : 0 0}\end{array}$ & $\begin{array}{c}\mathbf{R} \\
\mathbf{1 2 : 0 0 - 1 6 : 0 0}\end{array}$ & $\begin{array}{c}\mathbf{R} \\
\mathbf{1 7 : 0 0 - 2 3 : 0 0}\end{array}$ \\
\hline $\mathrm{U}_{\text {Door }}(\mathrm{m} / \mathrm{s})$ & 0.56 & -0.68 & -0.01 & 0.0 \\
\hline $\mathrm{U}_{\mathrm{VP}}(\mathrm{m} / \mathrm{s})$ & 0.59 & $\mathbf{0 . 9 7}$ & -0.002 & 0.0 \\
$\mathrm{~T}_{\text {top }}\left(\mathrm{C}^{\circ}\right)$ & 0.50 & -0.67 & 0.10 & -0.67 \\
$\Delta \mathrm{T}_{\text {top-bot }}$ & 0.59 & -0.66 & 0.32 & -0.58 \\
$\mathrm{~T}_{\text {bot }}\left(\mathrm{C}^{\circ}\right)$ & -0.58 & -0.77 & -0.68 & $\mathbf{- 0 . 9 1}$ \\
$\Delta \mathrm{T}_{\mathrm{ss}-\text { bot }}$ & -0.27 & -0.76 & -0.20 & -0.88 \\
$\mathrm{~T}_{\mathrm{ss}}\left(\mathrm{C}^{\circ}\right)$ & -0.38 & -0.77 & -0.42 & $\mathbf{- 0 . 9 4}$ \\
\hline $\mathrm{T}_{\mathrm{am}}\left(\mathrm{C}^{\circ}\right)$ & 0.52 & -0.60 & 0.78 & -0.78 \\
\hline
\end{tabular}




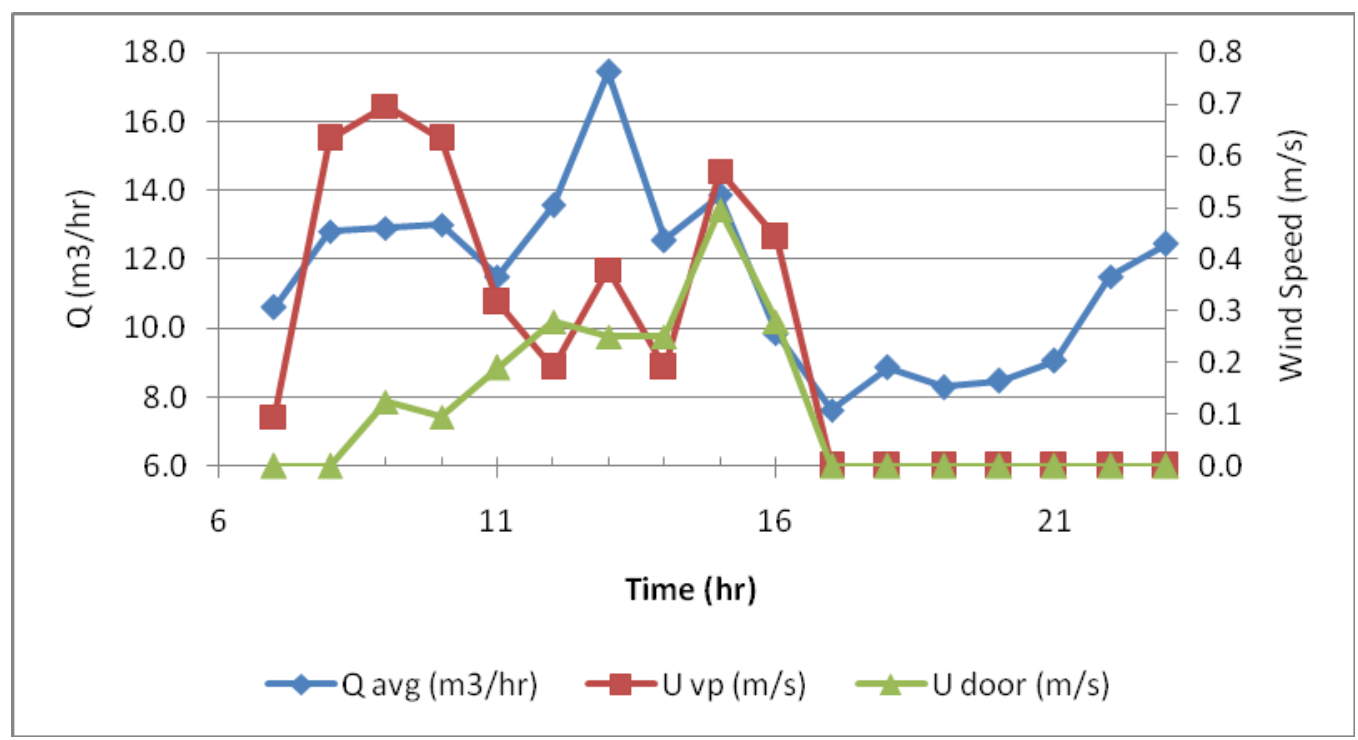

Figure 43: K16 - Q vs. Wind Speed Variables

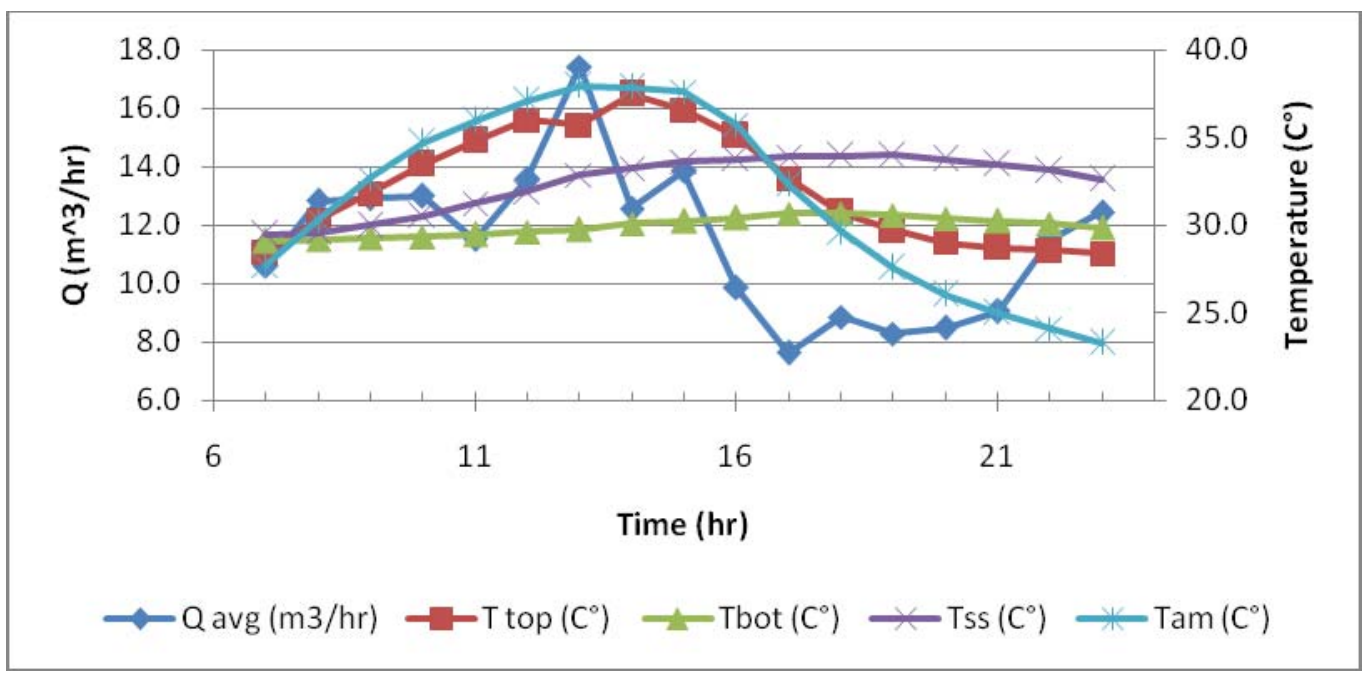

Figure 44: K-16, Q vs. Temperature Variables 


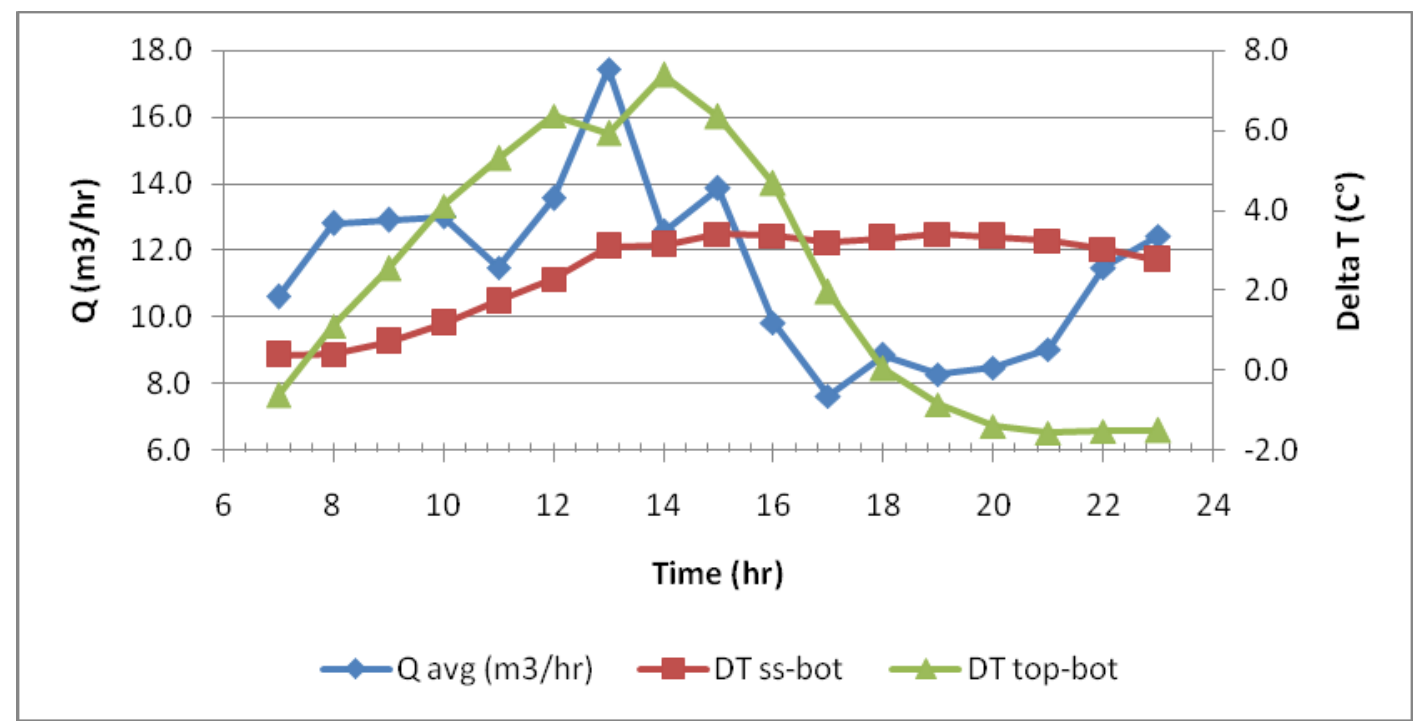

Figure 45: K-16, Q vs. Delta T variables

\subsection{Chapter Summary}

From the above analysis, the key mechanisms identified as having the closest relationship to the ventilation flow rate of UWR VIP latrines are: 1) air buoyancy during times in which bottom/pit temperature are warmer than ambient air temperatures; and 2) wind speed across the top of the ventilation pipe when ambient temperature is warmer than bottom/pit temperature. An illustration of this summary is presented in Figure 46

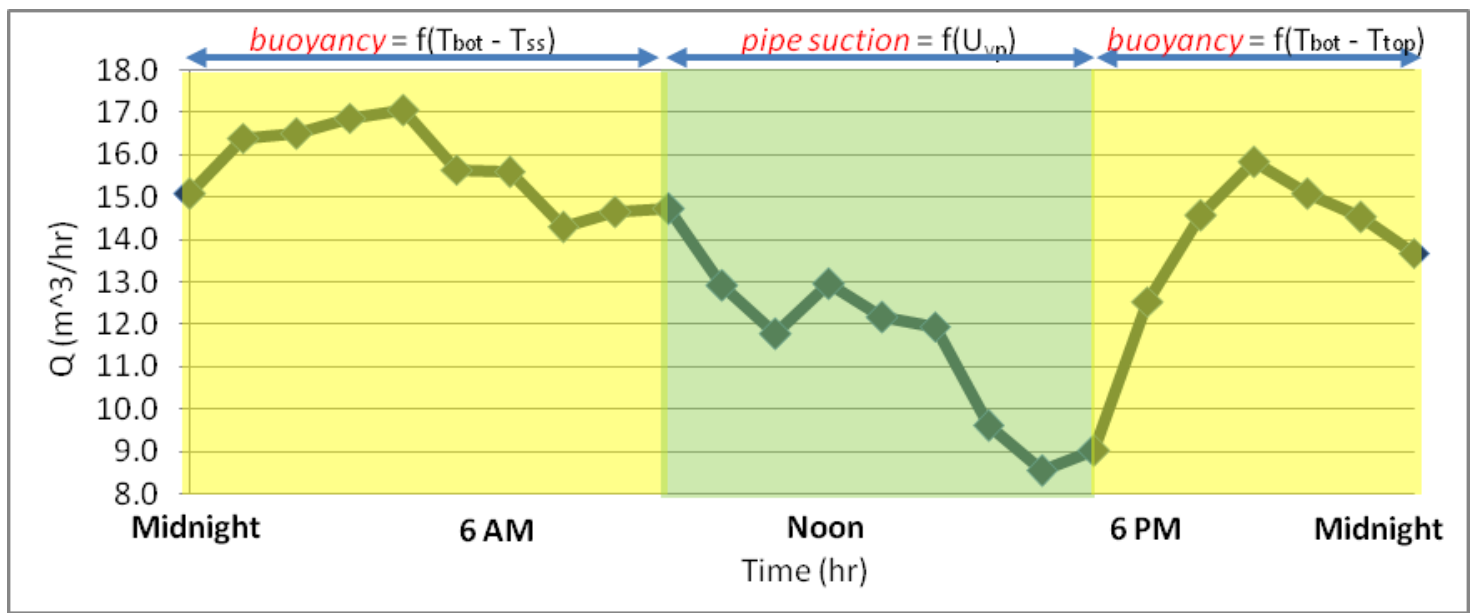

Figure 46: Cumulative average flow rate highlighted by the key driving mechanisms over the relative time in which they occur. 


\section{Chapter 7: Visual Inspection Results and Discussion}

Results presented in this chapter stem from the visual inspection and measurements of 30 household VIP latrines sampled from 6 communities in the UWR. As stated in the objectives of this study, the purpose of the visual inspection was to evaluate the actual design and condition of a sample of household VIP latrines in the Upper West Region of Ghana, and compare them with the standard designs proposed by the CWSA of Ghana, the UNDP and the World Bank.

In this discussion, comparisons are often made between the average flow rates for latrines with one type of variable versus the average flow rate for latrines with the opposite variable. For example, comparisons are made of the average flow rate for latrines with lids over the drop hole versus latrines with no lid over the drop hole. To determine the significance of these comparisons the Wilcoxon Rank-Sum Test was used. Regretfully, in some cases not enough samples were available to make a statistically significant comparison. These comparisons are still presented, however with the understanding that they do not represent the entire sample.

\subsection{Superstructure Characteristics}

Within most latrine promotion programs in Ghana, the construction of the superstructure is typically left up to the community, or each individual household. This is in step with the commonly held philosophy that beneficiary contribution/participation is a crucial component of user adoption and claimed ownership. As important as it may be to include user participation and contribution into the design of sanitation promotion program, this type of approach may not be compatible with the VIP latrine design due to the relatively high technical nature of its specifications. In this section an attempt is made to assess if the ways in which UWR VIP latrine superstructures were sited and constructed has any effect on ventilation. 


\subsubsection{Shape and Volume}

Common to all of the latrines surveyed were superstructures made from mud-brick and built in a rectangular shaped floor plan. The average interior air volume over the entire sample was $4.65 \mathrm{~m}^{3}(\mathrm{n}=29, \mathrm{stdv}=1.07)$. The smallest VIP latrine had a volume of 2.53 $\mathrm{m}^{3}$, and the largest was $7.02 \mathrm{~m}^{3}$.

One of the 30 latrines sampled (G02) was omitted from the average volume calculation due to an abnormally large superstructure of $16.45 \mathrm{~m}^{3}$. Due to the atypical size, the author felt that this latrine's internal volume was not representative of the average UWR VIP latrine.

When it comes to superstructures there are general recommendations for the shape of the floor plan, but there are no guidelines for latrine volume. This is to allow design freedom for local building styles and desires. As a comparison, the Mara \& Ryan investigation's VIP latrine superstructures were spiral in floor plan and had an interior volume of $1.8 \mathrm{~m}^{3}$. This volume is almost 1.5 times less than the smallest UWR VIP latrine.

Although the volume of the superstructure does not necessarily affect airflow, it does have an effect on the value for ACH. For odorless conditions inside the superstructure 6 ACH is recommended (Mara D. D., 1984). The ventilation flow rate required to achieve $6 \mathrm{ACH}$ can be calculated using the equation for the air exchange rate and solving it for the flow rate $\mathrm{Q}$ (see Chapter 3, equation 1).

With a volume of $1.8 \mathrm{~m}^{3}$ the Zimbabwean VIP latrines were able to achieve $6 \mathrm{ACH}$ with a flow rate of $10.8 \mathrm{~m}^{3} / \mathrm{hr}$. Using the average UWR latrine volume $\left(4.65 \mathrm{~m}^{3}\right)$ the flow rate needed to achieve $6 \mathrm{ACH}$ would be $27.9 \mathrm{~m} / \mathrm{hr}$, a value nearly two-and-a-half times greater than that for the Zimbabwean latrines. Therefore, in most cases the air exchange rate is less for UWR VIP latrines simply due to the volume of the superstructure.

\subsubsection{Orientation}

The guidelines for VIP latrine orientation state that the VIP latrine's main ventilation entrance, which is typically the doorway, should face the prevailing wind direction (Mara 
D. D., 1984; Pickford \& Shaw, 1998). This is to encourage ventilation utilizing the mechanism of wind passing through the superstructure. During the 50 individual monitoring setups it was observed that $36 \%$ of the latrines were facing, or at least partially facing, the prevailing wind direction on the day measurements took place. A summary of the orientation results is presented in Figure 47.

The wind directional sensor had a starting threshold of $0.5 \mathrm{~m} / \mathrm{s}$. Therefore if wind speeds in front of the main ventilation opening did not exceed $0.5 \mathrm{~m} / \mathrm{s}$ then no wind directional data could be collected. Monitoring setups in which this occurred were categorized as low wind.

For the UWR VIP latrines the orientation does appear to affect the average ventilation flow rate. The average ventilation flow rate for each category of latrine is plotted in Figure 23. The graph shows latrines that faced or partially faced the prevailing wind direction had a $4.44 \%(\mathrm{P}=0.38)$ greater average ventilation flow rate than compared to latrines measured during adverse and no wind conditions. 


\section{Wind Orientation}
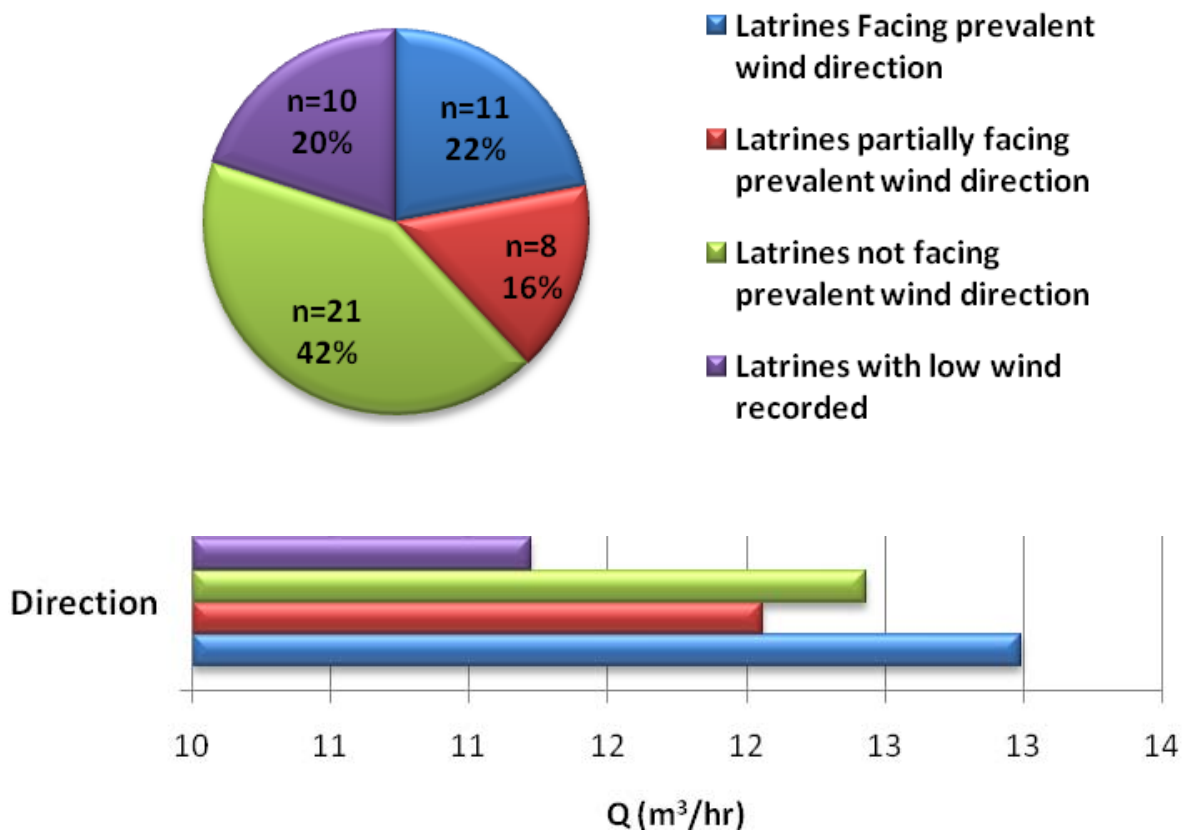

Figure 47: Latrine/Wind Orientation and its effects on flow rate

The most substantial difference was found between latrines that faced the prevailing wind and those that recorded low wind; $13.62 \%(\mathrm{P}=0.14)$. However, several other factors could be affecting this data. For instance, latrines that recorded no wind in front of their ventilation opening could have been measured on a low wind day. Therefore low ventilation in this case could be a factor of the environment rather than the design. To explore this possibility, the wind speed recorded by the anemometer in front of the ventilation entrance (WS) was compared with the wind speed recorded at the height of the vent pipe (WS2) for each of the 'low wind' recorded setups (see Figure 48). 


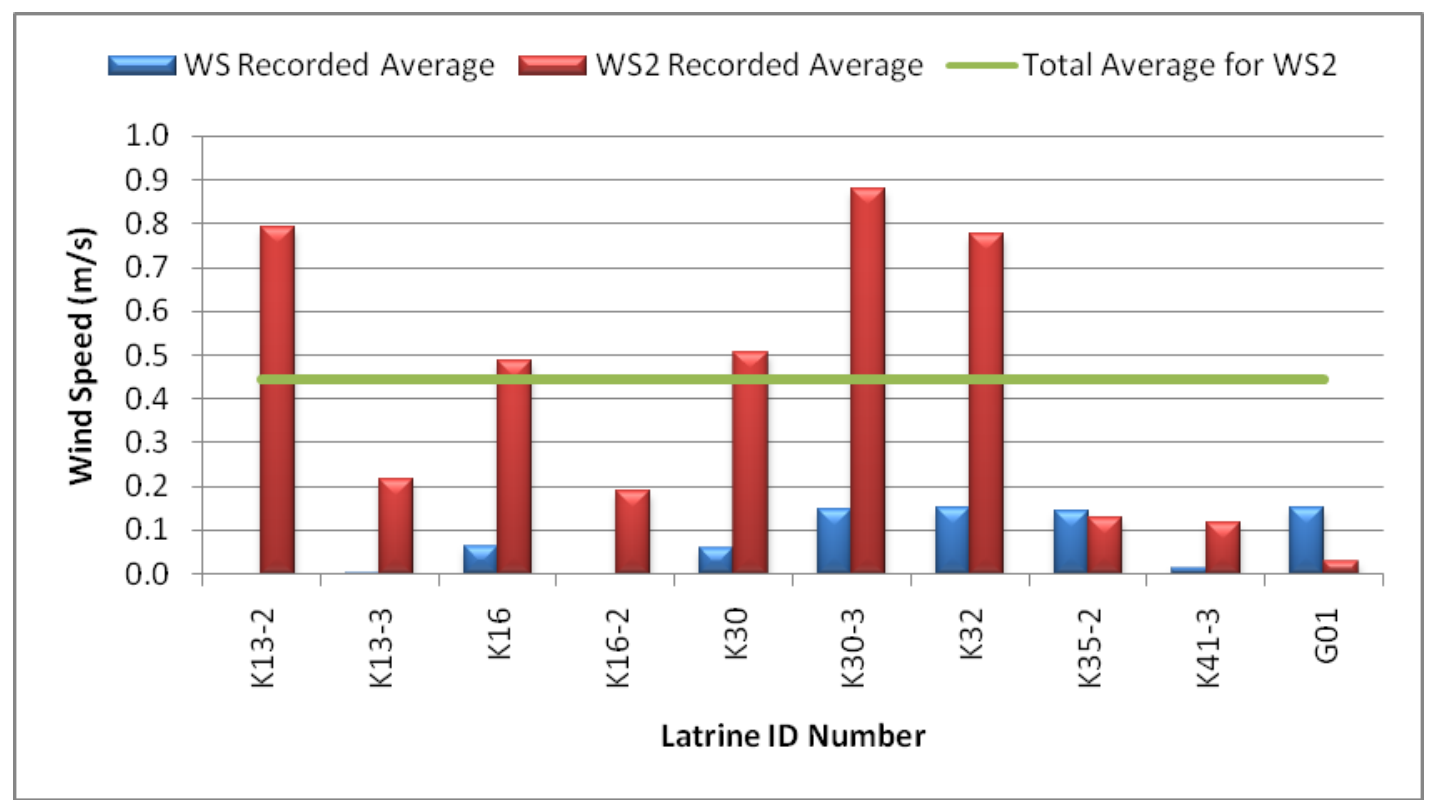

Figure 48: Setups with 'low wind' recorded by anemometer WS compared to the average wind speed recorded by WS2

The horizontal line on Figure 48 represents the average wind speed recoded by WS2 over the entire sample set $(0.44 \mathrm{~m} / \mathrm{s}$, stdev: 0.28$)$. Using this line it can be observed that the wind speeds were above average during the setups of K13-2, K16, K30, K30-3 and K32. This suggests that for those five setups, low recorded wind speeds in front of the ventilation opening were a factor of design rather than environment. This is further validated when looking at different setups in which K13, K16, K30 and K32 recorded a wind direction that showed that these latrines were facing adversely or only partially in the direction of the wind.

As for the remaining setups in Figure 48 (K35-2, K41-4, and G01), low wind appears to be the primary factor responsible for no recorded wind direction. Yet, because of instrument sensitivity it is unknown whether or not these latrines were facing the prevailing wind.

\subsubsection{Drop Hole Lids and Doors}

The presence of a lid over the drop hole is stated by the guidelines to be a crucial factor that affects ventilation. When present, higher pressure air in the superstructure is unable 
to pass into the lower pressured pit chamber. Figure 49 shows that $90 \%$ of the VIP latrines sampled had a lid over the drop hole of some kind. The bar graph on Figure 49 show that $\mathrm{Q}_{\text {avg }}$ is higher for latrines that do not have a lid covering the drop hole by approximately $23.6 \%(\mathrm{P}=0.09)$.

\section{Drop Hole Lid}
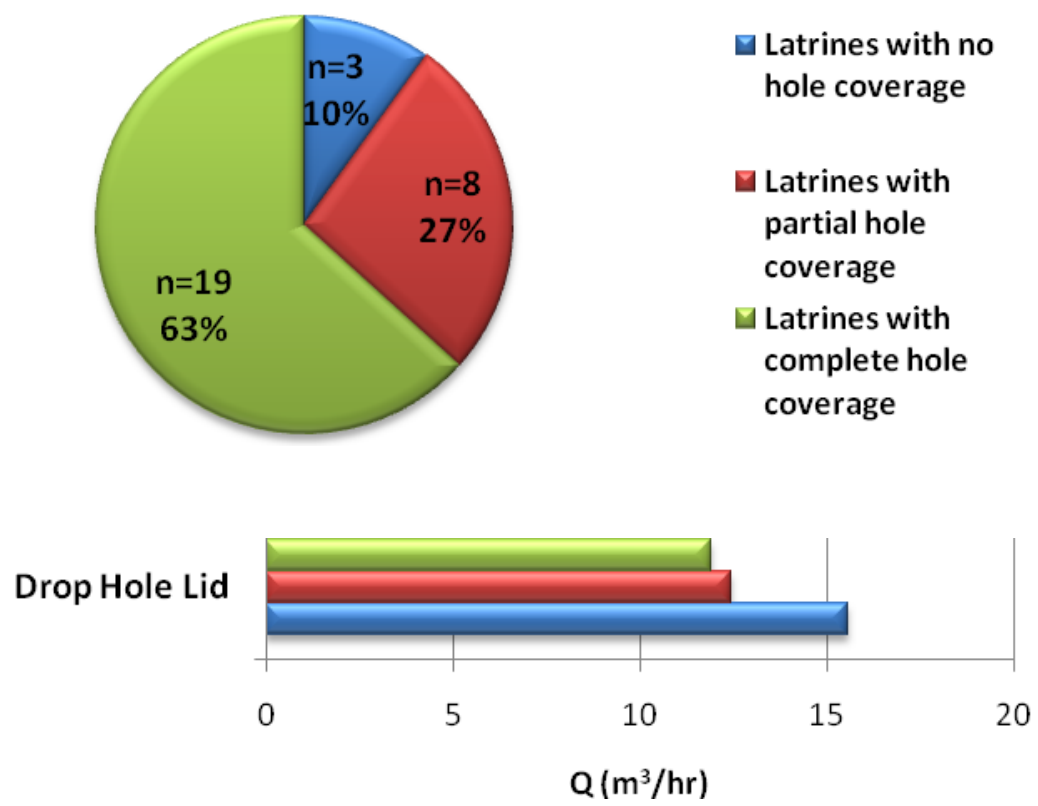

Figure 49: Proportion of sample with no, partial and full lid over the drop hole and the respective effect on flow rate.

For effective ventilation using the mechanism of wind passing through the latrine, the guidelines state that it is crucial that wind is allowed to pass into the superstructure. If a door completely covers the entranceway then an additional ventilation opening should be provided. In the sample pool there were a total of 7 out of 30 latrines that possessed full doors. The remaining latrines either had no door present or a partial door, the proportion of each variation and its effect on flow rate is shown in Figure 50.

A clear pattern to the effect coverings over the entranceway on flow rate could not be determined by simply observing the values presented in Figure 50. The reason for this is indicated by evidence that can be seen in Figure 51, where it shows that the highest observed $\mathrm{Q}_{\text {avg }}$ comes from one latrine that had a completely covered doorway without a 
lid over the drop hole. This could mean one of two things: 1) wind speed into the superstructure has little or no effect on $\mathrm{Q}_{\mathrm{avg}}$ or 2) wind is allowed into the superstructure through other means besides the entranceway. To investigate either possibility, additional ventilation openings need also to be taken into account.

\section{Entrance Covering}
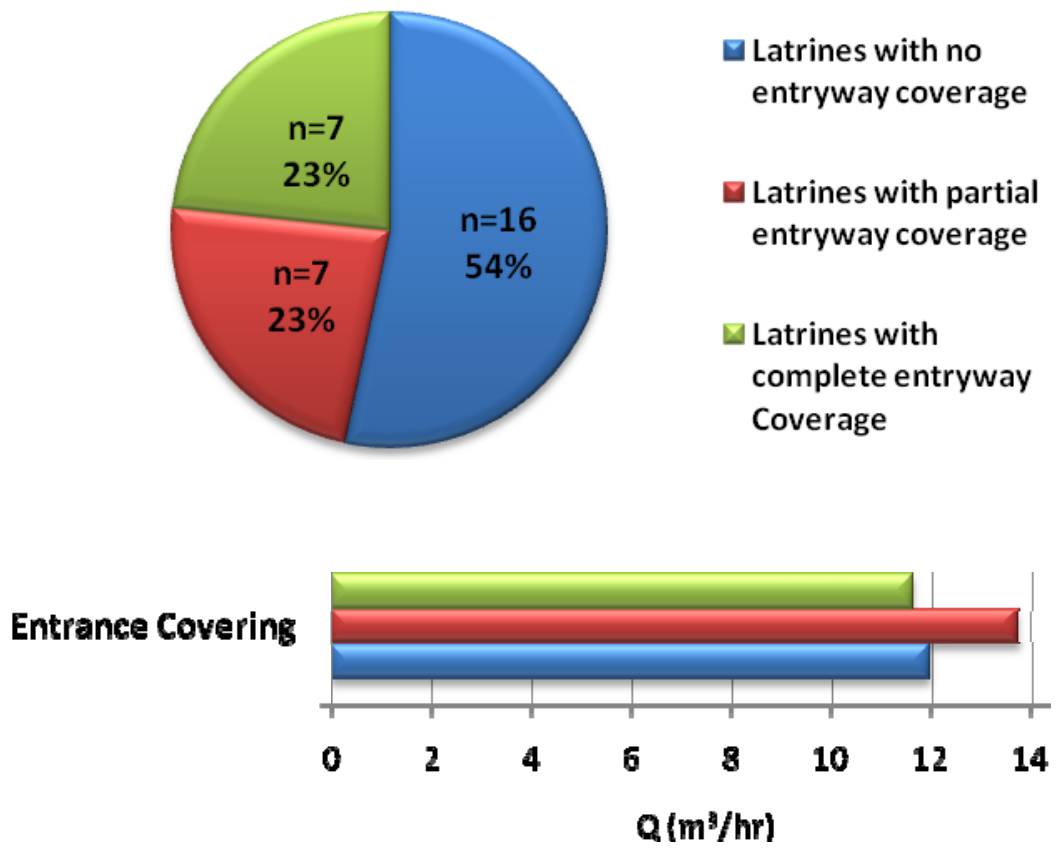

Figure 50: Proportion of sample with no, partial and full entrance covering and the respective effect on flow rate. 


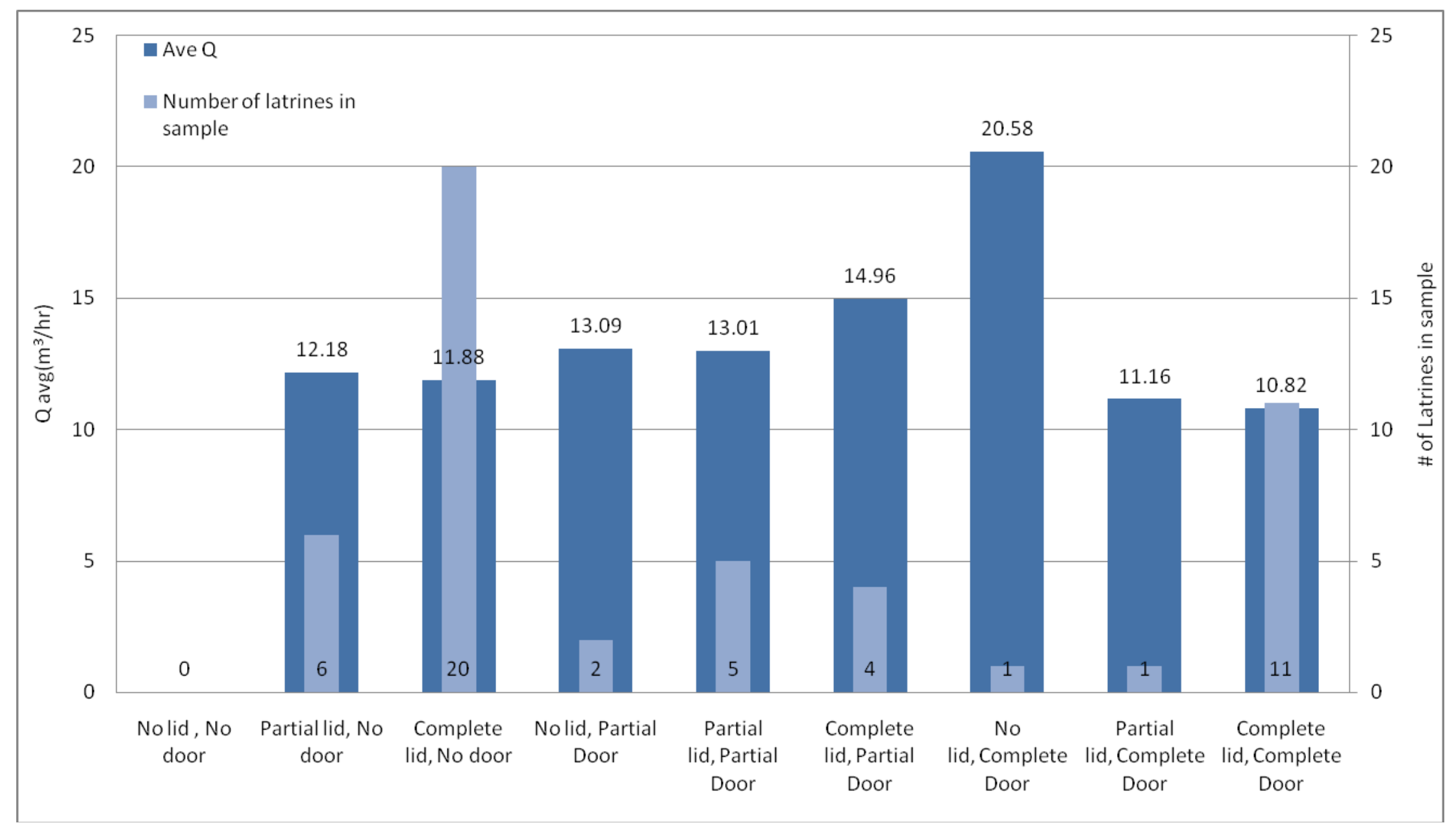

Figure 51: Combined average flow rate for latrines categorized by the presence of a door over the entrance way and or a lid over the drop hole. 


\subsubsection{Additional Ventilation Openings}

In addition to what has been previously stated about having an opening to allow wind/air to enter the superstructure, one further recommendation states that; "It is extremely important to avoid openings on opposite sides (of the main ventilation opening), as this would significantly reduce the pressure difference causing updraught in the vent pipe (Mara \& Ryan, 1983 B, p. 10).”

From the sample study, 15 out of the 30 latrines (50\%) had additional ventilation openings. Of those 15,6 (20\% of total sample) were openings located on the opposite side of the main ventilation opening. Latrines with additional openings had a cumulative average flow rate $24.5 \%(\mathrm{P}=0.01)$ higher than latrines that did not have openings. Average flow rates in latrines with opposite additional openings were less than nonopposite opening latrines by only $4.3 \%(\mathrm{P}=0.36)$. Additional comparisons of variable options are presented in Figure 52 below.

\section{Additional Openings}
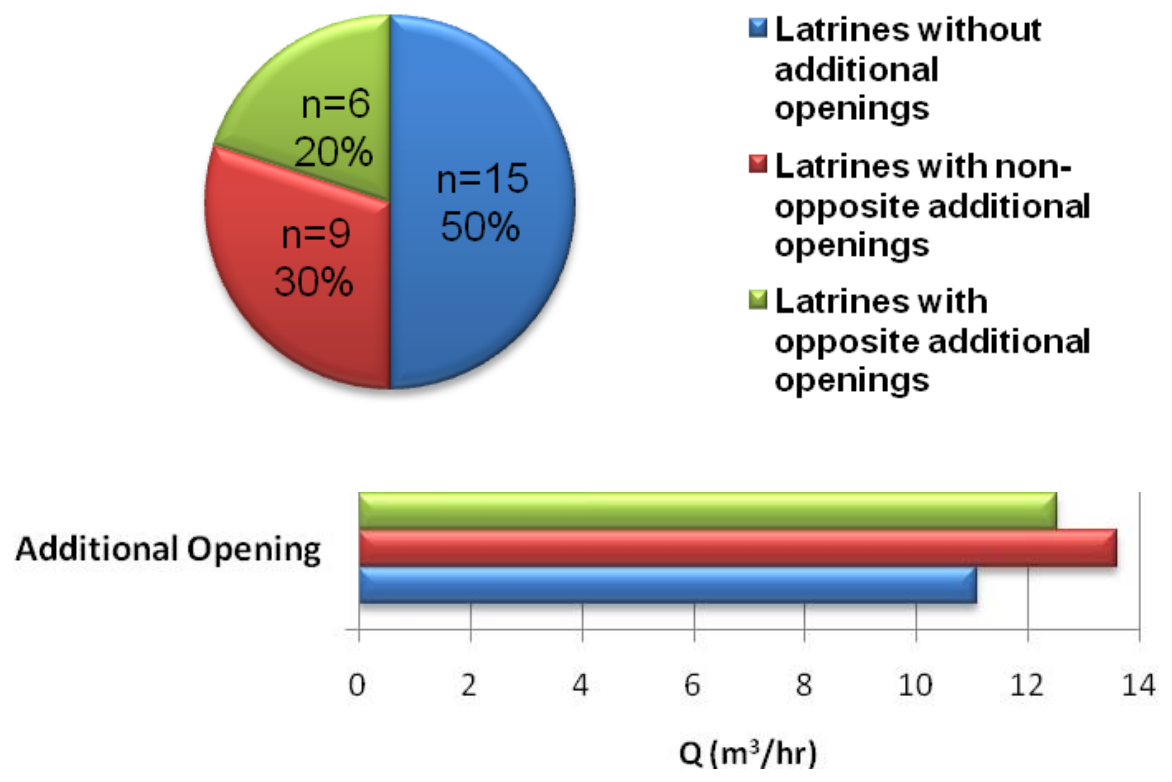

Figure 52: Combined average flow rate for latrines categorized by presence of an additional opening in the superstructure 
The evidence suggests that having an additional opening in a superstructure may actually improve the average ventilation flow rate in a latrine. The presence of an opening opposite the main ventilation entrance appears only to have a slight adverse effect on $\mathrm{Q}_{\text {avg }}$, but not as much as it would to have no additional opening at all. This evidence does help to support that wind flowing into a UWR VIP latrine superstructure would have a positive effect on the flow rate.

Keep in mind however that additional openings would also increase light levels within the superstructure, thereby potentially attracting phototrophic flies to exit the latrine pit through the squat hole rather than via the vent pipe.

\subsubsection{General Condition}

As part of the selection criteria, all of the thirty latrines sampled were in working order during the time of the survey. However, observations of some of the other latrines in the communities, as well as knowledge of local building techniques, would show that the typical mud-brick superstructure has a design life of just a couple of years.

Every year, members of the community will spend a good portion of the dry season making repairs or reconstructing their houses in preparation for rainy season. Sometimes, these repairs are not enough to withstand the rains and the structures collapse. A collapsed VIP latrine superstructure at the end of the rainy season is not an uncommon sight, but just like their houses the superstructure are likely to be reconstructed again in the dry season. Yet one problem is that when a superstructure collapses it can cause damage to the PVC vent pipe. Replacing the superstructure will cost the household nothing more than time and energy. On the other hand, replacing the PVC vent pipe will require monetary funds. 


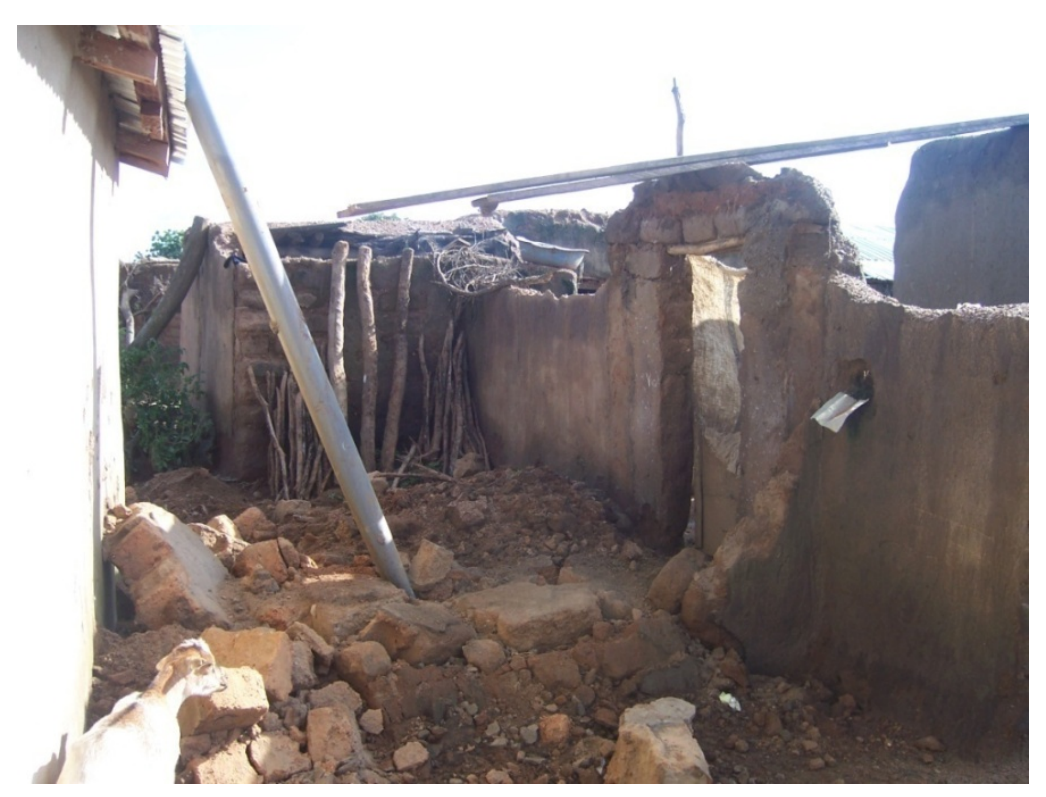

Figure 53: A collapsed superstructure, in this case the vent pipe remained intact. Photo by Author

\subsection{Ventilation Pipe Characteristics}

\subsubsection{Size and location}

As mentioned in previous chapters, the ventilation pipes used by UWR VIP latrines all have the same characteristics of being grey colored PVC pipes that are approximately 3 $\mathrm{m}$ in length and $100 \mathrm{~mm}$ in diameter. Additionally, all of the sampled latrines had vent pipes passing through the superstructure and out the roof.

The design recommendations for vent pipes specify that $100 \mathrm{~mm}$ diameter vent pipes are appropriate in areas where wind speeds are greater than $3 \mathrm{~m} / \mathrm{s}$. The mean wind speed throughout the study was $0.41 \mathrm{~m} / \mathrm{s}$ ( standard deviation $=0.51$ ), with a maximum recorded mean velocity of $1.22 \mathrm{~m} / \mathrm{s}$. This information would suggest that UWR VIP latrine vent pipes are undersized for the regional environment.

Furthermore, design recommendations specify that the top of the vent pipe must have a clearance of no less than $500 \mathrm{~mm}$ above the roof of the superstructure. In this case, only one of the thirty latrines was found to be below this specification. 


\subsubsection{Fly screen}

Securely fastened to the top of the vent pipe should be a fly screen made from aluminum alloy with a suggested aperture of $1.2 \mathrm{~mm} \times 1.5 \mathrm{~mm}$. Within the study, $40 \%(\mathrm{n}=12)$ of the latrines were found to have a fly screen compromised in some way; such as a rip or tear, or - in the case of two of the sampled latrines - no fly screen at all. Damage to the fly screens can oftentimes occur during installation, but generally because of weathering and corrosive gasses emanating from the pit, fly screens generally have a short effective life span. Without the presence of an uncompromised fly screen, the VIP latrine can no longer control fly populations or prevent them from becoming vectors of fecal oral diseases. Therefore, frequent maintenance and replacement of the fly screen is necessary for proper use.

When fly screens were found, the aperture of the grid for each screen was $2 \mathrm{~mm} \times 2 \mathrm{~mm}$. This aperture appears to be large enough not to hinder flow rate, but still small enough to prevent flies from entering into the vent pipe. Interesting to note, the latrine with highest average flow rate, A01 $\left(20.58 \mathrm{~m}^{3} / \mathrm{hr}\right)$, was one of the two latrines that were found to not possess a fly screen.

\subsubsection{General Condition}

Within the sampled latrines only one of the ventilation pipes was found to have a broken vent pipe. In this case the damage was a hole near the top of the pipe, which according to the household was the result of one of the children hitting the pipe with a slingshot propelled rock. Although the damage did not severely hinder airflow, it did provide a means by which flies could enter and exit out of the latrine.

After months of exposure to direct sunlight, PVC vent pipes can become more brittle over time. This affects the pipe's ability to withstand a traumatic event, such as a collapsed superstructure or a projectile. Therefore, it is likely that the PVC vent pipes will need to be repaired or replaced within a couple of years. 


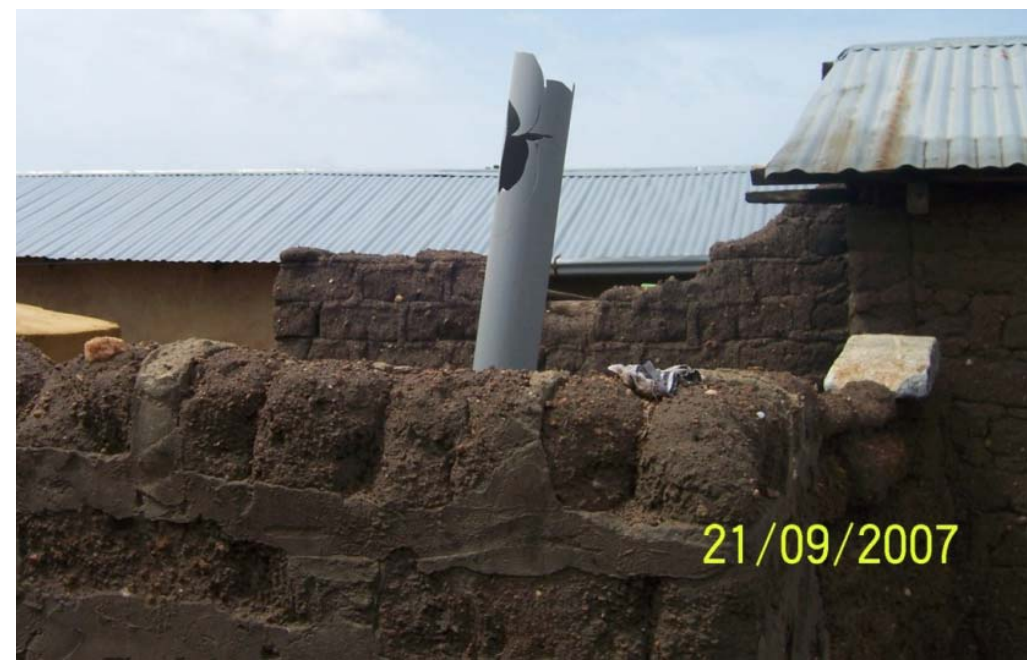

Figure 54: A broken PVC vent pipe, cause unknown. Photo by Author

In the case of the two latrines that were found to have no fly screen, both of them were located in the community of Kandeu. By looking into the tops of the vent pipes it was discovered that fly screens were present at one time, yet within the two years since their construction the screens had rusted away (see Figure 55). A quick survey of the community found that out of the 13 erected vent pipes 11 had had their fly screens rust through.

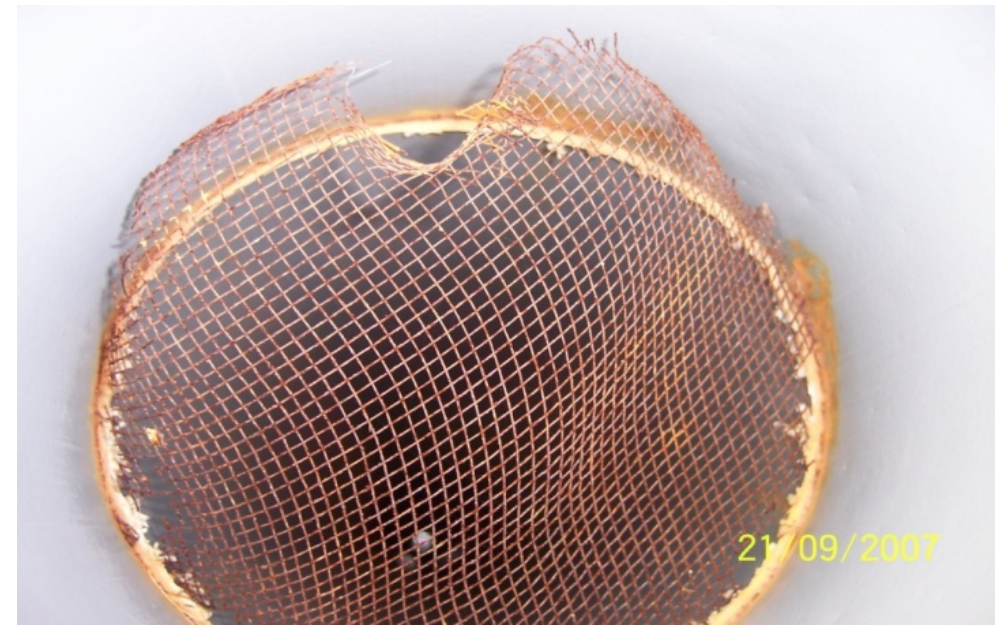

Figure 55: Looking down into the top of a vent pipe, with a fly screen that has almost completely rusted away. Photo by Author 


\subsection{Chapter Summary}

The key points from each section are summarized below:

\section{Superstructure}

- The air volume of most UWR VIP latrines is too large to achieve the recommended air exchange rate of $6 \mathrm{ACH}$.

- Of the experimental setups, $64 \%(\mathrm{n}=32)$ were recorded as not having a ventilation opening facing the prevailing wind direction.

- The ventilation flow rate for experimental setups with favorable positioning and conditions were on average $4.44 \%$ higher than those recorded during adverse conditions.

- Ninety percent $(\mathrm{n}=27)$ of the latrines surveyed were found to have a cover of some kind over the drop hole. Evidence suggests that without a cover, flow rate out the vent pipe improves by nearly $23.6 \%$.

- Latrines with ventilation openings in addition to the entrance way were observed to have a flow rate of $24.5 \%$ higher than those latrines with no additional openings. Where the additional opening is located appeared to have no significant effect on flow rate.

- Conversely, the addition of openings within the superstructure would theoretically increase the amount of light within the latrine. This would be counterproductive to the VIP latrine's fly control mechanisms.

- Superstructures constructed in local mud-brick fashion have the propensity to collapse, potentially damaging the PVC ventilation pipe.

\section{Ventilation Pipe}

- All of the ventilation pipes in this study were gray, PVC pipes of three meters in length and $100 \mathrm{~mm}$ in diameter.

- Recommendations specify that $100 \mathrm{~mm}$ diameter vent pipes are appropriate in areas where wind speeds exceed $3 \mathrm{~m} / \mathrm{s}$. The mean wind speed during the study 
was recorded to be $0.41 \mathrm{~m} / \mathrm{s}$. This suggests that the UWR VIP latrine vent pipes are inappropriately sized for the environmental conditions of the region.

- Both ventilation pipes and fly screens are highly susceptible to damage and require regular maintenance in order to stay in functioning condition. 


\section{Chapter 8: Use and Cost Analysis}

The chapter provides insight into the second and third questions posed by the WHO's Minimum Evaluation Procedure (MEP), introduced in Chapter 1, which are:

- Are the sanitation facilities being used properly?

- Are the optimal health, social and economic impacts being obtained?

\subsection{Use Assessment}

\subsubsection{User acceptance of sanitation facility}

Before discussing if UWR VIP latrines are being used properly, the question of whether or not the latrines are being used at all must be first addressed. Using the methodology described in Section 4.5, an assessment of use was conducted within the focus community of Kulkpong. There it was found that 76 latrines in Kulkpong were in usable condition. Usable condition meant that each latrine was fully assembled with a ventilation pipe and a roofed superstructure. Of these 76 usable latrines 52 were found to have feces present inside the pit. These 52 latrines were then considered to be in use. Therefore it was concluded that with 52 out of 76 usable latrines in use, the user acceptance percentage in Kulkpong was 68.4\%.

A separate survey, conducted by The Carter Center, selected 12 communities from the Northern Region of Ghana that had previously participated in a VIP latrine promotion program. Their study found that of the 327 households interviewed, $88 \%$ had a usable latrine of which $74 \%$ were in use at the time of the survey. (The Carter Center, 2008)

Furthermore, another study conducted in The Gambia evaluated the sustained use of simple pit latrines 25-47 months after they were constructed. This study found that of 666 latrines surveyed 585 (87.3\%) were usable. Of the usable latrines $87.2 \%$ were in use at the time of the study (Simms, Makalo, Bailey, \& Emerson, 2005). 
Caution must be taken when comparing these surveys side-by-side, due to discrepancies among the definition of a usable latrine. For instance, The Carter Center study did not consider a roof necessary to be considered a usable latrine. Nevertheless, when looking at the information provided by each of these surveys it can at least be concluded that when a latrine of any kind is present the majority of households will adapt their behavior and use the facility.

Table 18: Summary of findings from latrine use studies

\begin{tabular}{lcccc}
\hline \multicolumn{1}{c}{ Study } & Location & Type of Latrine & $\begin{array}{c}\text { Time since } \\
\text { construction }\end{array}$ & \% Use \\
\hline This Study & Ghana & VIP latrine & $12-36$ months & $68.4 \%$ \\
Carter Center & Ghana & VIP latrine & +12 months & $74.0 \%$ \\
Simms & The Gambia & Simple pit latrine & $25-47$ months & $87.2 \%$ \\
\hline
\end{tabular}

\subsubsection{Proper use of UWR VIP latrines}

Proper use of a VIP latrine requires a basic knowledge of the ventilation and fly control components. For example users should at least be aware that: a means by which ambient air can pass through the superstructure and into the pit should be provided, there should not be anything that would impede air from exiting the vent pipe, a fly screen should always be present and properly maintained, and light levels should always be kept low inside the superstructure.

Evidence to support whether or not UWR users are aware or comprehend these concepts has already been presented in Chapter 7. A summary of that evidence is given below in Table 19. These descriptive statistics show that $90 \%$ of the households prefer to have a lid of some kind placed over the drop hole. This is understandable when taking into account that approximately half of the users place a door over the entrance way; therefore a lid over the drop hole can often be the only barrier for preventing anything from unintentionally falling (or getting) into the pit.

Keeping the superstructure dark for fly control is also not widely practiced as evident by the observation that less than half of the latrines have a covering of some kind over the 
doorway. Also under the topic of fly control, $40 \%$ of the fly screens were found compromised. As described in Chapter 7, two of the latrines from the community of Kandeu had their screens completely rusted away. These latrines were constructed nearly three years prior to the investigation, whereas the remaining latrines used in the study were just over a year old. If the Kandeu latrines are representative of things to come, than it can be expected that the number of latrines with compromised fly screens will increase, unless maintenance occurs.

Table 19: Summary of user choice statistics from Chapter 7

\begin{tabular}{lcc}
\hline Description & $\#$ & $\begin{array}{c}\text { \% of total } \\
\text { (n=30) }\end{array}$ \\
\hline \# Latrines with a lid over the drop hole & 27 & $90.0 \%$ \\
\# Latrines without a door over the entrance way & 16 & $53.3 \%$ \\
\# Latrines with compromised fly screen & 12 & $40.0 \%$ \\
\hline
\end{tabular}

Further evidence to suggest a poor understanding of VIP latrine operation can be seen by a few cases in which the users choose to put a cap over the mouth of the vent pipe (see Figure 56). This was observed by the author several times throughout the study. When the latrine owners were asked why they had capped their vent pipe, the two commonly given reasons were: 1) to prevent rain from entering into the pit, and 2) because the smell was getting too bad. One of the capped latrine owners was asked if he thought the inside of his latrine had a bad odor. He replied back "no." When asked why it didn't smell he replied, "Because I put ash down the hole every time I use it." 


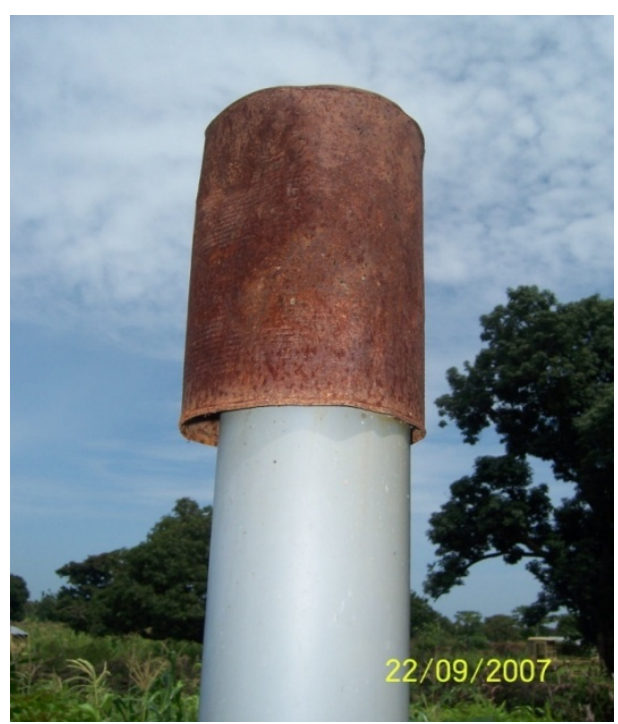

Figure 56: A capped vent pipe. Photo by Author

\subsubsection{Summary of use assessment}

In summary, UWR VIP latrines are for the most part (+90\%) not being used or maintained in ways that would facilitate proper function. The lack of proper use could be as a result of poor education and ignorance. On the other hand, in keeping with the belief that engineers should design not to a technical specification but instead toward user preference, perhaps the UWR would be better off promoting latrines that would not be hindered by a lid over the drop hole, do not require a door covering the entrance way, and do not require routine and sometimes costly maintenance. As it was said by Elmendorf and Buckles in 1980, “...it is easier to change technology than to change behavior, and it is more difficult to determine cultural acceptability than technical feasibility." (Cotton, et al. 1995 , p. 28)

\subsection{Comparative cost analysis}

The last question of the MEP asks if the sanitation facility is helping to achieve optimal health, social and economic impacts. It is difficult to quantifiably determine the impacts that UWR VIP latrines have on health for the same reasons why many other studies have failed to determine the health impacts of sanitation facilities (Cairncross, 2007). Yet 
when optimal health impacts are viewed in terms of the effective prevention of sanitation related diseases, such as parasitic worms and trachoma, these interventions are predicated on an entire population practicing good sanitation behavior and having access to sanitation facilities. From this perspective, in order to achieve optimal health impacts the goal is simple: total access to sanitation.

Total access leads to achieving optimal social impacts as well, particularly for the marginalized populations of women and children. When latrines are viewed as rare and expensive they have the propensity to become status symbols rather than sanitation facilities for common use. In such cases the latrines are sometimes used for other purposes such as storage rooms for the household's valued possessions. Or if used, use is limited to special houseguests and locked up the majority of the time in order to keep the latrine a pristine trophy of status. (Pickford, 1995) Conversely, if latrines are perceived as common household items, then they are more likely to be used and used by everyone.

In order to achieve total sustainable access, the sanitation facility must be affordable by every household in the community. Therefore the key to evaluating the UWR VIP latrine for its health, social and, the economic impacts is to examine the costs associated.

\subsubsection{The cost of a UWR VIP latrine}

Table 21 presents an itemized list of the estimated costs associated with the construction of just one UWR VIP latrine. Not included in Table 20 are the added costs of transportation for materials and the mason, as well as food for the mason and the laborers. For instance, if this latrine were being constructed by a household in Kulkpong, one member of the household would have to travel by lorry to the regional capital, Wa, to collect the necessary supplies and hire a mason. The costs of transportation to and from for one household member, a trained mason, and materials would be about $\$ 5.50$. To feed the mason and the labors, as is the custom in Kulkpong, would cost roughly $\$ 2.00$. This would bring the total cost to approximately $\$ 70$. 
The pie chart shown in Figure 57 distinctly shows that the largest contributor to the total cost is cement. The PVC pipe and the fly screen accounts for $25 \%$ of the total costs.

Table 20: Itemized list and estimated cost of a UWR VIP latrine at 2007 prices

\begin{tabular}{|c|c|c|c|c|c|c|}
\hline Item & Description & Unit & $\begin{array}{l}\text { Unit Cost } \\
\text { (Gh cedis) }\end{array}$ & $\begin{array}{c}\text { Unit } \\
\text { Cost } \\
\text { (USD) }\end{array}$ & $\begin{array}{c}\# \\
\text { Units }\end{array}$ & $\begin{array}{l}\text { Total } \\
\text { Cost } \\
\text { (USD) }\end{array}$ \\
\hline Cement & Bags & per bag & 12.00 & $\$ 13.00$ & 2 & $\$ 26.00$ \\
\hline PVC Pipe & $\begin{array}{l}100 \mathrm{~mm} \text { dim, 3m } \\
\text { length }\end{array}$ & per pipe & 11.00 & $\$ 11.93$ & 1 & $\$ 11.93$ \\
\hline Fly Screen & $\begin{array}{l}\text { Aluminum Screen } \\
203 \mathrm{~mm} \text { square }\end{array}$ & 1 square & 3.50 & $\$ 3.80$ & 1 & $\$ 3.80$ \\
\hline \multirow[t]{3}{*}{ Labor } & Mason Fee & per latrine & 15.00 & $\$ 16.30$ & 1 & $\$ 16.30$ \\
\hline & Unskilled Labor & per latrine & 4.50 & $\$ 4.89$ & 1 & $\$ 4.89$ \\
\hline & & & & Total & & $\$ 62.92$ \\
\hline
\end{tabular}

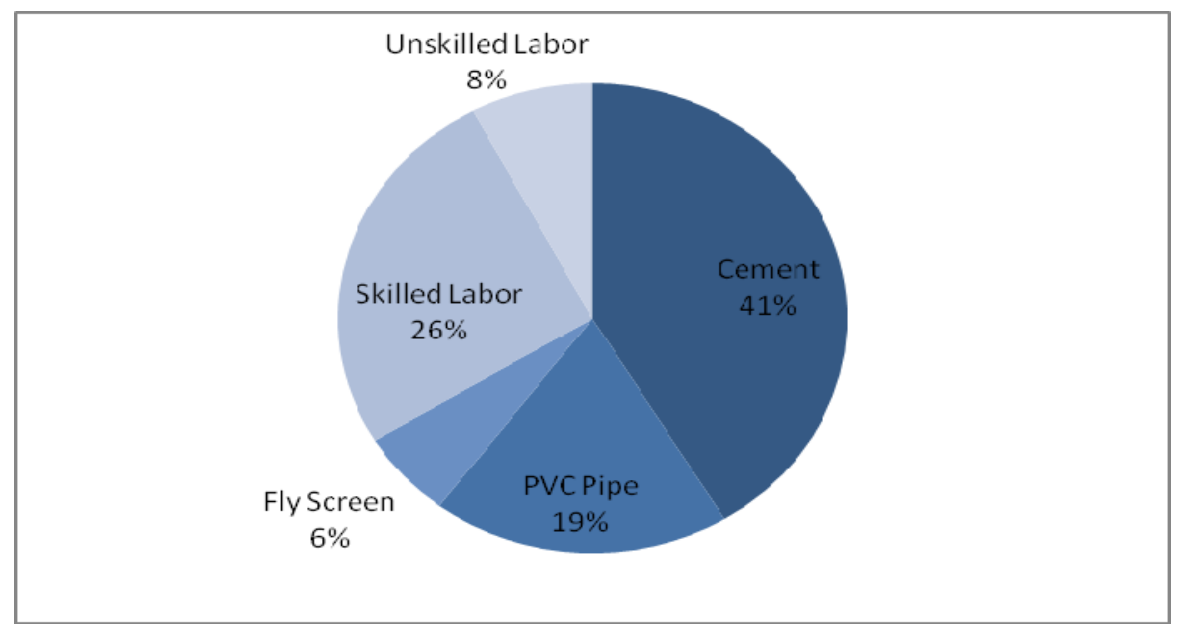

Figure 57: Pie chart showing the proportion of the total cost for each item

The Ghana Statistical Services, estimated that mean annual household income for the Upper West Region in the year 2000 was $\$ 396.67$ (Ghana Statistical Service, 2000). According to the World Bank there has been a 30\% increase in the national purchasing power parity per capita from 2000 to 2006 (The World Bank Group, 2007). Assuming the same growth for household income in the UWR, the 2006 mean annual household 
income was estimated to be $\$ 516$. The cost of constructing a latrine would therefore be approximately $12 \%$ of the annual income for the average household in the UWR. For people who earn less than a dollar and a half a day, the cost of a UWR VIP latrine is not a trivial investment.

To replace a UWR VIP latrine, assuming the slab and vent pipe are still in usable condition, would cost approximately $\$ 28.19$. Again, this is not including the cost of transportation for the materials and the mason, or feeding the laborers. If the vent pipe needed replacement the cost would be $\$ 15.73$. To put these costs more into perspective, for the average person living in the Upper West Region, to replace a UWR VIP latrine or just the vent pipe would equate to 21 and 11 earning days, respectively.

\subsubsection{Comparing the cost of UWR latrines to other appropriate solutions}

From the original Zimbabwe VIP latrine assessments the costs among different types of latrines varied widely, as presented in Table 22. The lowest cost VIP latrine used in Zimbabwe was the Rural Spiral; the cost of these latrines was cited as $\$ 8.00$ in 1981 (Morgan \& Mara, 1982). These latrines were designed specifically for Zimbabwe's subsistence farmers and could be fabricated at a fraction of the cost of the rural brick VIP latrine. Based on the information in Table 21 a rural Ghanaian farmer today would have to pay three times as much for basic sanitation as compared to a rural Zimbabwean (current events and inflation aside).

The Bangladesh and the Ethiopian latrines referenced in are not VIP latrines. Instead they are versions of the simple pit latrine. These models however provide proof that low cost/no cost latrine solutions are possible. 
Table 21: Approximate cost of latrine designs

Sources: ${ }^{1}$ Mara D. D., 1984, p. 69 - 73; ${ }^{2}$ Morgan \& Mara, 1982, p. 15; ${ }^{3}$ Kar, 2003 p. 12;

${ }^{4}$ O'Loughlin, Fentie, Flannery, \& Emerson, 2006

\begin{tabular}{|c|c|c|}
\hline VIP Latrine Type & Recorded Cost, USD (year) & $\begin{array}{c}\text { Adjusted Cost (2007 } \\
\text { USD)* }\end{array}$ \\
\hline Zimbabwe Urban Brick VIP Latrine ${ }^{1}$ & $\$ 145.95-\$ 244.87(1983)$ & $\$ 519.92$ \\
\hline Zimbabwe Rural Brick VIP Latrine ${ }^{1}$ & $\$ 70.99-\$ 122.00(1983)$ & $\$ 150.65$ \\
\hline UWR VIP Latrine & & $\$ 62.92$ \\
\hline Zimbabwe Rural Spiral VIP Larine $^{2}$ & $\$ 8.00(1981)$ & $\$ 19.89$ \\
\hline Bangladesh Community Innovated Models ${ }^{3}$ & $\$ 1.90-\$ 5.96(2003)$ & $\$ 6.84$ \\
\hline Ethiopia $^{4}$ & & $\$ 0.00$ \\
\hline
\end{tabular}

* Inflation conversion according to the Consumer Price Index from the annual Statistical Abstracts of the United States.

In review of this section, to achieve the total sanitation coverage requires a solution that is within the economic capabilities of the beneficiaries. The high cost of the UWR VIP latrine does not make it a likely candidate for independent and sustainable use. 


\section{Chapter 9: Conclusions}

The objectives for this study were to:

1. Evaluate the actual design and condition of a sample of household latrines in the Upper West Region of Ghana, and compare them with the standard designs proposed by the Community Water and Sanitation Agency (CWSA) of Ghana, the United Nations Development Programme (UNDP) and the World Bank.

2. Measure the daily and seasonal airflow rates within vent pipes of a random sample and a selected sample of VIP latrines, and compare the observed findings against the theoretical flow rates specified for odorless conditions as specified by the UNDP and World Bank. Measure the microenvironment and physical characteristics of the VIP latrine sample, and compare it to the concurrent flow rate data to determine if an adequate flow rate is a function of the vent pipe, the superstructure, the local environment, or any combination thereof.

3. For one of the sample communities, observe the proportion of usable VIP latrines compared to VIP latrines that are in actual use, as an indicator of user acceptance. Compare observations with studies that had similar objectives but occurred in different locations and with different types of latrines.

4. Conduct a comparative cost analysis of latrine options and an examination of the availability of materials to aid in assessing the VIP latrine as an appropriate technology for sustainable development within rural communities in the Upper West Region of Ghana.

\subsection{Major Findings}

Based on the results from the five objectives of this research project it can be concluded that the UWR VIP latrine is not an appropriate technology for sustainable rural sanitation development in the Upper West Region of Ghana.

\subsubsection{Function}

The mechanisms driving ventilation in UWR VIP latrines are: 1) air buoyancy forces resulting in a stack effect at times in which ambient temperatures are less than 
temperatures inside the pit of the latrine. This usually occurs during the early morning and evening hours; 2) wind passing over the mouth of the vent pipe; and when possible 3) wind passing into the superstructure. Typically the latter two mechanisms occur during the late morning to the early evening hours when wind speeds are high and ambient temperatures are greater than pit temperatures. However, throughout the midday period there is an overall decreasing trend in ventilation flow rate. It is theorized that this downward trend is primarily due to increasing ambient air temperatures resulting in a reduction of the ambient air density, thereby reducing the effectiveness that wind has at drawing up air from the ventilation pipe.

A technical performance evaluation indicated that $73 \%(n=22 / 30)$ of the latrines were able to achieve ventilation flow rates greater than the minimum rate recommended by the UNDP/World Bank guidelines of $10 \mathrm{~m}^{3} / \mathrm{hr}$. These flow rates however were not adequate enough to achieve the suggested air exchange rate of $6 \mathrm{ACH}$. This is mostly due to the fact that UWR VIP latrine superstructures are generally larger in air volume than those that were used to determine $6 \mathrm{ACH}$ as a reasonable rate. Using a less stringent air exchange rate of $4 \mathrm{ACH}$ still resulted in only a $10 \%$ attainment. These facts suggest that the UWR VIP latrines are not achieving a high enough air exchange rate to maintain odorless conditions within the superstructure.

Design factors that contribute to poor ventilation are: 1) the ventilation pipe is inadequately sized to accommodate wind speeds of less than $3 \mathrm{~m} / \mathrm{s}$ and a superstructure volume of greater than $1.8 \mathrm{~m}^{3}$; and 2$)$ most $(64 \%, \mathrm{n}=32 / 50)$ ventilation openings and entrances were found to be facing away from the wind direction.

\subsubsection{Use}

A latrine usage proportion of $68 \%(n=52 / 76)$ in one community indicates that the majority of latrine owners accepted the latrine and changed their behavior accordingly. However, studies using similar comparisons came to the same conclusions even when evaluating communities outside of the UWR and with other basic sanitation facilities. 
Despite favorable adoption, few latrines were being properly used and maintained to facilitate of odor removal and fly control. Of the 30 latrines in the sample, $90 \%(n=27)$ were found with a lid over the drop hole; $53.3 \%(\mathrm{n}=16)$ were found without a door over the entry; and $40 \%(\mathrm{n}=12)$ had the vent pipe fly screen compromised in some manner.

\subsubsection{Cost}

High unit cost relative to annual household income does not make the UWR VIP latrine favorable to independent repair, replacement or diffusion by rural households in the UWR. The high cost is therefore impeding the implementation of rural sanitation programs in the UWR.

\subsection{Recommendations}

\subsubsection{Design recommendations}

Based on the technical aspects of this study and in regards to sustained operation and maintenance, the following recommendations are made to improve odor and insect control in VIP latrines if they are to continue being used for sanitation development within rural communities of the Upper West Region:

1. Inadequate design and improper use is a demonstration of the lack of understanding of the technical requirements for VIP latrines to effectively operate. To adhere more closely to design guidelines and to facilitate proper use, extension agents should receive in depth technical training on how to site and construct VIP latrines using local construction methods and materials. The extension agents should also be given the training and materials needed to convey their knowledge to the beneficiaries on how to properly construct and maintain their VIP latrines - as well as the reasoning behind it.

2. To mitigate odors during times in which the stack effect is the driving mechanism of ventilation, VIP latrine owners should be instructed to place a lid over the drop hole at night and during the early morning hours. During the day, the drop hole 
should be left uncovered in order to maximize the ventilation effects of wind. This however adds a level of complexity and behavior modification.

3. To account for the low wind conditions and the large air volume of most UWR VIP latrine superstructures, the UNDP recommends a ventilation pipe with an internal diameter of at least $150 \mathrm{~mm}$ (approximately 6 inches). However, increases in size for PVC piping will likely result in an increase in cost. Therefore it is recommended that, whenever possible, vent pipes should be made from locally available material. For example, mud-brick is the most commonly used building material in the UWR. An adequate ventilation chimney could be made from mud-brick as long as the internal area was at least $230 \mathrm{~mm}^{2}$. It is not recommended that households be instructed to reduce the size of their superstructures, as this could have adverse effects on personal preferences and thus user adoption.

4. Regardless of the type of latrine used, when materials and or specialized labor is donated from non-local sources by a government agency or an NGO, that institution should then be prepared to make continued inspections and repairs throughout the lifetime of the facility in order to minimize disrepair. In the case of UWR VIP latrines such responsibilities would include repairs or replacements of PVC ventilation pipes if damaged, and the routine replacement of fly-screens. Furthermore, passing off the responsibility of operation and maintenance to the local government has proven to be ineffective and unsustainable. Therefore, only affordable locally available materials and labor should be used, unless the donating institution is willing to provide continued operation and maintenance services to every facility it constructs.

\subsubsection{General recommendations}

With respect to policy, implementation and cost, the following recommendations are made to improve sanitation coverage in the Upper West Region. 
1. Ghana's national sanitation policy should be amended to allow all low-cost and no-cost sanitation facilities, such as the basic pit latrine or community developed solutions. Selection of an appropriate sanitation design should be based on the needs and customs of the community, taking into account the level of income and pre-existing sanitation. An example of a sanitation decision-making tree is included in Appendix C. These decisions should be made on case-by-case basis and not due to national policy.

2. To empower rural communities/households to develop and finance their own sanitation solutions, development approaches such as community-based models, and social marketing should be used in lieu of top-down approaches. These approaches require extension agents to be well-trained in community sensitization and motivation, as well as have a broad knowledge of business and market development. The broader benefit to these approaches is a lower financial burden on national and international aid without compromising sanitation goals. The limited resources available for sanitation development can become more focused on urban development, where sanitation problems tend to be a higher threat to health, more complicated, and more expensive to solve.

3. When direct interventions are necessary, such as in the cases of emergency disease mitigation, the most basic and least costly sanitation facility should be used. This is to prevent the undermining of any long-term sustainable approaches, such as community-based models and social marketing.

\subsection{Future Work}

It is with great hope that this report is useful in improving knowledge of basic sanitation technologies and their implications. This report should hopefully inspire decision-makers at all levels to begin to think more critically of the technologies used in the context of the developing world. And if anything, this report should function as a starting place for future research and projects. Presented in this section are some suggestions on how the 
methodology could be made stronger should another investigation be conducted, as well as other possible avenues of study.

Future research related to VIP latrine performance should include a significantly larger sample in order to make definitive comparisons among variables. Another option would also be to use one model VIP latrine and study the impact that alterations, such as placing a lid over the drop hole, would have on ventilation performance. Furthermore, the development of a mathematical model of the ventilation mechanisms in VIP latrines would be useful when evaluating design modifications.

To make this study more complete, an examination of the odor-causing gasses found within pit latrines should be conducted. Odor tolerance levels could be determined using a methodology similar to those used in waste-water treatment plants, where a committee of "noses" is used to establish acceptable odor concentration levels. It would also be useful to understand which gases attract flies and at what concentrations. With this information a more accurate air exchange rate within the VIP latrines superstructure could then be determined.

Although air pressure sensors were recommended by the Mara \& Ryan field investigation, appropriate sensors could not be found for the current study. For future investigations it is still recommended that air pressure sensors be used at the same locations as the temperature sensors. This information would be useful in verifying the mechanisms identified in this, and Mara \& Ryan's report. Furthermore, future studies should also consider placing an added directional anemometer over the drop hole to monitor air that may be coming in or out of the pit.

There is certainly skepticism as to whether or not rural Upper West Region communities would be willing to adopt a sanitation facility of anything less than a VIP latrine with a PVC pipe. However, to the author's knowledge there has never been an attempt to introduce any other type of low-cost alternative design to the region. Therefore, future work should examine the possibility of the adoption of other types of sanitation designs 
by rural households. This information would also be useful in conjunction with a market analysis for developing a social market for sanitation facilities in the region. 


\section{References}

ASHRAE. (2005). ASHRAE Handbook - Fundamentals. Atlanta: self published.

Berry, L. (1995). Ghana: a country study. Retrieved March 13, 2008, from The Library of Congress, Federal Research Division: http://catalog.loc.gov/cgibin/Pwebrecon.cgi?v3=1\&DB=local $\& \mathrm{CMD}=010 \mathrm{a}+95018891 \& \& \mathrm{CNT}=10+$ records + per + page

Cairncross, S. (2007). Measuring the Health Impact of Water and Sanitation. Retrieved March 4, 2008, from WELL: http://www.lboro.ac.uk/well/resources/fact-sheets/factsheets-htm/mthiws.htm

Cairncross, S. (2003). Sanitation in the developing world: current status and future solutions. 13, S123-S131.

Cairncross, S., Shordt, K., Zacharia, S., \& Govindan, B. K. (2005). What causes sustainable changes in hygiene behaviour? A cross-sectional study from Kerala, India. 61 (10), 2212-2220.

Cotton, A., Francey, R., Pickford, J., \& Saywell, D. (1995). On-plot sanitation in lowincome-urban communities. Loughborough: Water, Engineering and Development Centre.

Courtright, P., Sheppard, J., Lane, S. S., Schachter, J., \& Dawson, C. R. (1991). Latrine ownership as a protective factor in inflammatory trachoma in Egypt. British Journal ofOphthalmology , 75, 322-325.

Curtis, C. F., \& Hawkins, P. (1982). Entomological studies of on-site sanitation systems in Tanzania and Botswana. Transactions of the Royal Society of Tropical Medicinie anld Hygiene, 99-108. 
Curtis, V., \& Cairncorss, S. (2003). Effect of washing hands with soap on diarrhoea risk in the community: a systematic review. The Lancet Infectious Diseases , 3 (5), 275-281.

Easterly, W. (2006). The White Man's Burden. New York: The Penguin Press.

Emerson, P., Simms, V. M., Makalo, P., \& Bailey, R. L. (2005). Household pit latrines as a potential source of the fly Musca sorbens - a one year longitudinal study from The Gambia. Tropical Medicine and International Health , 10 (7), 706-709.

Evans, B., \& Haller, L. (2005). Securing Sanitation - the Compelling Case to Address the Crisis . Stockholm: Stockholm International Water Institute, SIWI.

Fewtrell L, K. R. (2005). Water, sanitation and hygiene interventions to reduce diarrhoea in less developed countries: a systematic review and mata-analysis. Lancet Infectious Diseases , 5 (1), 42-52.

Fewtrell, L., Kaufmann, R., Kay, D., Enanoria, W., Haller, L., \& Calford, J. J. (2005). Water, sanitation hygiene interventions to reduce diarrhoea in less developed countries systematic review and mata-analysis. Lancet Infectious Diseases , 5 (1), 42-52.

Ghana Statistical Service (GSS), Noguchi Memorial Institute for Medical Research (NMIMR), and ORC. (2004). Ghana Demographic and Health Survey 2003. Accra: U.S. Agency for International Development.

Ghana Statistical Service. (2000). Ghana Living Standards Survey Report fot the Fourth Round (GLSS4). Accra: Government of Ghana.

Governing Council of the United Nations Environmental Programme. (2004). Finaancing wastewater collection and treatment in relation to the Millenium Developmetn Goals and World Summit on Sustainable Development targets on water and sanitation. United Nations. The Hague: United Nations.

International Fund for Agricultural Development. (2006). Republic of Ghana, Upper West Agricultural Development Project. Interim Evaluation. 
International Fund for Agricultural Development. (2007, March 7). Rural Povery in Ghana. Retrieved March 13, 2008, from Rural Poverty Portal:

http://www.ruralpovertyportal.org/english/regions/africa/gha/index.htm

Joint Monitoring Programme. (2006 A). Sub-Saharan Africa: sanitation data. (WHO and UNICEF) Retrieved March 15, 2008, from Joint Monitoring Programme for Water Supply and Sanitation: http://www.wssinfo.org/en/333_san_africaS.html

Joint Monitoring Programme. (2006 B). Water \& sanitation data quary tool. Retrieved March 5, 2008, from Joint Monitoring Programme for water supply and sanitation: http://www.wssinfo.org/en/sanquery.html

Kaiser, J. (2006). An Analysis of the Use of Desiccant as a Method of Pathogen Removal in Compost Latrines in Rural Panama. Masters Report, Michigan Technological Unversity, Civil \& Environmental Engineering.

Kalbermatten, J. M., Julius, D. S., Gunnerson, C. G., \& Mara, D. D. (1982, Jan 1). Appropriate sanitation alternatives : a planning and design manual. World Bank studies in Water Supply and Sanitation; no. 2 .

Kar, K. (2003). Subsidy or self-respect? Participatory total community sanitation in Bangladesh. Institute of Development Studies, England.

Mara, D. D. (1984). The design of Ventilated Improved Pit Latrines . TAG Technical Note Number 13 . Washington DC.: United Nations Development Programme and World Bank.

Mara, D. D. (2008, February 23). VIP Latrine Investigation Questions. Personal Communication .

Mara, D. D., \& Ryan, A. B. (1983 A). Pit Latrine Ventilation: Field Investigation Methodology. TAG Technical Note Number 4 . Washington DC.: United Nations Development Programme and the World Bank. 
Mara, D. D., \& Ryan, A. B. (1983 B). Ventilated Improved Pit Latrines: Vent Pipe Design Guidelines. TAG Technical Note Number 6 . Washington, DC.: United Nations Development Programme and World Bank.

McPherson, H., \& McGarry, M. (1987). User participation and implementation strategies in water and sanitatino projects. International journal of water resources development , 3 (1), 23-30.

Ministry of Local Governement and Rural Development. (1999, May). Environmental Sanitation Policy. 34-36. Ghana: Government of Ghana.

Morgan, P. R., \& Mara, D. D. (1982). Ventilated Improved Pit Latrines: Recent Developments in Zimbabwe. Washington: The World Bank.

Myre, E., Kaiser, J., M., H. D., Huart, J. N., \& Tawney, E. (2007). Latrines and Sanitation. Unpublished.

O’Loughlin, R., Fentie, G., Flannery, B., \& Emerson, P. M. (2006). Follow-up of a low cost latrine promotion programme in one district of Amhara, Ethiopia: characteristics of early adopters. II (9), 1406-1415.

Pickford, J. (1995). Low-Cost Sanitation. London: Intermediate Technology Publications.

Pickford, J., \& Shaw, R. (1998). The Worth of Water. Intermediate Technology Publications.

Quansah, K. (2006, October 25). Status on Sanitation in Ghana from the National Perspective. Northern Sanitation Forum Presentation . Tamale, Norther Region, Ghana.

Rheingans, R., Dreibelbis, R., \& Freeman, M. (2006). Beyond the Millennium Development Goals: Public health challenges in water and sanitation. Global Public Health , 1 (1), 31-48. 
Rodgers, A. (2006). NGO Performance \& Accountability: An Assessment of Latrine Promotion Programs in Northern Ghana. Master of Public Health Thesis, Yale University, Epidemiology and Public Health.

Simms, V. M., Makalo, P., Bailey, R. L., \& Emerson, P. M. (2005). Sustainability and acceptability of latrine provision in The Gambia. Transactions of the Royal Society of Tropical Medicine and Hygiene , 99, 631-637.

The Carter Center. (2008). Carter Center Supported Latrine Promotion in Ghana Analyzed. Eye of the Eagle , 9 (1).

The World Bank Group. (2007, April). Ghana Data Profile. Retrieved May 11, 2008, from The World Bank:

http://devdata.worldbank.org/external/CPProfile.asp?PTYPE=CP\&CCODE=GHA

UN Millennium Project. (2005). Health, Dignity, and Development: What Will it take? London: Earthscan.

UNDP. (2006). Human Development Report, Beyond Scarcity: Power, Poverty and the Global Water Crisis. New York.

UNICEF. (2006). Human Development Report 2006. New YorK: UNICEF.

United Nations. (2007). The Millenium Development Goals Report 2007. New York.

United Nations. (2007). The Millennium Development Goals Report. New York: United Nations.

United Nations. (2007, August 15). UN Action Plan. Retrieved March 20, 2008, from International Year of Sanitation: http://esa.un.org/iys/ap.shtml

Viessman, W. (1964). Ventilation Control of Odors. Annals of the New York Academy of Sciences , 630-637. 
Water Aid. (2007). Tecnology Notes. Retrieved March 12, 2008, from Water Aid UK:

http://www.wateraid.org/documents/plugin_documents/technology_notes_07_web_1.pdf

Water and Sanitation Program. (2004). The Case for Marketing Sanitation. Kenya: World Bank.

World Bank. (2002). VIP Latrines in Zimbabwe: From Loacal Innovation to Global Sanitation Solution. Kenya: World Bank. 
Appendix A: Visual Inspection Survey and Results 
Serial No:

Data Entry: Initials \#1

Initials \#2

\begin{tabular}{|c|c|c|}
\hline \multirow{2}{*}{\multicolumn{3}{|c|}{ VIP Latrine Investigation Survey }} \\
\hline & & \\
\hline \multicolumn{2}{|c|}{ District } & Village \\
\hline \multicolumn{3}{|c|}{ Assigned Latrine Number } \\
\hline \multicolumn{3}{|c|}{ Name of Head of Household } \\
\hline \multicolumn{2}{|c|}{ Date of this follow-up DD/MM/YYYY } & 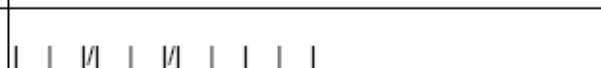 \\
\hline \multicolumn{3}{|c|}{ Observer/Interviewer Initials } \\
\hline \multicolumn{3}{|c|}{ Informed consent given? $\quad$ Initial/ Thumbprint } \\
\hline \multicolumn{2}{|c|}{ Latrine GPS coordinates } & $\begin{array}{l}\text { Lat: } \\
\text { Lon: }\end{array}$ \\
\hline \multicolumn{2}{|c|}{ Photograph of latrine'sfront and side profile as well as drop hole. } & Photo Ref \#s: \\
\hline \multicolumn{3}{|c|}{ General Background Questions } \\
\hline Q1 & When was this latrine finished? & Year and season \\
\hline Q2 & $\begin{array}{l}\text { Is kitchen ash or an insecticide regularly applied to the } \\
\text { latrine pit? (Estimate volume in cups) }\end{array}$ & $\begin{array}{r}N=0 \\
Y, \text { Kitchen Ash (indicate quantity and } \\
\text { frequency) }=1 \\
Y, \text { Insecticide (indicated name, quantity and } \\
\text { frequency) }=2\end{array}$ \\
\hline \multicolumn{3}{|c|}{ Latrine Measurements } \\
\hline M1 & Distance and direction to nearest structure & $\begin{array}{r}\text { Enter distance }(m) \\
\text { Enter Direction }\end{array}$ \\
\hline M2 & $\begin{array}{l}\text { What is the general shape of the floor plan Draw a rough } \\
\text { engineering sketch, including dimensions, of the } \\
\text { superstructure on the back of this survey. }\end{array}$ & $\begin{array}{r}\text { Square }=1 \\
\text { Circular }=2 \\
\text { Other (please specify) }=9\end{array}$ \\
\hline M3 & $\begin{array}{l}\text { What are the dimensions of the inside of the } \\
\text { superstructure? And calculate the volume }\end{array}$ & $\begin{array}{l}\text { Length or Ave.Diameter }(m)= \\
\text { Width }(m)= \\
\text { Height }(m)= \\
\text { Volume }\left(m^{\wedge} 3\right)=\end{array}$ \\
\hline M4 & What are the pit dimentions? And calculate the volume & $\begin{array}{l}\text { Diameter }(m, \text { assume uniform diameter throughout })= \\
\text { Total Depth }(m)= \\
\text { Depth of free space }(m)= \\
\text { Total Volume }\left(m^{\wedge} 3\right)= \\
\text { Volume of free space }\left(m^{\wedge} 3\right)=\end{array}$ \\
\hline M5 & What are the dimensions of the vent pipe? & $\begin{array}{l}\text { Diameter }(m)= \\
\text { Height }(m)= \\
\text { Hight Above Superstructure }(m)=\end{array}$ \\
\hline M6 & $\begin{array}{l}\text { If a fly screen is present on the vent pipe what is the } \\
\text { aperture? }\end{array}$ & $A p(m m)=$ \\
\hline M7 & $\begin{array}{l}\text { What are the dimensions of the doorway3And calculate the } \\
\text { area }\end{array}$ & $\begin{array}{l}\text { Width }(m)= \\
\text { Length }(m)= \\
\text { Area }\left(m^{\wedge} 2\right)=\end{array}$ \\
\hline M8 & $\begin{array}{l}\text { Which direction is the doorway facing?l.e } 15 \text { deg North, } \\
\text { West, South-East... }\end{array}$ & Enter direction: \\
\hline M9 & $\begin{array}{l}\text { What are the dimensions of any other openings in the } \\
\text { latrine's superstructure, and in which direction do they face } \\
\text { Label each opening on the sketch and calculate the area }\end{array}$ & $\begin{array}{l}\text { Opening A: Area }\left(m^{\wedge} 2\right)= \\
\text { Opening B: Area }\left(m^{\wedge} 2\right)= \\
\text { Opening C: Area }\left(m^{\wedge} 3\right)=\end{array}$ \\
\hline M10 & $\begin{array}{l}\text { If a fly screen is present on any of the openings in the } \\
\text { latrine's superstructure, what is the aperture? }\end{array}$ & $A p(m m)=$ \\
\hline
\end{tabular}




\begin{tabular}{|c|c|c|c|}
\hline \multicolumn{4}{|c|}{ Latrine Observations } \\
\hline Ob1 & \begin{tabular}{|l|l|} 
Does the pit show any signs of a collapse? If \\
Yes, how long has it been since the collapse?
\end{tabular} & $\begin{array}{r}N=0 \\
\text { (Enter number of approx months) } Y=1\end{array}$ & \\
\hline Ob2 & Are there faeces present inside the pit? & $\begin{array}{r}N=0 \\
Y=1\end{array}$ & \\
\hline Ob3 & $\begin{array}{l}\text { Does the cover slab show any serious cracks? These } \\
\text { are cracks that connect to the drop hole }\end{array}$ & $\begin{array}{l}N=0 \\
Y=1\end{array}$ & \\
\hline Ob4 & Is the slab higher than ground level to prevent flooding? & $\begin{array}{l}N=0 \\
Y=1\end{array}$ & \\
\hline Ob5 & Are human faeces and/or urine on the slab? & $\begin{array}{l}N=0 \\
Y=1\end{array}$ & \\
\hline Ob6 & $\begin{array}{l}\text { Is there a vent pipe present, intact, and in place? } \\
\text { Enter Yes, if all conditions are satisfied }\end{array}$ & $\begin{array}{l}N=0 \\
Y=1\end{array}$ & $\rightarrow \mathrm{Ob} 10$ \\
\hline Ob7 & What is the color of the vent pipe? & $\begin{aligned} \text { Gray } & =1 \\
\text { Black } & =2 \\
\text { Other (please specify) } & =9\end{aligned}$ & \\
\hline Ob8 & Is there a fly screen on top of the vent pipe? & $\begin{array}{r}N=0 \\
Y=1\end{array}$ & $\rightarrow$ Ob10 \\
\hline Ob9 & $\begin{array}{l}\text { Is the fly screen compromised in any way? Loosely } \\
\text { secured, or a hole present }\end{array}$ & $\begin{array}{r}N=0 \\
Y=1 \\
\end{array}$ & \\
\hline Ob10 & Are there walls present around the latrine? & $\begin{aligned} N & =0 \\
Y, \text { made of mud } & =1 \\
Y, \text { made of woven grass } & =2 \\
Y, \text { made of cement } & =3 \\
Y, \text { other material (please specify) } & =9\end{aligned}$ & \\
\hline Ob11 & Does the latrine have a roof? & $\begin{array}{r}N=0 \\
Y, \text { made of local materials= } \\
Y, \text { made of metal }=2 \\
Y, \text { other material (please specify) }=9\end{array}$ & $\rightarrow \mathrm{Ob} 13$ \\
\hline Ob12 & What is the general shape of the roof? & $\begin{array}{r}\text { Flat }=1 \\
\text { Conic }=2 \\
\text { Other (please specify) }=9\end{array}$ & \\
\hline Ob13 & Is the drop hole covered? & $\begin{array}{r}N=0 \\
Y, \text { partially }=1 \\
Y, \text { completely }=2\end{array}$ & \\
\hline Ob14 & Is the doorway covered? & $\begin{array}{r}N=0 \\
Y, \text { partially }=1 \\
Y, \text { completely }=2\end{array}$ & \\
\hline Ob15 & $\begin{array}{l}\text { Aside from the doorway are there any other openings in the } \\
\text { latrine superstructure? Enter all that apply }\end{array}$ & $\begin{array}{r}N=0 \\
Y, \text { unscreened window= } \\
Y, \text { screened window }=2 \\
Y, \text { water drain hole }=4 \\
Y, \text { screened window but compromised }=3 \\
Y \text { please specify) }=9\end{array}$ & \\
\hline Ob16 & $\begin{array}{l}\text { Is there anything present that may be shading the latrine, } \\
\text { I.e. overhanging tree branches? }\end{array}$ & $\begin{array}{r}N=0 \\
Y=1\end{array}$ & \\
\hline Ob17 & $\begin{array}{l}\text { What is the observed concentration of flies gathered around } \\
\text { the top of the vent pipe? }\end{array}$ & $\begin{array}{r}\text { None }=0 \\
\text { Low }(1 \text { to } 3)=1 \\
\text { Medium }(4 \text { to } 10)=2 \\
\text { High }(11+)=3 \\
\end{array}$ & \\
\hline Ob18 & $\begin{array}{l}\text { What is the observed concentration of flies gathered inside } \\
\text { the superstructure? }\end{array}$ & $\begin{array}{r}\text { None }=0 \\
\operatorname{Low}(1 \text { to } 3)=1 \\
\text { Medium }(4 \text { to } 10)=2 \\
\text { High }(11+)=3\end{array}$ & \\
\hline Ob19 & $\begin{array}{l}\text { Please indicate any other type of insect present inside the } \\
\text { superstructure and its observed concentration. }\end{array}$ & $\begin{array}{r}\text { None }=0 \\
\text { Low }(1 \text { to } 3)=1 \\
\text { Medium }(4 \text { to } 10)=2 \\
\text { High }(11+)=3\end{array}$ & \\
\hline
\end{tabular}




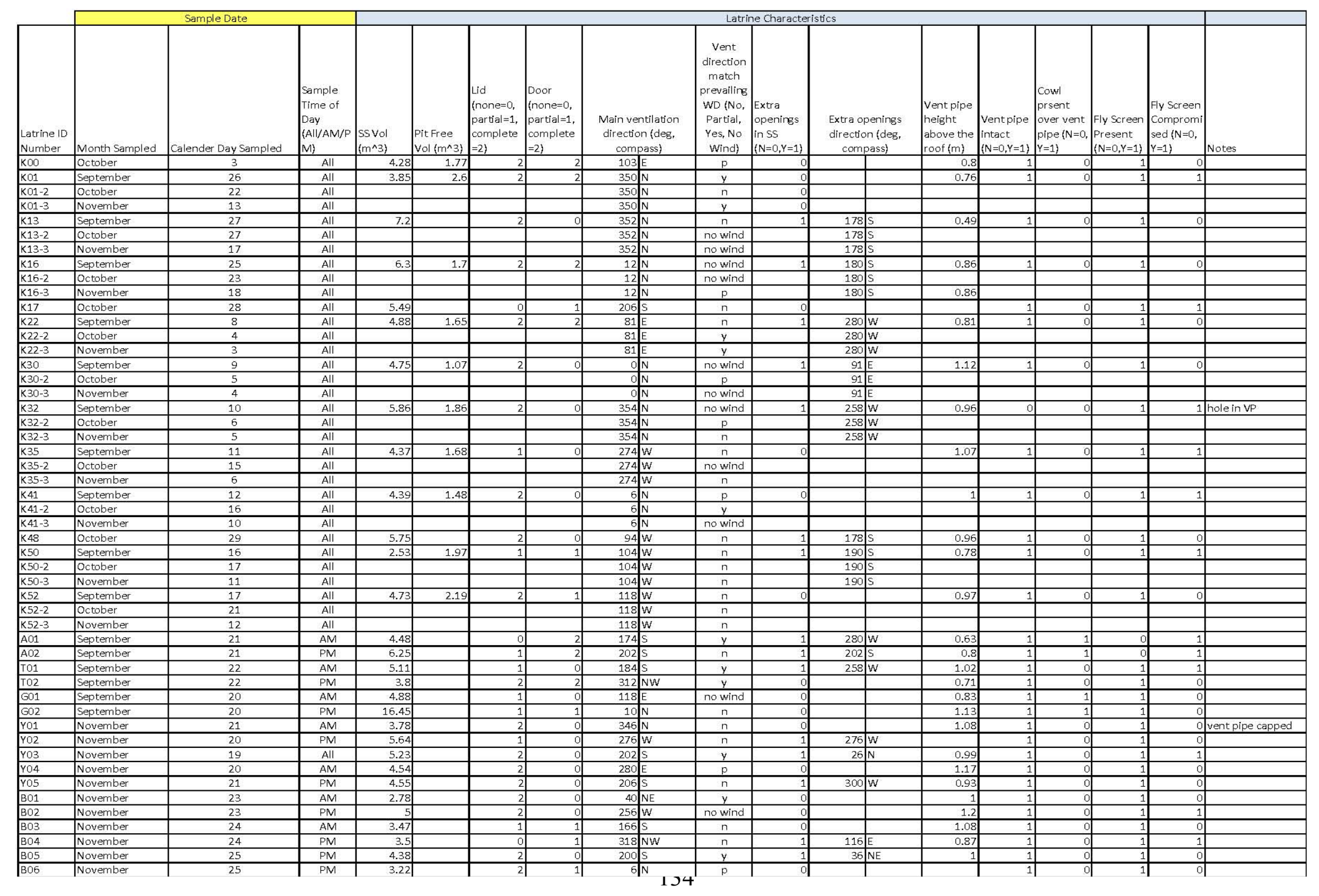


Appendix B: Instrumentation 


\section{Mannix Hot Wire Anemometer}

Model Number: HWA2005DL

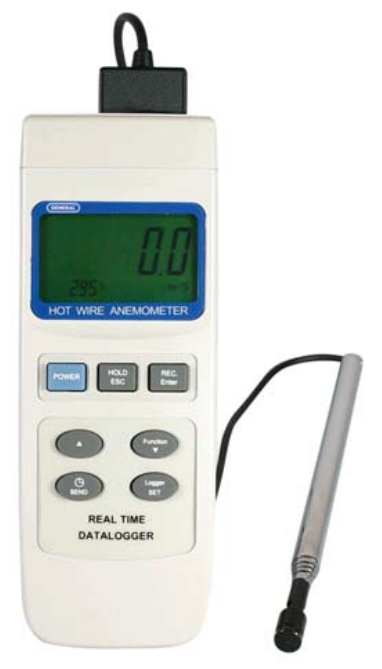

\section{Discription}

Mannix HWA2005DL Hot Wire Anemometer Data Logger is a hot wire anemometer that reads reads Air Velocity, Airflow, Temperature and "K" and "J" Type temperature. Mannix HWA2005DL Hot Wire Anemometer Data Logger provides real time data logging - records Year, Month, Date, Hour, Minute and Second.

\section{General Specifications}

CMM and CFM:

Size:

Power Source Requires:
0.2 to 20.0 m-per-s CMM and CFM

$203 \times 76$ × $38 \mathrm{~mm}$

4 AA Batteries not included and 1 UM3 Battery included 


\title{
Onset HОВО® Weather Station
}

\author{
Model Number: H21-001
}

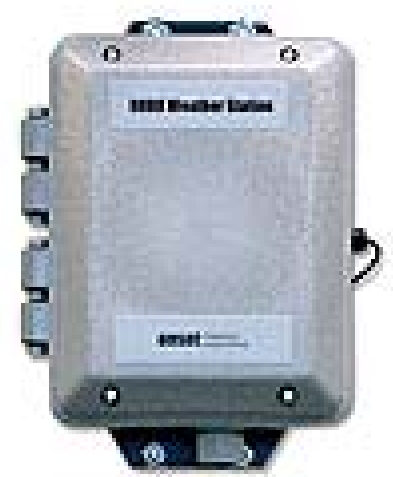

\section{Description}

The HOBO Weather Station records up to 15 channels of measurements, and a broad range of plug-andplay smart sensors are available for monitoring all kinds of environmental conditions - from temperature and humidity to soil moisture, wind speed/direction, rainfall, leaf wetness, solar radiation, and barometric pressure. Input adapters for 4-20mA, DC voltage, and pulses increase the range of possible measurements.

\section{General Specifications}

Operating Range: $-20^{\circ}$ to $50^{\circ} \mathrm{C} \quad\left(-4^{\circ}\right.$ to $\left.122^{\circ} \mathrm{F}\right)$ with alkaline batteries, $-40^{\circ}$ to $70^{\circ} \mathrm{C}\left(-40^{\circ}\right.$ to $\left.158^{\circ} \mathrm{F}\right)$ with lithium batteries

Sensor Inputs: 10, expandable to 15 with optional adapters

Data Channels: Maximum of 15 (some sensors use more than one data channel; see sensor manual for details)

Communication: $3.5 \mathrm{~mm}$ serial port or weatherproof external connector

Dimensions: $23 \mathrm{~cm} \mathrm{H} \mathrm{x} 10 \mathrm{~cm} \mathrm{D} \mathrm{x} 18 \mathrm{~cm} \mathrm{~W}(9 \times 4 \times 7$ inches $)$

Weight: $0.9 \mathrm{~kg}(2 \mathrm{lbs})$

Memory: $512 \mathrm{~K}$ nonvolatile flash data storage

Memory Modes: Stop when full, wrap around when full

Operational Indicators: Seven status lights provide logging and sensor network status

Logging Interval: 1 second to 18 hours, user-specified interval

Battery Life: 1 year typical use (up to 10 sensors with 10 minutes or longer logging interval)

Battery Type: Four standard AA alkaline batteries included (for operating conditions $-20^{\circ}$ to $50^{\circ} \mathrm{C}\left[-4^{\circ}\right.$ to $\left.122^{\circ} \mathrm{F}\right]$ ); optional AA lithium batteries available for operating conditions of $-40^{\circ}$ to $70^{\circ} \mathrm{C}\left(-40^{\circ}\right.$ to $\left.158^{\circ} \mathrm{F}\right)$

Time Accuracy: 0 to 2 seconds for the first data point and \pm 5 seconds per week at $25^{\circ} \mathrm{C}\left(77^{\circ} \mathrm{F}\right)$

Data Type: Supports measurement averaging based on availability of supporting data from sensor

Logger Start Modes: Immediate, push-button, or delayed start options

Data Communication: Current reading while logging, offload while logging, or offload when stopped

Environmental Rating: Weatherproof

More information is available at http://www.onsetcomp.com 


\section{Silicon Pyranometer Smart Sensor (Part \# S-LIB-M003)}

The Silicon Pyranometer smart sensor is designed to work with the HOBO $0^{\text {Th }}$ Weather Station logecr. The smart sensor has a plug-in modular connector that allows it to be added easily to a HOBO Weather Station. All calibration parameters are stored inside the smart sensor, which automatically communicates configuration information to the logger without the need for any programming, calibration, or extensive sclup.

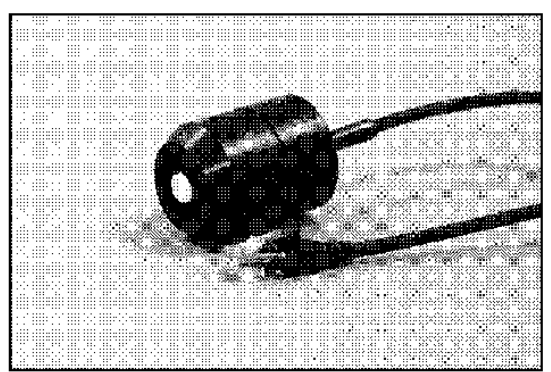

\begin{tabular}{|c|c|}
\hline Specifications & Silicon Pyranometer Smart Sensor \\
\hline Measurement Range & 0 to $1280 \mathrm{~W}^{\prime} \mathrm{m}^{2}$ \\
\hline Spectral Range & 300 to $1100 \mathrm{~nm}$ (see Figure 4) \\
\hline Accuracy & $\begin{array}{l}\text { Typically within } \pm 10 \mathrm{~W} / \mathrm{m}^{2} \text { or } \pm 5 \% \text {, whichever is greater in } \\
\text { sunlight, Additional temperature induced error } \pm 0.38 \mathrm{~W} / \mathrm{m}^{\prime} / \mathrm{C} \\
\text { from }+25 \mathrm{C}\left(0.21 \mathrm{~W} / \mathrm{m}^{2} /{ }^{\circ} \mathrm{F} \text { from }+77^{\circ} \mathrm{F}\right)\end{array}$ \\
\hline Angular Aocuracy & $\begin{array}{l}\text { Cosine corrected } 0 \text { to } 80 \text { degrees from vertical (see Figure } 5 \text { ) } \\
\text { Azimuth Error }< \pm 2 \% \text { error at } 45 \text { degrees from vertical, } 360 \\
\text { degree rotation }\end{array}$ \\
\hline Resolution & $1.25 \mathrm{~W} / \mathrm{m}^{2}$ \\
\hline Drift & $\measuredangle \pm 2 \%$ per year \\
\hline Calibration & Factory recalibration available \\
\hline Operating Temperature Range & $-40^{\circ}$ to $+75 \mathrm{C}\left(-4 \mathrm{Q}^{\prime \prime}\right.$ to $\left.+167^{\prime \prime} \mathrm{F}\right)$ \\
\hline Environmental Rating & Weatherproof \\
\hline Housing & $\begin{array}{l}\text { Anodized aluminum housing with acrylic diffuser and O-ring } \\
\text { seal }\end{array}$ \\
\hline Dimensions & $4.1 \mathrm{~cm}$ height $\times 3.2 \mathrm{~cm}$ diameter $(15 / 8 \mathrm{in} . \times 11 / 4 \mathrm{in})$ \\
\hline Weight & $120 \mathrm{~g}(4 \mathrm{oz})$ \\
\hline Bits per Sample & 10 \\
\hline Number of Data Channels * & 1 \\
\hline Measurement Averaging Option & Yes \\
\hline Cable Length Available & $3.0 \mathrm{~m}(9.8 \mathrm{ft})$ \\
\hline $\begin{array}{l}\text { Length of Smart Sensor Network } \\
\text { Cable * }\end{array}$ & $3.0 \mathrm{~m}(9.8 \mathrm{ft})$ \\
\hline Part Number & S-LIB-M003 \\
\hline (6) Specification & $\begin{array}{l}\text { This product meets CE specification ENG } 1326 \text { criterion C for ESD, } \\
\text { criterion C for Radiated Immunity, criterion B for Fast Tran sient criterion } \\
\text { A for Conducted Immunity, and criterion A for Power Frequency } \\
\text { Magnetic Fields. To minimize measurement errors due to ambient RF, } \\
\text { use the shortest possible probe cable length and keep the probe cable } \\
\text { as far as possible from other cables. }\end{array}$ \\
\hline
\end{tabular}

A single HOBO Weather Station can accommodate 15 data channels and up to $100 \mathrm{~m}$ ( 328 ft) of smart sensor cable (the digital communications portion of the sensor cables). 


\section{2-Bit Temperature Smart Sensor (Part \# S-TMB-MOXX)}

The 12-Bit Temperature smart sensor is designed to work with the HOBO ${ }^{\text {min }}$ Weather Station. The smart sensor has a plug-in modular connector that allows it to be added easily to a HOBO Weather Station. All sensor parameters are stored insicle the smart sensor, which automatically communicates configuration information to the logger without any programming or extensive

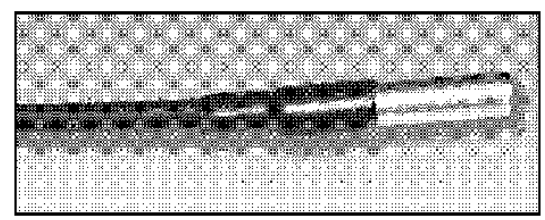
user setup.

\begin{tabular}{|c|c|}
\hline Specification & 12-Bit Temperature Smart Sensor \\
\hline Measurement Range & $-40^{\circ}$ to $+100^{\circ} \mathrm{C}\left(-40^{\prime}\right.$ to $\left.+212^{\circ} \mathrm{F}\right)-$ sensor tip \\
\hline Accuracy & $\begin{array}{l}\leq \pm 0.2^{\circ} \mathrm{C} \text { from } 0^{\prime} \text { to }+50^{\circ} \mathrm{C}\left(< \pm 0.36^{\circ} \mathrm{F} \text { from }+32^{\circ} \text { to }+122^{\prime} \mathrm{F}\right) \text {, see } \\
\text { Figure } 1\end{array}$ \\
\hline Resolution & $\begin{array}{l}<0.03^{\prime} \mathrm{C} \text { from } 0^{\prime} \text { to }+50^{\circ} \mathrm{C}\left(<0.054^{\prime} \mathrm{F} \text { from }+32^{\prime} \text { to }+122^{\circ} \mathrm{F}\right) \text {, see } \\
\text { Figure } 1\end{array}$ \\
\hline Drift & $<0.1^{\circ} \mathrm{C}\left(0.18^{\prime} \mathrm{F}\right)$ per year \\
\hline Response Time & $\begin{array}{l}<2 \text { minutes typical in } 2 \mathrm{~m} / \mathrm{sec}(4.5 \mathrm{mph}) \text { moving air flow } \\
<1 \text { minute typical in stirred water bath }\end{array}$ \\
\hline $\begin{array}{l}\text { Operating Temperature } \\
\text { Range (in-cable electronics) }\end{array}$ & $-40^{\circ}$ to $+75^{\circ} \mathrm{C}\left(-40^{\circ}\right.$ to $\left.+167^{\circ} \mathrm{F}\right)$ \\
\hline Environmental Rating & $\begin{array}{l}\text { Sensor tip and cable jacket: Immersion in water up to }+50^{\circ} \mathrm{C} \\
\left(+122^{\circ} \mathrm{F}\right) \text { for } 1 \text { year }\end{array}$ \\
\hline Housings & $\begin{array}{l}\text { Stainless steel waterproof sensor tip; weatherproof PVC housing } \\
\text { for smart sensor adapter }\end{array}$ \\
\hline Dimensions & Temperature probe: $7 \times 38 \mathrm{~mm}(0.28 \times 1.5 \mathrm{in})$. \\
\hline Weight & $\begin{array}{l}2 \text { meter: } .09 \mathrm{~g}(3.3 \mathrm{oz}) \\
6 \text { meter: } 14 \mathrm{~g}(5.2 \mathrm{oz}) \\
17 \text { meter: } .30 \mathrm{~g}(11.2 \mathrm{oz})\end{array}$ \\
\hline Bits per Sample & 12 \\
\hline Number of Data Channels * & 1 \\
\hline $\begin{array}{l}\text { Measurement Averaging } \\
\text { Option }\end{array}$ & Yes \\
\hline Cable Lengths Available & $\begin{array}{l}2 \mathrm{~m}(6.6 \mathrm{ft}) \text { S-TMB-MO02 } \\
6 \mathrm{~m}(19.7 \mathrm{ft}) \text { S-TMB-MO06 } \\
17 \mathrm{~m}(55.8 \mathrm{ft}) \text { S-TMB-M017 }\end{array}$ \\
\hline $\begin{array}{l}\text { Length of Smart Sensor } \\
\text { Network Cable* }\end{array}$ & $0.5 \mathrm{~m}(1.6 \mathrm{ft})$ for all models \\
\hline Part Number & $\begin{array}{l}\text { S-TMB-M002 (2 meter cable) } \\
\text { S-TMB-M006 ( } 6 \text { meter cable) } \\
\text { S-TMB-M017 ( } 17 \text { meter cable) }\end{array}$ \\
\hline C Especification & $\begin{array}{l}\text { This product meets CE specification EN61326 criterion C for ESD, criterion } \\
\text { C for Radiated Immunity, criterion C for Fast Transient, criterion B for } \\
\text { Conducted Immunity, criterion A for Power Frequency Magnetic Fields, and } \\
\text { criterion B for Radiated Emissions Group } 1 \text {. To minimize measurement } \\
\text { errors due to ambient RF, use the shortest possible probe cable length and } \\
\text { keep the probe cable as far as possible from other cables. }\end{array}$ \\
\hline
\end{tabular}

10 2002-2007 Onset Computer Corporation

Part \#: MAN-S-TMB

Doc \# 7105-E 
Temperature/RH Smart Sensor (S-THB-M00x)

The Temperature/RI I smart sensor is designed to work with smart scensor-compatible HOBO ${ }^{\mathbb{E}}$ data loggers. All sensor paramelers are stored inside the smart sensor. which automalically communicates configuration information to the logger without any programming, calibration or extensive user setup.

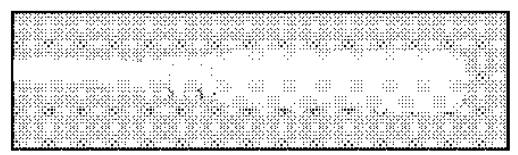

\begin{tabular}{|c|c|c|}
\hline Specifications & Temperature & $\mathbf{R H}$ \\
\hline Measurement Range & $-40^{\circ} \mathrm{C}$ to $75^{\circ} \mathrm{C}\left(-40^{\circ} \mathrm{F}\right.$ to $\left.167^{\circ} \mathrm{F}\right)$ & $\begin{array}{l}0-100^{\circ} \mathrm{RH} \text { at }-40^{\circ} \text { to } 75^{\circ} \mathrm{C} \\
\left(-40^{\circ} \text { to } 167^{*} \mathrm{~F}\right) \text {; exposure to } \\
\text { conditions below }-20^{\circ} \mathrm{C}\left(-4^{\circ} \mathrm{F}\right) \text { or } \\
\text { above } 95 \% \text { RH may temporarily } \\
\text { increase the maximum } \mathrm{RH} \text { sensor } \\
\text { error by an additional } 1 \%\end{array}$ \\
\hline Accuracy & $\begin{array}{l}0.2^{\circ} \mathrm{C} \text { over } 0^{\circ} \text { to } 50^{\circ} \mathrm{C}\left(0.36^{\circ} \mathrm{F} \text { over }\right. \\
\left.32^{\prime \prime} \text { to } 122^{\circ} \mathrm{F}\right) \text {; see Figure } 1\end{array}$ & $\begin{array}{l} \pm 2.5 \% \text { from } 10 \text { to } 90 \% \text {; see Figure } 2 \\
\text { for full range }\end{array}$ \\
\hline Resolution & $\begin{array}{l}0.02^{\circ} \mathrm{C} \text { at } 25^{\circ} \mathrm{C}\left(0.04^{\circ} \mathrm{F} \text { at } 77^{\circ} \mathrm{F}\right) \text {; see } \\
\text { Figure } 1\end{array}$ & $0.1 \% \mathrm{RH}$ at $25^{\circ} \mathrm{C}\left(77^{\circ} \mathrm{F}\right)$ \\
\hline Bits Per Sample & 12 & 10 \\
\hline Drift & $<0.1^{\circ} \mathrm{C}\left(0.18^{\circ} \mathrm{F}\right)$ per year & $<1 \%$ per year typical; hysteresis $1 \%$ \\
\hline Response Time & 5 minutes in air moving $1 \mathrm{~m} / \mathrm{sec}$ & $\begin{array}{l}10 \text { minutes in air moving } 1 \mathrm{~m} / \mathrm{sec} \text { with } \\
\text { protective cap }\end{array}$ \\
\hline Operating Temperature Range & \multicolumn{2}{|l|}{$-40^{\circ} \mathrm{C}$ to $+75^{\circ} \mathrm{C}\left(-40^{3} \mathrm{~F}\right.$ to $\left.+167^{\circ} \mathrm{F}\right)$} \\
\hline Environmental Rating & \multicolumn{2}{|c|}{$\begin{array}{l}\text { Weatherproof. } 0 \text { to } 100 \% \text { RH intermittent condensing environments. For best } \\
\text { results, the Temp/RH Smart Sensor should be mounted inside a protective } \\
\text { enclosure. such as a solar radiation shield. }\end{array}$} \\
\hline Housing & \multicolumn{2}{|c|}{$\begin{array}{l}\text { PVC cable jacket with ASA styrene polymer RH sensor cap; modified } \\
\text { hydrophobic polyethersulfone membrane }\end{array}$} \\
\hline Sensor Dimensions & \multicolumn{2}{|c|}{$10 \times 35 \mathrm{~mm}(0.39 \times 1.39 \mathrm{in})$} \\
\hline Weight & \multicolumn{2}{|l|}{$\begin{array}{l}\text { S-THB-MOO2 - } 110 \mathrm{~g}(3.88 \mathrm{oz}) \\
\text { S-THB-MO08 - } 180 \mathrm{~g}(6.35 \mathrm{oz})\end{array}$} \\
\hline Number of Data Channels * & \multicolumn{2}{|l|}{2} \\
\hline Measurement Averaging Option & \multicolumn{2}{|l|}{ No } \\
\hline Cable Lengths Available & \multicolumn{2}{|l|}{$2.5 \mathrm{~m}(8.2 \mathrm{ft}) ; 8 \mathrm{~m}(26.2 \mathrm{ft})$} \\
\hline $\begin{array}{l}\text { Length of Smart Sensor Network } \\
\text { Cable * }\end{array}$ & \multicolumn{2}{|l|}{$0.5 \mathrm{~m}(1.6 \mathrm{ft}) ; 6 \mathrm{~m}(19.6 \mathrm{ft})$} \\
\hline Part Numbers & \multicolumn{2}{|l|}{ S-THB-M002, S-THB-MOOB } \\
\hline C $\epsilon_{\text {Specification }}$ & \multicolumn{2}{|c|}{$\begin{array}{l}\text { This product meets CE specification ENG1326 criterion C for ESD, criterion C for } \\
\text { Radiated Immunity criterion C for Fast Transient. criterion B for Conducted IImmunity. } \\
\text { criterion A for Power Frequency Magnetic Fields, and Radiated Emissions Group } 1 \text {. } \\
\text { Class } B \text {. To minimize measurement errors due to ambient RF, use the shortest possible } \\
\text { probe cable length and keep the probe cable as far as possible from other cables. }\end{array}$} \\
\hline
\end{tabular}

* A single smart sensor-compatible HOBO logger can accommodate 15 data chamils and up to $100 \mathrm{~m}$ ( $325 \mathrm{ft}$ ) of smatt semsor cable (the digital communications portion of the setnor cabless. 
Wind Speed/Direction Smart Sensor (Part \# S-WCA-M003)

The Wind Speed Direction smatt sensor is designed to work with the HOBO ${ }^{\mathbb{K}}$ Weather Station logger. The smart sensor has a plug-in modular connector that allows it to be added easily to a HOBO Weather Station. All sensor parameters are stored inside the smart sensor, which automatically communicates configuration information to the logger without the need for any programming or extensive setup.

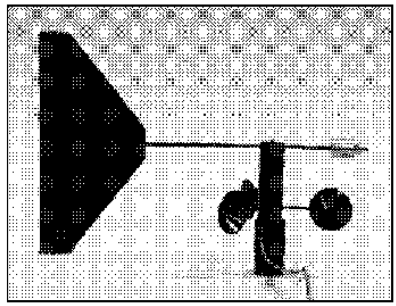

\begin{tabular}{|c|c|c|}
\hline Specifications & Wind Speed/Gust & Wind Direction \\
\hline Measurement Range & 0 to $44 \mathrm{~m} / \mathrm{s}(0$ to $99 \mathrm{mph})$ & 0 to 358 degrees, 2 degree dead band \\
\hline Accuracy & $\begin{array}{l} \pm 0.5 \mathrm{~m} / \mathrm{s}( \pm 1.1 \mathrm{mph}) \\
\pm 3 \% 171030 \mathrm{~m} / \mathrm{s}(38 \text { to } 67 \mathrm{mph}) \\
\pm 4 \% 30 \text { to } 44 \mathrm{~m} / \mathrm{s}(67 \text { to } 99 \mathrm{mph})\end{array}$ & \pm 5 degrees \\
\hline Resolution & $0.19 \mathrm{~m} / \mathrm{s}(0.42 \mathrm{mph})$ & 1.4 degrees \\
\hline Starting Threshold & $0.5 \mathrm{~m} / \mathrm{s}(1.1 \mathrm{mph})$ & $0.5 \mathrm{~m} / \mathrm{s}(1.1 \mathrm{mph})$ \\
\hline Damping Ratio & NA & 0.4 \\
\hline Distance Constant & Approximately $3 \mathrm{~m}(9.8 \mathrm{n})$ & $0.8 \mathrm{~m}(2.6 \mathrm{ft})$ \\
\hline $\begin{array}{l}\text { Maximum Wind Speed } \\
\text { Survival }\end{array}$ & \multicolumn{2}{|l|}{$54 \mathrm{~m} / \mathrm{sec}(120 \mathrm{mph})$} \\
\hline Measurement Definition & $\begin{array}{l}\text { Cup revolutions are accumulated every three } \\
\text { seconds for the duration of the logging interval. } \\
\text { Wind speed is the average speed for the entire } \\
\text { logging interval. Gust speed is the highest } \\
\text { three-second wind recorded during the logging } \\
\text { interval. }\end{array}$ & $\begin{array}{l}\text { Vector components of wind direction are } \\
\text { accumulated every three seconds for duration } \\
\text { of logging interval, Average direction is } \\
\text { calculated from the sum of the vector } \\
\text { components every logging interval. }\end{array}$ \\
\hline Operating Temperature Range & \multicolumn{2}{|l|}{$-40^{\circ} \mathrm{C}$ to $+75^{\circ} \mathrm{C}\left(-40^{\mathrm{F}} \mathrm{F}\right.$ to $\left.+167^{\mathrm{r}} \mathrm{F}\right)$} \\
\hline Environmental Rating & \multicolumn{2}{|l|}{ Weatherproof } \\
\hline Service Life & \multicolumn{2}{|c|}{2 to 5 years typical depending upon environmental conditions } \\
\hline Housing & \multicolumn{2}{|c|}{$\begin{array}{l}\text { Anodized aluminum housing, injection-molded fiberglass-reinforced plastic cups, stairless steel } \\
\text { fasteners, Acetal base, and powder-coated steel mounting rod }\end{array}$} \\
\hline Bearing Type & Stainless steel shielded ball bearing & Bushing \\
\hline Turning Radius & $108 \mathrm{~mm}(4.25 \mathrm{in})$. & Approximately $305 \mathrm{~mm}$ (12.5 in.) \\
\hline Dimensions & \multicolumn{2}{|c|}{$317 \mathrm{~mm}(12.5 \mathrm{in},) \mathrm{H} \times 419 \mathrm{~mm}(16.5 \mathrm{in}.) \mathrm{W}, 12.7 \mathrm{~mm}(0.5 \mathrm{in}$.$) diameter mounting pole$} \\
\hline Weight & \multicolumn{2}{|c|}{ Approximately $700 \mathrm{~g}(1.5 \mathrm{Ibs})$} \\
\hline Bits per Sample & \multicolumn{2}{|l|}{8 for each channel, 24 total } \\
\hline Number of Data Channels * & \multicolumn{2}{|l|}{3} \\
\hline $\begin{array}{l}\text { Measurement Averaging } \\
\text { Option }\end{array}$ & \multicolumn{2}{|l|}{ Automatic averaging (see Measurement Defin ition) } \\
\hline Cable Length Available & \multicolumn{2}{|l|}{$3.0 \mathrm{~m}(9.8 \mathrm{ft})$} \\
\hline $\begin{array}{l}\text { Length of Smart Sensor } \\
\text { Network Cable * }\end{array}$ & \multicolumn{2}{|l|}{$3.0 \mathrm{~m}(9.8 \mathrm{ft})$} \\
\hline Part Number & \multicolumn{2}{|l|}{ S-WCA-M003 } \\
\hline (60) Specification & \multicolumn{2}{|c|}{$\begin{array}{l}\text { This product meets CE specification EN61326 criterion C for ESD, criterion C for Radiated } \\
\text { Immunity, criterion B for Fast Transient, criterion A for Conducted Immunity, and criterion A for } \\
\text { Power Frequency Magnetic Fields. To minimize measurement errors due to ambient RF, use the } \\
\text { shortest possible probe cable length and keep the probe cable as far as possible from other } \\
\text { cables. }\end{array}$} \\
\hline
\end{tabular}

* A single HOBO Weather Station logger can accommodate 15 data channels and up to $100 \mathrm{~m}(325 \mathrm{ft}$ ) of smart sensor cable (the digital communications portion of the sen sor cablesi.

4 On set Computer Corporation

Onset Part \#: MAN-S-WCA

Doc \#: 6858-D 
Wind Speed Smart Sensor (Part \# S-WSA-M003)

The Wind speed smart sensor is designed to work with the IO Weather Station Jogger. The smart sensor has a plug-in modular connector that allows it to be added easily to a HOBO Weather Station. All sensor paramelers are stored inside the smart sensor, which automatically communicates configuration information to the logger without the need for any programming or extensive user setup.

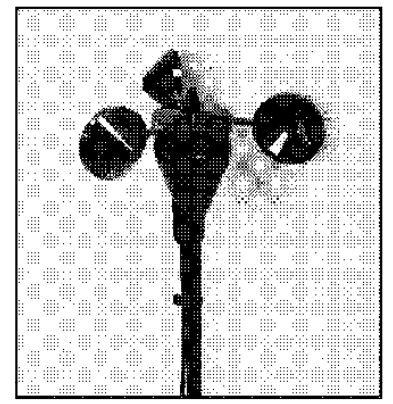

\begin{tabular}{|c|c|}
\hline Specifications & Wind Speed Smart Sensor \\
\hline Measurement Range & 0 to $45 \mathrm{~m} / \mathrm{sec}(0$ to $100 \mathrm{mph})$ \\
\hline Accuracy & $\pm 1.1 \mathrm{~m} / \mathrm{sec}(2.4 \mathrm{mph})$ or $\pm 4 \%$ of reading, whichever is greater \\
\hline Resolution & $0.38 \mathrm{~m} / \mathrm{sec}(0.8 \mathrm{mph})$ \\
\hline Service Life & $>5$ year life typical, factory replaceable mechanism \\
\hline Distance Constant & $3 \mathrm{~m}(9.8 \mathrm{ft})$ \\
\hline Starting Threshold & $\leq 1 \mathrm{~m} / \mathrm{sec}(2.2 \mathrm{mph})$ \\
\hline Maximum Wind Speed Survival & $54 \mathrm{~m} / \mathrm{sec}(120 \mathrm{mph})$ \\
\hline Measurement Definition & $\begin{array}{l}\text { Wind speed: Average wind speed over logging interval } \\
\text { Gust: Fastest } 2 \text { second gust during the logging interval }\end{array}$ \\
\hline Operating Temperature Range & $-40^{\prime}$ to $+75^{\prime} \mathrm{C}\left(-40^{\prime \prime}\right.$ to $\left.+167^{\prime} \mathrm{F}\right)$ \\
\hline Environmental Rating & Sensor and Cable Jacket: Weatherproof \\
\hline Housing & $\begin{array}{l}\text { Three cup polycarbonate anemometer: Modified Teflon }{ }^{\text {in }} \text { bearings } \\
\text { and hardened beryllium shaft with ice shedding design }\end{array}$ \\
\hline Dimensions & $19.0 \times 8.1 \mathrm{~cm}(7.5 \times 3.2 \mathrm{in})$ \\
\hline Weight & $300 \mathrm{~g}(10 \mathrm{oz})$ \\
\hline Bits per Sample & $\begin{array}{l}\text { Wind Speed: } 8 \\
\text { Gust Speed: } 8\end{array}$ \\
\hline Number of Data Channels * & 2 \\
\hline Measurement Averaging Option & No \\
\hline Cable Length Available & $3.0 \mathrm{~m}(9.8 \mathrm{ft})$ \\
\hline $\begin{array}{l}\text { Length of Smart Sensor Network } \\
\text { Cable* }\end{array}$ & $0.5 \mathrm{~m}(1.6 \mathrm{ft})$ \\
\hline Part Number & S-WSA-M003 \\
\hline (C) Specification & $\begin{array}{l}\text { This product meets CE specification EN61326 criterion C for ESD, criterion C } \\
\text { for Radiated lmmunity, criterion B for Fast Transient, criterion A for } \\
\text { Conducted Immunity, and criterion A for Power Frequency Magnetic Fields. } \\
\text { To minimize measurement errors due to ambient RF, use the shortest } \\
\text { possible probe cable length and keep the probe cable as far as possible from } \\
\text { other cables. }\end{array}$ \\
\hline
\end{tabular}

* A single HOBO Weather Station can accommodate 15 data channels and up to $100 \mathrm{~m}$ (328 ft) of smart sensor cable (the digital communications portion of the sensor cables).

ic 2001-2003 Onset Computer Corporation

Onset Part \#: MAN-S-WSA

Doc \# 6064-B 


\section{Appendix C: Recommended Structure of Feasibility Studies for Sanitation Program Planning}

Source: (Kalbermatten, Julius, Gunnerson, \& Mara, 1982) 


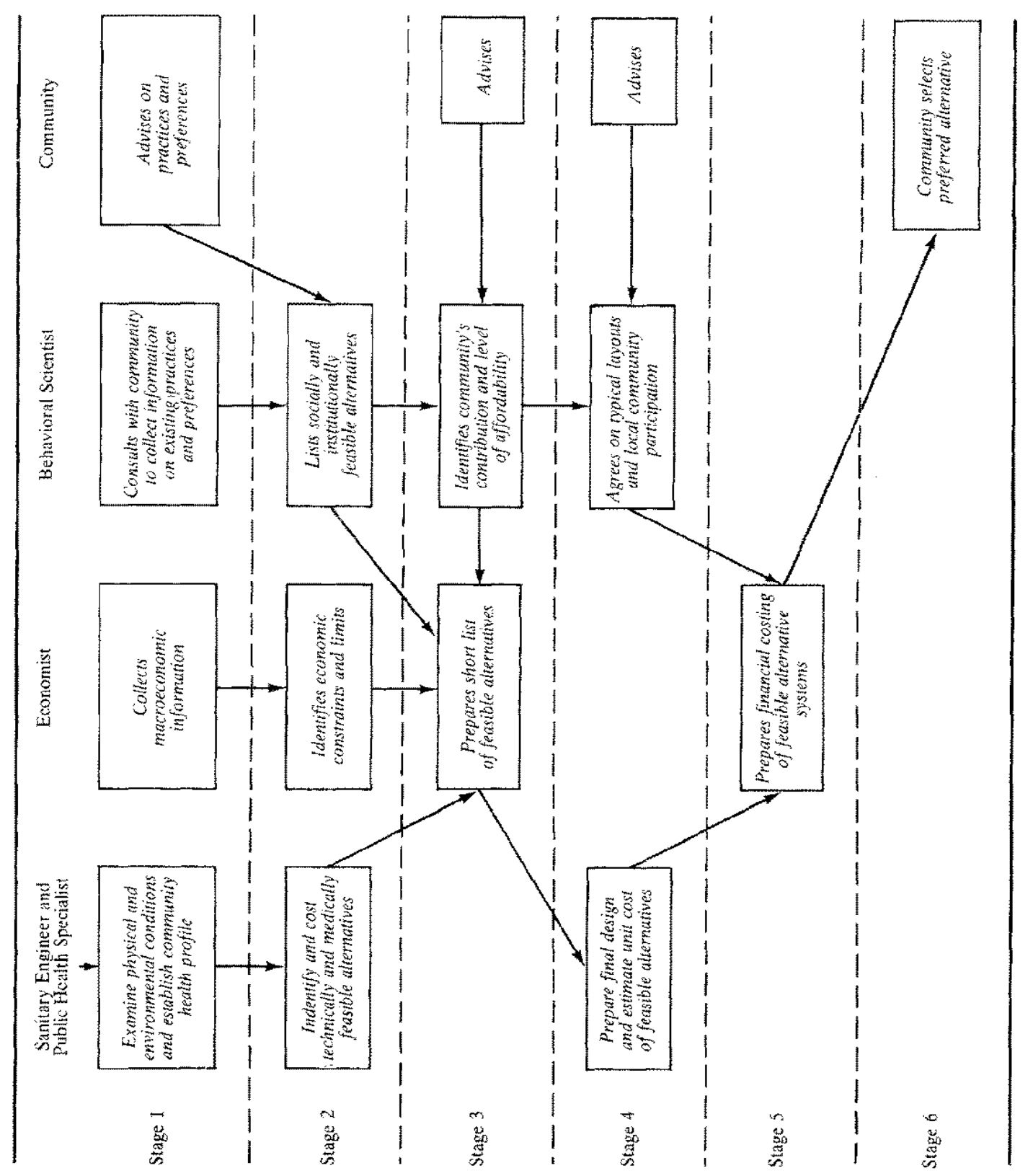

